UNIVERSIDADE DE SÃO PAULO

ESCOLA DE ENGENHARIA DE SÃO CARLOS

INSTITUTO DE FÍSICA DE SÃO CARLOS

INSTITUTO DE QUÍMICA DE SÃO CARLOS

\title{
UTILIZAÇÃO DE FIBRAS DE CARBONO E DE FIBRAS DE VIDRO PARA REFORÇO DE VIGAS DE MADEIRA
}

Juliano Fiorelli

Dissertação apresentada à Área Interunidades em Ciência e Engenharia de Materiais, para obtenção do título de Mestre em Ciência e Engenharia de Materiais

Orientador: Prof. Dr. Antonio Alves Dias

São Carlos

2002 
“A sabedoria não nos é dada.

É preciso descobri-la por nós mesmos, depois de uma viagem que ninguém nos pode poupar ou fazer por nós"

Marcel Proust - Escritor Francês 
Dedicatória:

Aos meus pais e à Erika, incentivadores incansáveis. 


\section{AGRADECIMENTOS}

A Deus, pela saúde, coragem e esperança em todas as etapas de minha vida.

Ao professor e orientador Antonio Alves Dias, pela grande amizade, confiança e interminável dedicação, desde o período de graduação, meu eterno muito obrigado.

Aos professores Carlito Calil Jr., Francisco Antonio Rocco Lahr e Almir Sales pelo incentivo e amizade.

À FAPESP - Fundação de Amparo a Pesquisa do Estado de São Paulo, pelo suporte financeiro.

Aos meus pais, Carlos e Marta, que tiveram especial participação em minha formação e acreditaram nos meus sonhos.

À Erika pelo apoio infinito, força, compreensão e sobretudo pelo carinho durante estes anos.

Aos meus irmãos, Alexandre e Bruno, pelo incentivo.

A todos os amigos e funcionários do LaMEM, pelo companheirismo e colaboração.

A todos aqueles que, de alguma maneira, contribuíram para a elaboração deste trabalho. 


\section{SUMÁRIO}

Lista de figuras

Lista de tabelas iv

Lista de símbolos vi

RESUMO viii

ABSTRACT $\quad$ ix

1 - INTRODUÇÃO 01

$\begin{array}{ll}1.1 \text { Objetivos do trabalho } & 03\end{array}$

2 - REVISÃO BIBLIOGRÁFICA 04

2.1 Métodos tradicionais para reforço e recuperação de estruturas de 04 madeira

2.2 Fibras reforçadas com polímeros (FRP) 07

2.2.1 Fibra de Vidro 08

2.2.2 Fibra kevlar $\quad 10$

2.2.3 Fibra de Carbono 11

2.2.3.1 Propriedades da fibra de carbono 11

2.2.3.2 Sistemas de reforço com fibra de carbono 13

2.2.4 Comparação entre propriedades das fibras 15

2.2.5 Análise de custos 16

$\begin{array}{ll}2.3 \text { Adesivos } & 17\end{array}$

2.3.1 Adesivos Inorgânicos 17

$\begin{array}{ll}\text { 2.3.2 Adesivos Orgânicos } & 18\end{array}$

$\begin{array}{ll}\text { 2.3.3. Termofixos } & 18\end{array}$

2.3.4 Adesivo epóxi AR-300 21

2.3.5 Termoplásticos $\quad 22$

2.3.6 Adesivo poliuretano à base de mamona 22

2.4 Mecanismos de adesão 23

2.5 Emprego de FRP em reforços de estruturas de madeira 24

2.6 Efeitos de altas temperaturas em reforços com FRP 32

2.7 Critério para dimensionamento de vigas de madeira reforçadas com 33 fibras 
3 - DETERMINAÇÃO DAS PROPRIEDADES MECÂNICAS DE 38 FIBRAS DE VIDRO E DE FIBRAS DE CARBONO LAMINADAS COM ADESIVOS COMERCIAIS E A BASE DE MAMONA

3.1 - Materiais e métodos 38

3.1.1 Materiais utilizados para a confecção dos corpos-de-prova $\quad 40$

3.1.2 Confecção dos corpos-de-prova $\quad 41$

3.1.3 Equipamentos utilizados no ensaio $\quad 42$

3.1.4 Determinação da resistência à tração e do módulo de elasticidade $\quad 42$

3.1.5 Ensaio realizado 43

3.2 Resultados obtidos 45

3.2.1 Ensaios preliminares (corpos-de-prova com adesivo de mamona, 45 cascophen e epóxi)

3.2.2 Corpos-de-prova laminados com resina epóxi 46

3.2.3 Corpos-de-prova sem adesivo $\quad 46$

3.2.4 Corpos-de-prova de fibras de carbono laminados com resina 46 epóxi

3.3 Análise dos resultados $\quad 54$

3.3.1 Comparação da eficiência dos adesivos na laminação dos corpos- 54 de-prova (ensaios preliminares)

3.3.2 Resistência à tração e módulo de elasticidade para fibras de 55 carbono e fibras de vidro laminadas com adesivo epóxi

3.3.3 Fibras de vidro sem adesivo

4 - AVALIAÇÃO DE ADESIVOS NA INTERFACE FIBRA MADEIRA 61

$\begin{array}{ll}\text { 4.1 Materiais e métodos } & 61\end{array}$

4.1.1 Confecção dos corpos-de-prova $\quad 61$

4.1.2 Ensaio realizado $\quad 62$

4.2 Resultados obtidos $\quad 63$

$\begin{array}{ll}4.3 \text { Análise dos resultados } & 64\end{array}$

5 - MODELO TEÓRICO DE CÁlCULO E ANÁliSE DE VIGAS 67 REFORÇADAS COM FIBRAS

5.1 Introdução 
5.2 Análise da rigidez à flexão das vigas $\quad 68$

5.2.1 Cálculo da seção transformada $\quad 68$

5.2.2 Análise da eficiência do reforço $\quad 70$

5.2.3 Comentários $\quad 74$

5.3 Análise da resistência

5.3.1 Cálculo do momento fletor último $\quad 74$

5.3.1.1 Modo de ruptura: compressão

5.3.1.2 Modo de ruptura - tração 78 teórico

5.3.2 Análise de vigas reforçadas com fibras, utilizando o modelo 80

5.3.2.1 Reforço com fibra de vidro $\quad 80$

5.3.3.2 Reforços com fibra de carbono $\quad 85$

5.3.2.3 Comentários $\quad 89$

5.3.3 Avaliação do parâmetro "k" $\quad 89$ carbono

5.3.4 Análise comparativa dos reforços de fibra de vidro e de fibra de 91

5.3.4.1 Comentários 95

6 - AVALIAÇÃO EXPERIMENTAL DE VIGAS 96

REFORÇADAS COM FIBRAS

6.1 Ensaios de flexão preliminares 96

6.1.1 Materiais utilizados para a confecção das vigas 96

6.1.2 Equipamentos utilizados no ensaio 97

6.1.3 Método de ensaio empregado 97

6.1.4 Método de aplicação de FRP 99

6.1.5 Realização do ensaio 101

6.1.6 Resultados obtidos 102

6.1.7 Análise dos resultados 105 teórico

6.1.7.1 Análise do momento máximo resistido - experimental e 105

6.1.7.2 Análise da rigidez a flexão 107

$\begin{array}{ll}6.2 \text { Ensaios principais } & 109\end{array}$

6.2.1 Materiais utilizados para a confecção das vigas 109

6.2.2 Caracterização das peças de madeira 111

6.2.3 Instrumentação das vigas 111 
6.2.4 Resultados obtidos

6.2.5 Análise dos resultados

116

6.2.5.1 Análise do momento máximo resistido - experimental e 116 teórico

6.2.5.2 Análise da rigidez à flexão

118

6.2.5.3 Análise das deformações

119

7 - CONCLUSÕES

132

8 - REFERÊNCIAS BIBLIOGRÁFICAS

134 


\section{Lista de figuras}

FIGURA 01: Pilar de madeira recuperado com reforço de "camisa" de 05 concreto

FIGURA 02: Reforço com chapa metálica 06

FIGURA 03: Modelo do processo de protensão transversal 06

FIGURA 04: Produtos em fibra de vidro 09

FIGURA 05: Tecido Multi-axial de fibra de vidro $\quad 10$

FIGURA 06: Fibra Kevlar 11

FIGURA 07: Arranjo HCP dos átomos de carbono 12

FIGURA 08: Tecido unidirecional e lâmina de fibra de carbono 14

FIGURA 09: Aplicação do reforço de lâminas de fibra de carbono 27

FIGURA 10: Fibra reforçando juntas de viga laminada colada 30

FIGURA 11: Ensaio de tração para verificar a resistência das peças 31

FIGURA 12: Possibilidades de reforço com fibra de vidro em ligações 31

FIGURA 13: Distribuição de tensões em vigas reforçadas 35

FIGURA 14: Dimensões de corpos-de-prova para ensaio de tração 39

FIGURA 15: Tecido de fibras de carbono $\quad 40$

FIGURA 16: Tecido de fibras de vidro $\quad 40$

FIGURA 17: Laminação de corpos-de-prova de fibras de vidro com resina 41 epóxi

FIGURA 18: Corpos-de-prova de fibras de carbono laminados com duas 42 camadas de tecido

FIGURA 19: Ensaio de tração em fibras de carbono 43

FIGURA 20: Corpos-de-prova de fibras de vidro sem laminação 44

FIGURA 21: Corpo-de-prova de fibras de vidro laminado com cascophen. $\quad 54$

FIGURA 22: Corpo-de-prova de fibras de vidro laminado com mamona 54

FIGURA 23: Corpos-de-prova de fibras de carbono e de fibras de vidro 55 laminados com epóxi.

FIGURA 24: Gráfico comparativo entre forças máximas resistidas por 58 corpos-de-prova de fibras de carbono e de fibras de vidro

FIGURA 25: Curva tensão x deformação fibras de vidro laminadas 59

FIGURA 26: Curva tensão deformação fibras de carbono laminadas 59

FIGURA 27: Colagem de fibras de vidro nos corpos-de-prova de madeira 62 adesivo cascophen

FIGURA 28: Ensaio de tração em corpos-de-prova de madeira (adesivo de 62 mamona) 
FIGURA 29: Formas de ruptura para adesivo epóxi - ruptura na madeira 64 (pinus) e ruptura por cisalhamento (eucalipto)

FIGURA 30: Formas de ruptura para adesivo de mamona e cascophen 64

FIGURA 31: Comparação da resistência dos adesivos em corpos-de-prova de 65 Pinus elliotti

FIGURA 32: Comparação da resistência dos adesivos em corpos-de-prova de 65 eucalipto Grandis

FIGURA 33: Viga constituída por dois materiais diferentes (a) e seção 69 equivalente (b)

FIGURA 34: Variação do momento de inércia - reforço com fibra vidro

FIGURA 35: Variação do momento de inércia reforço com fibra de carbono

FIGURA 36: Diagrama de deformação na seção transversal

FIGURA 37: Diagrama $\sigma \times \varepsilon \quad$ na compressão paralela às fibras 75

FIGURA 38: Distribuição de tensões na seção transversal (ruptura por 77 compressão)

FIGURA 39: Distribuição de tensões na seção transversal (ruptura por tração 79 na madeira)

FIGURA 40: Relação entre momento x número de camadas de fibra de vidro

FIGURA 41: Relação entre momento x número de camadas de fibra de vidro

FIGURA 42: Relação entre momento x número de camadas de fibra de vidro 84

FIGURA 43: Relação entre momento x número de camadas de fibra de 86 carbono

FIGURA 44: Relação entre momento x número de camadas de fibra de 87 carbono

FIGURA 45: Relação entre momento x número de camadas de fibra de 88 carbono

FIGURA 46: Diagrama tensão por deformação 90

FIGURA 47: Gráficos comparativos entre os reforços com fibra de vidro e 92 fibra de carbono

FIGURA 48: Gráficos comparativos entre os reforços com fibra de vidro e 93 fibra de carbono

FIGURA 49: Gráficos comparativos entre os reforços com fibra de vidro e 94 fibra de carbono

FIGURA 50: Modelo do ensaio de flexão em vigas simplesmente apoiadas $\quad 98$

FIGURA 51: Ciclo de carregamento 98

FIGURA 52: Procedimento de aplicação de fibras de vidro em vigas 100

FIGURA 53: Ensaio de flexão em viga de eucalipto 102

$\begin{array}{ll}\text { FIGURA 54: Flecha viga de Pinus } & 105\end{array}$ 
FIGURA 55: Comparação entre momento fletor de ruptura (experimental e 106 teórico)

FIGURA 56: Comparação entre momento fletor de ruptura (experimental e 107 teórico)

FIGURA 57: Valores EI (reforço)/EI x número de camadas 108

FIGURA 58: Valores EI (reforço)/EI x número de camadas 109

FIGURA 59: Esquema dos ensaios de flexão nas vigas 111

FIGURA 60: Posição dos extensômetros na seção transversal da viga 112

$\begin{array}{ll}\text { FIGURA 61: Flecha na viga } & 115\end{array}$

FIGURA 62: Ruptura por tração na madeira 116

FIGURA 63: Força x deformação específica de vigas de Pinus seção 6x12 cm $\quad 120$

FIGURA 64: Força x deformação específica de vigas de Pinus seção 6x16 cm $\quad 121$

FIGURA 65: Força x deformação específica de vigas de Pinus seção 6x12 cm $\quad 121$

FIGURA 66: Força x deformação específica de vigas de Peroba Rosa 122

FIGURA 67: Variação da deformação na seção transversal da viga 01 sem 123 reforço e reforçada

FIGURA 68: Variação da deformação na seção transversal da viga 02 sem 124 reforço e reforçada

FIGURA 69: Variação da deformação na seção transversal da viga 03 sem 125 reforço e reforçada

FIGURA 70: Variação da deformação na seção transversal da viga 04 sem 126 reforço e reforçada

FIGURA 71: Variação da deformação na seção transversal da viga 06 sem 127 reforço e reforçada

FIGURA 72: Variação da deformação na seção transversal da viga 08 sem 128 reforço e reforçada

FIGURA 73: Variação da deformação na seção transversal da viga 09 sem 129 reforço e reforçada com 20 camadas de fibra

FIGURA 74: Variação da deformação na seção transversal da viga 11 sem 130 reforço e reforçada 


\section{Lista de tabelas}

$\begin{array}{ll}\text { TABELA 01: Características da fibra de vidro } & 08\end{array}$

$\begin{array}{ll}\text { TABELA 02: Tipos de fibra de vidro para reforço } & 09\end{array}$

TABELA 03: Emprego de FRP em estruturas $\quad 14$

TABELA 04: Características dos tecidos de fibras a $20^{\circ} \mathrm{C} \quad 15$

$\begin{array}{ll}\text { TABELA 05: Custo das fibras } & 17\end{array}$

TABELA 06: Características das fibras aramid e vidro 25

TABELA 07: Características das fibras aramid e vidro 29

TABELA 08: Geometria dos corpos-de-prova $\quad 40$

TABELA 09: Informações referentes aos corpos-de-prova ensaiados 45

TABELA 10: Resistência à tração de fibras de vidro laminada com mamona 46

TABELA 11: Resistência à tração de fibras de vidro laminada com cascophen $\quad 46$

TABELA 12: Resistência à tração de fibras de vidro laminada com epóxi 46

TABELA 13: Valores de resistência à tração e módulo de elasticidade de 48 fibras de vidro (duas camadas de tecido)

TABELA 14: Valores de resistência à tração e módulo de elasticidade de 49 fibras de vidro (quatro camadas de tecido)

TABELA 15: Valores de resistência à tração e módulo de elasticidade de 50 fibras de vidro (seis camadas de tecido)

TABELA 16: Valores de resistência à tração e módulo de elasticidade de 51 fibras de vidro sem laminação (uma camada de tecido)

TABELA 17: Valores de resistência à tração e módulo de elasticidade de 52 fibras de carbono (duas camadas de tecido)

TABELA 18: Valores de resistência à tração e módulo de elasticidade de 53 fibras de carbono (quatro camadas de tecido)

TABELA 19: Valores de resistência à tração e módulo de elasticidade de 54 fibras de carbono (seis camadas de tecido)

TABELA 20: Valores médios e coeficientes de variação da resistência a 56 tração de fibras de vidro

TABELA 21: Valores médios de resistência e módulo de elasticidade de 57 fibras de vidro laminadas (2 lâminas de fibras)

TABELA 22: Valores médios de resistência e módulo de elasticidade de 57 fibras de vidro laminadas (4 lâminas de fibras)

TABELA 23: Valores médios de resistência e módulo de elasticidade de 57 fibras de vidro laminadas (6 lâminas de fibras)

TABELA 24: Valores médios de resistência e módulo de elasticidade de 58 fibras de carbono laminadas (2 lâminas de fibras)

TABELA 25: Valores médios de resistência e módulo de elasticidade de 58 
fibras de carbono laminadas (4 lâminas de fibras)

TABELA 26: Valores médios de resistência e módulo de elasticidade de 58 fibras de carbono laminadas (6 lâminas de fibras)

TABELA 27: Valores médios de resistência e módulo de elasticidade de 60 fibras de vidro sem adesivo

TABELA 28: Valores das forças máximas resistidas pelos adesivos na 64 interface fibra madeira

TABELA 29: Valores médios e coeficiente de variação das forças de 66 cisalhamento

TABELA 30: Valores de elasticidade utilizados no cálculo da inércia 72

TABELA 31: Valores de elasticidade e resistência de madeira 82

TABELA 32: Valores do parâmetro "k" $\quad 91$

TABELA 33: Informações referentes às vigas de madeira 98

$\begin{array}{ll}\text { TABELA 34: Médias e coeficiente de variação } & 101\end{array}$

$\begin{array}{ll}\text { TABELA 35: Viga de Pinus seção 3x6 cm } & 102\end{array}$

TABELA 36: Viga de Pinus seção 3x12 cm 102

TABELA 37: Viga de Eucalipto seção 3x6 cm 103

TABELA 38: Viga de Eucalipto seção 3x12 cm 103

TABELA 39: Informações referentes às vigas de madeira 109

TABELA 40: Médias e coeficiente de variação 112

TABELA 41: Médias e coeficiente de variação 113

TABELA 42: Vigas de Pinus Caribea 113

TABELA 43: Vigas de Peroba Rosa 114

TABELA 44: Vigas de Pinus Caribea 116

TABELA 45: Vigas Peroba Rosa 116

TABELA 46: Vigas de Pinus Caribea 117

$\begin{array}{ll}\text { TABELA 47: Vigas Peroba Rosa } & 117\end{array}$ 


\section{Lista de símbolos}

Letras romanas maiúsculas

A - Área do corpo-de-prova

C1 e C2 - Forças de compressão resultantes na madeira;

E - Módulo de Elasticidade

$\mathrm{E}_{1}$ - módulo de elasticidade da madeira

$E_{2}$ - módulo de elasticidade da fibra

$\mathrm{E}_{\mathrm{c}}$ - módulo de elasticidade à compressão paralela da madeira

$\mathrm{E}_{\mathrm{t}}$ - módulo de elasticidade à tração paralela da madeira

$\mathrm{E}_{\mathrm{f}}$ - módulo de elasticidade à tração da fibra

EI - Rigidez à flexão

$\mathrm{EI}_{\mathrm{r}}-$ Rigidez a flexão de vigas reforçadas

$\mathrm{F}_{\text {máx }}$ - Força máxima aplicada

I - Momento de Inércia

$\mathrm{K}$ - relação entre as deformações $\left(\varepsilon_{2} / \varepsilon_{1}\right)$

L - distância entre apoios

$\mathrm{M}_{\mathrm{c}}$ - momento resistente à compressão

$\mathrm{M}_{\mathrm{t}}$ - momento resistente à tração

$\mathrm{M}_{\mathrm{u}}$ - momento último resistido pela viga

$\mathrm{M}_{\mathrm{r}, \mathrm{u}}$ - Momento último de vigas reforçadas

$\mathrm{P}$ - força máxima

TM - Força de tração resultante na madeira

TF - Força de tração na fibra

W - módulo de resistência da seção transversal transformada

Letras romanas minúsculas

b - base

b` - base equivalente 
e - espessura da fibra

$\mathrm{f}_{\mathrm{b}}$ - resistência da Madeira a Flexão

$\mathrm{f}_{\mathrm{c} 0}$ - resistência à compressão paralela às fibras da madeira

$\mathrm{f}_{\mathrm{t} 0}$ - resistência à tração paralela às fibras da madeira

$\mathrm{f}_{\mathrm{tu}}$ - Resistência à tração

$\mathrm{h}$ - altura da viga

$\mathrm{m}$ - coeficiente angular

$y_{c g}$ - distância do cg a borda comprimida

Letras gregas

$\delta$ - deslocamento vertical

$\sigma_{\mathrm{c}}$ - tensão de compressão

$\Delta \mathrm{P}$ - variação da força (10\% e 50\%)

$\Delta v$ - variação da flecha $(10 \%$ e $50 \%)$ 


\section{RESUMO}

A necessidade de recuperação e reforço em estruturas de madeira, concreto e aço exigiu da construção civil uma procura por métodos mais eficientes que pudessem cumprir esse papel. Com este objetivo vários estudos estão sendo realizados utilizando fibras reforçadas com polímeros (FRP). Dentre estas fibras, as que vêm apresentando melhores resultados como reforço para peças estruturais de madeiras são as fibras de carbono e as fibras de vidro. Dentro deste escopo, este trabalho tem como objetivo estudar o comportamento estrutural de vigas de madeira de espécies nacionais reforçadas com fibras de carbono e com fibras de vidro, verificando a eficiência deste reforço e adequando modelos de cálculo para avaliação da resistência e da rigidez das vigas reforçadas, e também verificar a eficiência de uma formulação de adesivos à base de mamona e do adesivo Cascophen, para fixação das respectivas fibras na madeira, em substituição ao adesivo epóxi, normalmente utilizado. Foram efetuados ensaios de vigas de madeira reforçadas com polímeros, em modelo reduzido, e em protótipos, para diversas configurações de geometria e quantidade de fibras utilizadas. Os resultados obtidos indicam uma boa concordância entre os modelos teóricos para avaliar a resistência e a rigidez das vigas reforçadas, e os resultados experimentais, e a eficiência do reforço. Também foram conduzidos ensaios de tração em corpos-de-prova de fibras laminado com os adesivos, caracterizando a sua resistência e elasticidade e comparando o comportamento dos adesivos estudados. Os resultados indicaram o melhor comportamento do adesivo epóxi. 


\begin{abstract}
The necessity of rehabilitation and reinforcement in wood structures, concrete and steel demanded a search for more efficient methods that could to carry this paper. With this objectives several studies are using fibers reinforced polymers (FRP). These fibers which presenting better results in structural reinforcement for structural pieces of wood are the fibers of carbon and the glass fibers. This work has as objective studies the structural behavior of wood beams of national species reinforced with carbon fibers and with glass fibers, verifying the efficiency of this reinforcement and adapting calculation models for evaluation of the strength and stiffness of the reinforced beams, and also to verify the efficiency of a formulation of adhesives to the castor oil and of the adhesive Cascophen, for fixation of the respective fibers in the wood, in substitution the adhesive epoxy, usually used. Experimental work was made with wood beams reinforced with polymeric, in reduced model, and in prototypes, for several geometry configurations and amount of used fibers. The obtained results indicate a good agreement among the theoretical models to evaluate the strength and stiffness of the reinforced beams, and the experimental results, and the efficiency of the reinforcement. Traction rehearsals were also led in body-of-proof of fibers laminated with the adhesives, characterizing your strength and elasticity and comparing the behavior of the studied adhesives. The results indicated the best behavior of the adhesive epoxy.
\end{abstract}




\section{1 - INTRODUÇÃO}

Problemas relacionados à baixa eficiência de elementos estruturais, aumento de sobrecarga e degradação por envelhecimento existem com bastante freqüência na construção civil. Estas patologias vêm motivando o desenvolvimento de novas técnicas de reforço e recuperação para estruturas.

A recuperação estrutural abrange edificações abaladas por sinistros de qualquer natureza ou por falhas no planejamento, projeto, execução ou por empregos de materiais e componentes de baixa qualidade, procurando retornar às características originais de projeto, tornando as estruturas novamente aptas para uso. Já o reforço proporciona um aumento da capacidade de carga do elemento estrutural através da combinação de outros materiais com propriedades mecânicas iguais ou superiores as das estruturas originais.

Atualmente, em alguns casos mostra-se mais viável, em termos econômicos, promover a recuperação ou o reforço de estruturas e de edificações sem demoli-las. O reforço e a recuperação estrutural também podem ser utilizados para resolver problemas de envelhecimento de obras, sendo que muitas delas fazem parte do patrimônio histórico e arquitetônico.

Recentemente, materiais alternativos vêm sendo estudados para recuperar e reforçar estruturas. Uma maior atenção está sendo dada para o uso de fibras reforçadas com polímeros (FRP), que são materiais flexíveis, altamente resistentes e que podem substituir com vantagens, em alguns casos, as técnicas que já vem sendo utilizadas. Atualmente as fibras mais utilizadas são as fibras de carbono e as fibras de vidro. 
Segundo Bakoss; Greenland (1998), apesar de ainda pequeno, o uso de (FRP) na construção civil vem crescendo, e as técnicas de aplicação estão sendo desenvolvidas rapidamente na América do Norte, Europa e Japão. Estas fibras, por apresentarem facilidade de composição com outros tipos de materiais, estão se associando aos tradicionais materiais da construção civil como madeira, concreto e aço, compondo estruturas mais resistentes e com um peso próprio levemente alterado. Além disso, o potencial para recuperação de estruturas de madeira é altamente significativo, devido a vários fatores como redução do custo de materiais quando usados adequadamente, aumento da durabilidade, redução da manutenção para elementos estruturais de madeira e capacidade de recuperar estruturas danificadas.

Segundo Dagher (2000), as propriedades físicas, mecânicas e químicas das FRP são muito versáteis. As fibras podem ser um complemento para as propriedades ortotrópicas da madeira. Ressalta ainda a possibilidade de uso do material em muitos processos de manufaturas, freqüentemente usados para produzir compósitos estruturais de madeira.

A utilização de FRP para recuperação e reforço estrutural é um campo extenso e tecnologicamente vasto, que proporcionará economia de tempo e de materiais na construção civil. Percebe-se, também, que a facilidade de associar a outros materiais, o baixo aumento no peso próprio da estrutura, o significativo aumento da resistência e da rigidez e a facilidade de aceitação do produto no mercado de todo o mundo, poderá fazer destas fibras um material bastante utilizado na recuperação e reforço de elementos estruturais. 
É neste contexto, que o conhecimento a ser desenvolvido na presente pesquisa representa uma contribuição no sentido de ampliar o uso das madeiras nacionais, nativas e de reflorestamento, como material estrutural, estudando a aplicação de reforço de fibras de carbono e de vidro em vigas de madeira.

Este trabalho apresenta uma avaliação teórica e experimental de vigas de madeira de baixa e média densidade reforçada com fibras de vidro e com fibras de carbono e também uma verificação da eficiência de adesivos comerciais e a base de mamona na fixação das respectivas fibras à madeira.

\subsection{Objetivos do trabalho}

No contexto apresentado, este trabalho possui como objetivo:

- Estudar o comportamento estrutural de vigas de madeira reforçadas com fibras de carbono e com fibras de vidro, verificando a eficiência destes reforços e a adequação de modelos de cálculo para avaliação da resistência e da rigidez destes elementos estruturais;

- Avaliar a possibilidade de utilização dos adesivos à base de mamona e Cascophen, em substituição ao adesivo epóxi, normalmente empregado, para o reforço de vigas de madeira com fibras de vidro. 


\section{2 - REVISÃO BIBLIOGRÁFICA}

Com o intuito de situar os principais métodos de recuperação e reforço de estruturas de madeira, este capítulo apresenta um levantamento do conhecimento científico das técnicas mais utilizadas pela indústria da construção civil.

Com relação ao reforço com fibra, são apresentadas as propriedades mecânicas dos tecidos de fibra de vidro, de fibra de carbono e da fibra aramid, propriedades dos principais adesivos comerciais e à base de mamona, utilizados junto à madeira e também resultados de estudos teóricos e experimentais que verificaram a eficiência da respectiva técnica no reforço de elementos estruturais de madeira.

\subsection{Métodos tradicionais para reforço e recuperação de estruturas de}

\section{madeira}

A idéia de reforçar estruturas de madeiras não é nova. Muitos estudos vêm sendo desenvolvidos no campo de recuperação e reforço.

De acordo com Mettem; Robinson (1991) existem métodos para reparar estruturas de madeira, sem comprometê-las. As técnicas mais utilizadas para se fazer estas recuperações são:

- Método tradicional - a estrutura de madeira é recuperada com novas peças, que substituirão as degradadas, de dimensões e propriedades semelhantes às originais.

- Método mecânico - os reparos estruturais são feitos utilizando conectores metálicos.

- Método adesivo - são utilizadas variações de resinas epóxi combinadas com peças metálicas, para realizar a recuperação. 
Em muitos casos, faz-se necessária a adoção de outras medidas, como a utilização de "camisas" de concreto, visando proteger regiões da estrutura expostas a condições severas de intemperismo. As razões para o sucesso deste tipo de reforço são o aumento da resistência à compressão e baixo custo do material empregado, (Dagher, 2000). A figura 01 apresenta um exemplo de reforço em pilar de madeira de uma ponte, situado na região correspondente à de variação do nível do rio (Ritter, 1990).

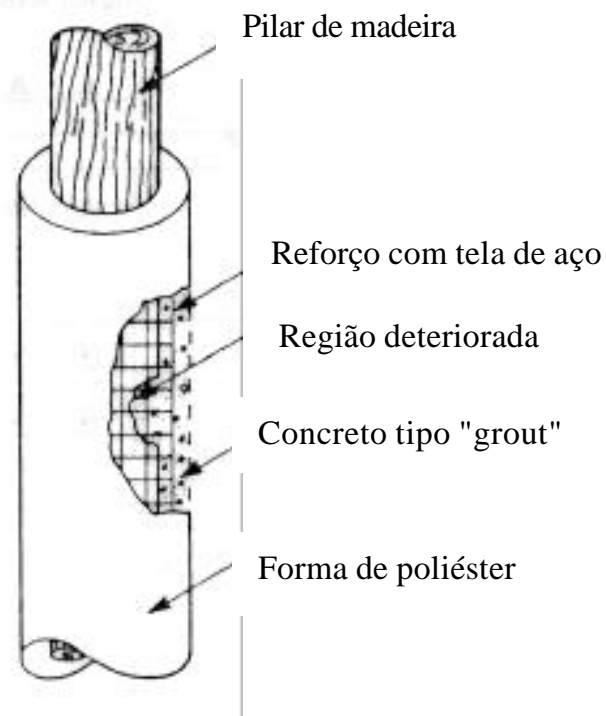

FIGURA 01: Pilar de madeira recuperado com reforço de "camisa" de concreto. Fonte: Ritter (1990)

Ritter (1990) também estudou outros tipos de recuperação pelo método mecânico, entre eles o reparo por emenda, que consiste em adicionar peças de madeira associadas com parafusos. Esta técnica é muito utilizada quando a peça estrutural apresenta rachaduras longitudinais.

Outro tipo de reparo, também muito utilizado em rachaduras longitudinais, consiste em introduzir chapas metálicas, fixando-as com parafusos ou com adesivo epóxi. A figura 02 mostra a fixação da chapa com parafusos. O objetivo desta técnica não é o de fechar a rachadura, mas sim, prevenir a separação da peça em duas partes. 
Este método tem sido muito utilizado, pois não ocorre a redução da seção da peça estrutural. No entanto, quando a fixação da chapa metálica é feita com adesivo, foi observado que após muito tempo exposta a intempéries, pode ocorrer corrosão na sua interface com o adesivo, comprometendo a aderência entre os elementos. Esta patologia é muito difícil de ser identificada durante as inspeções de rotina.

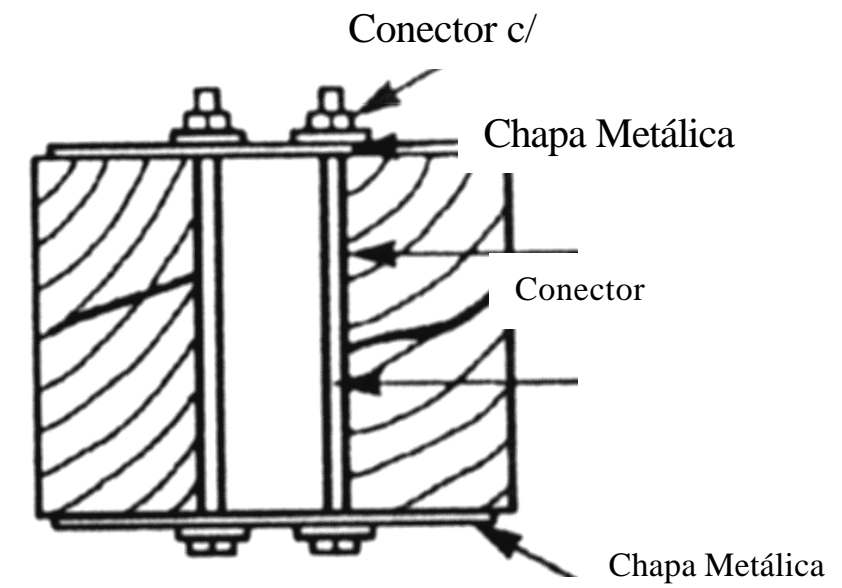

FIGURA 02: Reforço com chapa metálica. Fonte: Ritter (1990)

Outra técnica, denominada protensão transversal, é muito utilizada para unir decks horizontais de tabuleiros de pontes. Muitas vezes os tabuleiros são danificados pelo aumento do tráfego de veículos, ou por rachaduras no asfalto, que possibilitam a penetração de água e consequentemente à deterioração das peças de madeira. A respectiva técnica consiste em introduzir uma tensão de protensão que reduz as distâncias entre as peças de madeira. A figura 03 ilustra o respectivo processo.

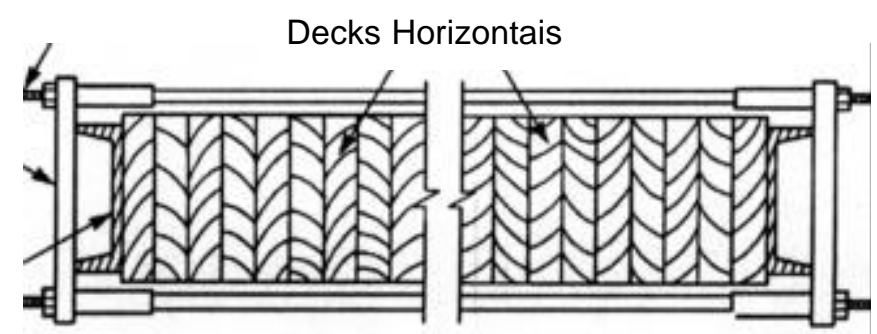

FIGURA 03: Modelo do processo de protensão transversal. Fonte: Ritter (1990) 
De acordo com Ritter (1990), a técnica mais eficiente para recuperar peças de madeira é aquela que utiliza epóxi. O epóxi é um gel de betume, que pode ser injetado manualmente nas partes danificadas, promovendo o aumento da resistência da peça estrutural. Este material é usado para preencher rachaduras, superfícies atacadas por insetos e espaços vazios. O epóxi, além de vedar a área danificada, aumenta a capacidade de carga da estrutura e reduz o aparecimento de futuras rachaduras.

Forsberg (1996) utilizou epóxi em regiões danificadas de treliças de madeira, reparando a estrutura. Resultados satisfatórios de aumento de resistência dos componentes estruturais foram atingidos.

\subsection{Fibras reforçadas com polímeros (FRP)}

Recentemente, materiais alternativos vêm sendo estudados para recuperar e reforçar estruturas. Uma maior atenção vem sendo dada para o uso de fibras reforçadas com polímeros (FRP), que podem substituir as técnicas descritas anteriormente.

As fibras que vem apresentando melhores resultados são: fibra de vidro, Kevlar 49 (aramid) e fibra de carbono. O processo de fabricação se difere para cada um destes materiais, resultando em microestruturas com propriedades distintas.

O emprego do tecido de fibra deve ser feito em conjunto com algum tipo de adesivo, formando um compósito que consiste na combinação de dois materiais para produzir um produto que exceda as propriedades individuais de cada um. Em particular, as fibras reforçadas com polímeros (FRP), são formadas pela combinação das fibras com uma matriz. As fibras são responsáveis pela resistência do compósito, 
e a matriz é o produto que as une, sendo responsável pela transmissão dos esforços, (Norris; Saadatmanesh, 1994).

\subsubsection{Fibra de Vidro}

Segundo Hull (1995) muitas composições de minerais têm sido utilizadas para produzir fibras. As fibras de vidro são produzidas a partir da sílica $\left(\mathrm{SiO}_{2}\right)$, através da adição de óxido de cálcio, boro, sódio e alumínio. Estas fibras são materiais amorfos e sua cristalização ocorre após prolongado tratamento com altas temperaturas.

Dentre as vantagens do uso de fibra de vidro em reforços de estruturas podem ser destacadas: baixo custo, em relação às fibras de carbono e as fibras aramid, (aproximadamente $\mathrm{R} \$ 5,00 / \mathrm{m}^{2}$ ), alta resistência ao impacto e à corrosão. Além disso, pode ser destacado como um produto que também é fabricado no Brasil.

As fibras de vidro se dividem em três categorias: E (electrical), C (chemical) e S (high tensile strength). Suas principais características e formas encontradas no mercado estão apresentadas nas tabelas 01 e 02 .

TABELA 01: Características da fibra de vidro. Fonte: Hull (1995)

\begin{tabular}{|c|l|}
\hline Fibra de Vidro & \multicolumn{1}{c|}{ Características } \\
\hline E glass & $\begin{array}{l}\text { Alta resistência e alto módulo de elasticidade; } \\
\text { Boa condutividade elétrica. }\end{array}$ \\
\hline C glass & $\begin{array}{l}\text { Alta resistência a corrosão; } \\
\text { Baixa propriedade de resistência. }\end{array}$ \\
\hline S glass & $\begin{array}{l}\text { Alto módulo de elasticidade; } \\
\text { Resistente a altas temperaturas; }\end{array}$ \\
\hline
\end{tabular}


TABELA 02: Tipos de fibra de vidro para reforço. Fonte: (catálogo Saint-Gobain Vetrotex )

\begin{tabular}{|c|l|}
\hline Fibra de Vidro & \multicolumn{1}{|c|}{ Características } \\
\hline Fios Têxteis & $\begin{array}{l}\text { Formado por duas ou mais fibras simples de vidro, } \\
\text { torcidos em sentidos inversos para formarem um único } \\
\text { fio, bobinados em um suporte cônico. }\end{array}$ \\
\hline Mantas de Fios Contínuos & $\begin{array}{l}\text { Fabricadas com fios contínuos de vidro, dispostos de } \\
\text { forma aleatória em múltiplas camadas unidos por um } \\
\text { ligante. São compatíveis com resinas poliéster, } \\
\text { estervinílica, epóxi. }\end{array}$ \\
\hline Mantas de Fios Picados & $\begin{array}{l}\text { Fabricadas com fios picados de vidro, unidos por um } \\
\text { ligante solúvel em estireno, que lhe confere uma } \\
\text { excelente compatibilidade com resinas poliéster e epóxi. }\end{array}$ \\
\hline Roving & $\begin{array}{l}\text { Produzido a partir de fios de vidro indicados para } \\
\text { aplicação por projeção simultânea. }\end{array}$ \\
\hline Roving Direto & $\begin{array}{l}\text { Produzido a partir de fios de vidro destinados a } \\
\text { fabricação de produtos nos processos de moldagem por } \\
\text { enrolamento. }\end{array}$ \\
\hline Tecido Unidirecional (TRB) & $\begin{array}{l}\text { Produzido a partir de mechas contínuas de fios de vidro } \\
\text { com agentes de acoplamento compatíveis com resinas } \\
\text { poliéster e epóxi. É utilizado na moldagem de peças em } \\
\text { plástico reforçado e recomendado para laminação } \\
\text { manual. }\end{array}$ \\
\hline
\end{tabular}

A figura 04 ilustra os produtos comerciais de fibra de vidro.

Fios Têxteis

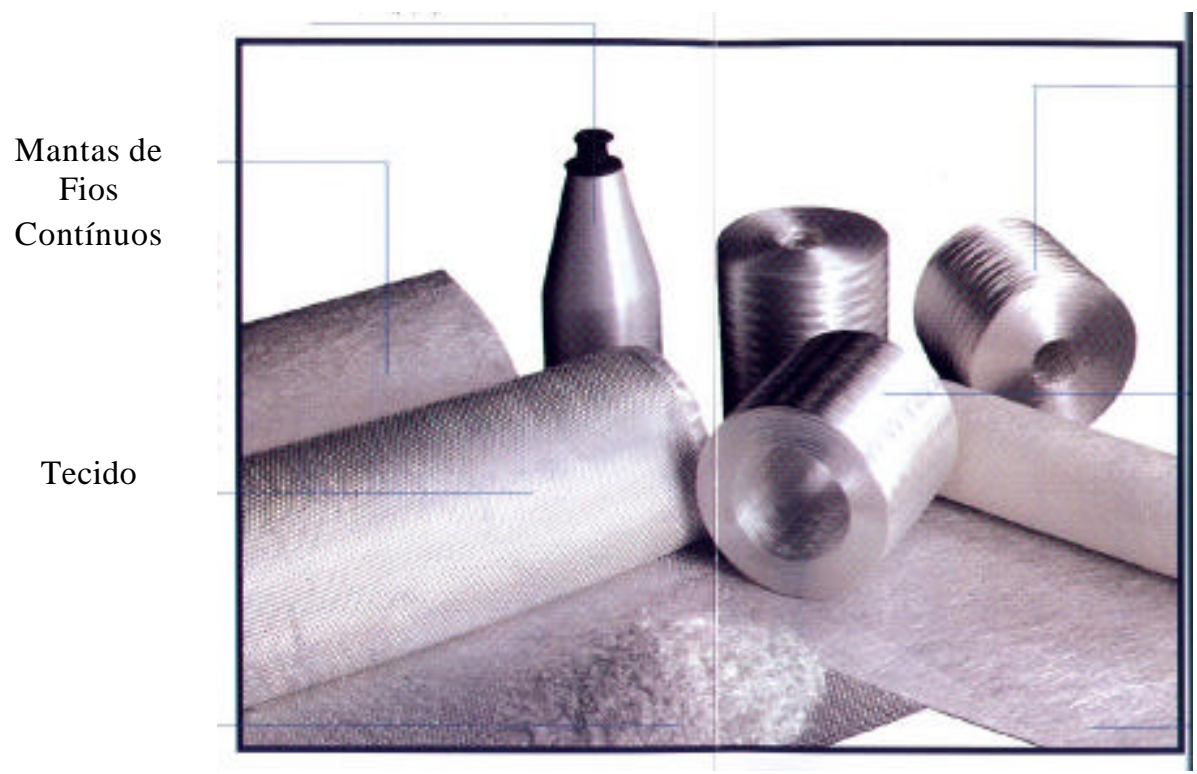

Roving

Roving

Direto

Manta de

Fios Picados

FIGURA 04: Produtos em fibra de vidro. Fonte: Saint-Gobain (2000) 
Dentre os produtos derivados da fibra de vidro, os tecidos de fibras unidirecionais são os mais recomendados para reforço e recuperação de elementos estruturais. Dentre estes tecidos, os Multi-axiais, formados pela superposição de fibras unidirecionais unidas por uma costura de fio poliéster, são os que apresentam melhores condições para manuseio, além de apresentar excelentes propriedades mecânicas, em comparação aos outros produtos. A figura 05 lustra o tecido Multiaxial.

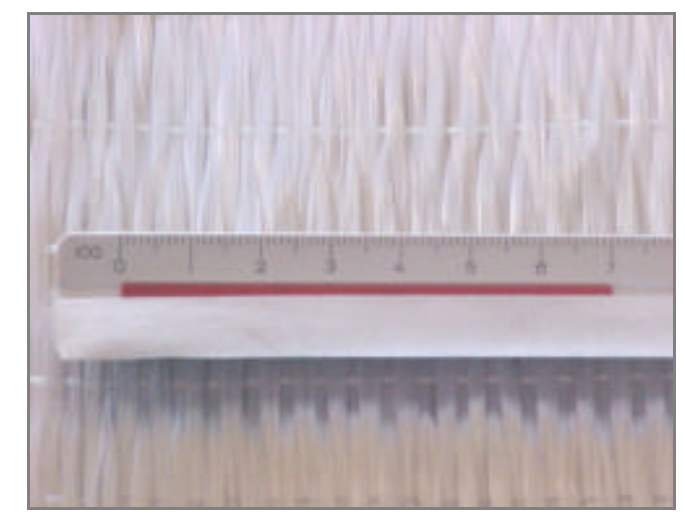

FIGURA 05: Tecido Multi-axial de fibra de vidro

\subsubsection{Fibra kevlar}

As fibras orgânicas, também conhecidas por Kevlar, marca registrada da empresa Dupont apresentam três estruturas moleculares diferentes nylon, aramida e poliestireno.

Este tipo de fibra é utilizado principalmente na indústria aeroespacial e automobilística. Nos últimos anos, as fibras aramidas têm se tornado um material muito utilizado em construção de barcos, buscando-se maior rigidez e leveza. Quando comparadas com outros materiais, as fibras aramidas mostram uma 
resistência específica (resistência/densidade) muito grande, acima de qualquer outro tipo de fibra disponível no mercado. A figura 06 ilustra este tipo de material.

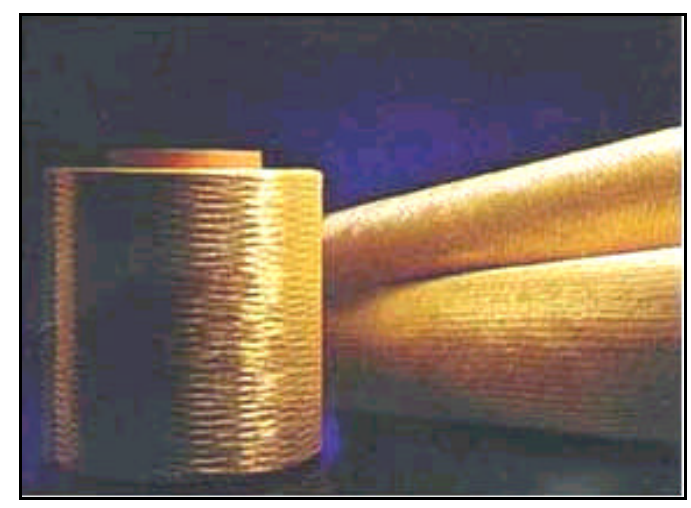

FIGURA 06: Fibra Kevlar. Fonte: Barracuda (2000)

\subsubsection{Fibra de Carbono}

As fibras de carbono vêm sendo utilizadas nas indústrias aeroespaciais, automotivas e de equipamentos esportivos nos últimos cinqüenta anos, principalmente por apresentarem altas propriedades mecânicas de resistência e rigidez, baixo peso e facilidade em associar a outros materiais.

\subsubsection{Propriedades da fibra de carbono}

As fibras de carbono são produzidas a partir de um componente básico conhecido como PAN (Poliacrilonitrila). Dependendo do tipo de tratamento recebido pela fibra básica, o qual inclui carbonização, oxidação e grafitização, é possível fabricar fibras de carbono em diversas configurações de resistência e de módulo de elasticidade (fibra tipo I e tipo II). Algumas são mais resistentes que o aço. Sua cor natural é preta. 
O polímero reforçado com fibras de carbono, ou mais especificamente carbon fiber reinforced polymers (CFRP), é o material que vem sendo utilizado como alternativa para reforçar peças estruturais, mostrando-se altamente promissor no desempenho desta função, além de apresentar uma excelente resistência à corrosão [Taylor et al., (1994) apud Beber et al., (1999)].

As fibras de carbono são caracterizadas por uma combinação de baixo peso próprio, grande durabilidade, facilidade de assumir formas complexas, alta resistência e grande rigidez.

De acordo com Hull (1995) a alta resistência à tração e o alto módulo de elasticidade se devem ao paralelismo entre os eixos das fibras. Seus diâmetros estão entre 7 e $8 \mu \mathrm{m}$ e são formadas por mono cristais, que se juntam e formam o grafite, que é uma forma alotrópica do carbono. Possuem arranjo hexagonal, os planos são alinhados e possuem forma de empilhamento $\mathrm{ABAB}$ (figura 07). Entre os átomos de carbono as ligações são covalentes (ligações químicas fortes) e entre os planos existe ligações do tipo Van der Waals (ligações fracas).

O alto módulo de elasticidade e a alta resistência das fibras de carbono se devem à orientação dos planos do grafite e também às ligações covalentes (ligações fortes) entre os átomos. Os respectivos planos possuem um alinhamento paralelo ao eixo das fibras. Muitos modelos vêm sendo propostos para ilustrar a estrutura das fibras de carbono, (Matthews, 1996). 


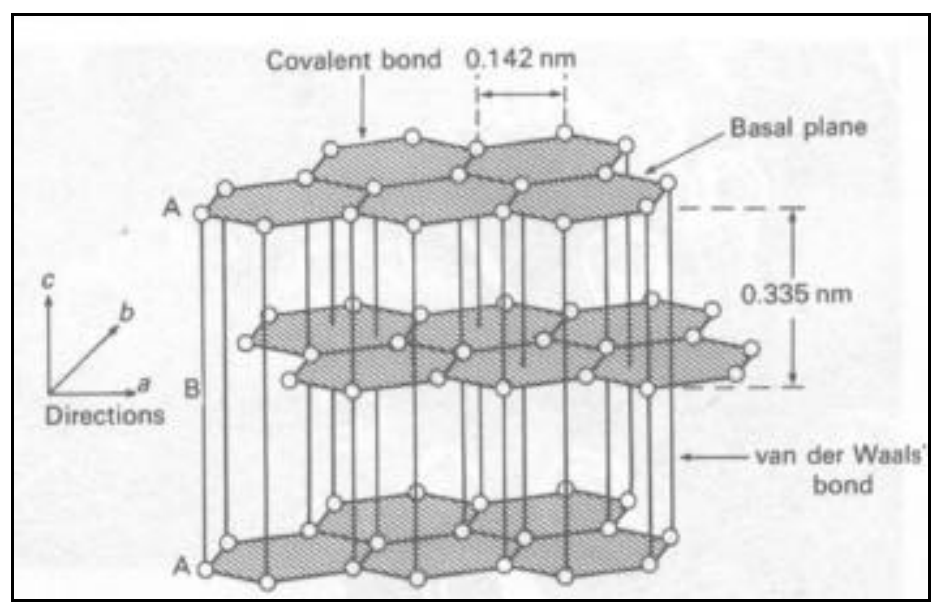

FIGURA 07: Arranjo HCP dos átomos de carbono. Fonte: Matthews (1996)

Tingley ; Cegelka (1996) informam que são as fibras de vidro, carbono e aramid que vêm sendo utilizadas em reforço de estruturas de madeira. A mais popular delas é a fibra de vidro por possuir um custo bastante baixo em relação as outras fibras de carbono e aramid. Afirmam, porém, que são as fibras de carbono que possuem maior resistência e maior durabilidade.

\subsubsection{Sistemas de reforço com fibra de carbono}

Existem no mercado nacional três sistemas de reforços que utilizam as (CFRP) [Robery ; Innes, 1997 apud Beber et. al., (1999)]:

1 Lâminas de CFRP de alta resistência impregnadas com resina epóxi ou poliéster, que resultam em perfis contínuos dos mais diversos e complexos formatos que são, então, coladas sobre a superfície a ser reparada;

2 Fios de fibra de carbono, enrolados sob tensão, que são colados como filamentos sobre a superfície ou enrolados a seco e então curados a quente;

3 Tecidos pré-impregnadas (prepreg), com espessura similar a do papel de parede que são coladas sobre a superfície a ser reparada com resina, seguindo exatamente a curvatura do elemento e permitindo a aplicação em cantos vivos. 
O sistema de reforço com tecidos pré-impregnadas é fabricado a partir de filamentos de fibra de carbono esticados unidirecionalmente e levemente impregnados com resina. Este material é o que vem sendo utilizado com maior freqüência para reforço de estruturas.

Os dois tipos de materiais mais utilizados (tecido e lâmina de fibra de carbono) pouco diferem em desempenho e modo de aplicação (BEBER et.al., 1999). A diferença principal está na forma de apresentação do produto. Enquanto o tecido de fibra de carbono apresenta espessura de $0,5 \mathrm{~mm}$ e largura de aproximadamente 1,5m, as lâminas de fibra de carbono possuem espessura que varia de 1,2 a 1,4 mm e largura que varia de 5 a $10 \mathrm{~cm}$. Para melhor ilustrar estes produtos a figura 08 apresenta os respectivos materiais.
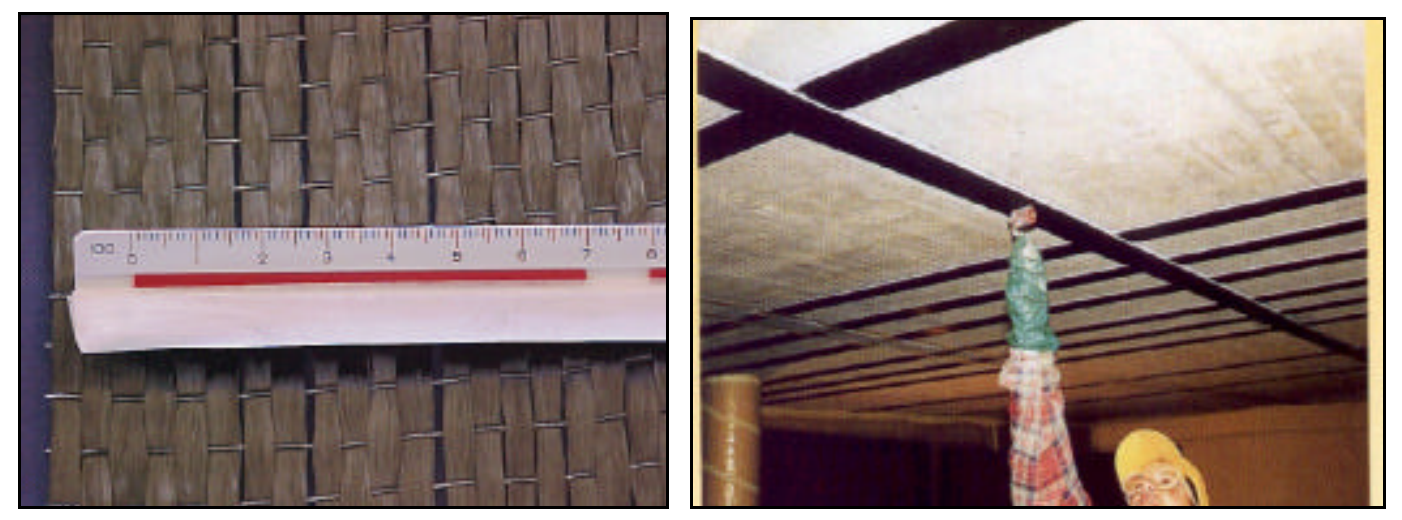

FIGURA 08: Tecido unidirecional. Fonte (do autor) e Lâmina de fibra de carbono. Fonte: Sika (2000)

Tanto as lâminas quanto os tecidos de CFRP (carbon fiber reinforced polymer) podem ser colados depois da preparação da superfície da madeira e do concreto, não necessitando nenhuma instalação adicional. São empregados quando estas estruturas apresentarem as seguintes condições: 
TABELA 03: Emprego de FRP em estruturas (Fonte: SIKA 2000)

\begin{tabular}{|c|c|}
\hline \multicolumn{2}{|c|}{ Empregado de FRP em estruturas de madeira e concreto } \\
\hline Sobrecargas & $\begin{array}{l}\text { - Aumento dos valores das ações; } \\
\text { - Crescimento do tráfego de veículos em pontes; } \\
\text { - Estruturas com vibrações; } \\
\text { - Mudanças de uso da estrutura. }\end{array}$ \\
\hline Estruturas danificadas & $\begin{array}{l}\text { - Envelhecimento dos materiais usados na construção; } \\
\text { - Corrosão das armaduras; } \\
\text { - Impacto de veículos; } \\
\text { - Incêndio. }\end{array}$ \\
\hline $\begin{array}{l}\text { Melhoria no funcionamento da } \\
\text { estrutura }\end{array}$ & $\begin{array}{l}\text { - Redução das deformações; } \\
\text { - Redução da fadiga das armaduras; } \\
\text { - Redução da largura das fissuras. }\end{array}$ \\
\hline Alteração do sistema estrutural & $\begin{array}{l}\text { - Remoção de paredes ou pilares; } \\
\text { - Seccionamento de laje para criar aberturas. }\end{array}$ \\
\hline $\begin{array}{l}\text { Defeitos de construção ou } \\
\text { projeto }\end{array}$ & $\begin{array}{l}\text { - Armaduras insuficientes na estrutura; } \\
\text { - Profundidade estrutural insuficiente. }\end{array}$ \\
\hline
\end{tabular}

Segundo Belperio et al. (1999) que avaliaram o uso de lâminas de fibra de carbono, com espessura de $1,2 \mathrm{~mm}$ e largura de $50 \mathrm{~mm}$, o produto apresenta uma excelente resistência à tração $(2400 \mathrm{MPa})$, e seu módulo de elasticidade variando de $155 \mathrm{GPa}$ a $300 \mathrm{GPa}$, semelhante ao do aço $\left(\mathrm{E}_{\mathrm{aço}}=210 \mathrm{GPa}\right)$.

\subsubsection{Comparação entre propriedades das fibras}

Segundo Beber (1999) é a fibra de carbono, combinada com uma matriz polimérica (CFRP - Carbon Fiber Reinforced Polymer), que apresenta as melhores características para desempenhar função de recuperação e reforço de estruturas, devido aos altos valores de sua resistência e módulo de elasticidade. A tabela 04 apresenta valores de propriedades das fibras de vidro, das fibras de carbono e do kevlar. 
TABELA 04: Características dos tecidos de fibras a $20^{\circ} \mathrm{C}$ (Fonte: Barracuda 2000)

\begin{tabular}{|c|c|c|c|}
\hline Fibras & \multicolumn{3}{|c|}{ Características } \\
\hline & $\begin{array}{c}\text { Resistência a } \\
\text { Tração } \\
(\mathrm{MPa})\end{array}$ & $\begin{array}{c}\text { Módulo de } \\
\text { Elasticidade } \\
(\mathrm{GPa})\end{array}$ & $\begin{array}{c}\text { Densidade } \\
\left(\mathrm{g} / \mathrm{cm}^{3}\right)\end{array}$ \\
\hline Unidirecional vidro (E) & 900 & 76 & 2,55 \\
\hline Orgânica (Kevlar) & 1500 & 125 & 1,44 \\
\hline Unidirecional carbono & 2200 & $160-300$ & 1,75 \\
\hline Lâmina carbono & 2400 & $165-300$ & 1,90 \\
\hline
\end{tabular}

Para o uso em reforço de estruturas, as fibras devem ser laminadas com algum tipo de adesivo formando desta forma um compósito FRP (Fiber Reinforced Polymers). Entre os adesivos mais utilizados na laminação destes tecidos pode-se destacar as resinas poliéster, vinílicas e epoxídicas.

Segundo Askeland (1996), os materiais compósitos são formados através da combinação de propriedades de resistência, rigidez, densidade, condutividade, resistência à corrosão entre outras.

Os fabricantes das respectivas fibras estão constantemente melhorando as propriedades mecânicas de resistência e rigidez, impulsionando sua associação aos materiais da construção (Jang, 1994).

\subsubsection{Análise de custos}

Com relação ao emprego de tecido de fibra de carbono e de fibra de vidro em reforço de estruturas de madeira, cabe ao projetista avaliar a relação custo beneficio da técnica em questão, em alguns casos torna-se mais vantajoso realizar o reforço e a recuperação da estrutura ao invés de substituir os elementos degradados. 
Com relação aos tecidos de fibra de carbono o maior entrave para sua popularização como reforço estrutural no Brasil não são as limitações do sistema, mas o preço do material. Um dos motivos do alto custo desses reparos está na origem dos materiais, todos importados do Japão, Estados Unidos e Suíça.

Devido ao alto custo, os reforços normalmente não cobrem toda a superfície da peça. A instalação do material em faixas racionaliza o gasto com fibras e diminui bastante o preço final da obra (Beber et al., 1999).

Porém, os tecidos de fibra de vidro apresentam um custo de aproximadamente 1/20 do custo do reforço com fibra de carbono. A tabela 05 apresenta um custo aproximado dos tecidos e lâminas de fibra de carbono e do tecido de fibra de vidro.

TABELA 05: Custo das fibras

\begin{tabular}{|l|c|}
\hline \multicolumn{1}{|c|}{ Fibras } & Custo (U\$\$) \\
\hline Tecido de Fibra de Carbono & $60,00 / \mathrm{m}^{2}$ \\
\hline Lâmina de Fibra de Carbono & $60,00 / \mathrm{m}$ linear \\
\hline Tecido de Fibra de Vidro & $3,00 / \mathrm{m}^{2}$ \\
\hline
\end{tabular}

\subsection{Adesivos}

A definição do melhor adesivo para ser utilizado em conjunto com fibra de carbono e fibra de vidro, sua classificação e os tipos existentes no mercado é de fundamental importância para o desenvolvimento deste trabalho que tem por objetivo determinar o adesivo que apresenta melhor desempenho no conjunto madeira - fibra.

Adesivo é definido como: "substância capaz de unir materiais através do contato entre suas superfícies". A capacidade de unir os materiais não é uma 
propriedade intrínseca da substância, mas depende do contexto em que a substância é utilizada.

Os adesivos são classificados em vários tipos. De acordo com sua composição química podem ser inorgânicos e orgânicos.

\subsubsection{Adesivos Inorgânicos}

Os adesivos inorgânicos são geralmente à base de silicatos, e proporcionam uma ligação entre os materiais com elevada resistência mecânica, ficando difícil diferenciar o adesivo e o cimento. Nos adesivos a ligação se dá pela desidratação do solvente. O cimento, no entanto, é formado através de reações químicas (Mantilla Carrasco, 1984).

\subsubsection{Adesivos Orgânicos}

Dentre os adesivos mais recomendados para serem utilizados na madeira, destacam-se os de origem orgânica. Estes adesivos dividem-se em dois grupos, o primeiro de origem natural e o segundo de origem sintética (Olmos, 1992). Dentre os de origem natural pode-se destacar: animal, amido, caseína e albumina de proteína vegetal. O grupo sintético é o mais importante e o mais empregado pela indústria madereira, por apresentar grande resistência à ação da água e por não sofrerem à ação de microorganismos. Estes adesivos podem ser classificados em termofixos e termoplásticos.

\subsubsection{Termofixos}


Adesivos termofixos são aqueles que endurecem por meio de reações químicas ativadas pela temperatura ou catalisadores. Possuem elevada resistência a umidade e ao calor. Dentre eles pode destacar: resorcinol-formaldeído, fenolformaldeído, uréia formaldeído, poliuretanos e epóxi.

- Resorcinol-Formaldeído

São empregados geralmente em estruturas de madeira expostas à temperatura ambiente ou pouco aquecidas. Quando a colagem é feita com aquecimento moderado, estes são misturadas com resinas fenólicas, formando o fenol-resorcinolformaldeído.

São comercializados na forma líquida, utiliza-se um agente endurecedor que deve ser adicionado pouco antes do seu uso, evitando o endurecimento rápido e a perda de material. Segundo Peterson (1964) apud Henriques de Jesus (2000), este tipo de adesivo veio preencher as necessidades do mercado por um adesivo impermeável e usado a baixas temperaturas. Sua resistência estrutural é elevada, superando a da própria madeira.

Segundo Henriques de Jesus (2000) este tipo de adesivo suporta quaisquer condições a que venha a ser exposta, mesmo as alterações climáticas, mantendo sua capacidade resistente em relação ao carregamento.

São empregados quando as condições de impermeabilidade são obrigatórias e onde as colas fenólicas, cuja cura ocorre em altas temperaturas, não forem adequadas. A colagem de vigas e painéis estruturais e a colagem de laminados marítimos são algumas das aplicações.

- Fenol-Formaldeído

São adesivos formados a partir de resinas fenólicas sintéticas (Mantilla Carrasco, 1984), necessitam de altas temperaturas para cura $\left(130\right.$ a $\left.160^{\circ} \mathrm{C}\right)$, sendo 
comercializados em filmes secos, reconstituídos pela ação da água. Necessitam de um endurecedor a ser dosado com a resina, produzindo boa resistência das uniões coladas mesmo que atuem em condições extremamente adversas. Estas condições podem ser: longo tempo de exposição à água quente ou fria, ciclos de secagem e de endurecimento, variações extremas de temperaturas e umidade relativa, temperaturas em torno da temperatura de carbonização da madeira, ataque de microorganismos e exposição à ação de vários tipos de componentes, como aqueles usados na preservação de componentes (Kollmann et al., 1975).

Segundo Henriques de Jesus (2000) se os processos de colagem e endurecimento forem adequadamente conduzidos, as colagens feitas com adesivos fenólicos apresentarão grande durabilidade, podendo ultrapassar a da própria madeira. Sua linha de cola possui coloração escura e um dos fatores negativos é o alto custo do fenol, cuja matéria prima é o petróleo.

\section{- Uréia-Formaldeído}

São classificados como resistentes à ação da umidade, no entanto perdem resistência quando atuam sob a ação da umidade por tempo relativamente curto. Dessa forma exposições repetidas a ambientes com alto teor de umidade, temperaturas iguais ou superiores a $65^{\circ} \mathrm{C}$, poderão provocar um mau desempenho das peças, afetando-as negativamente.

São apresentados freqüentemente na forma líquida, adicionando-se um catalisador, ou na forma de pó, quando se emprega um catalisador combinado, necessitando apenas serem misturados com água (Samlaic, 1983).

\section{- Poliuretanos}

Este adesivo foi muito utilizado na década de 60 para produção de chapas de madeira aglomerada. Estas chapas apresentavam as mesmas características das 
produzidas com adesivos fenólicos e usadas externamente. Segundo Henriques de Jesus (2000), alguns estudos desenvolvidos indicaram que o emprego dessas chapas coladas com adesivos à base de poliuretano, apresentavam propriedades superiores às chapas coladas com adesivo fenólico.

\section{- Epóxi}

Segundo Pardini (1990) as resinas epóxi são polímeros que se caracterizam pela presença de pelo menos dois grupamentos epóxi na molécula.

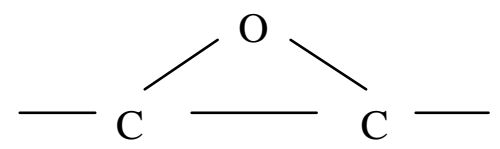

A propriedade mais singular das resinas epóxi é sua habilidade em transformar-se em um sólido termorrígido, tendo como ponto de partida o estado líquido. A viscosidade é então parâmetro de particular importância em resinas líquidas.

Conclui ainda, que as resinas epóxi em seu estado termoplástico são caracterizadas principalmente pela sua viscosidade, ponto de fusão, porcentagem de insaturação, peso molecular e distribuição de peso molecular.

Henriques de Jesus (2000) relata que este tipo de adesivo é produzido a partir de resinas à base de epicloritina e resinas formadas por peroxidação, tem pouca utilização na indústria madereira devido ao seu alto custo e a dificuldade de afinidade com algumas espécies. Tem aplicação em ligações com concreto, metais, vidros e cerâmica.

Alguns estudos referentes à utilização de adesivos termofixos para fixação de tecidos de fibras de carbono à madeira estão sendo realizados, entre eles pode-se destacar o de Belperio; Grad (1999). Neste estudo, testou-se três tipos de adesivos para confecção de vigas laminada colada: Resorcinol Formaldeído (com nome 
comercial Cascophen), Resorcinol Sikadur (epóxi) e um poliuretano, combinando-os com fibra de carbono. Como conclusão, pode-se dizer que o adesivo Resorcinol Formaldeído apresentou baixo desempenho na interface fibra - madeira, contrariando o desempenho admirável deste adesivo entre elementos estruturais de madeira. O adesivo Sikadur apresentou dificuldade na aplicação. Já o poliuretano utilizado foi o que apresentou melhor desempenho.

\subsubsection{Adesivo epóxi AR-300}

Este tipo de adesivo é constituído por resina e endurecedor, e foi desenvolvido para fornecer uma excelente penetração a todos os tipos de fibras. Possui uma viscosidade extremamente baixa, possuindo um manuseio semelhante a uma resina poliéster. Este sistema de resina não desenvolve uma superfície pegajosa após o processo de cura, possibilitando laminações sucessivas de outras camadas de fibras.

\subsubsection{Termoplásticos}

A característica principal dos adesivos termoplásticos é a sua cura reversível. Podem ser fundidos ou amolecidos quando é aumentada a temperatura, tornando a solidificar ao serem resfriados. São usados como solução ou em dispersão em água.

O grupo dos acetatos sintéticos polivinílicos, que são adesivos prépolimerizados, é empregado em colagem de madeira onde a cura é feita por perda do solvente dispersante. Tem vida útil muito longa devido à alta estabilidade química e física da dispersão. Com grande resistência à ação de microorganismos, não mancham a madeira. São facilmente manuseados, apresentando propriedades de contato e prensagem semelhantes aos adesivos anteriormente citados e exigindo 
pouca pressão de prensagem. Não devem ser aplicados em construções pesadas, onde a resistência das juntas deve ser alta e em peças coladas de construções expostas ao intemperismo. (Henriques de Jesus, 2000).

Os adesivos que se enquadram neste grupo são: adesivos animais, albumina de sangue, caseína, soja, tanino. Dentre estes os que apresentam melhores características para fins estruturais são os de caseína e tanino, porém não são resistentes a ambientes agressivos.

\subsubsection{Adesivo poliuretano à base de mamona}

Outro tipo de adesivo que pode vir a ser empregado em reforços com fibras de carbono a madeira, no Brasil, foi estudado por Henriques de Jesus (2000). Este adesivo poliuretano à base de mamona, foi testado em vigas de madeira laminadas coladas e apresentou resultados satisfatórios quanto à adesão.

O adesivo de mamona utilizado é a resina poliuretânica originária de óleo vegetal (Ricinus communis), constituída a partir de um poliol 25040 e um prépolímero A249 formulado com óleo de mamona e MDI (p-fenileno dimetil

diisocianato). A resina é do tipo bicomponente de cura a frio, não é agressivo ao homem e ao meio ambiente, além do óleo de mamona ser obtido de um recurso natural e renovável. Os dois componentes devem ser misturados segundo proporções cabíveis para cada caso, dependendo da aplicação e das necessidades técnicas.

\subsection{Mecanismos de adesão}

Houwink; Solomon (1965) definem adesão como sendo a atração entre uma superfície sólida e uma segunda fase. Esta segunda fase pode consistir de partículas 
individuais, como pequenas gotas, pó ou de uma película líquida ou sólida. Pode-se dizer também que adesão é a força atrativa entre moléculas de substâncias diferentes, ao contrário de coesão que é a força de atração verificada entre moléculas ou átomos de uma mesma substância.

Segundo Mantilla Carrasco (1984) as forças de adesão têm sua origem nas ligações químicas primárias (interatômicas) e nas ligações atrativas secundárias (intermoleculares). As forças produzidas pelas ligações primárias são de natureza essencialmente eletrônica (ligações entre átomos ou íons), podendo ser: ligações metálicas, ligações eletrovalentes, ligações covalentes e ligações coordenadas covalentes. As ligações atrativas secundárias são de natureza eletrostática ou magnética, associam as moléculas entre si, de maneira razoavelmente forte, mas não são suficientemente capazes de formarem uma nova individualidade química.

Segundo Oliveira ; Freitas (1995), a adesão é atribuída a várias e diferentes forças, como as forças moleculares e forças de Van der Waals. Estas só podem ser desenvolvidas quando as moléculas estão muito próximas entre si. Por esta razão aplica-se pressão sobre as superfícies das juntas a serem coladas, tanto para colagem a frio, quanto para colagem a quente.

Sabe-se que existe três mecanismos de adesão definidos: a adesão mecânica, a adesão específica e a adesão química.

Segundo Galaz (1979) apud. Henriques de Jesus (2000), a adesão mecânica se dá entre superfícies porosas baseadas no entrelaçamento da cola endurecida na junta de colagem e nos poros do aderente. A colagem fica então dependente da estrutura superficial do substrato, da pressão, da viscosidade etc. 
Já a adesão específica ocorre entre duas superfícies lisas, onde as forças básicas de adesão entre as macromoléculas existem devido as ligações químicas secundárias de atração.

Na adesão química, as forças básicas envolvidas são as de ligações primárias, de natureza essencialmente eletrônica (ligações entre átomos ou íons, podendo ser ligações metálicas, eletrovalentes e covalentes).

\subsection{Emprego de FRP em reforços de estruturas de madeira}

Segundo Belperio et al. (1999), atualmente as FRP vêm sendo estudadas, como material para adequar estruturas de madeira, de concreto e de aço, para novos usos, com a finalidade de cumprir normas não atendidas no projeto (aumento de sobrecarga), e em reparos devidos a acidentes, envelhecimento, ataques químicos e erros de cálculo estrutural.

De acordo com Taylor et al. (1994) apud Beber et al. (1999) a principal razão em utilizar reforços com polímeros é aumentar a rigidez e a resistência das peças estruturais.

Abdel-Magid et al. (1994) avaliaram o comportamento de vigas de madeira reforçadas com fibra de carbono, kevlar 49 e kevlar 49 prepreg, verificando o incremento de resistência e rigidez. Os tecidos de fibras utilizados como reforço eram unidirecionais e foram aplicados paralelamente às fibras da madeira, utilizando um adesivo epóxi. Este adesivo apresentou excelente resultado de adesão entre as fibras e a madeira. As propriedades mecânicas das fibras utilizadas estão apresentadas na tabela 06. 
TABELA 06: Características das fibras aramid e vidro. (Fonte: Abdel-Magib et al. 1994)

\begin{tabular}{|c|c|c|}
\hline Tipo de Fibra & $\begin{array}{c}\text { Módulo de Elasticidade } \\
\text { (MPa) }\end{array}$ & $\begin{array}{c}\text { Resistência a Tração } \\
\text { (MPa) }\end{array}$ \\
\hline Carbono AS4 & 58000 & 612 \\
\hline Kevlar 49 & 28100 & 407 \\
\hline Kevlar 49 prepreg & 62540 & 936 \\
\hline
\end{tabular}

Concluíram que o reforço com fibra de carbono foi o que acarretou o aumento mais significativo na resistência das vigas de madeiras (acréscimo de 31,5\%). Porém, foi a fibra kevlar 49 prepreg que apresentou maior aumento da rigidez (acréscimo de $21,7 \%$ ) das vigas. Outro fator identificado refere-se ao modo de ruptura das vigas que foi inicialmente por compressão das fibras superiores seguida por uma ruptura por tração das fibras inferiores.

Segundo Bakoss; Greenland (1999), apesar de pequeno, o uso de (FRP) na construção civil vem avançando, e as técnicas de aplicação estão sendo desenvolvidas rapidamente na América do Norte, Europa e Japão. Estas fibras, por apresentarem facilidade de composição com outros tipos de materiais, estão se associando aos tradicionais materiais da construção civil como madeira, concreto e alvenaria, compondo estruturas mais resistentes e com um peso próprio levemente alterado. Acrescenta também que o potencial para a sua utilização em estruturas de madeira na Europa e na América do Norte é altamente significativo, devido a vários fatores: redução do custo de materiais quando usados adequadamente, aumento da durabilidade e redução da manutenção para elementos estruturais de madeira, capacidade de reparar e reforçar estruturas danificadas.

Tingley; Cegelka (1996), relatam que estas fibras vêm sendo utilizadas em maior quantidade para reforço de peças estruturais de madeira (pilar e viga), devido principalmente a: queda do preço do material, baixa variação dimensional do 
material, de aproximadamente $0,1 \%$, facilidade de aceitação do produto pelo mercado do mundo todo, surgimento de novos adesivos para serem utilizados junto com fibras de carbono.

Tingley; Gilham (1994) estudaram o comportamento de vigas de pontes de madeira reforçadas com fibra mistas de carbono e aramid, sujeitas à ação do peso próprio, das cargas acidentais e das variações dos fatores do meio ambiente como umidade e temperatura. Obtiveram os seguintes resultados: aumento da resistência estrutural das peças reforçadas, redução no custo de reabilitação, em torno de $25 \%$ a $30 \%$, devido ao baixo grau de substituição de madeira, diminuição de custos com tratamento, utilização de pouca madeira para recuperação e conseqüente diminuição do peso próprio, uso de seções menores, que apresentam as mesmas propriedades de resistência e rigidez a seções maiores sem reforço.

A figura 09 ilustra a aplicação de fibra de carbono em vigas de ponte de madeira.

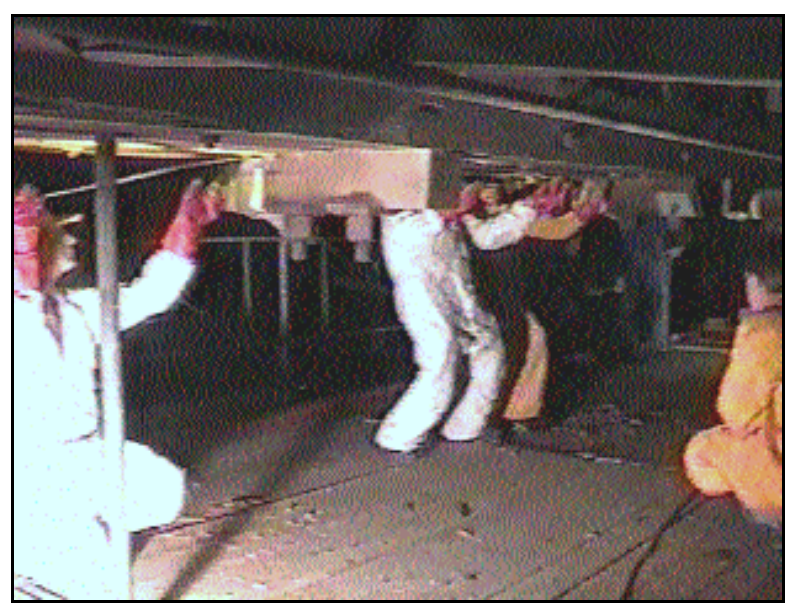

FIGURA 09: Aplicação do reforço de lâminas de fibra de carbono em vigas de ponte de madeira 
Triantafillou; Deskovic (1992) avaliaram vigas maciças de madeira reforçadas com tecido unidirecional de fibra de carbono fixados com adesivo epóxi. Utilizaram tecidos com espessura variando de 0,55 a $0,75 \mathrm{~mm}$. Optaram pela utilização deste tipo de material para reforçar estruturas por apresentar alta resistência, baixa densidade, resistência à corrosão, combinando as vantagens oferecidas pelos materiais compósitos com a eficiência dos reforços externos, resultando em peças estruturais com excelentes propriedades mecânicas de resistência, rigidez e ductilidade. Conseguiram um aumento de $20 \%$ a $40 \%$ na capacidade de carga da peça estrutural reforçada.

Bakoss et al. (1998) estudaram o comportamento de vigas retangulares de pinho e vigas I reforçadas com tecido de fibra de carbono fixados com resina epóxi. Foi avaliado o aumento da resistência e da rigidez das peças, chegando a valores até $135 \%$ superiores aos apresentados pelas vigas sem o reforço.

Dagher (1999) estudou a utilização de reforço com lâminas de fibras de carbono (espessura 1,5mm) em vigas laminadas coladas, com o objetivo de avaliar o aumento da capacidade de carga dos elementos estruturais. Estas fibras proporcionaram um melhor desempenho estrutural às peças, permitindo uma maior utilização deste tipo de viga na construção civil.

O ensaio de flexão realizado nas vigas tinha o objetivo de avaliar deformações lentas. Para isso adotou um sistema bi-apoiado com duas forças concentradas localizadas a $1 / 3$ dos apoios. As fibras foram aplicadas entre as duas lâminas inferiores, por ser a região submetida a maiores tensões. Avaliaram-se três tipos de amostras de controle, a primeira sem nenhum tipo de reforço, a segunda com uma camada de reforço e a terceira com três camadas de fibra. 
Resultados positivos de aumento da resistência foram conseguidos. Para vigas reforçadas com uma camada de reforço o incremento na capacidade de carga foi de $25 \%$ e para vigas reforçadas com três camadas o incremento foi de $60 \%$.

Bergmeister, K.; Luggin, W. (2001) estudaram vigas de madeira laminada colada reforçadas com tecido de fibra de carbono. Durante os ensaios experimentais observaram a ocorrência de dois tipos de ruptura nas vigas reforçadas. Ruptura por tração das fibras inferiores da madeira, após a ocorrência de plastificação da seção comprimida da viga. E também a ocorrência de ruptura na linha de cola.

Tingley, D.; Kent, S (2001), avaliaram vigas de seção caixão reforçadas com fibras aramid aplicadas ao longo da direção longitudinal das fibras da madeira. Estas fibras possuíam valor de módulo de elasticidade igual a 59.000 MPa e de resistência a tração igual a $1034 \mathrm{MPa}$. Como resultado observou um aumento de 21,5\% na resistência e 4,69\% na rigidez, comparando com resultados obtidos para vigas sem reforço. O tipo de ruptura que ocorreu nas vigas reforçadas foi por compressão nas fibras superiores, após a ocorrência de uma grande deformação plástica. Diferente da ruptura das vigas sem reforço, que foi por tração.

Tingley et al., (1996) nos seus estudos sobre reforços em vigas de madeira e viga laminada colada, identificaram alguns problemas a serem considerados:

1. Comportamento da união fibra-madeira;

2. Estabilidade dimensional da madeira em relação à fibra;

3. Porosidade da fibra utilizada e a da madeira;

Segundo Dagher (2000), as propriedades físicas, mecânicas e químicas das FRP são muito versáteis. As fibras podem ser um complemento para as propriedades ortotrópicas da madeira. Consequientemente problemas de incompatibilidade entre madeira e reforço são minimizados. Ressalta ainda a possibilidade de uso do material 
em muitos processos de manufaturas, freqüentemente usados para produzir compósitos estruturais de madeira. Apesar de existirem estes problemas, a utilização de FRP para reforço de elementos estruturais de madeira, é uma alternativa promissora, pois se trata de um material resistente a corrosão, que proporciona boa economia e um pequeno aumento do peso próprio.

Martin et al (2000) avaliaram a resistência e rigidez de decks de madeira de baixa densidade reforçados com FRP. Foram utilizadas fibras mistas vidro-aramid, e apenas fibras aramid, cujas propriedades mecânicas estão apresentadas na tabela 07.

TABELA 07: Características das fibras aramid e vidro. (Fonte: Martin et al. 2000)

\begin{tabular}{|c|c|c|c|}
\hline Tipo de Fibra & $\begin{array}{c}\text { Módulo de Elasticidade } \\
(\mathbf{M P a})\end{array}$ & $\begin{array}{c}\text { Resistência a Tração } \\
\text { (MPa) }\end{array}$ & $\begin{array}{c}\text { Espessura } \\
(\mathbf{m m})\end{array}$ \\
\hline Aramid & 80.000 & 986 & 1,78 \\
\hline Vidro-Aramid & 55.000 & 241 & 1,27 \\
\hline
\end{tabular}

Os ensaios de flexão realizados nas peças de madeira permitiram concluir que ocorreu um aumento de 40 a $70 \%$ na rigidez das peças e um aumento de $85-140 \%$ na resistência, para espécies de madeira de baixa densidade.

De acordo com Tichy (1998) a utilização destas fibras reforçadas com polímeros (FRP) para reforço e recuperação de estruturas de madeira é uma tendência para este século. Acrescenta a necessidade de se criar um ecossistema sustentável e renovável, onde, certamente, a madeira é o centro desse processo, por ser o material da construção civil mais amigo do meio ambiente. Por isso, a utilização destas fibras para reabilitação de estruturas de madeira não é uma ameaça para o meio ambiente, mas sim, uma nova tendência de se recuperar estruturas danificadas, preservando a natureza. 
Alguns trabalhos que vem sendo desenvolvidos avaliam o potencial de utilização de FRP para reforço de elementos de ligações.

Bui; Miller (1996) testaram a utilização de fibra de vidro laminadas com adesivo epóxi como reforço de juntas dentadas (finger joints) de vigas de madeira laminada colada, conforme mostra a figura 10.

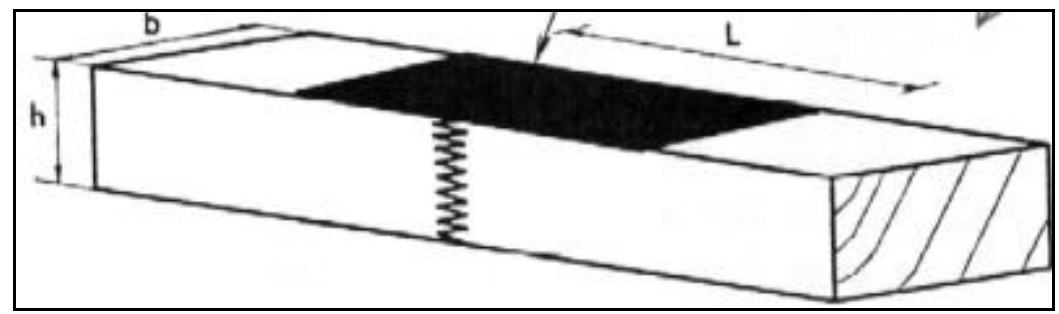

FIGURA 10: Fibra reforçando juntas de viga laminada colada. Fonte: Ritter (1990)

Nas regiões inferiores das vigas, as tensões de tração atuantes são elevadas, e as emendas apresentam uma resistência inferior à da peça maciça. Dessa forma, a realização de reforços de emendas localizadas nesta região proporciona um aumento de resistência e de rigidez, facilitando a utilização de peças com maiores dimensões.

A avaliação destes reforços foi feita através da aplicação de ensaio de tração nas respectivas peças, avaliando o aumento de resistência e rigidez, com a introdução da fibra, conforme mostra a figura 11 .

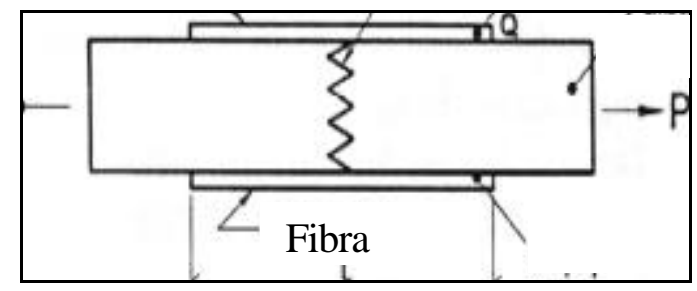

FIGURA 11: Ensaio de tração para verificar a resistência das peças. Fonte: Ritter (1990) 
Concluem que com um baixo custo e com um aumento mínimo da seção da peça, obtêm-se valores de resistência à tração da ligação finger joint, 60\% superiores, em média, aos obtidos sem a utilização de reforço.

Chi-Jean (2000) verificou o comportamento mecânico da fibra de vidro no reforço de ligações entre elementos estruturais de madeira. A figura 12 apresenta algumas destas possibilidades.

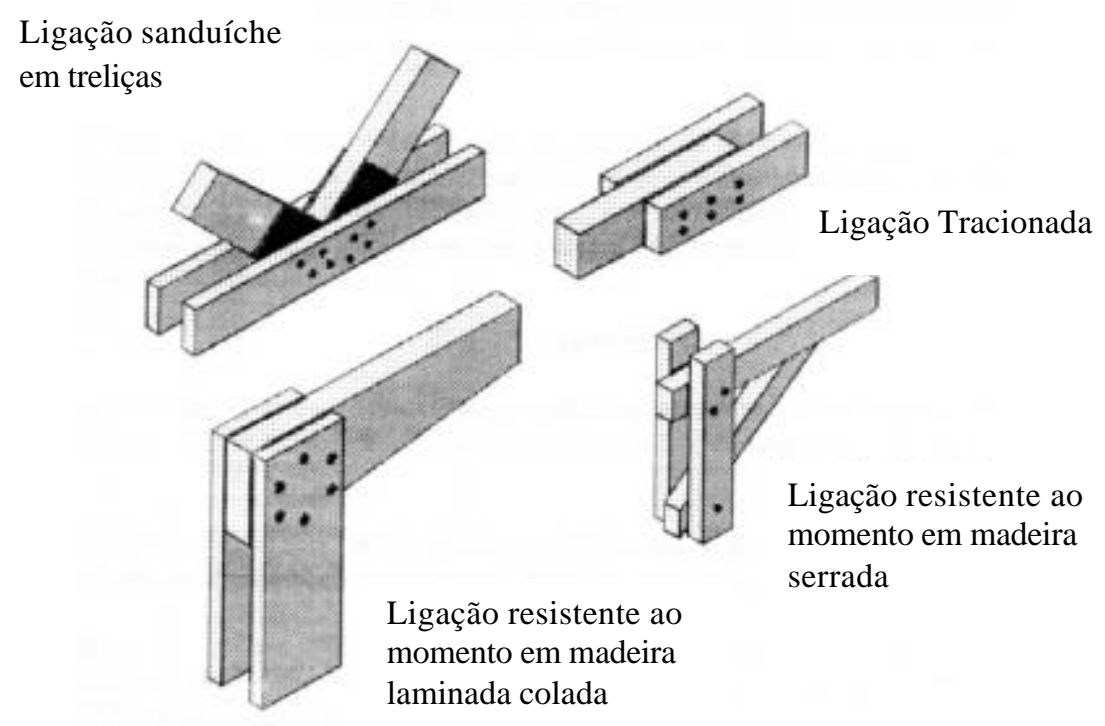

FIGURA 12: Possibilidades de reforço com fibra de vidro em ligações

Observou um melhor comportamento mecânico das ligações reforçadas. Aumento da resistência ao embutimento de aproximadamente $44 \%$, em relação às ligações sem reforço, quando utilizadas duas camadas de fibra. Afirma também que a associação destes materiais possibilita a execução de projetos mais ousados em madeira. 
Tingley et al. (1999) verificaram o efeito de altas temperaturas em reforços com polímeros em vigas de madeira. A verificação foi realizada por meio de ensaios, fornecendo calor ao sistema até atingir a temperatura de $104^{\circ} \mathrm{C}$, e monitorando o comportamento das vigas.

Concluíram que o reforço externo com fibra de carbono não é aceitável para altas temperaturas, pois as juntas de cola aumentam e se abrem, soltando a fibra da madeira.

Já em vigas onde as fibras são protegidas com uma lâmina de madeira, o seu comportamento é melhor. Usando este tipo de proteção, consegue-se manter a temperatura das fibras abaixo de $80 \%$ da aplicada diretamente sobre a peça de madeira.

Constatou ainda que o módulo de elasticidade e a resistência da fibra diminuem em temperaturas elevadas. Recomenda-se, portanto, a utilização de algum tipo de proteção sobre o reforço de fibra de carbono, para garantir um melhor desempenho durante toda a sua vida útil.

Martin; Tingley (2000) avaliaram a resistência ao fogo de um total de trinta (30) vigas de madeira, sendo que vinte e seis (26) eram reforçadas com FRP e quatro (4), não possuíam reforço. Os ensaios foram realizados de acordo com a norma ASTM E 199-88 (1993) - Standard Test Methods for Fire Tests of Building Construction Materials. Três diferentes tipos de fibras foram avaliadas, entre elas Aramid, carbono-aramid e vidro-aramid. Conclusões relatam que as fibras apresentaram uma boa resistência ao fogo. No entanto, esta resistência varia para cada tipo de material utilizado. As fibras que foram protegidas por uma lâmina de 
madeira apresentaram melhor desempenho em relação àquelas que estavam em contato direto com o fogo.

\subsection{Critério para dimensionamento de vigas de madeira reforçadas com}

\section{fibras}

Belperio; Grad (1999) apresentam uma análise teórica comparando a deformação sofrida por vigas de madeira laminada colada com duas espécies diferentes de madeira reforçadas com FRP e vigas laminadas sem reforço.

A análise das vigas sem reforço é baseada na teoria da seção transformada, considerando o material elástico-linear.

O momento resistente da viga sem reforço é dado por:

$$
\mathrm{M}_{\mathrm{u}}=\mathrm{f}_{\mathrm{b}} \cdot \mathrm{W}
$$

onde:

$\mathrm{M}_{\mathrm{u}}=$ Momento último resistido pela viga

$\mathrm{f}_{\mathrm{b}}=$ Resistência da Madeira a Flexão

W= Módulo de resistência da seção transversal transformada

Considerando que o carregamento é composto por uma força concentrada no meio do vão da viga, a máxima força resistida pela viga pode ser determinada por:

$$
\mathrm{M}_{\mathrm{u}}=\frac{\mathrm{PL}}{4} \quad \mathrm{P}=\frac{4 \cdot \mathrm{M}_{\mathrm{u}}}{\mathrm{L}}
$$

onde:

$\mathrm{L}=$ Comprimento do vão

P= Força Máxima 
O deslocamento vertical no meio do vão é estimado por:

$$
\delta=\frac{P \cdot L^{3}}{48 E I}
$$

onde:

I= Momento de Inércia da seção transformada

E= Módulo de Elasticidade

Para a análise das vigas reforçadas, o método da seção transformada foi utilizado apenas para avaliação da rigidez. Para o cálculo da resistência, foi utilizada uma analogia similar à utilizada no cálculo de vigas de concreto armado.

A figura 13 apresenta a distribuição de tensões assumida pelo modelo na seção da viga reforçada, na fase de ruptura. Nesta aproximação, foi considerado que cada região atua com a resistência máxima. A parte da seção acima da linha neutra se encontra solicitada pela resistência máxima de compressão (observa-se que existem dois materiais diferentes, o que causa dois níveis diferentes de tensões de compressão). Abaixo da linha neutra, a região tracionada da madeira é considerada com distribuição linear de tensões, atuando em conjunto com a força resultante do material de reforço. 


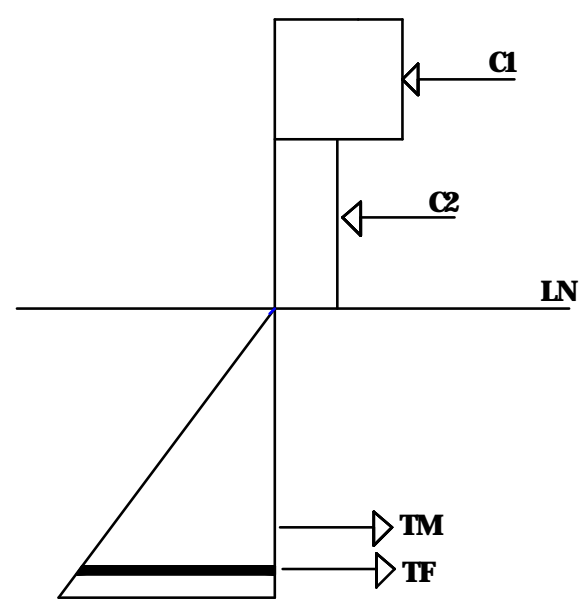

FIGURA 13: Distribuição de tensões em vigas reforçadas

Com o valor do momento último das vigas reforçadas, pode-se determinar a máxima força resistida pela viga através da seguinte equação:

$$
\mathrm{P}=\frac{4 \cdot \mathrm{M}_{\mathrm{r}, \mathrm{u}}}{\mathrm{L}}
$$

onde:

$\mathrm{L}=$ Comprimento do vão

$\mathrm{P}=$ Força Máxima

$\mathrm{M}_{\mathrm{r}, \mathrm{u}}=$ Momento último de vigas reforçadas

Conclusões relatam que os valores de deslocamentos estimados pela teoria da seção transformada foram próximos aos valores obtidos com a realização dos ensaios. Porém os valores experimentais, para força máxima resistida pela viga, apresentaram-se inferiores aos estimados pela teoria.

\subsection{Conclusões da revisão}

Uma análise da revisão bibliográfica permite concluir que existem vários métodos de recuperação e reforço de elementos estruturais de madeira. Dos métodos 
de recuperação apresentados o mais utilizado é o método tradicional. Para o método mecânico, a chapa metálica não deve ser fixada com adesivo pois ocorre um acúmulo de umidade nestas regiões, provocando uma degradação mais intensa da peça de madeira. Pode-se dizer também que o método de recuperação mais eficiente é o que utiliza variações de resina epóxi. Este material é usado para preencher rachaduras, superfícies atacadas por insetos e espaços vazios. Além de vedar a área danificada, aumenta a capacidade de carga da estrutura e reduz o aparecimento de futuras rachaduras.

Estudos em andamento indicam que as FRP (fibras reforçadas com polímeros) são um excelente material para atuar em reforço de estruturas. $\mathrm{O}$ uso destas fibras proporciona um ganho significativo de resistência e rigidez à estrutura, reduz o custo de recuperação, em torno de $25 \%$ a $30 \%$, devido ao baixo grau de substituição de madeira, diminui os custos com tratamento, utiliza pouca madeira para recuperação e conseqüentemente ocorre uma diminuição do peso próprio, proporciona o uso de seções menores, que apresentam as mesmas propriedades mecânicas das seções maiores sem reforço.

De acordo com os trabalhos anteriormente apresentados, pode-se dizer que os tecidos de fibras de vidro, apesar de possuírem propriedades mecânicas inferiores aos de fibras de carbono, apresentam uma boa eficiência quando aplicados em reforço de elementos estruturais de madeira.

Sugere-se a colocação de uma peça de madeira para proteção da fibra contra altas temperaturas.

O critério de dimensionamento apresentado utiliza a teoria da seção transformada para determinar o valor da rigidez de vigas reforçadas, obtendo valores 
satisfatórias quando comparados com valores obtidos experimentalmente. Com relação à ruptura, o critério apresentado não conduz a resultados apropriados.

As FRP devem ser aplicadas na face inferior das vigas, por ser a região solicitada por maiores esforços de tração. Cabe salientar que a correta aplicação dos respectivos tecidos de fibras reforçadas com polímeros, garante o bom desempenho do sistema estrutural reforçado. A definição do melhor adesivo para fixar fibras à madeira é importante para garantir o sucesso do reforço com fibras. 


\section{3 - DETERMINAÇÃO DAS PROPRIEDADES MECÂNICAS DE FIBRAS DE VIDRO E DE FIBRAS DE CARBONO LAMINADAS COM ADESIVOS COMERCIAIS E A BASE DE MAMONA}

Este capítulo apresenta o método de ensaio de tração e resultados de resistência e de rigidez para fibras de vidro e fibras de carbono laminadas com adesivo epóxi, cascophen, mamona e sem laminação.

\section{1 - Materiais e métodos}

O método de ensaio empregado foi o da norma ASTM D3039-95 - Standard Test Method for Tensile Properties of Polymer Matrix Composite Materials", da American Society for Testing and Materials, que especifica os procedimentos para determinação da resistência à tração e do módulo de elasticidade de materiais compósitos reforçados com matriz polimérica. Um resumo do método do ensaio está apresentado a seguir, abordando os aspectos referentes ao trabalho desenvolvido.

\section{Formas e dimensões}

Para que os corpos-de-prova tenham um número suficiente de fibras na seção transversal, que represente as propriedades do material, devem ser estabelecidas dimensões mínimas para os mesmos.

As dimensões mínimas dos corpos-de-prova para serem utilizados nos ensaios de tração estão apresentadas na figura 14. A tabela 08 exemplifica algumas destas dimensões, em função da direção das fibras.

Os corpos-de-prova com fibras unidirecionais devem ser confeccionados com abas, as quais previnem o aparecimento de falhas prematuras durante a aplicação de 
forças. Alguns cuidados devem ser tomados ao confeccionar as abas, tais como: alinhamento da aba, material a ser utilizado, ângulo de aplicação, tipo de adesivo, tipo de garra, pressão na garra e alinhamento da garra.

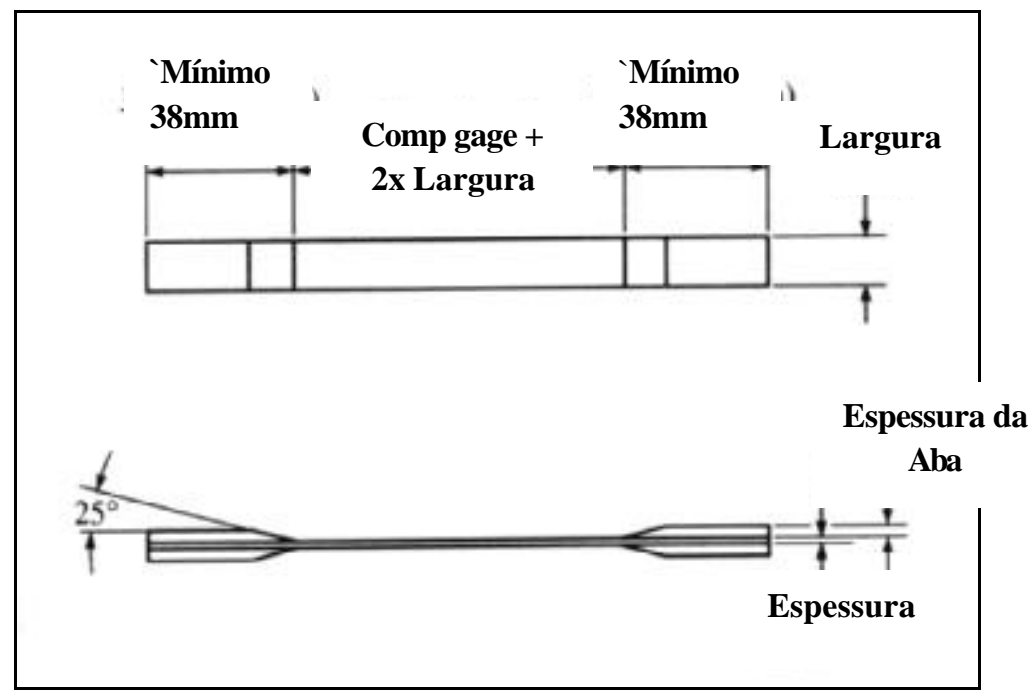

FIGURA 14: Dimensões de corpos-de-prova para ensaio de tração. Fonte: ASTM D3039/95

TABELA 08: Geometria dos corpos-de-prova. Fonte: ASTM D3039/95

\begin{tabular}{|c|c|c|c|c|c|c|}
\hline \multicolumn{7}{|c|}{ Geometrias recomendadas para ensaio de tração em fibras } \\
\hline $\begin{array}{c}\text { Orientação das } \\
\text { fibras }\end{array}$ & $\begin{array}{c}\text { Largura } \\
(\mathrm{mm})\end{array}$ & $\begin{array}{c}\text { Comp. } \\
(\mathrm{mm})\end{array}$ & $\begin{array}{c}\text { Esp. } \\
(\mathrm{mm})\end{array}$ & $\begin{array}{c}\text { Comp. } \\
\text { Aba } \\
(\mathrm{mm})\end{array}$ & $\begin{array}{c}\text { Esp. Aba } \\
(\mathrm{mm})\end{array}$ & $\begin{array}{c}\text { Angulo } \\
\text { da Aba } \\
\left({ }^{\circ}\right)\end{array}$ \\
\hline $0^{\circ}$ Unidirecional & 15 & 250 & 1,0 & 56 & 1.5 & 7 ou 90 \\
\hline $90^{\circ}$ Unidirecional & 25 & 175 & 2,0 & 25 & 1.5 & 90 \\
\hline Fios Descontínuos & 25 & 250 & 2,5 & - & - & - \\
\hline
\end{tabular}

\section{Aplicação do carregamento}

O ensaio de tração de fibras reforçadas com polímeros deve ser feito com velocidade constante de deformação igual a $2 \mathrm{~mm} / \mathrm{min}$.

\section{Cálculo da resistência e do módulo de elasticidade}

O cálculo da resistência de fibras reforçadas com polímeros deve ser feito de acordo com a formulação apresentada a seguir. 


$$
\mathrm{f}_{\mathrm{tu}}=\frac{\mathrm{F}_{\text {máx }}}{\mathrm{A}}
$$

Onde:

$\mathrm{f}_{\mathrm{tu}}-$ Resistência à tração $(\mathrm{MPa})$

$\mathrm{F}_{\text {máx }}$ - Força máxima aplicada $(\mathrm{N})$

A - Área do corpo-de-prova $\left(\mathrm{mm}^{2}\right)$

$\mathrm{O}$ módulo de elasticidade é calculado a partir do diagrama tensão $\mathrm{x}$ deformação, sendo igual ao coeficiente angular do mesmo.

\subsubsection{Materiais utilizados para a confecção dos corpos-de-prova}

Para a confecção dos corpos-de-prova utilizaram-se os seguintes materiais:

\section{Fibras}

Os ensaios de tração foram feitos com tecido unidirecional de fibras de carbono(VGW 095) e de fibras de vidro (VEW 130). As figuras 15 e 16 mostram estes dois tipos de materiais, respectivamente.

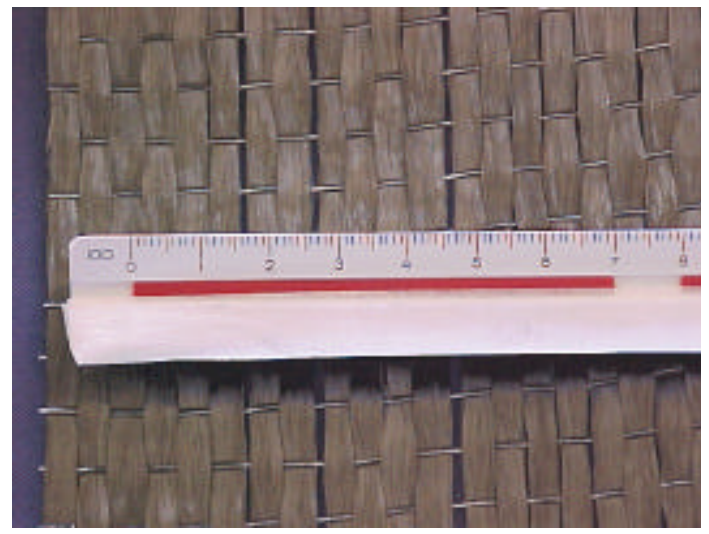

FIGURA 15: Tecido de fibras de carbono

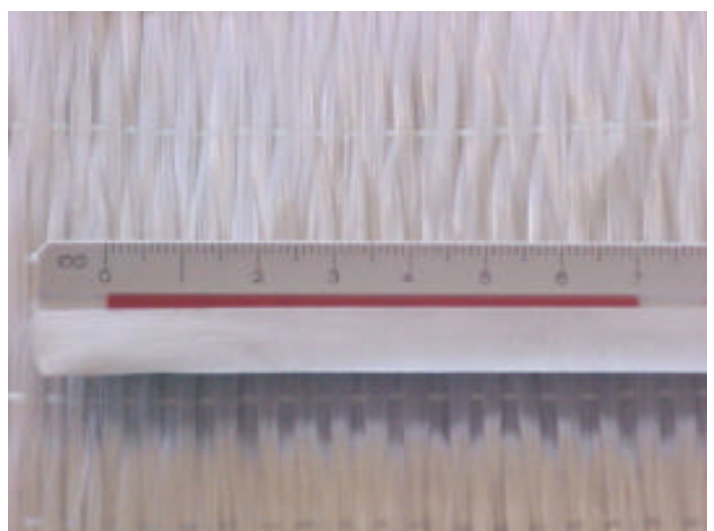

FIGURA 16: Tecido de fibras de vidro

\section{Adesivos}

Para a laminação dos corpos-de-prova foram utilizados três (3) tipos de 
adesivos: adesivo à base de óleo de mamona, Phenol Resorcinol Formaldehyde (com nome comercial Cascophen) e resina epóxi AR-300.

\subsubsection{Confecção dos corpos-de-prova}

Os corpos-de-prova foram confeccionados com as dimensões estabelecidas na tabela 08, para orientação unidirecional das fibras;

As fibras foram cortadas na direção paralela, obtendo-se tiras com largura igual a $15 \mathrm{~mm}$ e comprimento igual a $250 \mathrm{~mm}$. Foram dispostas sobre uma superfície impermeável para aplicação do adesivo sobre as mesmas, com o auxílio de um pincel. Retirou-se o ar do material com a utilização de um rolo de desaeração.

O procedimento foi repetido, para a laminação da segunda camada de fibra, obtendo-se um compósito de fibras reforçadas com polímero. A quantidade de adesivo utilizada foi cerca de 3,2 gramas por corpo-de-prova. Este procedimento foi adotado para os adesivos epóxi, cascophen e mamona.

A figura 17 ilustra o procedimento descrito, mostrando a laminação das fibras de vidro com resina epóxi. A figura 18 mostra os corpos-de-prova de fibras de carbono feitos com resina epóxi.

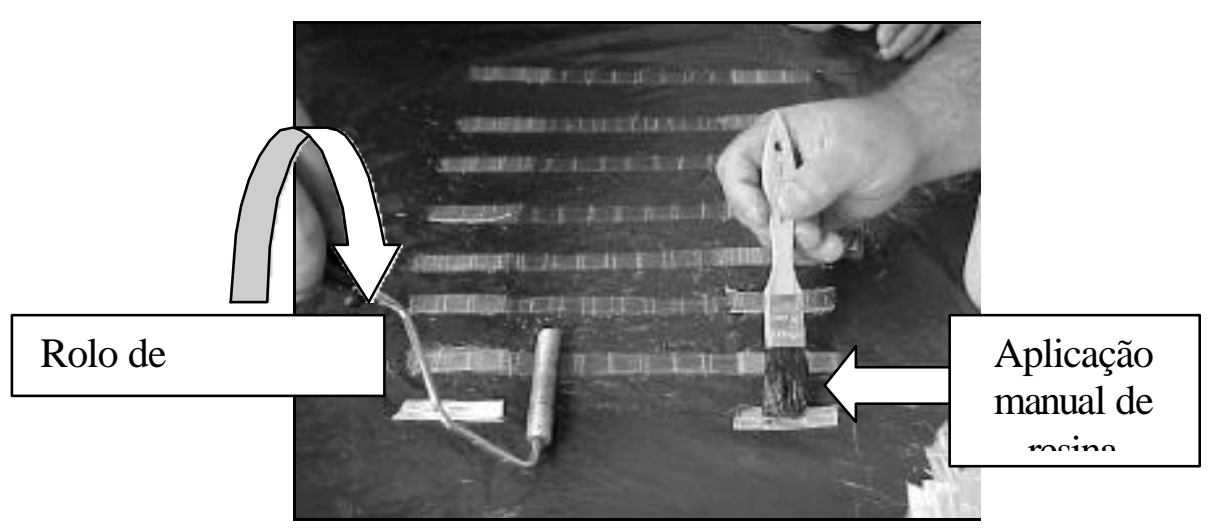

FIGURA 17: Laminação de corpos-de-prova de fibras de vidro com resina epóxi 


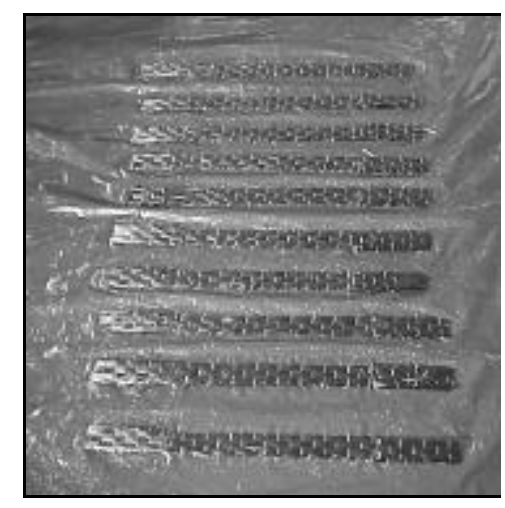

FIGURA 18: Corpos-de-prova de fibras de carbono laminados com duas camadas de tecido

\subsubsection{Equipamentos utilizados no ensaio}

As dimensões, largura e espessura, foram determinadas com paquímetro digital com resolução de centésimos de milímetro.

Os ensaios preliminares foram realizados utilizando máquina universal de ensaios, marca AMSLER, com capacidade para $250 \mathrm{kN}$. Os ensaios principais foram realizados na máquina universal de ensaios, marca DARTEC; com capacidade para $100 \mathrm{kN}$, servocontrolada, conectada a um computador que, por meio de um software específico, gerencia as operações do atuador e registra automaticamente os valores de força, deslocamentos e deformações.

As medidas de deformações foram feitas por meio de extensômetros elétricos do tipo "Clip-gage" marca Dartec, modelo EXA 50-5, amplitude de deslocamentos igual a $\pm 5 \mathrm{~mm}$, erro de medida $\pm 0,2 \%$. As deformações foram obtidas em um comprimento de $25 \mathrm{~mm}$, posicionado na região central do corpo-de-prova. Para evitar danos no equipamento, foram medidos valores de deformação até a aproximadamente $50 \%$ do valor da força máxima.

\subsubsection{Determinação da resistência à tração e do módulo de elasticidade}

$\mathrm{Na}$ determinação das tensões atuantes foram utilizadas duas maneiras para o 
cálculo da área da seção transversal dos corpos-de-prova laminados: a primeira considera a espessura final da seção transversal do corpo-de-prova (método A); a segunda considera a espessura das fibras utilizadas (método B), que são: e = 0,20 $\mathrm{mm}$ (fibras de vidro), $\mathrm{e}=0,25 \mathrm{~mm}$ (fibras de carbono).

Assim, são determinados dois valores para a resistência à tração e para o módulo de elasticidade.

\subsubsection{Ensaio realizado}

O ensaio de tração foi realizado com corpos-de-prova laminados com adesivo de mamona, cascophen e resina epóxi AR-300. A figura 19 ilustra o corpo-de-prova sendo ensaiado na máquina de ensaio DARTEC.

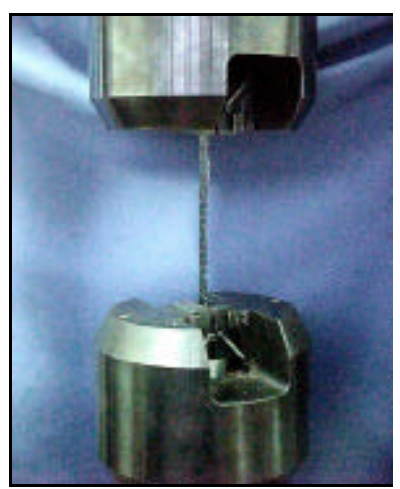

FIGURA 19: Ensaio de tração em fibras de carbono

Um segundo tipo de ensaio de tração, realizado com tecido unidirecional de fibras de vidro, objetivava caracterizar este material quanto à resistência e rigidez, determinando apenas as propriedades das fibras, desconsiderando a influência do adesivo. Neste caso, a laminação com resina epóxi, foi realizada apenas na parte da aba do material, para facilitar o ensaio e impedir o esmagamento das fibras na região da garra. A figura 20 ilustra os corpos-de-prova com laminação apenas na aba. 


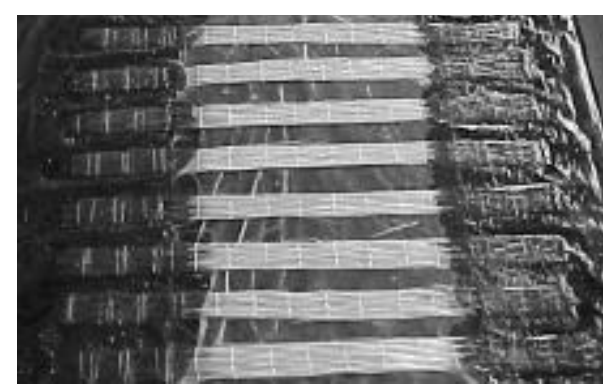

FIGURA 20: Corpos-de-prova de fibras de vidro sem laminação

A tabela 09 apresenta informações referentes aos corpos-de-prova ensaiados: materiais empregados na confecção; número de camadas de fibras utilizadas na laminação e quantidade.

Optou-se por realizar os ensaios preliminares apenas com tecido de fibras de vidro devido ao custo deste material ser aproximadamente vinte vezes menor às fibras de carbono.

Para avaliar a influência do número de camadas do tecido na resistência e m rigidez, foram realizados ensaios de tração para corpos-de-prova com duas, quatro e seis camadas, utilizando o adesivo epóxi.

TABELA 09: Informações referentes aos corpos-de-prova ensaiados

\begin{tabular}{|l|c|c|}
\hline \multicolumn{1}{|c|}{ Materiais utilizados } & $\begin{array}{c}\text { Número de } \\
\text { camadas de } \\
\text { fibras }\end{array}$ & $\begin{array}{c}\text { Quantidade de } \\
\text { corpos-de-prova }\end{array}$ \\
\hline Fibras de vidro - mamona* & 1 & 3 \\
\hline Fibras de vidro - cascophen* & 1 & 3 \\
\hline Fibras de vidro - epóxi* & 1 & 3 \\
\hline Fibras de vidro - epóxi & 2 & 12 \\
\hline Fibras de vidro - epóxi & 4 & 12 \\
\hline Fibras de vidro - epóxi & 6 & 10 \\
\hline Fibras de vidro sem adesivo & 1 & 12 \\
\hline Fibras de carbono - epóxi & 2 & 12 \\
\hline Fibras de carbono - epóxi & 4 & 12 \\
\hline Fibras de carbono - epóxi & 6 & \\
\hline
\end{tabular}

* ensaios preliminares 


\subsection{Resultados obtidos}

\subsubsection{Ensaios preliminares (corpos-de-prova com adesivo de mamona,}

cascophen e epóxi)

Os resultados dos ensaios de tração realizados nos tecidos unidirecionais de fibras de vidro laminados com adesivo de mamona, cascophen e epóxi são apresentados nas tabelas 10, 11 e 12 respectivamente. Estes ensaios iniciais foram realizados na máquina de ensaio AMSLER (controle manual), obtendo-se apenas o valor da força de ruptura. Para o cálculo da resistência a tração, considerou-se a espessura das fibras (método B).

TABELA 10: Resistência à tração de fibras de vidro laminada com adesivo de mamona

\begin{tabular}{|c|c|c|c|c|c|}
\hline Corpo-de-prova & $\begin{array}{c}\text { Espessura } \\
\text { da fibras } \\
(\mathbf{m m})\end{array}$ & $\begin{array}{c}\text { Largura } \\
(\mathbf{m m})\end{array}$ & Área $\left(\mathbf{m m}^{2}\right)$ & $\begin{array}{c}\text { Força de } \\
\text { ruptura }(\mathbf{N})\end{array}$ & $\begin{array}{c}\text { Resistência } \\
\text { à Tração } \\
(\mathbf{M P a})\end{array}$ \\
\hline 1 & 0,20 & 16,95 & 3,39 & 1915 & 565 \\
\hline 2 & 0,20 & 15,84 & 3,168 & 1438 & 454 \\
\hline 3 & 0,20 & 16,22 & 3,244 & 1346 & 415 \\
\hline
\end{tabular}

TABELA 11: Resistência à tração de fibras de vidro laminada com cascophen

\begin{tabular}{|c|c|c|c|c|c|}
\hline Corpo-de-prova & $\begin{array}{c}\text { Espessura } \\
\text { da fibras } \\
(\mathbf{m m})\end{array}$ & $\begin{array}{c}\text { Largura } \\
(\mathbf{m m})\end{array}$ & Área $\left(\mathbf{m m}^{2}\right)$ & $\begin{array}{c}\text { Força de } \\
\text { ruptura }(\mathbf{N})\end{array}$ & $\begin{array}{c}\text { Resistência } \\
\text { à Tração } \\
(\mathbf{M P a})\end{array}$ \\
\hline 1 & 0,20 & 15,85 & 3,17 & 2060 & 650 \\
\hline 2 & 0,20 & 15,63 & 3,126 & 2141 & 685 \\
\hline 3 & 0,20 & 16,72 & 3,344 & 1990 & 595 \\
\hline
\end{tabular}

TABELA 12: Resistência à tração de fibras de vidro laminada com epóxi

\begin{tabular}{|c|c|c|c|c|c|}
\hline Corpo-de-prova & $\begin{array}{c}\text { Espessura } \\
\text { da fibras } \\
(\mathbf{m m})\end{array}$ & $\begin{array}{c}\text { Largura } \\
(\mathbf{m m})\end{array}$ & Área $\left.\mathbf{( m m}^{2}\right)$ & $\begin{array}{c}\text { Força de } \\
\text { ruptura }(\mathbf{N})\end{array}$ & $\begin{array}{c}\text { Resistência } \\
\text { à Tração } \\
(\mathbf{M P a})\end{array}$ \\
\hline 1 & 0,20 & 16,47 & 3,28 & 3806 & 1160 \\
\hline 2 & 0,20 & 16,36 & 3,27 & 3985 & 1218 \\
\hline 3 & 0,20 & 16,12 & 3,22 & 3725 & 1157 \\
\hline
\end{tabular}




\subsubsection{Ensaios principais}

\subsubsection{Corpos-de-prova laminados com resina epóxi}

As tabelas 13, 14 e 15 apresentam os resultados obtidos para a resistência à tração e para o módulo de elasticidade, determinados de duas formas distintas, de acordo com o especificado no item 3.1.5. Estes corpos-de-prova foram laminados com duas, quatro e seis camadas de fibras respectivamente.

\subsubsection{Corpos-de-prova sem adesivo}

A tabela 16 apresenta os resultados obtidos para a resistência à tração e para 0 módulo de elasticidade nos corpos-de-prova feitos com uma camada de fibras de vidro sem adesivo, neste caso os corpos-de-prova possuíam apenas uma lâmina.

\subsubsection{Corpos-de-prova de fibras de carbono laminados com resina} epóxi

As tabelas 17, 18 e 19 apresentam os resultados obtidos para a resistência à tração e para o módulo de elasticidade de corpos-de-prova feitos com duas, quatro e seis camadas de fibras de carbono, laminados com resina epóxi. 
TABELA 13: Valores de resistência à tração e módulo de elasticidade de fibras de vidro (duas camadas de tecido)

\begin{tabular}{|c|c|c|c|c|c|c|c|c|c|c|}
\hline \multicolumn{11}{|c|}{ Tecido unidirecional de fibras de vidro } \\
\hline \multirow[t]{2}{*}{$\begin{array}{c}\text { Corpo-de- } \\
\text { prova }\end{array}$} & \multirow{2}{*}{$\begin{array}{c}\text { Espessura } \\
\text { da fibras } \\
(\mathrm{mm})\end{array}$} & \multirow{2}{*}{$\begin{array}{c}\text { Espessura } \\
\text { do corpo- } \\
\text { de-prova } \\
(\mathrm{mm})\end{array}$} & \multirow[t]{2}{*}{$\begin{array}{c}\text { Largura } \\
\text { (mm) }\end{array}$} & \multirow{2}{*}{$\begin{array}{c}\text { Área da } \\
\text { fibras } \\
\left(\mathrm{mm}^{2}\right)\end{array}$} & \multirow{2}{*}{$\begin{array}{c}\text { Área do } \\
\text { corpo-de- } \\
\text { prova } \\
\left(\mathrm{mm}^{2}\right)\end{array}$} & \multirow{2}{*}{$\begin{array}{l}\text { Força de } \\
\text { ruptura } \\
\text { (N) }\end{array}$} & \multicolumn{2}{|c|}{ Resistência (MPa) } & \multicolumn{2}{|c|}{$\begin{array}{c}\text { Módulo de } \\
\text { elasticidade(MPa) }\end{array}$} \\
\hline & & & & & & & Método A & Método B & $\begin{array}{c}\text { Método } \\
\text { A }\end{array}$ & $\begin{array}{c}\text { Método } \\
\text { B }\end{array}$ \\
\hline 1 & 0,40 & 1,19 & 16,69 & 6,676 & 19,86 & 6790 & 341 & 1017 & 29658 & 72505 \\
\hline 2 & 0,40 & 1,13 & 17,41 & 6,964 & 19,36 & 8396 & 434 & 1205 & 27771 & 68643 \\
\hline 3 & 0,40 & 1,23 & 16,95 & 6,78 & 20,85 & 7778 & 373 & 1147 & 32065 & 75349 \\
\hline 4 & 0,40 & 1,17 & 16,37 & 6,548 & 19,15 & 7515 & 392 & 1148 & 31536 & 79959 \\
\hline 5 & 0,40 & 1,00 & 17,14 & 6,856 & 17,14 & 8194 & 478 & 1195 & 30265 & 74516 \\
\hline 6 & 0,40 & 1,21 & 16,91 & 6,764 & 20,46 & 8281 & 405 & 1224 & 30248 & 72465 \\
\hline 7 & 0,40 & 1,01 & 16,38 & 6,552 & 16,54 & 6847 & 422 & 1045 & 27366 & 66371 \\
\hline 8 & 0,40 & 1,05 & 16,85 & 6,740 & 17,69 & 8274 & 465 & 1228 & 29985 & 73925 \\
\hline 9 & 0,40 & 1,12 & 17,26 & 6,904 & 19,33 & 8076 & 417 & 1170 & 27955 & 69887 \\
\hline 10 & 0,40 & 1,25 & 17,86 & 7,144 & 22,32 & 8304 & 372 & 1162 & 27436 & 68589 \\
\hline 11 & 0,40 & 1,08 & 17,96 & 7,184 & 19,39 & 8087 & 417 & 1126 & 27840 & 69599 \\
\hline 12 & 0,40 & 1,15 & 18,31 & 7,324 & 21,05 & 8525 & 405 & 1164 & 28127 & 70317 \\
\hline
\end{tabular}


TABELA 14: Valores de resistência à tração e módulo de elasticidade de fibras de vidro (quatro camadas de tecido)

\begin{tabular}{|c|c|c|c|c|c|c|c|c|c|c|}
\hline \multicolumn{11}{|c|}{ Tecido unidirecional de fibras de vidro } \\
\hline \multirow[t]{2}{*}{$\begin{array}{c}\text { Corpo-de- } \\
\text { prova }\end{array}$} & \multirow{2}{*}{$\begin{array}{c}\text { Espessura } \\
\text { da fibras } \\
(\mathrm{mm})\end{array}$} & \multirow{2}{*}{$\begin{array}{c}\text { Espessura } \\
\text { do corpo- } \\
\text { de-prova } \\
(\mathrm{mm})\end{array}$} & \multirow[t]{2}{*}{$\begin{array}{c}\text { Largura } \\
\text { (mm) }\end{array}$} & \multirow{2}{*}{$\begin{array}{c}\text { Área da } \\
\text { fibras } \\
\left(\mathrm{mm}^{2}\right)\end{array}$} & \multirow{2}{*}{$\begin{array}{c}\text { Área do } \\
\text { corpo-de- } \\
\text { prova } \\
\left(\mathbf{m m}^{2}\right)\end{array}$} & \multirow{2}{*}{$\begin{array}{l}\text { Força de } \\
\text { ruptura } \\
\text { (N) }\end{array}$} & \multicolumn{2}{|c|}{ Resistência (MPa) } & \multicolumn{2}{|c|}{$\begin{array}{c}\text { Módulo de } \\
\text { elasticidade(MPa) }\end{array}$} \\
\hline & & & & & & & Método A & Método B & Método A & Método B \\
\hline 1 & 0,8 & 2,08 & 15,88 & 12,704 & 33,030 & 15120 & 458 & 1190 & 26300 & 69800 \\
\hline 2 & 0,8 & 2,15 & 15,42 & 12,336 & 33,153 & 15000 & 452 & 1216 & 26016 & 69917 \\
\hline 3 & 0,8 & 2,07 & 15,15 & 12,12 & 31,361 & 12554 & 400 & 1036 & 26865 & 69513 \\
\hline 4 & 0,8 & 2,05 & 15,29 & 12,232 & 31,345 & 13780 & 440 & 1127 & 27916 & 71534 \\
\hline 5 & 0,8 & 2,05 & 15,32 & 12,256 & 31,406 & 15079 & 480 & 1230 & 28896 & 74045 \\
\hline 6 & 0,8 & 2,08 & 15,19 & 12,152 & 31,595 & 15290 & 484 & 1258 & 29118 & 75708 \\
\hline 7 & 0,8 & 2,03 & 15,70 & 12,56 & 31,871 & 14080 & 442 & 1121 & 28631 & 72651 \\
\hline 8 & 0,8 & 2,17 & 15,15 & 12,12 & 32,876 & 14332 & 436 & 1183 & 26235 & 71163 \\
\hline 9 & 0,8 & 1,95 & 15,07 & 12,056 & 29,387 & 14700 & 500 & 1219 & 31052 & 75688 \\
\hline 10 & 0,8 & 1,96 & 15,28 & 12,224 & 29,949 & 12413 & 414 & 1015 & 25460 & 62377 \\
\hline 11 & 0,8 & 2,13 & 15,37 & 12,296 & 32,738 & 15030 & 459 & 1222 & 33600 & 89460 \\
\hline 12 & 0,8 & 2,03 & 15,23 & 12,184 & 30,917 & 14600 & 472 & 1198 & 28868 & 73252 \\
\hline
\end{tabular}


TABELA 15: Valores de resistência à tração e módulo de elasticidade de fibras de vidro (seis camadas de tecido)

\begin{tabular}{|c|c|c|c|c|c|c|c|c|c|c|}
\hline \multicolumn{11}{|c|}{ Tecido unidirecional de fibras de vidro } \\
\hline \multirow[t]{2}{*}{$\begin{array}{c}\text { Corpo-de- } \\
\text { prova }\end{array}$} & \multirow{2}{*}{$\begin{array}{c}\text { Espessura } \\
\text { da fibras } \\
(\mathrm{mm})\end{array}$} & \multirow{2}{*}{$\begin{array}{c}\text { Espessura } \\
\text { do corpo- } \\
\text { de-prova } \\
\text { (mm) }\end{array}$} & \multirow[t]{2}{*}{$\begin{array}{c}\text { Largura } \\
\text { (mm) }\end{array}$} & \multirow{2}{*}{$\begin{array}{c}\text { Área da } \\
\text { fibras } \\
\left(\mathrm{mm}^{2}\right)\end{array}$} & \multirow{2}{*}{$\begin{array}{c}\text { Área do } \\
\text { corpo-de- } \\
\text { prova } \\
\left(\mathrm{mm}^{2}\right)\end{array}$} & \multirow{2}{*}{$\begin{array}{l}\text { Força de } \\
\text { ruptura } \\
\text { (N) }\end{array}$} & \multicolumn{2}{|c|}{ Resistência (MPa) } & \multicolumn{2}{|c|}{$\begin{array}{c}\text { Módulo de } \\
\text { elasticidade(MPa) }\end{array}$} \\
\hline & & & & & & & Método A & Método B & Método A & Método B \\
\hline 1 & 1,2 & 2,95 & 15,95 & 19,14 & 47,05 & 18039 & 383 & 942 & 27150 & 71240 \\
\hline 2 & 1,2 & 3,19 & 15,96 & 19,15 & 50,91 & 20100 & 395 & 1049 & 26762 & 71141 \\
\hline 3 & 1,2 & 3,06 & 15,58 & 18,69 & 47,67 & 18690 & 392 & 1000 & 27268 & 69534 \\
\hline 4 & 1,2 & 3,16 & 15,50 & 18,60 & 48,98 & 20680 & 422 & 1112 & 27715 & 72984 \\
\hline 5 & 1,2 & 3,03 & 15,16 & 18,19 & 45,93 & 19310 & 420 & 1061 & 28029 & 70773 \\
\hline 6 & 1,2 & 3,21 & 15,57 & 18,68 & 49,98 & 21250 & 425 & 1137 & 27261 & 72923 \\
\hline 7 & 1,2 & 3,26 & 15,51 & 18,61 & 50,56 & 19485 & 385 & 1047 & 26032 & 70721 \\
\hline 8 & 1,2 & 2,88 & 15,56 & 18,67 & 44,81 & 20660 & 461 & 1106 & 29344 & 70426 \\
\hline 9 & 1,2 & 2,91 & 15,79 & 18,95 & 45,95 & 20080 & 437 & 1060 & 31013 & 75206 \\
\hline 10 & 1,2 & 3,27 & 15,32 & 18,38 & 50,10 & 21120 & 422 & 1149 & 27297 & 74385 \\
\hline
\end{tabular}


TABELA 16: Valores de resistência à tração e módulo de elasticidade de fibras de vidro sem laminação (uma camada de tecido)

\begin{tabular}{|c|c|c|c|c|c|c|c|}
\hline \multicolumn{8}{|c|}{ Tecido unidirecional de fibras de vidro } \\
\hline $\begin{array}{l}\text { Corpo- } \\
\text { de-prova }\end{array}$ & $\begin{array}{c}\text { Espessura } \\
\text { da fibras } \\
(\mathbf{m m})\end{array}$ & $\begin{array}{c}\text { Largura } \\
\text { (mm) }\end{array}$ & $\begin{array}{c}\text { Área da } \\
\text { fibras } \\
\left(\mathrm{mm}^{2}\right)\end{array}$ & $\begin{array}{c}\text { Área do } \\
\text { corpo-de- } \\
\text { prova } \\
\left(\mathrm{mm}^{2}\right)\end{array}$ & $\begin{array}{c}\text { Força de } \\
\text { ruptura }(\mathrm{N})\end{array}$ & $\begin{array}{c}\mathrm{F}_{\mathrm{t} 0} \text { (espessura } \\
\text { da fibras) } \\
(\mathrm{MPa})\end{array}$ & $\begin{array}{c}\text { E (espessura } \\
\text { da fibras) } \\
(\mathrm{MPa})\end{array}$ \\
\hline 1 & 0,20 & 14,99 & 2,998 & 14,99 & 1579 & 526 & 69277 \\
\hline 2 & 0,20 & 14,00 & 2,80 & 14,00 & 1789 & 639 & 64945 \\
\hline 3 & 0,20 & 14,64 & 2,93 & 14,64 & 1400 & 478 & 75531 \\
\hline 4 & 0,20 & 14,97 & 2,99 & 14,97 & 1617 & 541 & 61385 \\
\hline 5 & 0,20 & 15,87 & 3,17 & 15,87 & 1834 & 578 & 77553 \\
\hline 6 & 0,20 & 13,97 & 2,79 & 13,97 & 1743 & 625 & 70412 \\
\hline 7 & 0,20 & 13,58 & 2,72 & 13,58 & 1808 & 665 & 67973 \\
\hline 8 & 0,20 & 14,64 & 2,93 & 14,64 & 1609 & 349 & 61804 \\
\hline 9 & 0,20 & 15,37 & 3,074 & 15,37 & 1773 & 577 & 75071 \\
\hline 10 & 0,20 & 14,31 & 2,86 & 14,31 & 1659 & 580 & 73913 \\
\hline 11 & 0,20 & 14,90 & 2,98 & 14,90 & 1569 & 526 & 68720 \\
\hline 12 & 0,20 & 14,17 & 2,83 & 14,17 & 1579 & 558 & 68215 \\
\hline
\end{tabular}


TABELA 17: Valores de resistência à tração e módulo de elasticidade de fibras de carbono (duas camadas de tecido)

\begin{tabular}{|c|c|c|c|c|c|c|c|c|c|c|}
\hline \multicolumn{11}{|c|}{ Tecido unidirecional de fibras de carbono } \\
\hline \multirow[t]{2}{*}{$\begin{array}{l}\text { Corpo-de- } \\
\text { prova }\end{array}$} & \multirow{2}{*}{$\begin{array}{c}\text { Espessura } \\
\text { da fibras } \\
(\mathbf{m m})\end{array}$} & \multirow{2}{*}{$\begin{array}{l}\text { Espessura } \\
\text { do corpo- } \\
\text { de-prova } \\
\text { (mm) }\end{array}$} & \multirow[t]{2}{*}{$\begin{array}{c}\text { Largura } \\
\text { (mm) }\end{array}$} & \multirow{2}{*}{$\begin{array}{c}\text { Área da } \\
\text { fibras } \\
\left(\mathrm{mm}^{2}\right)\end{array}$} & \multirow{2}{*}{$\begin{array}{c}\text { Área do } \\
\text { corpo-de- } \\
\text { prova } \\
\left(\mathrm{mm}^{2}\right)\end{array}$} & \multirow{2}{*}{$\begin{array}{c}\text { Força de } \\
\text { ruptura } \\
\text { (N) }\end{array}$} & \multicolumn{2}{|c|}{ Resistência (MPa) } & \multicolumn{2}{|c|}{$\begin{array}{c}\text { Módulo de } \\
\text { elasticidade(MPa) }\end{array}$} \\
\hline & & & & & & & Método A & Método B & $\begin{array}{c}\text { Método } \\
\text { A }\end{array}$ & $\begin{array}{c}\text { Método } \\
\text { B }\end{array}$ \\
\hline 1 & 0,50 & 1,33 & 16,93 & 8,465 & 22,51 & 21145 & 939 & 2498 & 61084 & 166895 \\
\hline 2 & 0,50 & 1,56 & 16,94 & 8,470 & 26,42 & 21076 & 798 & 2488 & 48826 & 151540 \\
\hline 3 & 0,50 & 1,62 & 16,86 & 8,430 & 27,31 & 17681 & 647 & 2097 & 50805 & 162952 \\
\hline 4 & 0,50 & 1,68 & 16,75 & 8,375 & 28,14 & 19146 & 680 & 2286 & 50043 & 161320 \\
\hline 5 & 0,50 & 1,57 & 17,01 & 8,505 & 26,70 & 19837 & 743 & 2332 & 49625 & 155537 \\
\hline 6 & 0,50 & 1,65 & 16,86 & 8,430 & 27,82 & 20218 & 727 & 2398 & 55830 & 157486 \\
\hline 7 & 0,50 & 1,37 & 16,87 & 8,435 & 23,11 & 21805 & 943 & 2585 & 57118 & 157017 \\
\hline 8 & 0,50 & 1,30 & 16,91 & 8,455 & 21,98 & 19210 & 874 & 2272 & 61191 & 157674 \\
\hline 9 & 0,50 & 1,49 & 15,92 & 7,960 & 23,72 & 22454 & 946 & 2656 & 60603 & 180775 \\
\hline 10 & 0,50 & 1,33 & 16,95 & 8,475 & 22,54 & 21660 & 961 & 2556 & 61453 & 157941 \\
\hline 11 & 0,50 & 1,28 & 16,84 & 8,420 & 21,55 & 21066 & 977 & 2503 & 62761 & 160761 \\
\hline 12 & 0,50 & 1,34 & 16,63 & 8,315 & 22,28 & 21187 & 951 & 2510 & 58910 & 157931 \\
\hline
\end{tabular}


TABELA 18: Valores de resistência à tração e módulo de elasticidade de fibras de carbono (quatro camadas de tecido)

\begin{tabular}{|c|c|c|c|c|c|c|c|c|c|c|}
\hline \multicolumn{11}{|c|}{ Tecido unidirecional de fibras de carbono } \\
\hline \multirow[t]{2}{*}{$\begin{array}{c}\text { Corpo-de- } \\
\text { prova }\end{array}$} & \multirow{2}{*}{$\begin{array}{c}\text { Espessura } \\
\text { da fibras } \\
(\mathrm{mm})\end{array}$} & \multirow{2}{*}{$\begin{array}{c}\text { Espessura } \\
\text { do corpo- } \\
\text { de-prova } \\
(\mathrm{mm})\end{array}$} & \multirow[t]{2}{*}{$\begin{array}{c}\text { Largura } \\
\text { (mm) }\end{array}$} & \multirow{2}{*}{$\begin{array}{c}\text { Área da } \\
\text { fibras } \\
\left(\mathrm{mm}^{2}\right)\end{array}$} & \multirow{2}{*}{$\begin{array}{c}\text { Área do } \\
\text { corpo-de- } \\
\text { prova } \\
\left(\mathrm{mm}^{2}\right)\end{array}$} & \multirow{2}{*}{$\begin{array}{c}\text { Força de } \\
\text { ruptura } \\
\text { (N) }\end{array}$} & \multicolumn{2}{|c|}{ Resistência (MPa) } & \multicolumn{2}{|c|}{$\begin{array}{c}\text { Módulo de } \\
\text { elasticidade(MPa) }\end{array}$} \\
\hline & & & & & & & Método A & Método B & Método A & Método B \\
\hline 1 & 1 & 2,36 & 15,37 & 15,37 & 36,27 & 35000 & 965 & 2277 & 82706 & 195185 \\
\hline 2 & 1 & 2,38 & 15,71 & 15,71 & 37,39 & 34320 & 918 & 2184 & 77561 & 184586 \\
\hline 3 & 1 & 2,47 & 15,38 & 15,38 & 37,99 & 33680 & 886 & 2190 & 72390 & 178804 \\
\hline 4 & 1 & 2,36 & 15,07 & 15,07 & 35,56 & 34120 & 959 & 2264 & 73808 & 174187 \\
\hline 5 & 1 & 2,54 & 15,56 & 15,56 & 39,52 & 34340 & 869 & 2207 & 69581 & 176735 \\
\hline 6 & 1 & 2,41 & 14,93 & 14,93 & 35,98 & 33020 & 918 & 2212 & 75039 & 180844 \\
\hline 7 & 1 & 2,34 & 15,32 & 15,32 & 35,85 & 34620 & 966 & 2260 & 76014 & 177872 \\
\hline 8 & 1 & 2,8 & 16,76 & 16,76 & 46,93 & 32090 & 895 & 1915 & 59131 & 165573 \\
\hline 9 & 1 & 2,6 & 16,51 & 16,51 & 42,93 & 33700 & 785 & 2041 & 65222 & 169594 \\
\hline 10 & 1 & 2,73 & 16,20 & 16,20 & 44,23 & 34660 & 784 & 2139 & 63305 & 172839 \\
\hline
\end{tabular}


TABELA 19: Valores de resistência à tração e módulo de elasticidade de fibras de carbono (seis camadas de tecido)

\begin{tabular}{|c|c|c|c|c|c|c|c|c|c|c|}
\hline \multicolumn{11}{|c|}{ Tecido unidirecional de fibras de carbono } \\
\hline \multirow[t]{2}{*}{$\begin{array}{l}\text { Corpo-de- } \\
\text { prova }\end{array}$} & \multirow{2}{*}{$\begin{array}{c}\text { Espessura } \\
\text { da fibras } \\
(\mathrm{mm})\end{array}$} & \multirow{2}{*}{$\begin{array}{l}\text { Espessura } \\
\text { do corpo- } \\
\text { de-prova } \\
\text { (mm) }\end{array}$} & \multirow[t]{2}{*}{$\begin{array}{c}\text { Largura } \\
(\mathbf{m m})\end{array}$} & \multirow{2}{*}{$\begin{array}{c}\text { Área da } \\
\text { fibras } \\
\left(\mathrm{mm}^{2}\right)\end{array}$} & \multirow{2}{*}{$\begin{array}{c}\text { Área do } \\
\text { corpo-de- } \\
\text { prova } \\
\left(\mathrm{mm}^{2}\right)\end{array}$} & \multirow{2}{*}{$\begin{array}{c}\text { Força de } \\
\text { ruptura } \\
\text { (N) }\end{array}$} & \multicolumn{2}{|c|}{ Resistência (MPa) } & \multicolumn{2}{|c|}{$\begin{array}{c}\text { Módulo de } \\
\text { elasticidade(MPa) }\end{array}$} \\
\hline & & & & & & & Método A & Método B & Método A & Método B \\
\hline 1 & 1,5 & 3,57 & 16,01 & 24,015 & 57,156 & 42650 & 746 & 1776 & 67358 & 160316 \\
\hline 2 & 1,5 & 3,44 & 15,76 & 23,64 & 54,214 & 43570 & 804 & 1843 & 69170 & 158629 \\
\hline 3 & 1,5 & 3,47 & 15,42 & 23,13 & 53,507 & 45910 & 858 & 1984 & 71486 & 165369 \\
\hline 4 & 1,5 & 3,43 & 15,78 & 23,67 & 54,125 & 45770 & 846 & 1933 & 69284 & 158428 \\
\hline 5 & 1,5 & 3,39 & 15,67 & 23,505 & 53,121 & 47320 & 891 & 2013 & 72005 & 162731 \\
\hline 6 & 1,5 & 3,42 & 15,42 & 23,13 & 52,736 & 42430 & 805 & 1834 & 72531 & 165369 \\
\hline 7 & 1,5 & 3,46 & 15,68 & 23,52 & 54,253 & 43840 & 808 & 1863 & 72346 & 166879 \\
\hline 8 & 1,5 & 3,41 & 15,45 & 23,175 & 52,685 & 43780 & 831 & 1889 & 71652 & 162891 \\
\hline 9 & 1,5 & 3,51 & 15,94 & 23,91 & 55,949 & 44980 & 804 & 1881 & 71047 & 166248 \\
\hline 10 & 1,5 & 3,54 & 15,47 & 23,205 & 54,764 & 45500 & 832 & 1960 & 69388 & 163758 \\
\hline
\end{tabular}




\subsection{Análise dos resultados}

3.3.1 Comparação da eficiência dos adesivos na laminação dos corpos-deprova (ensaios preliminares)

Os adesivos de mamona e Cascophen não apresentaram bons resultados no processo de laminação. Uma avaliação visual identificou que ambos adesivos não reagem com as fibras, apenas criam uma camada de cola superficial. Foi possível perceber vazios de adesivo entre as fibras. As figuras 21 e 22 ilustram corpo-de-prova de fibras de vidro laminado com cascophen e adesivo de mamona.

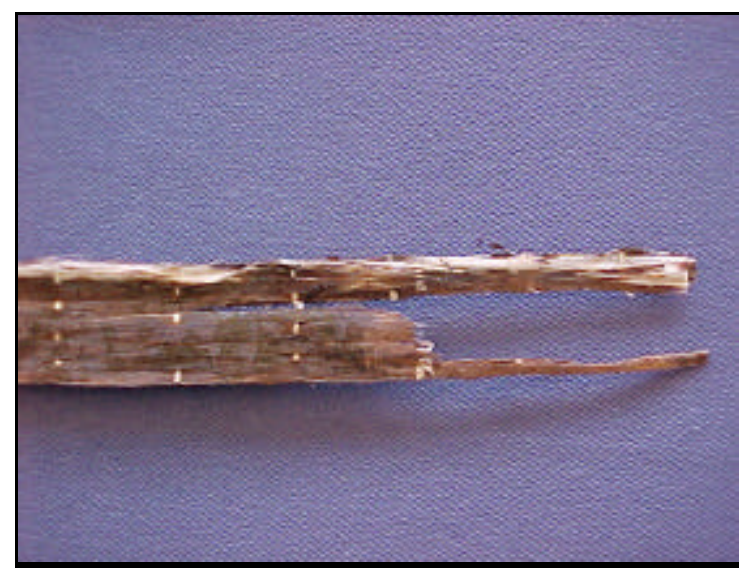

FIGURA 21: Corpo-de-prova de fibras de vidro laminado com cascophen.

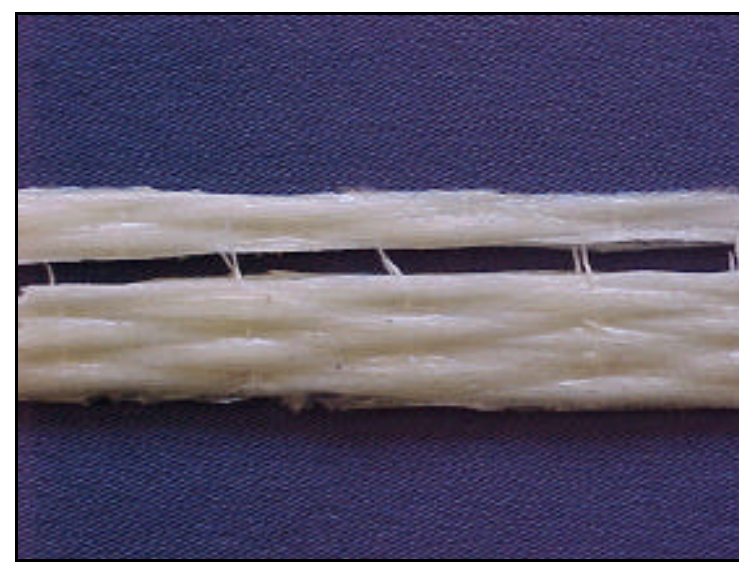

FIGURA 22: Corpo-de-prova de fibras de vidro laminado com adesivo de mamona. 
O adesivo epóxi foi o que apresentou melhores resultados no processo de laminação. A figura 23 mostra os corpos-de-prova de fibras de carbono e fibras de vidro laminados com adesivo epóxi.

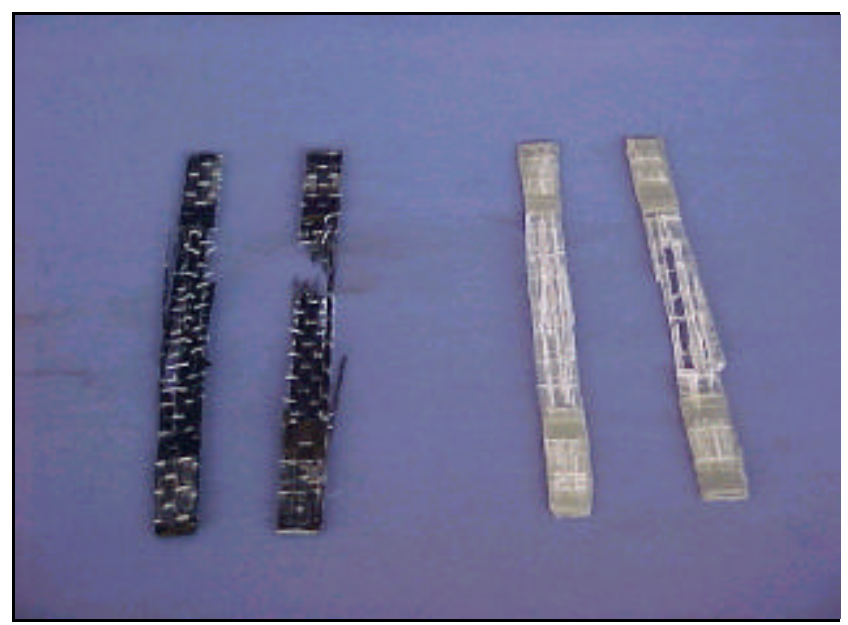

FIGURA 23: Corpos-de-prova de fibras de carbono e de fibras de vidro laminados com epóxi.

A tabela 20 apresenta a média e o coeficiente de variação dos resultados da resistência à tração, relacionados nas tabelas 10,11 e 12 do item 3.1.1.

TABELA 20: Valores médios e coeficientes de variação da resistência à tração de fibras de vidro

\begin{tabular}{|r|c|c|c|}
\cline { 2 - 4 } \multicolumn{1}{c|}{} & \multicolumn{3}{c|}{ Tipo de adesivo } \\
\cline { 2 - 4 } \multicolumn{1}{c|}{} & Mamona & Cascophen & Epóxi \\
\hline Valor médio da resistência à tração & 478 & 640 & 1178 \\
$(\mathbf{M P a})$ & & & 1,9 \\
\hline Coeficiente de variação (\%) & 16,3 & 7,1 & \\
\hline
\end{tabular}

Os resultados mostrados na tabela 20 indicam que o adesivo epóxi é o que apresenta melhores resultados para laminação de fibras de vidro.

3.3.2 Resistência à tração e módulo de elasticidade para fibras de carbono e 


\section{fibras de vidro laminadas com adesivo epóxi}

As tabelas 21 a 26 apresentam, respectivamente, os resultados da média e do coeficiente de variação da resistência a tração e do módulo de elasticidade de fibras de vidro e fib4ras de carbono laminadas com adesivo epóxi correspondentes aos resultados apresentados nas tabelas 13, 14, 15, 17, 18, 19.

TABELA 21: Valores médios de resistência e módulo de elasticidade de fibras de vidro laminadas (2 lâminas de fibras)

\begin{tabular}{|r|c|c|c|c|}
\cline { 2 - 5 } \multicolumn{1}{c|}{} & \multicolumn{2}{c|}{ Resistência } & \multicolumn{2}{c|}{ Módulo de elasticidade } \\
\cline { 2 - 5 } & Método A & Método B & Método A & Método B \\
\hline Média (MPa) & 410 & 1153 & 29187 & 71844 \\
\hline Coeficiente de variação (\%) & 9,0 & 5,4 & 5,4 & 4,9 \\
\hline
\end{tabular}

TABELA 22: Valores médios de resistência e módulo de elasticidade de fibras de vidro laminadas (4 lâminas de fibras)

\begin{tabular}{|r|c|c|c|c|}
\cline { 2 - 5 } \multicolumn{1}{c|}{} & \multicolumn{2}{c|}{ Resistência } & \multicolumn{2}{c|}{ Módulo de elasticidade } \\
\cline { 2 - 5 } \multicolumn{1}{c|}{} & Método A & Método B & Método A & Método B \\
\hline Média (MPa) & 453,2 & 1168 & 28423 & 73210 \\
\hline Coeficiente de variação (\%) & 6,1 & 6,3 & 7,9 & 8,2 \\
\hline
\end{tabular}

TABELA 23: Valores médios de resistência e módulo de elasticidade de fibras de vidro laminadas (6 lâminas de fibras)

\begin{tabular}{|r|c|c|c|c|}
\cline { 2 - 5 } \multicolumn{1}{c|}{} & \multicolumn{2}{c|}{ Resistência } & \multicolumn{2}{c|}{ Módulo de elasticidade } \\
\cline { 2 - 5 } \multicolumn{1}{c|}{} & Método A & Método B & Método A & Método B \\
\hline Média (MPa) & 414 & 1066 & 27787 & 71933 \\
\hline Coeficiente de variação (\%) & 5,7 & 5,6 & 4,8 & 2,4 \\
\hline
\end{tabular}

TABELA 24: Valores médios de resistência e módulo de elasticidade de fibras de carbono laminadas (2 lâminas de fibras)

\begin{tabular}{|r|c|c|c|c|}
\cline { 2 - 5 } \multicolumn{1}{c|}{} & \multicolumn{2}{c|}{ Resistência } & \multicolumn{2}{c|}{ Módulo de elasticidade } \\
\cline { 2 - 5 } \multicolumn{1}{c|}{} & Método A & Método B & Método A & Método B \\
\hline Média (MPa) & 849 & 2432 & 56521 & 160652 \\
\hline Coeficiente de variação (\%) & 13,8 & 6,2 & 9,0 & 4,4 \\
\hline
\end{tabular}


TABELA 25: Valores médios de resistência e módulo de elasticidade de fibras de carbono laminadas (4 lâminas de fibras)

\begin{tabular}{|r|c|c|c|c|}
\cline { 2 - 5 } \multicolumn{1}{c|}{} & \multicolumn{2}{c|}{ Resistência } & \multicolumn{2}{c|}{ Módulo de elasticidade } \\
\cline { 2 - 5 } \multicolumn{1}{c|}{} & Método A & Método B & Método A & Método B \\
\hline Média (MPa) & 894,5 & 2169 & 71276 & 177622 \\
\hline Coeficiente de variação (\%) & 7,1 & 4,9 & 9,4 & 4,4 \\
\hline
\end{tabular}

TABELA 26: Valores médios de resistência e módulo de elasticidade de fibras de carbono laminadas (6 lâminas de fibras)

\begin{tabular}{|r|c|c|c|c|}
\cline { 2 - 5 } \multicolumn{1}{c|}{} & \multicolumn{2}{c|}{ Resistência } & \multicolumn{2}{c|}{ Módulo de elasticidade } \\
\cline { 2 - 5 } & Método A & Método B & Método A & Método B \\
\hline Média (MPa) & 822,5 & 1897,6 & 70627 & 163062 \\
\hline Coeficiente de variação (\%) & 4,5 & 3,7 & 2,3 & 1,8 \\
\hline
\end{tabular}

Analisando as tabelas 24, 25, e 26, pode-se dizer que os valores médios da resistência à tração e do módulo de elasticidade dos tecidos de fibras de carbono são aproximadamente $100 \%$ maiores que os das fibras de vidro, para duas camadas de fibras.

Para fibras de vidro a variação do número de camadas de fibra não interfere no valor da resistência, a qual permanece constante.

Para as fibras de carbono, o aumento não foi proporcional, pois ocorria ruptura prematura do corpo-de-prova próximo a garra e também porque a força envolvida era bastante superior em relação a força necessária para romper corpos-de-prova com duas camadas de fibras. O valor da resistência para corpos-de-prova com seis camadas foi aproximadamente $25 \%$ inferior ao valor da resistência dos corpos-de-prova confeccionados com duas lâminas de fibras.

Observa-se, também, uma maior uniformidade nos valores calculados a partir do método B, que considera a espessura das fibras. Notou-se que a espessura do corpo-deprova laminado apresenta variações. Assim, parece mais interessante obter os resultados 
em função da espessura das fibras, com o intuito de especificar o reforço em termos do número de camadas.

O gráfico da figura 24, que representa a força aplicada em relação ao deslocamento da cabeça do pistão da máquina de ensaios, permite comparar as forças máximas resistidas pelos corpos-de-prova de fibras de vidro e de fibras de carbono (duas camadas de tecido) laminados com resina epóxi.

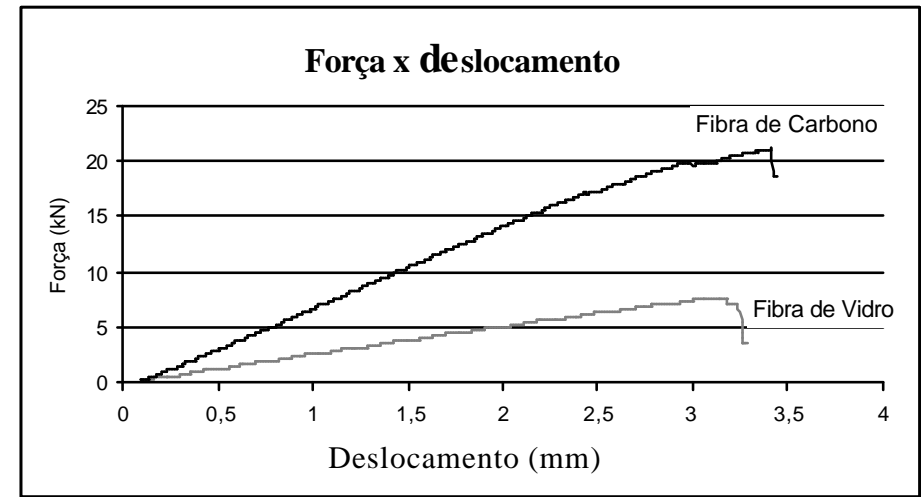

FIGURA 24: Gráfico comparativo entre forças máximas resistidas por corpos-de-prova de fibras de carbono e de fibras de vidro

As figuras 25 e 26 apresentam gráficos ilustrativos de tensão por deformação para cada uma das fibras. No cálculo da tensão, foi considerada a espessura das fibras.

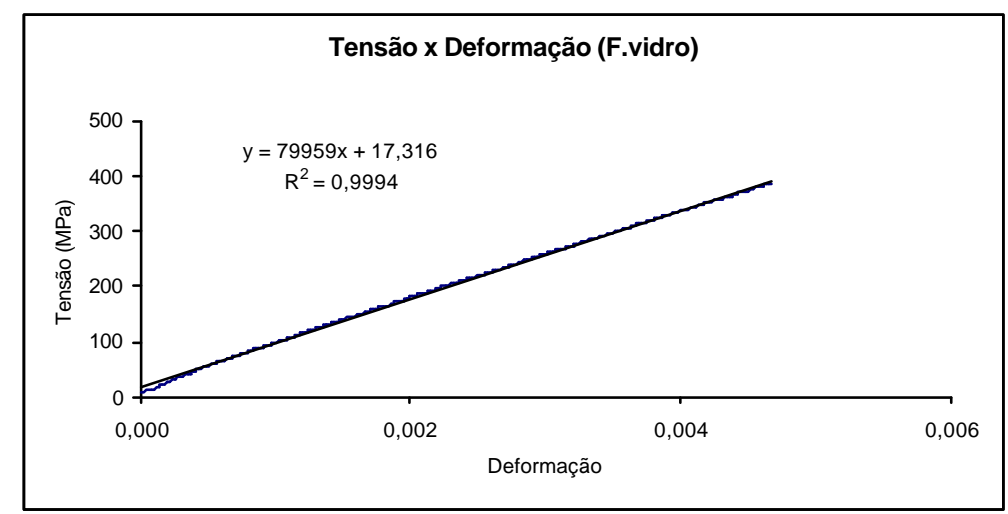

FIGURA 25: Curva tensão x deformação fibras de vidro laminadas 


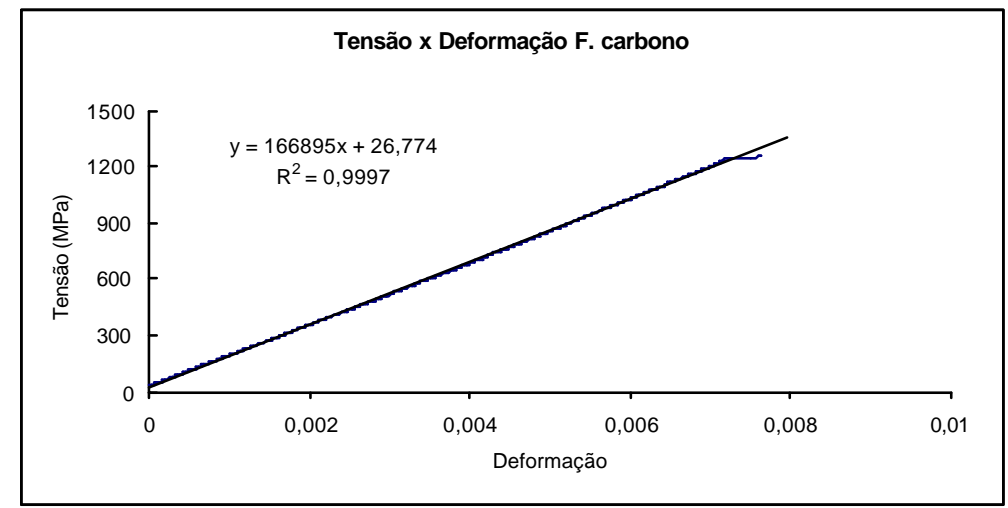

FIGURA 26: Curva tensão deformação fibras de carbono laminadas

\subsubsection{Fibras de vidro sem adesivo}

A tabela 27 apresenta os resultados da média e do coeficiente de variação da resistência à tração e do módulo de elasticidade de fibras de vidro sem adesivo.

TABELA 27: Valores médios de resistência e módulo de elasticidade de fibras de vidro sem adesivo

\begin{tabular}{|r|c|c|}
\cline { 2 - 3 } \multicolumn{1}{c|}{} & Resistência & Módulo de elasticidade \\
\hline Média (MPa) & 553 & 69566 \\
\hline Coeficiente de variação (\%) & 14,4 & 7,2 \\
\hline
\end{tabular}

Os valores de resistência à tração para corpos-de-prova sem adesivo são aproximadamente $50 \%$ menores que os encontrados para corpos-de-prova laminados com adesivo epóxi e também que os resultados apresentados na literatura. Esse resultado evidencia que o adesivo proporciona um aumento na resistência do material, principalmente na fase de ruptura, por proporcionar distribuição de tensões mais uniforme entre as várias fibras.

Comparando os resultados obtidos para o módulo de elasticidade de fibras de vidro laminadas e fibras de vidro sem laminação, percebe-se que não há uma grande variação entre eles pois os mesmos foram determinados na fase elástica. Porém, o 
coeficiente de variação dos resultados obtidos para os corpos-de-prova laminados é inferior ao dos corpos-de-prova sem laminação. Provavelmente, isto se deve a existência do adesivo que transfere de forma mais uniforme os esforços aplicados no material. 


\section{4 - AVALIAÇÃO DE ADESIVOS NA INTERFACE FIBRA MADEIRA}

Este capítulo apresenta a avaliação dos adesivos a base de mamona, cascophen e epóxi na interface fibra madeira, objetivando avaliar a eficiência dos respectivos adesivos na fixação de fibras de vidro à madeira.

\subsection{Materiais e métodos}

Foram realizados ensaios de tração, para verificar a eficiência dos adesivos na interface fibra madeira. Confeccionaram-se corpos-de-prova de madeira, previamente cortados na direção transversal. A ligação entre as duas partes do corpo-de-prova foi feita com fibras de vidro cortadas com comprimentos de aproximadamente $7 \mathrm{~cm} \mathrm{e}$ largura 1,5 cm (área de cola aproximadamente igual a 10,5 cm2), laminadas com adesivo. Este comprimento foi definido a partir de ensaios preliminares realizados com madeira da espécie Eucalipto Grandis, de forma a garantir ruptura por cisalhamento na interface de colagem.

\subsubsection{Confecção dos corpos-de-prova}

O ensaio foi realizado com corpos-de-prova de madeira da espécie Pinus elliottti (Pinus elliotti) e Eucalipto Grandis (Eucalyptus grandis), com forma semelhante aos utilizados nos ensaios de tração paralela às fibras, especificados no anexo B da norma NBR (7190/97) - Projetos de Estruturas de Madeira.

Os adesivos verificados foram: adesivo à base de mamona, Cascophen e adesivo epóxi AR 300. A figura 27 ilustra o procedimento de colagem das fibras de vidro nos 
corpos-de-prova de madeira.

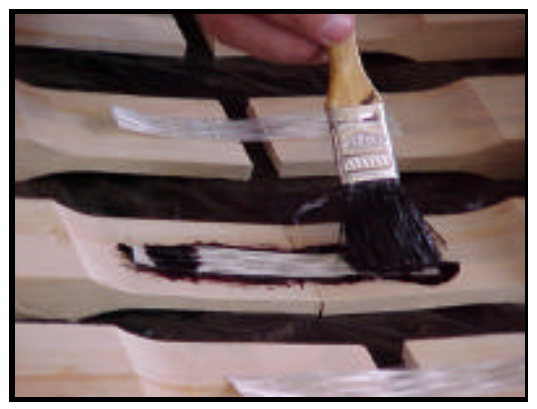

FIGURA 27: Colagem de fibras de vidro nos corpos-de-prova de madeira adesivo cascophen

\subsubsection{Ensaio realizado}

O ensaio de tração para verificar a eficiência do adesivo junto à madeira foi realizado na máquina de ensaio Dartec, com velocidade constante de deformação igual a $2 \mathrm{~mm} / \mathrm{min}$.

Com este ensaio foi possível medir o valor da força máxima necessária para que ocorresse cisalhamento na linha de cola entre fibra e madeira. A figura 28 ilustra o respectivo ensaio.

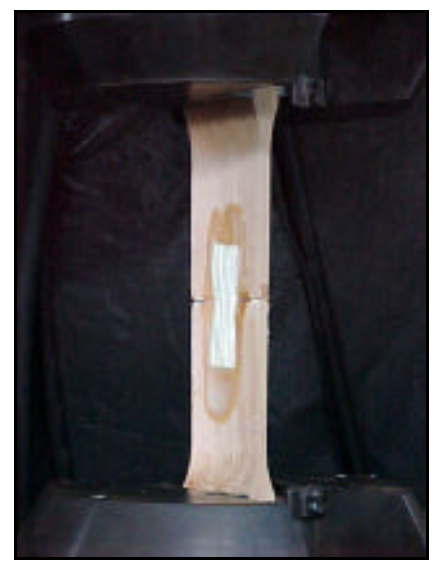

FIGURA 28: Ensaio de tração em corpos-de-prova de madeira (adesivo de mamona)

Foram ensaiados 36 corpos-de-prova de Pinus e 36 corpos-de-prova de Eucalipto. Para estes corpos-de-prova, variou-se apenas o tipo de adesivo. Como a área de colagem é igual para todos, os resultados obtidos podem ser comparados diretamente 
com a força de ruptura obtida nos ensaios.

\subsection{Resultados obtidos}

Os valores das forças de ruptura obtidos nos ensaios são apresentados na tabela 28.

Para os corpos-de-prova de Eucalipto grandis, a forma de ruptura observada em todos os ensaios foi de cisalhamento na interface madeira fibra.

Para os corpos-de-prova de Pinus, a ruptura por cisalhamento ocorreu apenas com os adesivos de mamona e Cascophen. Para o adesivo epóxi, observou-se a ruptura por tração da madeira, em todos os corpos-de-prova conforme mostra a figura 29.

TABELA 28: Valores das forças máximas resistidas pelos adesivos na interface fibra madeira

\begin{tabular}{|c|c|c|c|c|c|c|c|}
\hline $\begin{array}{c}\text { Corpo } \\
\text { de } \\
\text { Prova }\end{array}$ & $\begin{array}{c}\text { Área de } \\
\text { colagem }\left(\mathbf{c m}^{2}\right)\end{array}$ & \multicolumn{3}{|c|}{ Força máxima Pinus } & \multicolumn{3}{c|}{ Força máxima Eucalipto } \\
$(\mathbf{k N})$ & \multicolumn{2}{|c|}{${ }^{\prime}$} \\
\hline & & Cascophen & Mamona & Epóxi & Cascophen & Mamona & Epóxi \\
\hline 1 & 10,50 & 7,07 & 4,06 & 7,46 & 5,83 & 2,89 & 13,91 \\
\hline 2 & 10,50 & 6,95 & 3,94 & 7,29 & 4,70 & 2,21 & 13,05 \\
\hline 3 & 10,50 & 5,41 & 5,58 & 9,86 & 4,68 & 2,77 & 13,35 \\
\hline 4 & 10,50 & 6,06 & 5,10 & 6,88 & 3,54 & 3,09 & 14,49 \\
\hline 5 & 10,50 & 6,59 & 4,14 & 8,55 & 5,34 & 2,16 & 13,37 \\
\hline 6 & 10,50 & 5,72 & 3,41 & 10,10 & 5,13 & 3,06 & 13,72 \\
\hline 7 & 10,50 & 6,19 & 3,65 & 7,89 & 4,30 & 2,16 & 14,22 \\
\hline 8 & 10,50 & 5,25 & 4,03 & 10,40 & 4,46 & 2,19 & 14,59 \\
\hline 9 & 10,50 & 3,02 & 3,51 & 11,18 & 4,90 & 2,91 & 15,06 \\
\hline 10 & 10,50 & 6,38 & 4,38 & 10,97 & 3,72 & 3,90 & 13,69 \\
\hline 11 & 10,50 & 5,33 & 3,75 & 8,87 & 3,91 & 2,66 & 13,10 \\
\hline 12 & 10,50 & & & 7,83 & 3,63 & & 15,13 \\
\hline
\end{tabular}


Observa-se que na tabela 28 , os valores referentes ao corpo-de-prova de número 12, não são apresentados, pois o mesmo apresentou problemas durante o ensaio.
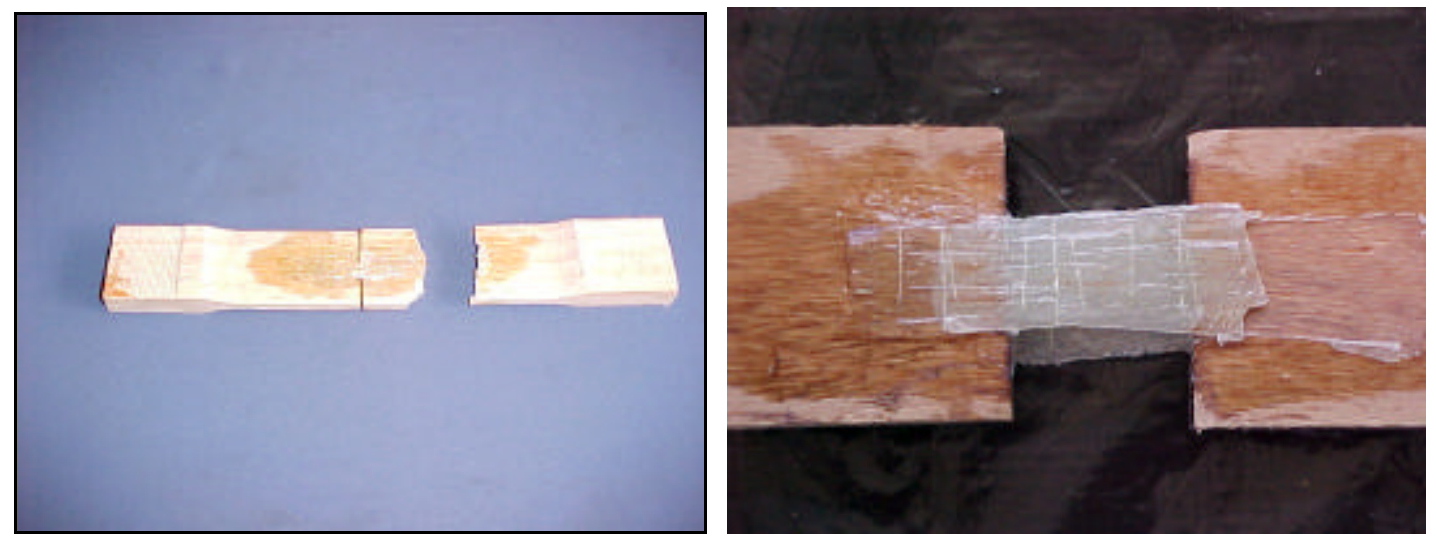

FIGURA 29 Formas de ruptura para adesivo epóxi - ruptura na madeira (Pinus) e ruptura por cisalhamento (Eucalipto)

A figura 30 apresenta corpos-de-prova de Eucalipto nos quais ocorreu cisalhamento na interface fibra madeira.
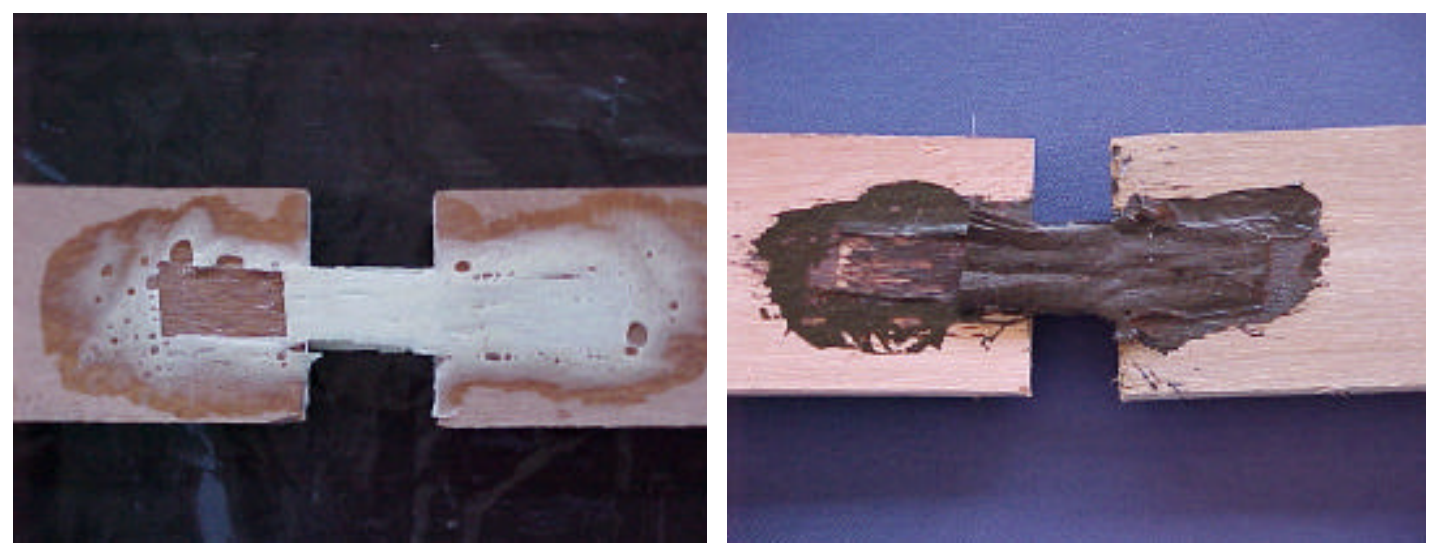

FIGURA 30: Formas de ruptura para adesivo de mamona e cascophen

\subsection{Análise dos resultados}

A tabela 29 apresenta os valores médios e o coeficiente de variação das forças de cisalhamento na interface fibra madeira.

TABELA 29: Valores médios e coeficiente de variação das forças de cisalhamento 


\begin{tabular}{|r|c|c|c|c|c|c|}
\cline { 2 - 7 } \multicolumn{1}{c|}{} & \multicolumn{3}{c|}{ Força máxima Pinus (kN) } & \multicolumn{3}{c|}{ Força máxima Eucalipto (kN) } \\
\cline { 2 - 7 } & Mamona & Cascophen & Epóxi & Mamona & Cascophen & Epóxi \\
\hline Média (MPa) & 4,41 & 5,42 & 8,94 & 2,73 & 4,71 & 13,97 \\
\hline $\begin{array}{r}\text { Coeficiente de } \\
\text { variação (\%) }\end{array}$ & $16 \%$ & $19 \%$ & $17 \%$ & $19 \%$ & $16 \%$ & $5 \%$ \\
\hline
\end{tabular}

Os valores médios de força de tração apresentados no item 4.3 estão ilustrados nas figuras 31 e 32 .

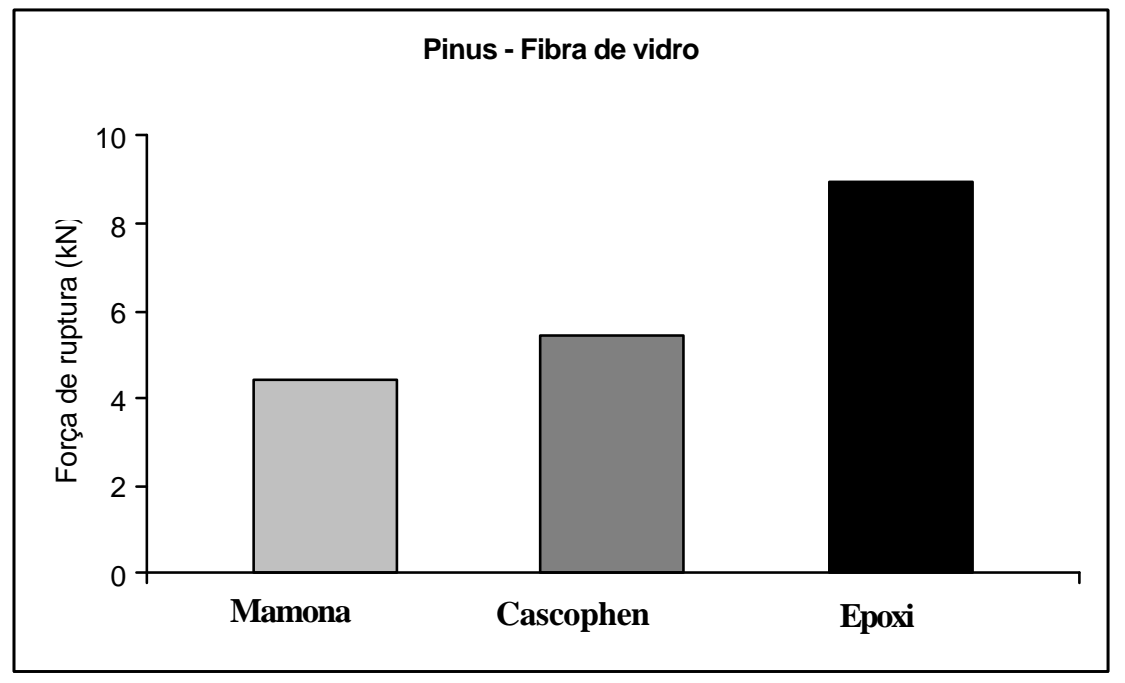

FIGURA 31: Comparação da resistência dos adesivos em corpos-de-prova de Pinus elliotti

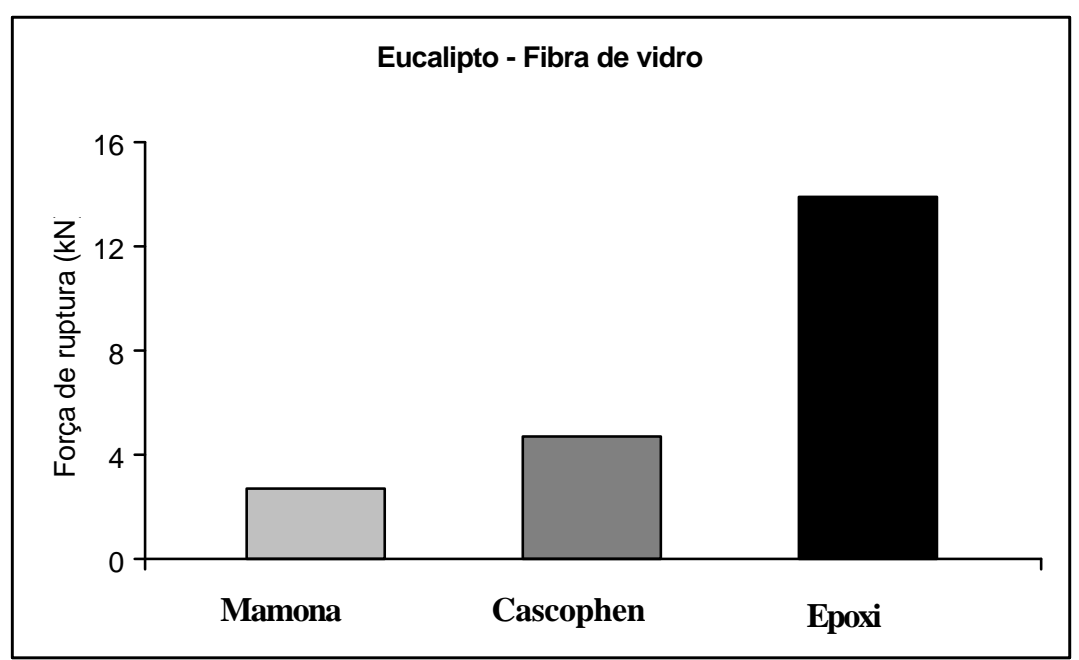

FIGURA 32: Comparação da resistência dos adesivos em corpos-de-prova de Eucalipto Grandis

Pode-se constatar, a partir dos dados apresentados na tabela 29 , que os corpos-

de-prova de Pinus suportam uma força maior na interface fibra - madeira quando são 
utilizados os adesivos de mamona e Cascophen, em comparação aos corpos-de-prova de Eucalipto. Esta diferença ocorre por se tratar de madeira com diferentes densidades: o Eucalipto grandis possui densidade, a $12 \%$ de umidade, de $\left(\rho=640 \mathrm{~kg} / \mathrm{m}^{3}\right)$; o Pinus elliotti $\left(\rho=560 \mathrm{~kg} / \mathrm{m}^{3}\right)$, de acordo com a referência da NBR 7190/97. Usualmente, madeiras menos densas são mais aptas à colagem.

Pode-se observar, também, que os corpos-de-prova de Eucalipto, confeccionados com adesivo de mamona e Cascophen, suportaram uma força de tração aproximadamente três vezes menor que a força resistida pelos corpos-de-prova feitos com adesivo epóxi.

A diferença entre os valores de resistência ao cisalhamento de corpos-de-prova de Pinus laminados com adesivo epóxi não foi tão significativa como no caso dos corpos-de-prova de Eucalipto. Isto ocorreu devido ao aumento na resistência dos adesivos à base de mamona e Cascophen para o Pinus, pelos motivos já observados, aliados ao fato da ruptura observada, no caso do adesivo epóxi, ter sido na madeira. 


\section{5 - MODELO TEÓRICO DE CÁlCULO E ANÁliSE DE VIGAS REFORÇADAS COM FIBRA}

Para a análise da rigidez de vigas de madeira será utilizado o método da seção transformada, o qual conduz a bons resultados. Já com relação à determinação do momento último, o método de dimensionamento apresentado na revisão bibliográfica, segundo os dados apresentados por Belperio; Grad (1999), conduz a resultados superiores aos determinados experimentalmente. Dessa forma foi desenvolvido um modelo mais preciso, considerando a compatibilidade de deformações entre os diferentes elementos que compõem a seção.

Será apresentado, também, uma avaliação teórica do comportamento das vigas reforçadas, quanto a resistência e a rigidez, utilizando estes modelos de cálculo.

\subsection{Introdução}

O desenvolvimento de um modelo de cálculo para o caso de vigas de madeira reforçadas com fibras é importante para a utilização correta e segura do material em reforço e recuperação de estruturas. Também possibilita ampliação do seu uso na construção civil.

A norma NBR 7190/97 - Projeto de Estruturas de Madeira está baseada no Método dos Estados Limites para verificação da segurança estrutural. Para o caso específico das vigas, os seguintes estados limites devem ser verificados:

- estado limite de utilização, referente ao deslocamento vertical (flecha) máximo;

- estado limite último referente às tensões normais devidas ao momento fletor; 
- estado limite último referente às tensões tangenciais devidas ao esforço cortante.

Para a verificação do estado limite de utilização, os deslocamentos verticais serão determinados a partir da rigidez à flexão avaliada segundo um modelo elástico linear de cálculo (método da seção transformada).

Para a determinação do momento fletor último será utilizado um modelo teórico que considera comportamento elasto-plástico para a madeira solicitada à compressão, e comportamento elasto-frágil para a madeira tracionada e para a fibra de reforço.

$\mathrm{Na}$ avaliação da resistência quanto ao esforço cortante, será desprezada a contribuição da fibra, considerando-se a peça de madeira como sendo responsável pela absorção total deste esforço.

\subsection{Análise da rigidez à flexão das vigas}

A seguir é apresentado um modelo teórico de cálculo da rigidez de vigas de madeira reforçadas com fibra utilizando o método da seção transformada.

\subsubsection{Cálculo da seção transformada}

A determinação da rigidez teórica de vigas de madeira constituiu em avaliar vigas com seção retangular (b x h) reforçadas com fibra.

As vigas de madeira, sem reforço, apresentam momento de inércia (I) igual a:

$$
I=\frac{b h^{3}}{12}
$$

As vigas reforçadas serão analisadas de acordo com a teoria clássica da flexão, que considera os alongamentos e encurtamentos das fibras longitudinais proporcionais 
às suas distâncias ao eixo neutro, considerando o material no regime elástico linear. Para este tipo de viga, constituída por dois materiais diferentes basta determinar a seção equivalente da viga idealizada constituída por apenas um dos materiais. A seção retangular mostrada na figura 33 (a), constituída por madeira (material 1) e fibra (material 2) ilustra este modelo. Para o reforço de fibra será estabelecida largura igual à da viga de madeira e espessura "e".

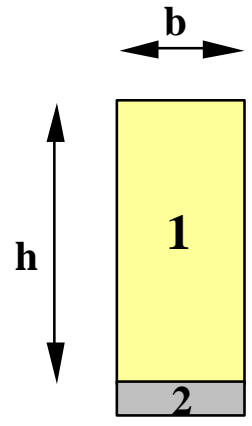

(a)

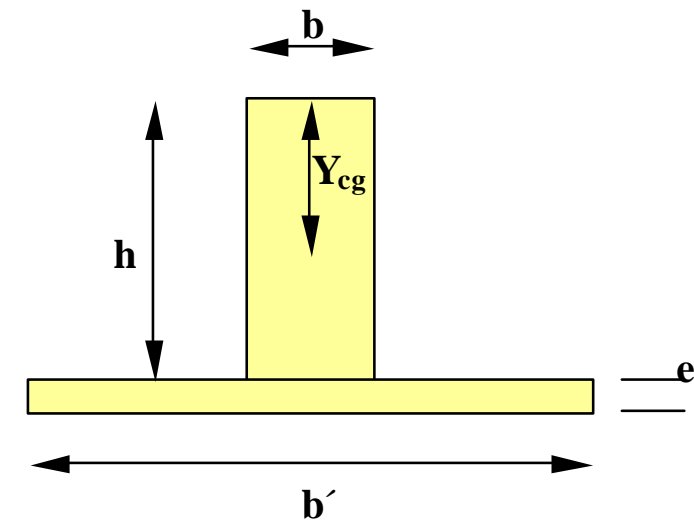

(b)

FIGURA 33: Viga constituída por dois materiais diferentes (a) e seção equivalente (b)

A seção transversal equivalente, apresentada na figura 33 (b), é considerada como sendo constituída apenas pelo material 1 (madeira). A largura b' é determinada pelo produto da relação dos módulos de elasticidade da fibra $\left(\mathrm{E}_{2}\right)$ e da madeira $\left(\mathrm{E}_{1}\right)$ pela largura $b$.

$$
\mathrm{b}^{\prime}=\mathrm{b} \cdot \frac{\mathrm{E}_{2}}{\mathrm{E}_{1}}
$$

Para a seção equivalente, foi determinada a posição do centro de gravidade da peça $\left(\mathrm{y}_{\mathrm{cg}}\right)$, cotado em relação à borda superior da viga de madeira.

$$
y_{c g}=\frac{(b \cdot h) \cdot(h / 2)+\left(b \cdot E_{2} \cdot e / E_{1}\right) \cdot(h+e / 2)}{(b \cdot h)+\left(b \cdot e \cdot E_{2} / E_{1}\right)}
$$


Chamando de $\mathrm{n}$ a relação entre a espessura da fibra e a altura da viga (n = e/h), obtêm-se:

$$
y_{c g}=\frac{\left(h / 2+(1+n / 2) \cdot\left(n \cdot E_{2} / E_{1}\right)\right)}{\left(1+\left(n \cdot E_{2} / E_{1}\right)\right)}
$$

$\mathrm{O}$ valor do momento de inércia para a seção equivalente da viga com reforço $\left(\mathrm{I}_{\mathrm{r}}\right)$ é dado por:

$$
\begin{gathered}
I_{r}=\frac{b h^{3}}{12}+b h\left(y_{c g}-h / 2\right)^{2}+\frac{b \cdot E_{2} \cdot e^{3}}{E_{1} \cdot 12}+b \cdot \frac{E_{2}}{E_{1}} \cdot e \cdot\left(e / 2+\left(h-y_{c g}\right)\right)^{2} \\
I_{r}=\frac{b \cdot h^{3}}{12}+b \cdot h \cdot\left(y_{c g}-h / 2\right)^{2}+\frac{b \cdot E_{2} \cdot n \cdot h^{3}}{E_{1} \cdot 12}+b \cdot \frac{E_{2}}{E_{1}} \cdot n \cdot h \cdot\left(n \cdot h / 2+h-y_{c g}\right)^{2}
\end{gathered}
$$

\subsubsection{Análise da eficiência do reforço}

O aumento da rigidez à flexão de vigas reforçadas, em comparação com as vigas sem reforço, será determinado por meio da relação entre os momentos de inércia:

$$
\frac{I_{r}}{I}=\frac{h^{3} / 12+h \cdot\left(y_{c g}-h / 2\right)^{2}+E_{2} \cdot(n \cdot h)^{2} / 12 \cdot E_{1}+E_{2} \cdot(n \cdot h) / E_{1}\left(n \cdot h+h-y_{c g}\right)^{2}}{\left(h^{3} / 12\right)}
$$

As figuras 34 e 35 mostram a relação entre os momentos de inércia de vigas de madeira com reforço e sem reforço, em função do número de camadas de fibra. Para estes cálculos foram consideradas vigas de madeira com três diferentes tipos de densidade, baixa, média e alta, com seção $(6 \times 12 \mathrm{~cm}, 6 \times 16 \mathrm{~cm}$ e $6 \times 20 \mathrm{~cm})$. As espécies adotadas na análise são Pinus hondurensis (Pinus caribea var. Hondurensis), Eucalipto Grandis (Eucalyptus grandis) e Jatobá (Hymenaea spp). Os valores dos módulos de elasticidade das fibras e da madeira utilizados nos cálculos estão apresentados na tabela 
30, estes últimos foram retirados na norma NBR 7190/97 - Projeto de Estruturas de Madeira. Para os tecidos de fibra de vidro e de fibra de carbono os valores apresentados são os determinados no capítulo 03.

Os cálculos do momento de inércia foram feitos considerando apenas a espessura da fibra, não foi considerado o acréscimo na espessura devido à aplicação do adesivo.

TABELA 30: Valores de elasticidade e resistência

\begin{tabular}{|c|c|c|c|c|c|c|}
\hline & \multirow{2}{*}{$\begin{array}{c}\text { Pinus caribea } \\
\text { var. } \\
\text { hondurensis }\end{array}$} & \multirow{2}{*}{$\begin{array}{c}\text { Eucalipto } \\
\text { grandis }\end{array}$} & \multirow[t]{2}{*}{ Jatobá } & & \multicolumn{2}{|c|}{ Fibras } \\
\hline & & & & & Vidro & Carbono \\
\hline E (MPa) & 9.868 & 12.513 & 23.607 & $\mathrm{E}(\mathrm{GPa})$ & 70 & 170 \\
\hline $\mathbf{f}_{\mathrm{co}}(\mathrm{MPa})$ & 42,3 & 40,3 & 93,3 & \multirow{2}{*}{$\mathbf{f}_{\mathbf{t}}(\mathbf{G P a})$} & \multirow{2}{*}{1.200} & \multirow{2}{*}{2.400} \\
\hline $\mathbf{f}_{\mathrm{to}}(\mathrm{MPa})$ & 50,3 & 70,2 & 157,5 & & & \\
\hline$\rho\left(\mathrm{g} / \mathrm{cm}^{3}\right)$ & 0,535 & 0,640 & 1,074 & $\rho\left(\mathrm{g} / \mathrm{cm}^{3}\right)$ & 2,2 & 1,4 \\
\hline
\end{tabular}



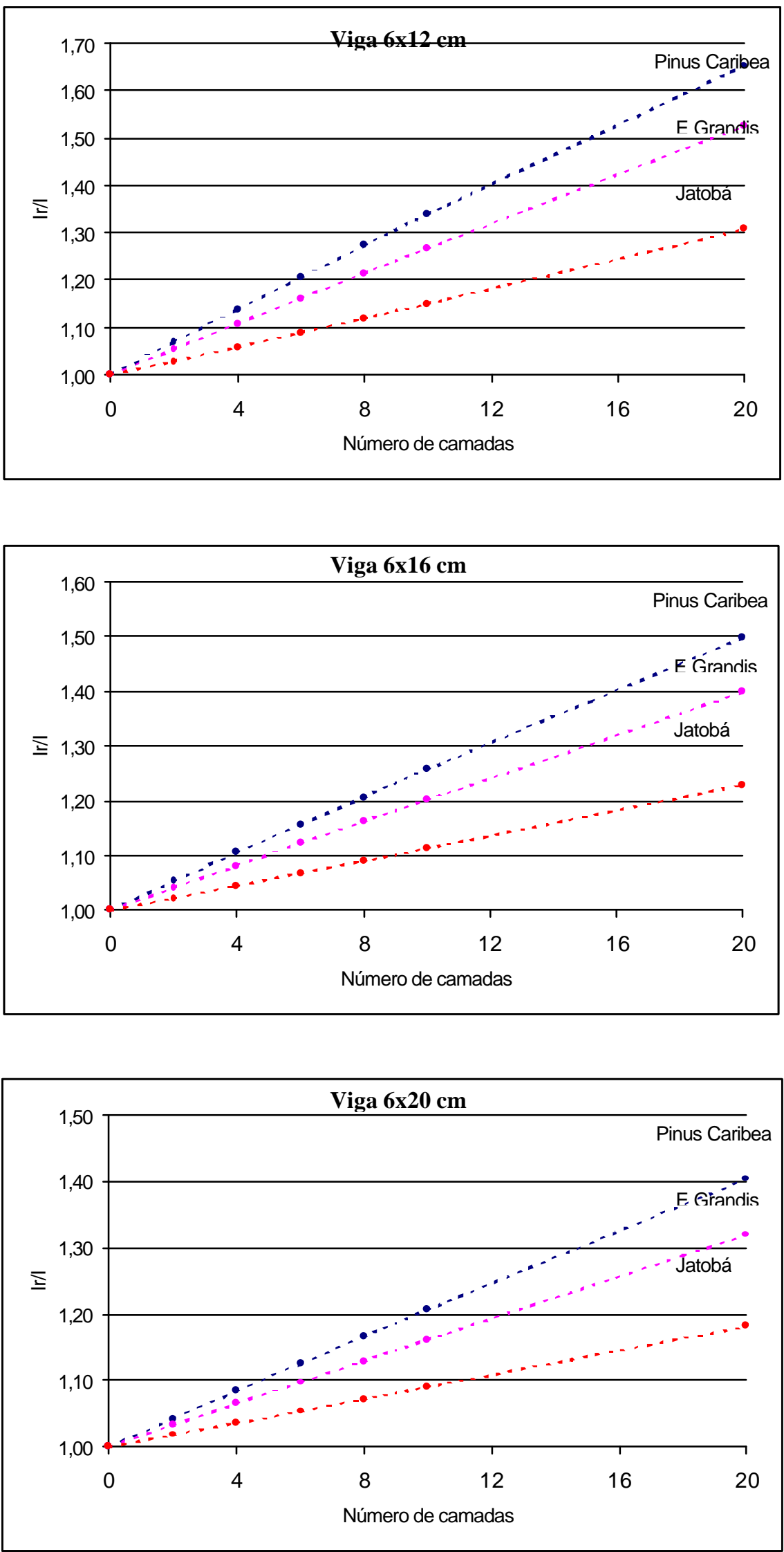

FIGURA 34: Variação do momento de inércia - reforço com fibra vidro 

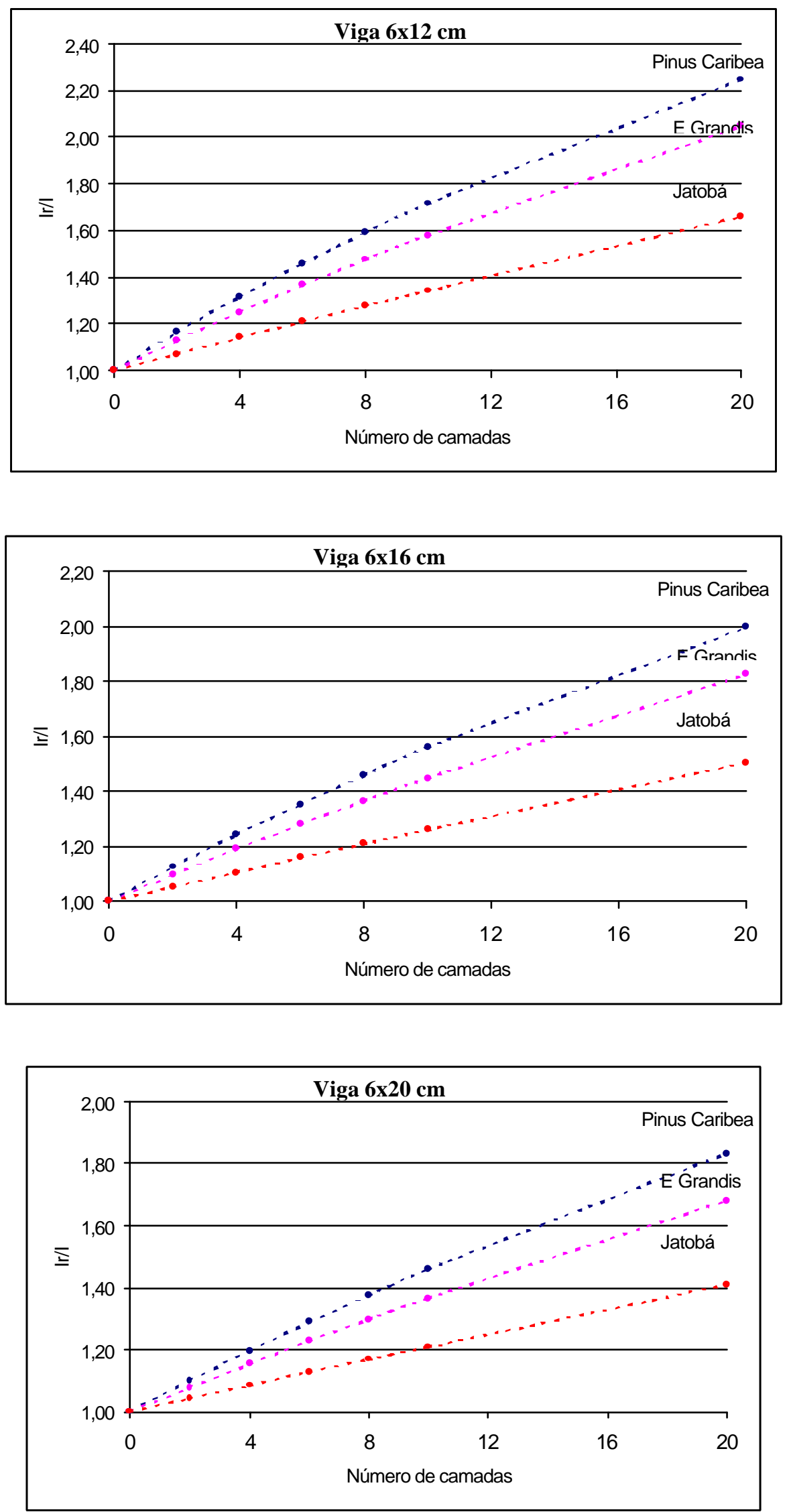

FIGURA 35: Variação do momento de inércia reforço com fibra de carbono 


\subsubsection{Comentários}

Observando as figuras 34 e 35 pode-se avaliar o aumento do momento de inércia em função da espessura da fibra. O maior aumento ocorre para as vigas reforçadas com fibra de carbono, devido ao seu maior módulo de elasticidade. Este aumento fica em torno de $70 \%$ para vigas de madeira de baixa densidade reforçadas com dez camadas de fibra.

Para as vigas reforçadas com fibra de vidro, o maior aumento do momento de inércia para vigas de baixa densidade é de aproximadamente $35 \%$. Observa-se também que, para vigas de madeira com alta densidade e alto módulo de elasticidade, o aumento da inércia de vigas reforçadas é muito inferior ao observado para madeira de baixa densidade.

\subsection{Análise da resistência}

Para a determinação do momento fletor último será utilizado um modelo teórico que considera comportamento elasto-plástico para a madeira solicitada à compressão, e comportamento elasto-frágil para a madeira tracionada e para a fibra de reforço.

\subsubsection{Cálculo do momento fletor último}

Para a avaliação do momento fletor último será considerado os estados limites de ruptura por tração e por compressão da madeira. Este modelo é obtido a partir da hipótese de Navier/Bernoulli (seções planas permanecem planas após a deformação), conforme ilustra a figura 36. 


\section{Seção transversal}

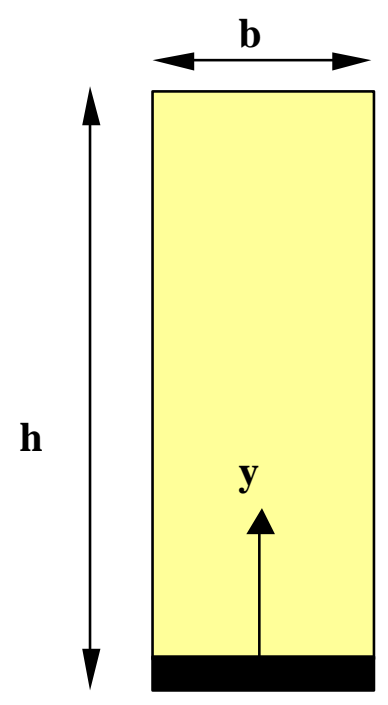

Distribuição de deformações

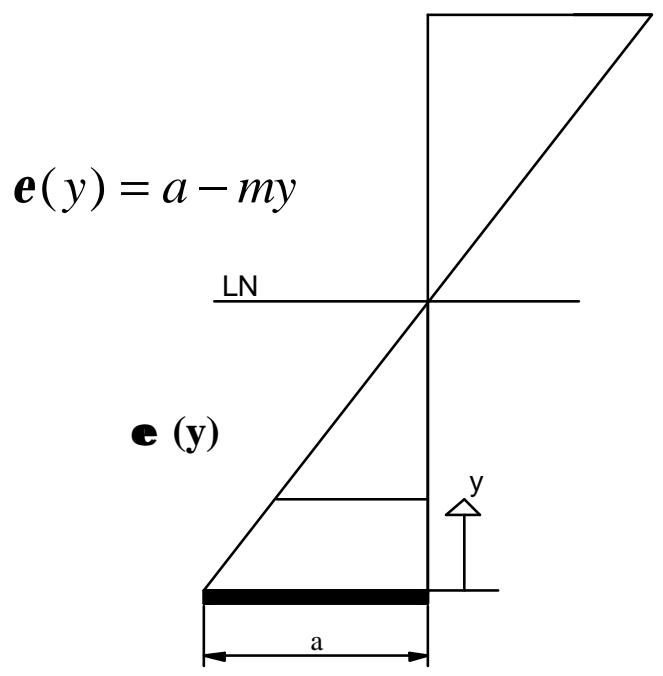

FIGURA 36: Diagrama de deformação na seção transversal

O valor do estado limite de compressão foi estipulado até o ponto que o corpode-prova possa absorver esforços. Este valor foi avaliado experimentalmente em ensaios de compressão paralela às fibras. A figura 37 apresenta um dos ensaios realizados, mostrando o diagrama tensão x deformação. A relação entre a deformação total $\left(\varepsilon_{2}\right)$ e a deformação na fase elástica do modelo elastoplástico $\left(\varepsilon_{1}\right)$ idealizado é denominada como "k". 


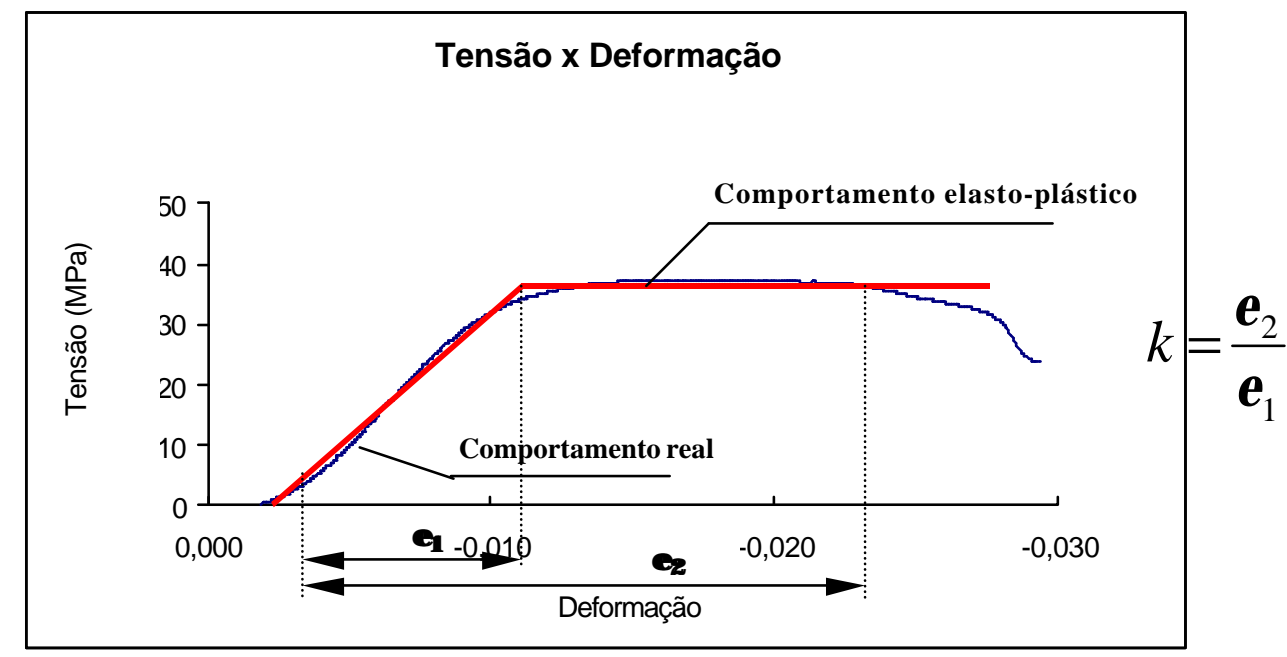

FIGURA 37: Diagrama $\sigma \times \varepsilon$ na compressão paralela às fibras

Para a madeira tracionada e para o reforço de fibra é considerado um comportamento elasto-frágil, admitindo-se que a deformação específica máxima da madeira é igual à da fibra. Então, a relação entre a máxima tensão atuante na fibra e a máxima tensão atuante na madeira é igual à relação entre os módulos de elasticidade da fibra e da madeira. Como esta relação sempre é muito inferior à relação observada para a resistência à tração da fibra e da madeira, pode-se concluir que a ruptura por tração sempre ocorrerá na madeira.

A seguir são apresentadas as deduções das expressões para avaliação do momento fletor último, considerando os estados limites de compressão e de tração na madeira. Obviamente, o momento fletor último deve ser avaliado pela expressão que fornecer o menor valor.

Para as duas avaliações (ruptura por compressão ou por tração), são feitas as seguintes considerações:

a) para $\varepsilon_{1} \leq \varepsilon \leq \varepsilon_{2}$, a tensão de compressão na madeira é igual a:

$$
\sigma_{\mathrm{c}}=\mathrm{f}_{\mathrm{c} 0}
$$


b) a deformação na fibra é igual à deformação máxima de tração na madeira, desprezando-se a variação da deformação ao longo da espessura da fibra.

Foram estabelecidas as seguintes denominações:

C1 e C2 - Forças de compressão resultantes na madeira;

TM - Força de tração resultante na madeira

TF - Força de tração na fibra

$\mathrm{h}$ - altura da viga

e - espessura da fibra

$\mathrm{f}_{\mathrm{c} 0}$ - resistência à compressão paralela às fibras da madeira

$\mathrm{f}_{\mathrm{t} 0}$ - resistência à tração paralela às fibras da madeira

$\mathrm{E}_{\mathrm{c}}$-módulo de elasticidade à compressão paralela da madeira

$\mathrm{E}_{\mathrm{t}}$-módulo de elasticidade à tração paralela da madeira

$\mathrm{E}_{\mathrm{f}}$ - módulo de elasticidade à tração da fibra

$$
\begin{aligned}
& s=\frac{f_{c 0}}{E_{c} \cdot m} \\
& p=\frac{f_{t 0}}{E_{t} \cdot m}
\end{aligned}
$$

\subsubsection{Modo de ruptura: compressão}

Considera-se atingido o estado limite último na compressão quando a máxima deformação na parte comprimida atingir o valor $\varepsilon_{2}$. A partir das relações estabelecidas entre tensões e deformações, a figura 38 apresenta a distribuição de tensões quando este limite é atingido, bem como as forças resultantes destas tensões e suas posições: 


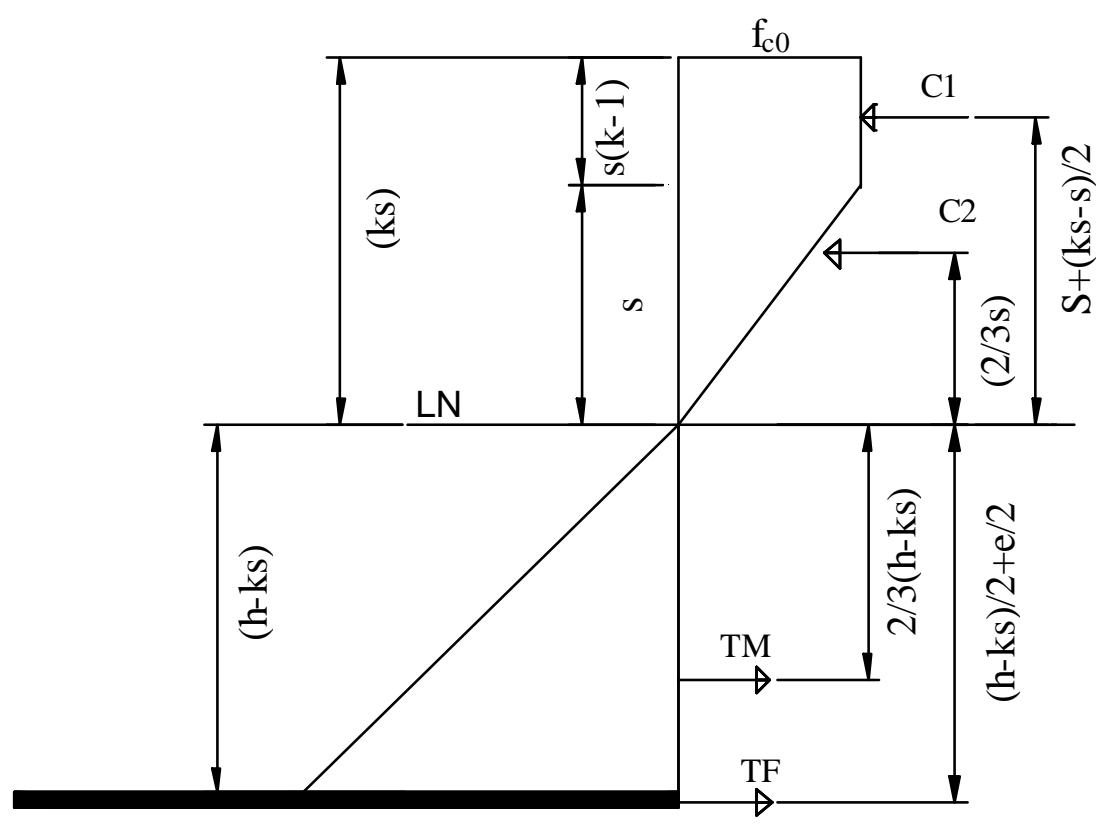

FIGURA 38: Distribuição de tensões na seção transversal (ruptura por compressão)

O valor das forças resultantes de compressão e de tração é igual a:

$$
\begin{aligned}
& C_{1}=f_{c 0} \cdot b \cdot s \cdot(k-1) \\
& C_{2}=f_{c 0} \cdot \frac{b \cdot s}{2} \\
& T_{m}=\frac{b}{2} \cdot(h-k s) \cdot E_{t} \cdot\left(m \cdot h-\frac{k f_{c 0}}{E_{c}}\right) \\
& T_{f}=b \cdot e \cdot E_{f} \cdot\left(m \cdot h-\frac{k f_{c 0}}{E_{c}}\right)
\end{aligned}
$$

A partir da condição de equilíbrio de forças horizontais, substituindo os valores de "s" na equação 9 e rearranjando os termos, obtém-se:

$$
\begin{aligned}
& \mathrm{m}^{2} \cdot\left(\mathrm{h}^{2} \mathrm{E}_{\mathrm{t}} \mathrm{E}_{\mathrm{c}}{ }^{2}+2 \mathrm{E}_{\mathrm{c}}{ }^{2} \mathrm{E}_{\mathrm{f}} \mathrm{eh}\right)+\mathrm{m}\left(-2 \mathrm{hE}_{\mathrm{t}} \mathrm{kf}_{\mathrm{c} 0} \mathrm{E}_{\mathrm{c}}-2 \mathrm{E}_{\mathrm{c}} \mathrm{eE}_{\mathrm{f}} \mathrm{kf}_{\mathrm{c} 0}\right)+ \\
& \left(\mathrm{k}^{2} \mathrm{f}_{\mathrm{c} 0}{ }^{2} \mathrm{E}_{\mathrm{t}}-2 \mathrm{E}_{\mathrm{c}} \mathrm{f}_{\mathrm{c} 0}{ }^{2}(\mathrm{k}-1)-\left(\mathrm{E}_{\mathrm{c}} \mathrm{f}_{\mathrm{c} 0}{ }^{2}\right)=0\right.
\end{aligned}
$$

Após a determinação de "m", por meio da equação 10 , pode ser avaliado o valor 
do momento resistente, a partir da soma dos momentos das forças. Foi adotada a posição da linha neutra para se fazer à somatória das forças envolvidas no problema, obtendo-se:

$$
\begin{aligned}
& M_{c}=\left[b \cdot \frac{f_{c 0}{ }^{2}}{E_{c} \cdot m} \cdot(k-1)\right] \cdot\left[\left(\frac{f_{c 0}}{E_{c} \cdot m}+\left(\frac{f_{c 0}}{2 \cdot E_{c} \cdot m} \cdot(k-1)\right)\right]+\left[\left(\frac{f_{c 0}{ }^{2} \cdot b}{2 E_{c} \cdot m}\right) \cdot\left(\frac{2}{3} \cdot \frac{f_{c 0}}{E_{c} \cdot m}\right)\right]+\right. \\
& {\left[\frac{b}{2} \cdot\left(h-\frac{k \cdot f_{c 0}}{E_{c} \cdot m}\right)\right] \cdot\left[\frac{2}{3} \cdot E_{t} \cdot\left(m h-\frac{k f_{c 0}}{E_{c}}\right) \cdot\left(h-\frac{k f_{c 0}}{E_{c} \cdot m}\right)\right]+} \\
& {\left[b \cdot e \cdot E_{f} \cdot\left(m h-\frac{k f_{c 0}}{E_{c}}\right) \cdot\left(h+\frac{e}{2}-\frac{k f_{c 0}}{E_{c} \cdot m}\right)\right]}
\end{aligned}
$$

\subsubsection{Modo de ruptura - tração}

Considera-se atingido o estado limite de tração na madeira, quando a máxima tensão atuante de tração na madeira é igual a sua resistência à tração. A partir das relações estabelecidas entre as tensões e as deformações, a figura 39 apresenta a distribuição de tensões quando este estado limite é atingido, bem como as forças resultantes destas tensões e suas posições.

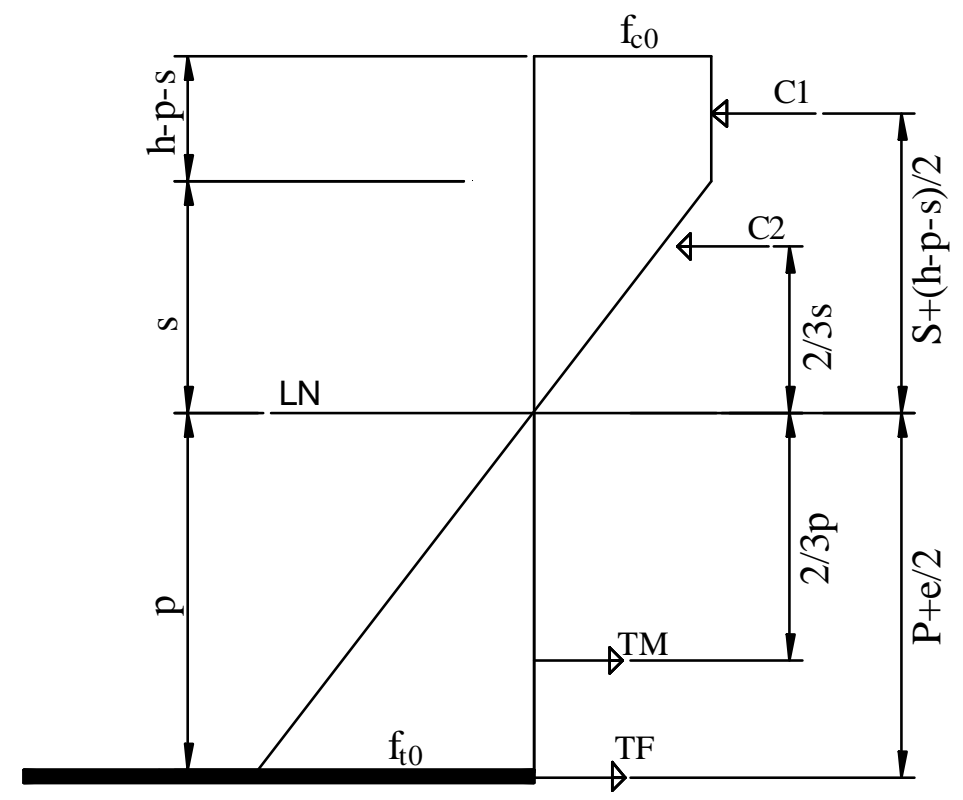

FIGURA 39: Distribuição de tensões na seção transversal (ruptura por tração na madeira) 
O valor das forças resultantes de compressão e de tração é igual a:

$$
\begin{aligned}
& C_{1}=f_{c 0} \cdot b \cdot(h-s-p) \\
& C_{2}=f_{c 0} \cdot \frac{b \cdot s}{2} \\
& T_{m}=f_{t 0} \cdot \frac{b}{2} \cdot\left(\frac{f_{t 0}}{E_{t} \cdot m}\right) \\
& T_{f}=b \cdot e \cdot E_{f} \cdot\left(\frac{f_{t 0}}{E_{t}}\right)
\end{aligned}
$$

A partir da condição de equilíbrio de forças horizontais, substituindo os valores de "s" e "p" na equação 12 e rearranjando os termos, obtém-se:

$$
m=\frac{f_{t 0}{ }^{2} \cdot E_{c}+2 \cdot E_{t} \cdot f_{c 0}{ }^{2}+2 \cdot E_{c} \cdot f_{c 0} \cdot f_{t 0}-f_{c 0}{ }^{2} \cdot E_{t}}{2 \cdot f_{c 0} \cdot h \cdot E_{t} \cdot E_{c}-2 \cdot E_{c} \cdot e \cdot E_{f} \cdot f_{t 0}}
$$

Após a determinação de "m", por meio da equação 13, pode ser avaliado o valor do momento resistente, a partir da soma dos momentos das forças. Foi adotada a posição da linha neutra para se fazer a somatória das forças envolvidas no problema, obtendo-se:

$$
\begin{aligned}
& M_{t}=f_{c 0} \cdot b \cdot\left[\left(h-\frac{f_{c o}}{E_{c} \cdot m}-\frac{f_{t 0}}{E_{t} \cdot m}\right) \cdot\left(\frac{f_{c 0}}{E_{c} \cdot m}+\left(\frac{h}{2}-\frac{f_{t 0}}{2 \cdot E_{t} \cdot m}-\frac{f_{c 0}}{2 \cdot E_{c} \cdot m}\right)\right]+\left[\left(\frac{f_{c 0}{ }^{2} \cdot b}{2 \cdot E_{c} \cdot m}\right)\right.\right. \\
& {\left[\left(\frac{2}{3} \cdot \frac{f_{c 0}}{E_{c} \cdot m}\right)\right]+\left[\left(\frac{f_{t o}{ }^{2} \cdot b}{2 \cdot E_{t} \cdot m}\right) \cdot\left(\frac{2 \cdot f_{t 0}}{3 \cdot E_{t} \cdot m}\right)\right]+\left[\left(\frac{b \cdot e \cdot E_{f} \cdot f_{t 0}}{E_{t}}\right) \cdot\left(\frac{f_{t 0}}{E_{t} \cdot m}+\frac{e}{2}\right)\right]}
\end{aligned}
$$

\subsubsection{Análise de vigas reforçadas com fibras, utilizando o modelo teórico}

Com o objetivo de avaliar a influência do número de camadas de reforço na 
resistência de vigas de madeira, são apresentados gráficos elaborados a partir do modelo teórico deduzido para tração e para compressão. Para este último foi variada a magnitude de plastificação (parâmetro k).

\subsubsection{Reforço com fibra de vidro}

As figuras 40, 41 e 42 apresentam os resultados da avaliação teórica descrita anteriormente, para três espécies de madeira (Pinus caribea var. hondurensis, Eucaliptus Grandis e Jatobá), com baixa, média e alta densidade.

Para as madeiras, utilizaram-se os valores estabelecidos pela norma NBR 7190/97 - Projeto de Estruturas de Madeira, da Associação Brasileira de Normas Técnicas ABNT, para as fibras os valores do módulo de elasticidade das fibras de vidro e das fibras de carbono são os apresentados determinados no capítulo 03, conforme apresentado na tabela 30, item 5.2.2. Salienta-se que, segundo a recomendação da NBR 7190/97, não é feita distinção entre os módulos de elasticidade na tração e na compressão.

As figuras 40, 41 e 42 relacionam momento x número de camadas de fibra de vidro, para vigas de madeira das espécies Pinus, Eucalipto e Jatobá, com seções 6x12 $\mathrm{cm}, 6 \times 16 \mathrm{~cm}$ e $6 \times 20 \mathrm{~cm}$.

São apresentados resultados para os modelos de ruptura por tração e também para os modelos de ruptura por compressão sendo, neste caso, considerados valores do parâmetro k variando de 1 a 4.

Observa-se que o valor do parâmetro $\mathrm{k}$ igual a um $(\mathrm{k}=1)$ equivale a considerar um comportamento elasto-frágil para a compressão. 
Para a avaliação da resistência da viga sem o reforço, também foi considerado a plastificação na compressão no modelo de ruptura, que é equacionado de forma semelhante aos casos com reforço, apenas não considerando a atuação da fibra. 

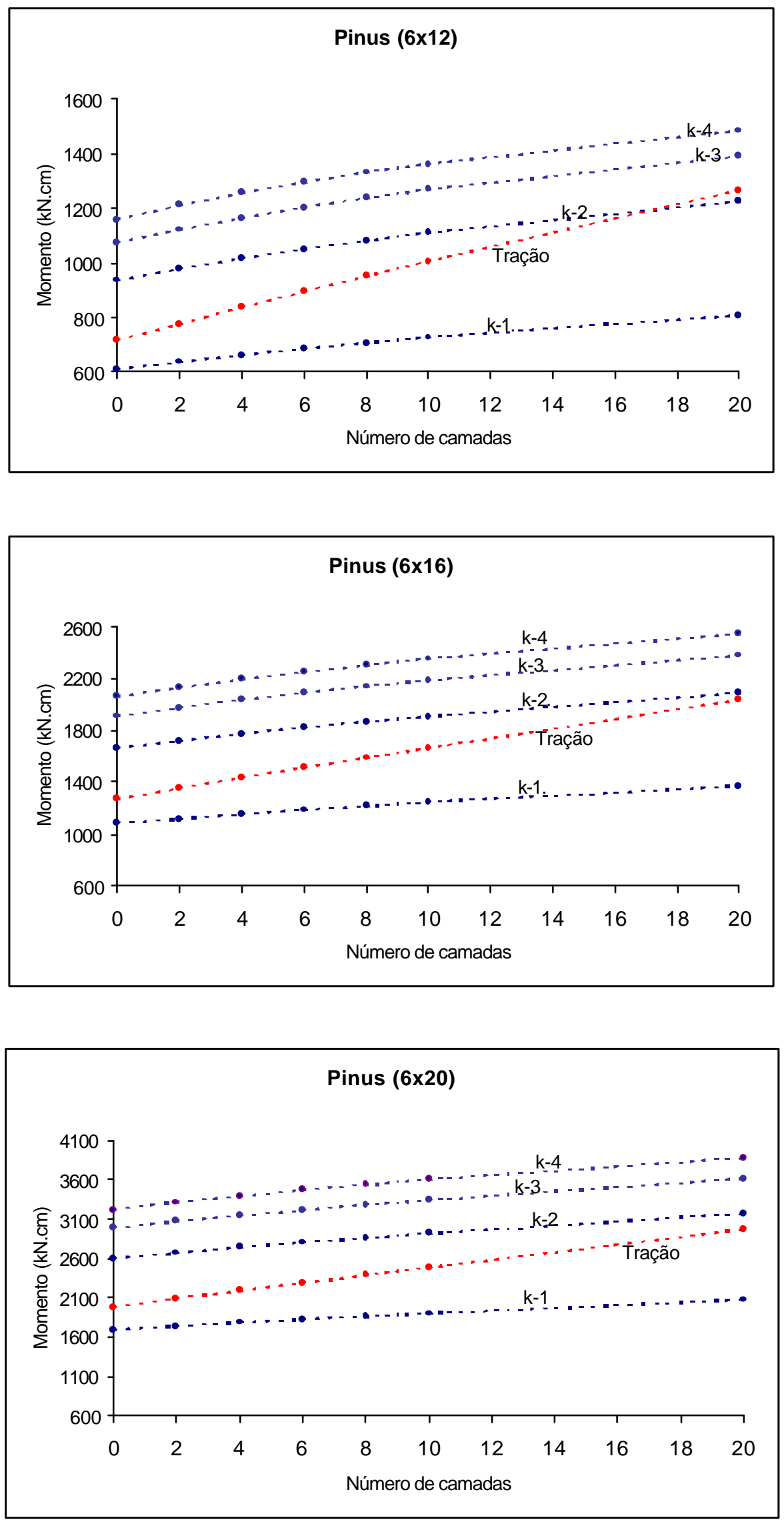

FIGURA 40: Relação entre momento x número de camadas de fibra de vidro 

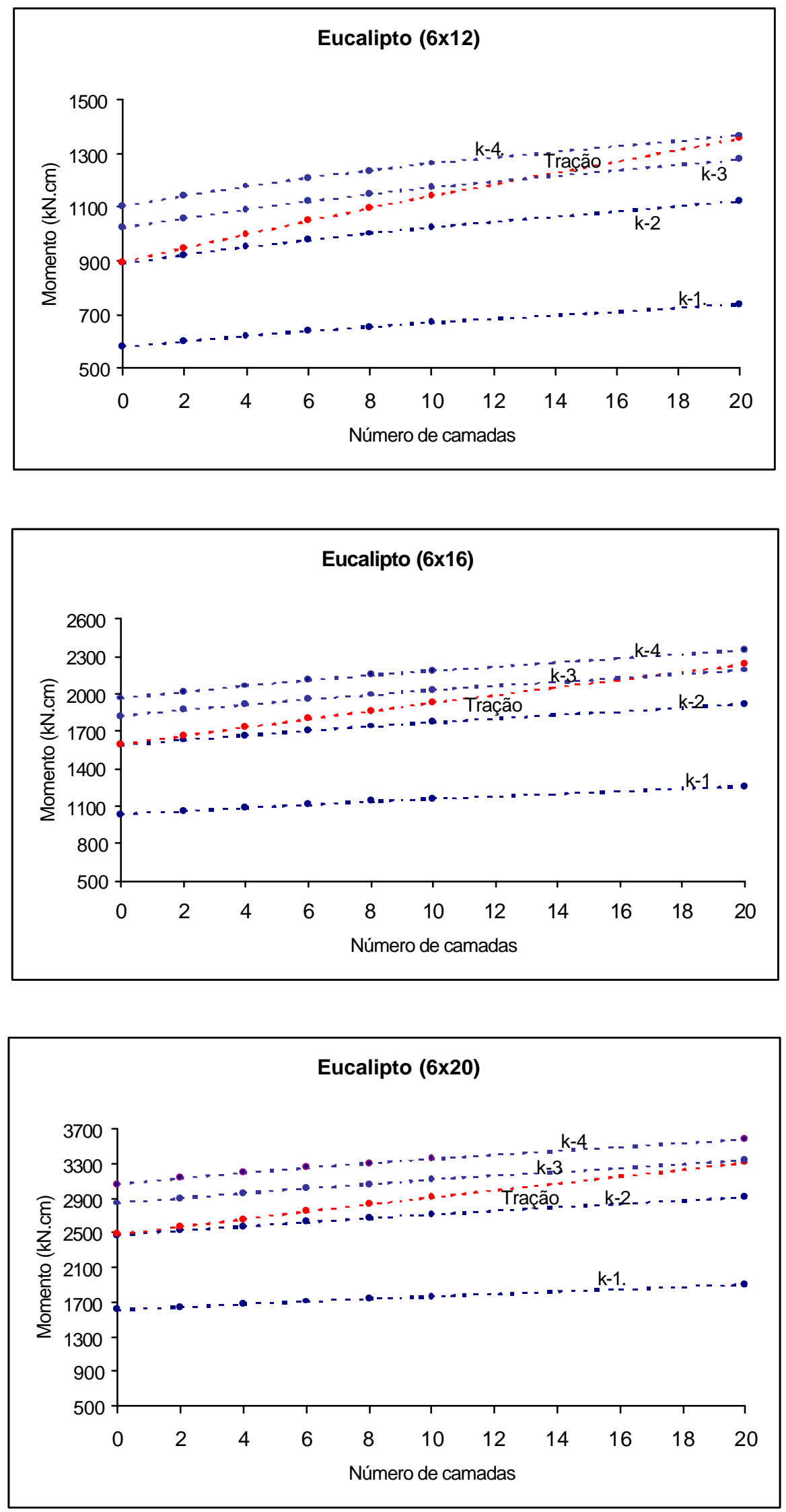

FIGURA 41: Relação entre momento x número de camadas de fibra de vidro 

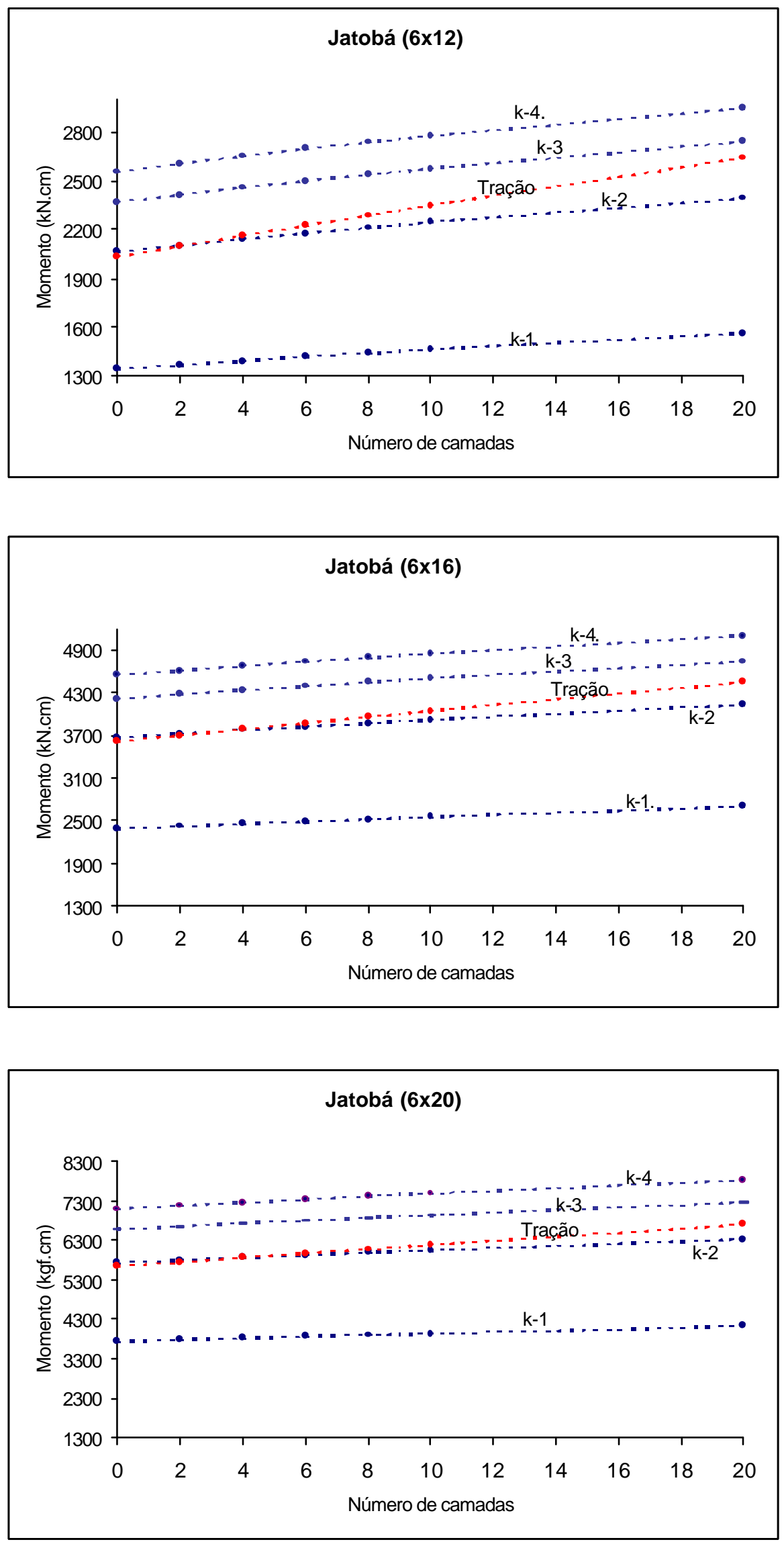

FIGURA 42: Relação entre momento x número de camadas de fibra de vidro 
De acordo com as figuras 40, 41 e 42 observa-se um aumento linear crescente, no valor do momento de ruptura de vigas de madeira reforçadas com fibra de vidro.

Para madeiras com alta densidade o ganho de resistência é baixo (aproximadamente 30\%), em comparação com o ganho conseguido para madeiras de baixa densidade (aproximadamente 70\%), para vigas reforçadas com vinte camadas de tecido. Conclui-se pela vantagem de aplicação do reforço neste tipo de madeira.

\subsubsection{Reforço com fibra de carbono}

A mesma análise apresentada anteriormente foi realizada para vigas de madeira reforçadas com fibra de carbono. As figuras 43, 44 e 45 apresentam a variação do momento máximo resistido em relação ao número de camadas de fibras.

Para esta análise também foram utilizadas três espécies de madeira com baixa, média e alta densidade. Pinus caribea var. hondurensis, Eucaliptus Grandis e Jatobá. 

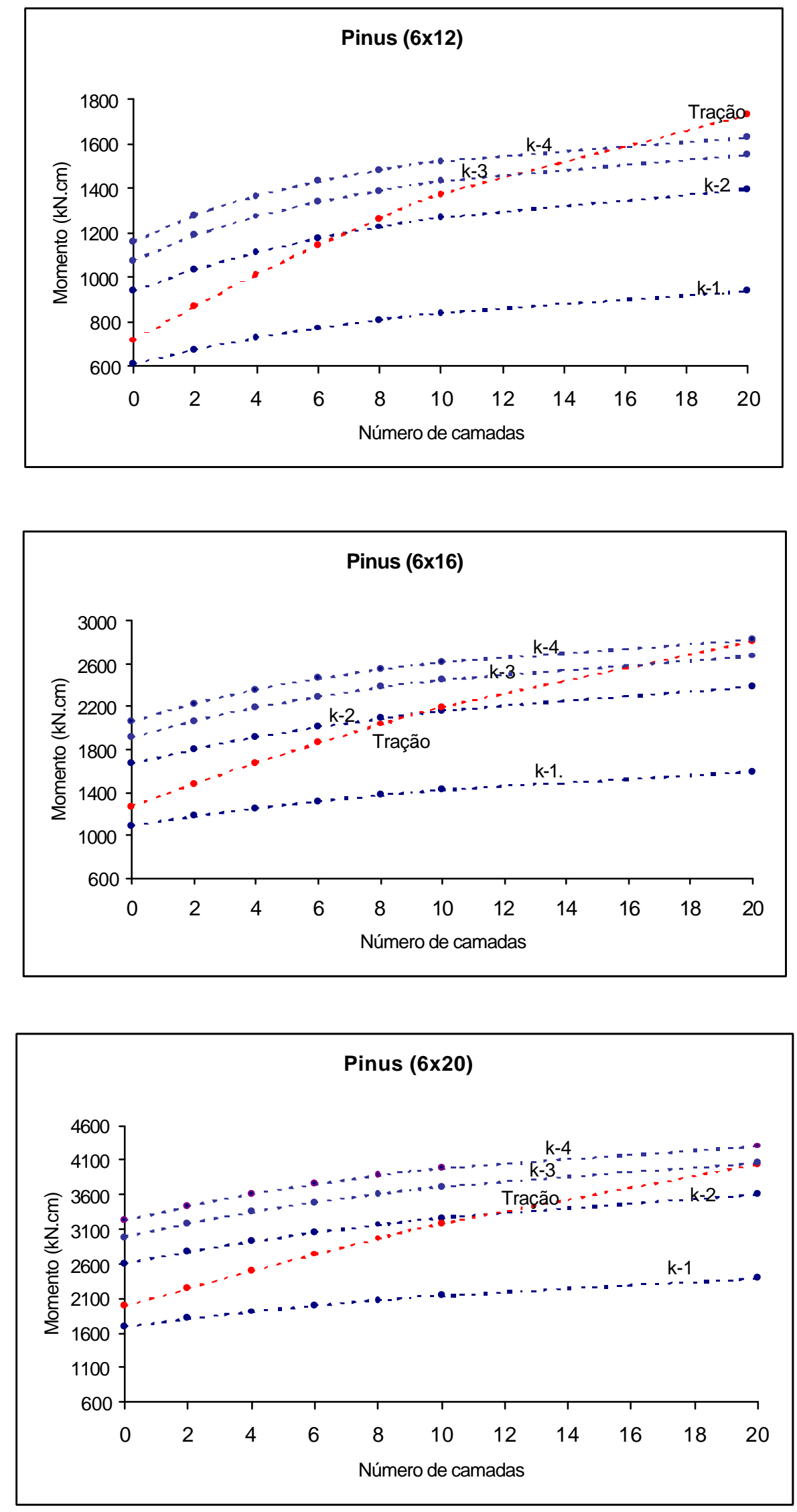

FIGURA 43: Relação entre momento x número de camadas de fibra de carbono 

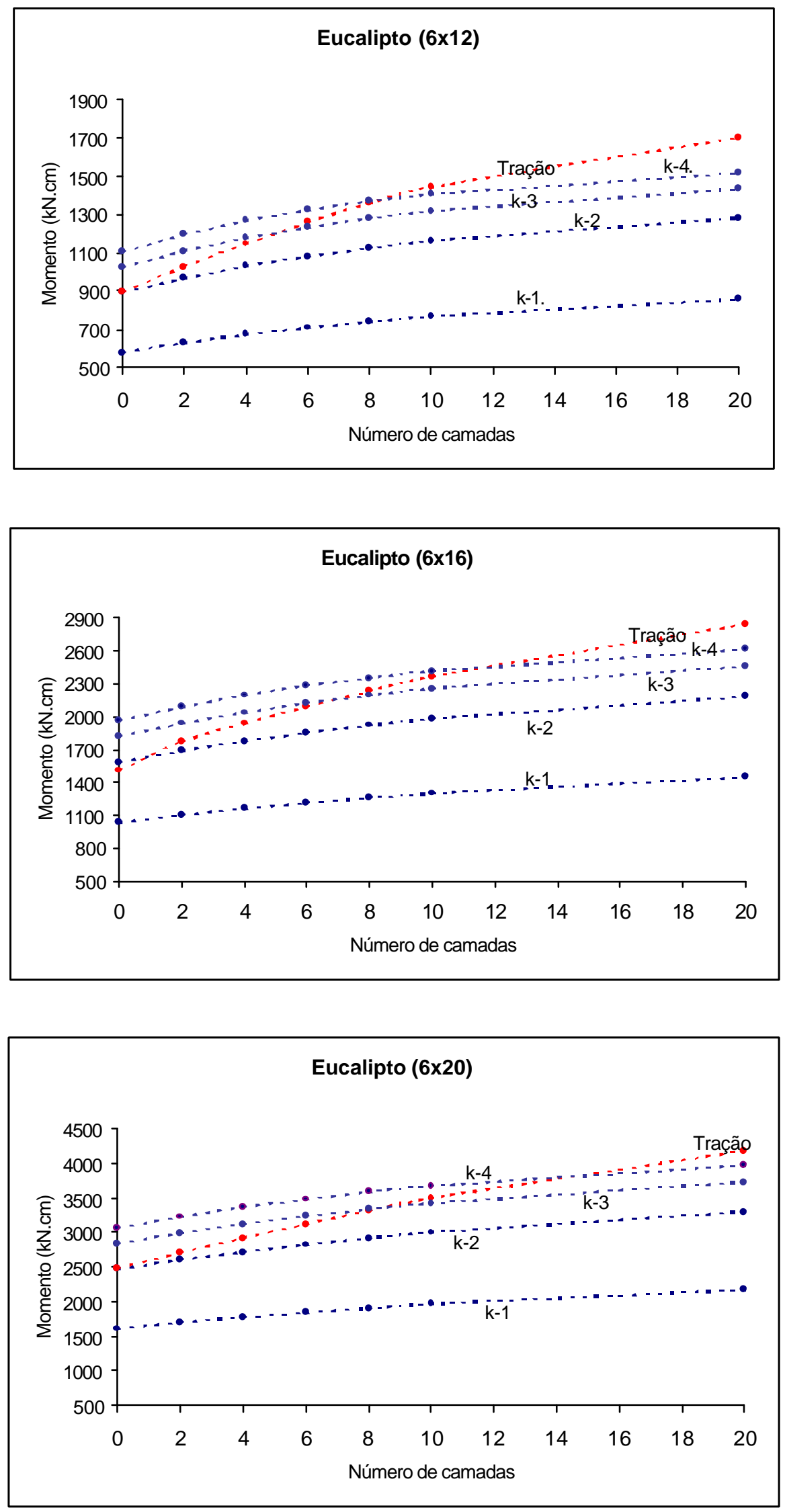

FIGURA 44: Relação entre momento x número de camadas de fibra de carbono 

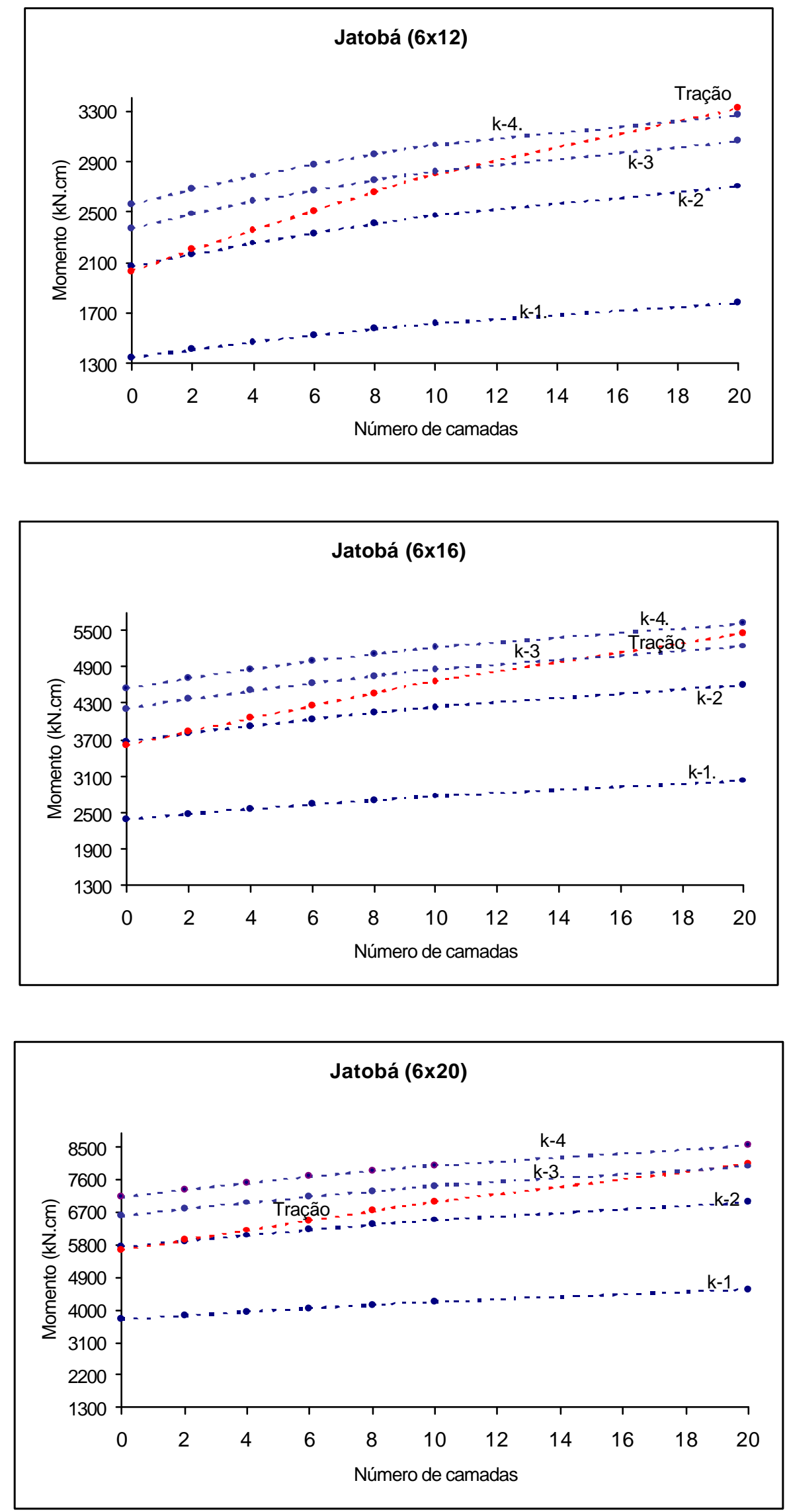

FIGURA 45: Relação entre momento x número de camadas de fibra de carbono 
De acordo com as figuras 43, 44 e 45, nota-se um ganho mais significativo no aumento da resistência e da rigidez das vigas reforçadas com fibra de carbono, em comparação com as vigas reforçadas com fibra de vidro. Isso ocorre, pois a fibra de carbono apresenta valores de módulo de elasticidade e de resistência à tração superiores aos da fibra de vidro.

Para ilustrar, vigas de Pinus de seção $(6 \times 12 \mathrm{~cm})$ reforçadas com dez camadas de fibra de vidro apresentaram um ganho de resistência de aproximadamente 50\%. Já a mesma viga reforçada com 10 camadas de fibra de carbono o ganho na resistência foi de $100 \%$.

\subsubsection{Comentários}

Vale ressaltar que o estado limite último mais crítico será o de tração, na grande maioria dos casos. Isto ocorre, pois uma pequena magnitude de plastificação já conduz a ocorrência do estado limite último por tração.

Quanto maior a diferença entre as resistências de compressão e de tração, maior deverá ser o valor de "k", para que o estado limite último seja por tração.

Apesar da resistência da madeira à tração ser superior a resistência à compressão, a norma NBR 7190/97 - Projeto de estruturas de madeiras, considera coeficientes de ponderações diferentes, conduzindo a valores iguais.

\subsubsection{Avaliação do parâmetro " $k$ ”}

Para o modelo de ruptura por compressão, o cálculo considera a relação entre as deformações, $\varepsilon_{2} / \varepsilon_{1}=\mathrm{k}$. Este valor foi avaliado experimentalmente por meio de ensaios de compressão paralela às fibras da madeira. Foram avaliadas as espécies Pinus caribea 
var. hondurensis, Eucalipto grandis, Jatobá e Peroba rosa, ensaiando 6 corpos-de-prova para cada uma delas. A tabela 32 apresenta os valores do parâmetro " $\mathrm{k}$ " obtidos experimentalmente.

Foram apresentados valores do parâmetro "k" para Peroba Rosa, pois foi a madeira utilizada na avaliação experimental.

TABELA 32: Valores do parâmetro "k"

\begin{tabular}{|c|c|c|c|c|}
\hline & $\begin{array}{c}\text { Pinus caribea } \\
\text { var. hondurensis }\end{array}$ & $\begin{array}{c}\text { Eucalipto } \\
\text { grandis }\end{array}$ & Jatobá & Peroba Rosa \\
\hline \multirow{4}{*}{$\begin{array}{c}\text { Valores K } \\
\left(\boldsymbol{\varepsilon}_{2} \boldsymbol{\varepsilon}_{\mathbf{1}}\right)\end{array}$} & 3,00 & 4,80 & 2,20 & 3,25 \\
\cline { 2 - 5 } & 4,00 & 3,50 & 2,35 & 2,60 \\
\cline { 2 - 5 } & 4,00 & 3,20 & 2,50 & 2,30 \\
\cline { 2 - 5 } & 3,00 & 3,10 & 1,90 & 2,80 \\
\cline { 2 - 5 } & 3,40 & 4,50 & 2,00 & 2,25 \\
\hline Média & 3,20 & 3,70 & 1,85 & 2,25 \\
\hline
\end{tabular}

Os gráficos de tensão por deformação ilustram o comportamento dos corpos-deprova submetidos a ensaios de compressão paralela as fibras da madeira.
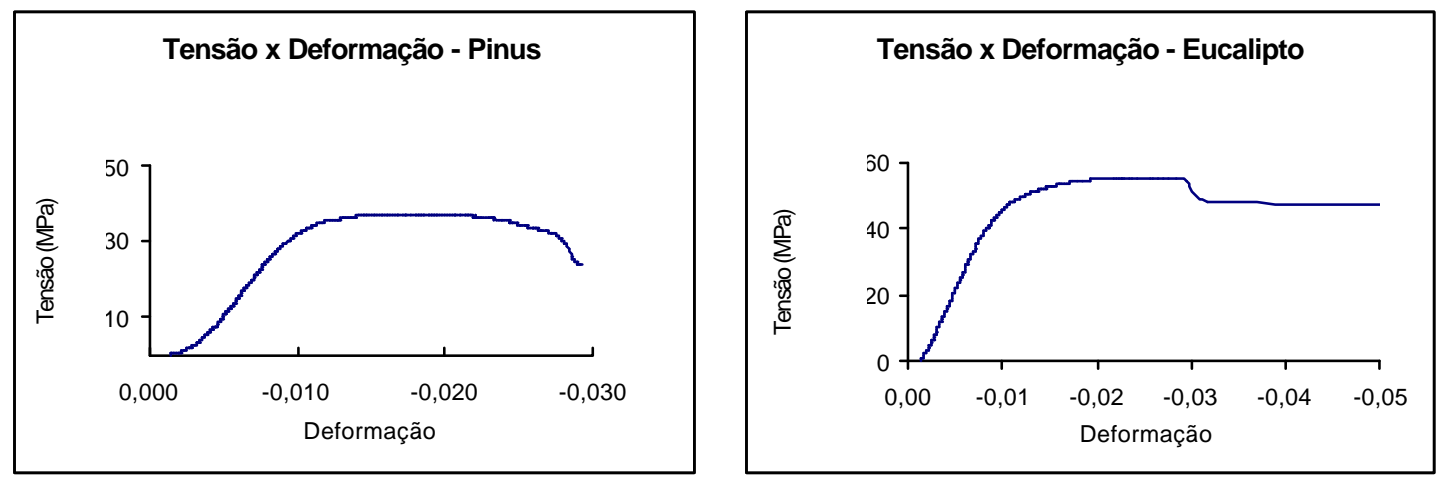

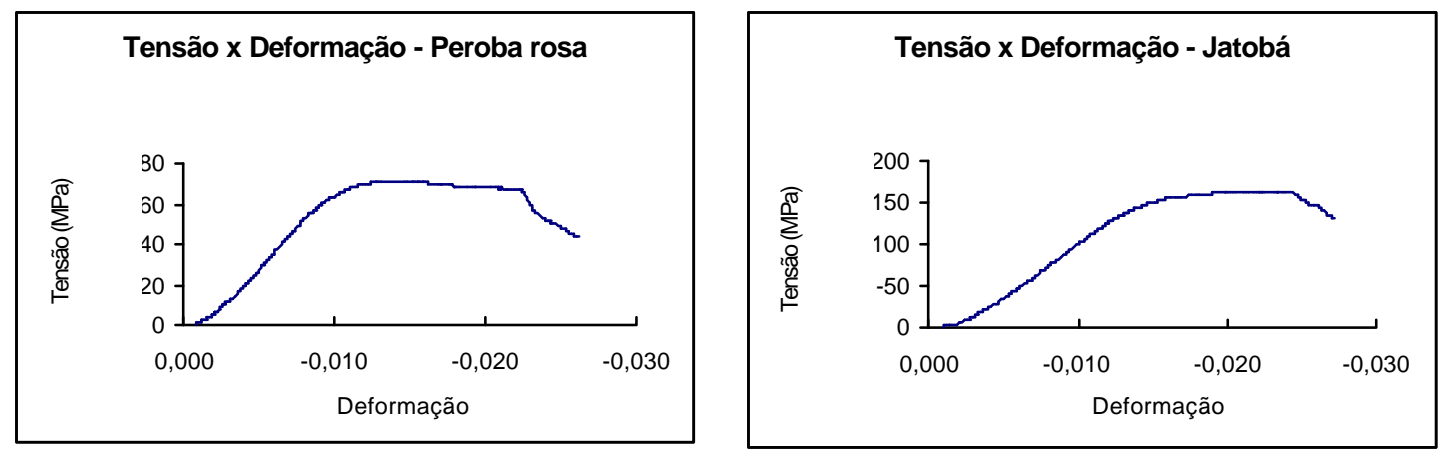

FIGURA 46: Diagrama tensão por deformação

\subsubsection{Análise comparativa dos reforços de fibra de vidro e de fibra de} carbono

Uma análise comparativa entre o reforço com fibra de vidro e com fibra de carbono está apresentada nas figuras 47, 48 e 49. Com esta comparação será possível estimar o ganho de resistência com o reforço de fibra de vidro e de fibra de carbono, possibilitando estimar o número de camadas correspondentes aos dois tipos de materiais.

Nesta comparação, foram utilizados parâmetro k=3 para Pinus e Eucalipto que são madeiras mais deformáveis, e parâmetro k=2 para Jatobá, pois esses são os valores obtidos experimentalmente, por meio de ensaios com corpos-de-prova de compressão paralela às fibras da madeira, conforme apresentado no item 5.3.3. 

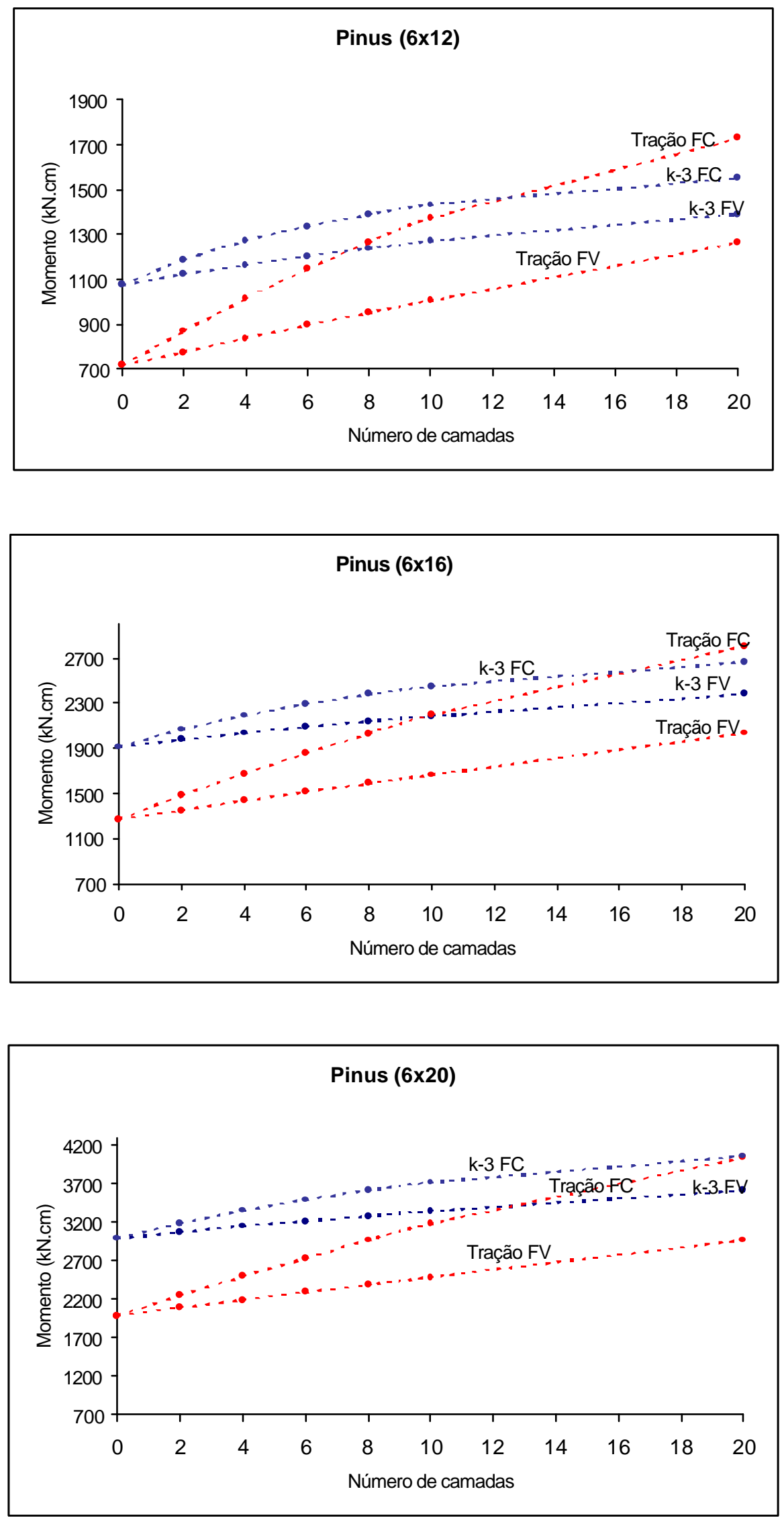

FIGURA 47: Gráficos comparativos entre os reforços com fibra de vidro e fibra de carbono 

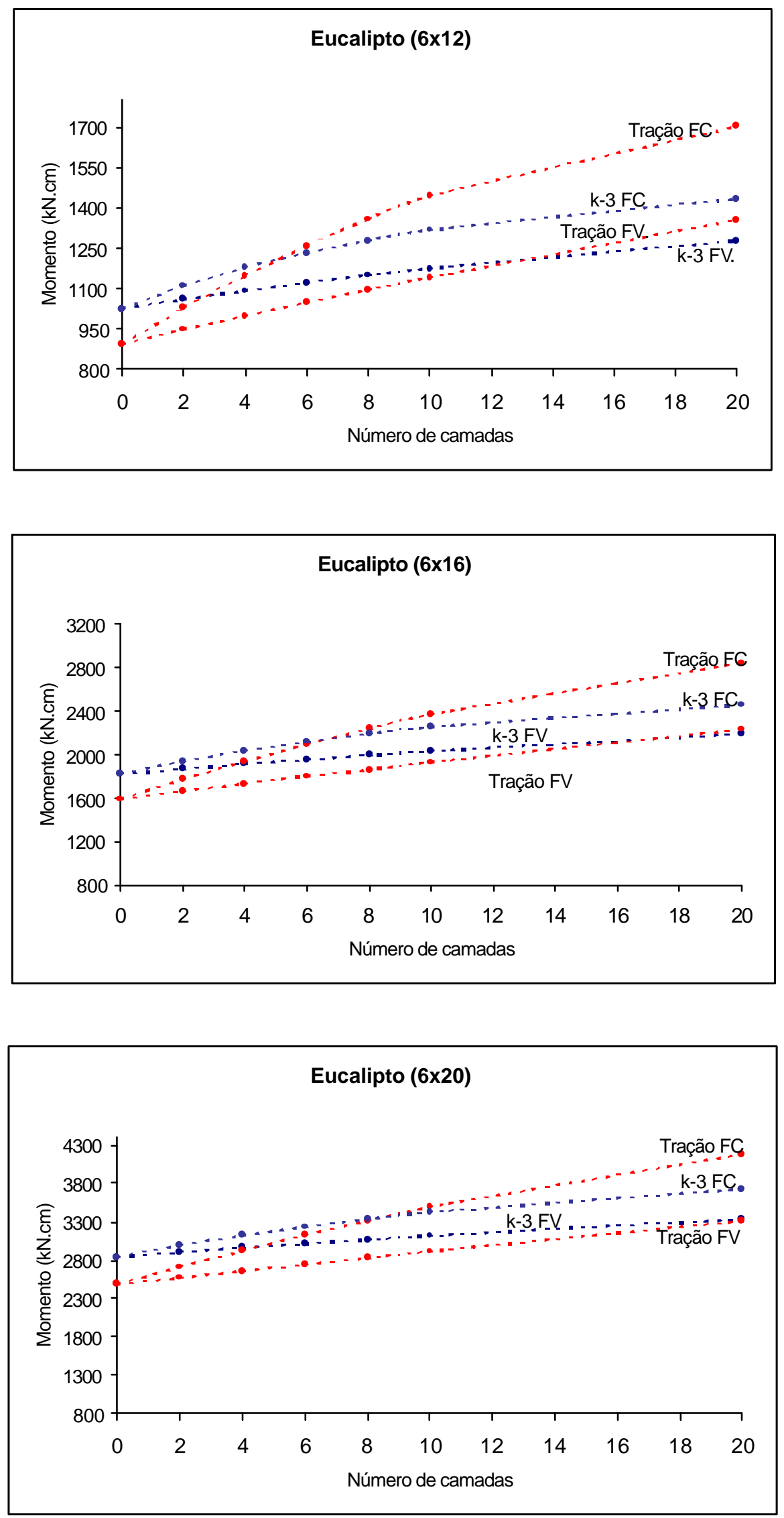

FIGURA 48: Gráficos comparativos entre os reforços com fibra de vidro e fibra de carbono 

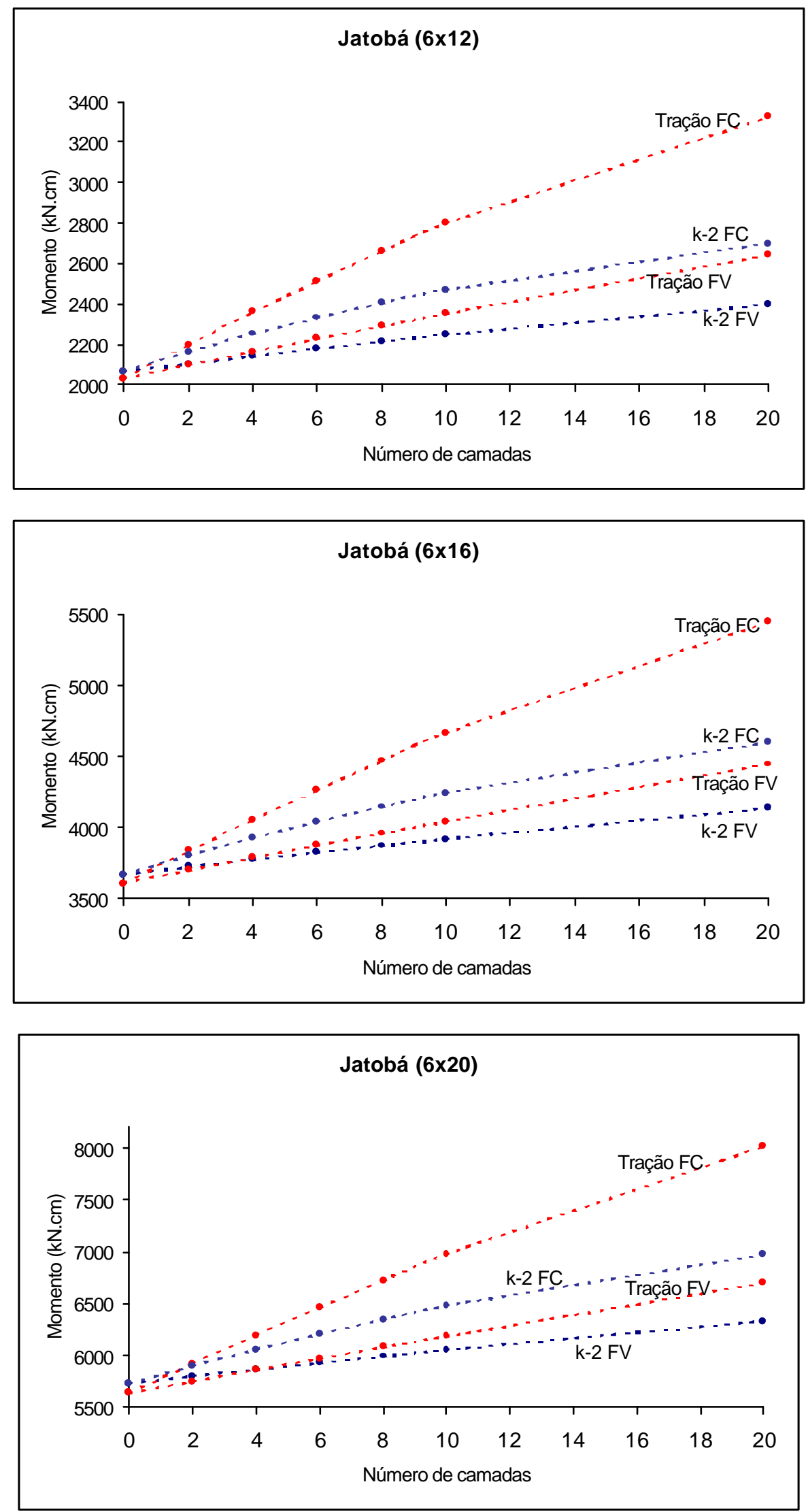

FIGURA 49: Gráficos comparativos entre os reforços com fibra de vidro e fibra de carbono 


\subsubsection{Comentários}

Para as três espécies de madeira analisadas, o ganho de resistência obtido com duas camadas de fibra de carbono é equivalente ao ganho de resistência conseguido com seis camadas de fibra de vidro.

Analisando as figuras 47, 48 e 49, observa-se que o reforço proporcionou uma melhor eficiência, quanto à resistência, às vigas de madeira de menor densidade e com menor resistência, como é o caso do pinus $\left(\rho=0,535 \mathrm{~g} / \mathrm{cm}^{3}\right)$, em comparação às vigas de alta densidade.

Para o jatobá, o modo de ruptura mais crítico foi por compressão, parâmetro k=2. Para este tipo de madeira, recomenda-se que o cálculo do momento último seja feito considerando o modo de ruptura por compressão. 


\section{6 - AVALIAÇÃO EXPERIMENTAL DE VIGAS REFORÇADAS COM FIBRAS}

Este capítulo apresenta os resultados experimentais obtidos nos ensaios para avaliação da resistência e da rigidez à flexão de vigas de madeira reforçadas com fibra de vidro e com fibra de carbono. Foram realizados ensaios preliminares em vigas de madeira das espécies Pinus caribea var. hondurensis e Eucalyptus grandis com vão igual a um metro e seção transversal $3 \times 6 \mathrm{~cm}$ e $3 \times 12 \mathrm{~cm}$, variando o número de camadas de fibras de vidro. Com estes ensaios foi possível verificar o aumento da resistência e da rigidez das vigas reforçadas com diferentes camadas de fibras. Os ensaios principais foram realizados em vigas com dimensões estruturais de Pinus caribea var. hondurensis e de Peroba Rosa com seções 6x12 cm e 6x16 cm, reforçadas com seis camadas de fibras de vidro ou duas camadas de fibra de carbono as quais foram fixadas com resina epóxi.

Os resultados experimentais são comparados com os teóricos obtidos pelo modelo de cálculo apresentado no capítulo 05, possibilitando uma avaliação do respectivo modelo de cálculo.

\subsection{Ensaios preliminares}

Estes ensaios foram realizados com o objetivo de verificar o comportamento de vigas de madeira reforçadas com fibras de vidro, a partir de ensaios em elementos de menores dimensões, possibilitando a retirada de uma série de corpos-de-prova de uma mesma peça de madeira, o que diminui a variabilidade esperada para as propriedades dos mesmos. 


\subsubsection{Materiais utilizados para a confecção das vigas}

Para a confecção das vigas dos ensaios preliminares foram utilizadas madeiras das espécies Pinus caribea var. hondurensis e Eucaliptus grandis, com comprimento de um metro. As seções transversais das vigas e a quantidade de vigas ensaiadas de cada espécie são apresentadas na tabela 33.

TABELA 33: Informações referentes às vigas de madeira ensaiadas

\begin{tabular}{|c|c|c|}
\hline Espécie de madeira & $\begin{array}{c}\text { Seção } \\
\text { transversal }\end{array}$ & $\begin{array}{c}\text { Número de vigas } \\
\text { confeccionadas }\end{array}$ \\
\hline Pinus caribea var. hondurensis & $(3 \times 6)$ & 8 \\
\hline Eucalipto grandis & $(3 \times 6)$ & 8 \\
\hline Pinus caribea var. hondurensis & $(3 \times 12)$ & 8 \\
\hline Eucalipto grandis & $(3 \times 12)$ & 8 \\
\hline
\end{tabular}

Três pares de vigas foram reforçados com fibra de vidro, variando-se o número de camadas do tecido. Tanto as vigas de Pinus como as de Eucalipto foram reforçadas com duas, quatro e seis camadas de fibras de vidro.

\subsubsection{Equipamentos utilizados no ensaio}

Os ensaios foram realizados na máquina universal de ensaios, marca AMSLER, com capacidade para $250 \mathrm{kN}$.

\subsubsection{Método de ensaio empregado}

As vigas de madeira foram caracterizadas preliminarmente sem reforço e posteriormente com reforço, por meio de ensaios de flexão. Para a realização destes ensaios foi utilizado um esquema estático de viga simplesmente apoiada, com aplicação de cargas iguais localizadas nos terços do vão (figura 50), conforme apresenta a norma ASTM D198/84 - Methods of Static Tests of Timbers in Structural Sizes. 
A velocidade de aplicação da força foi feita de modo que se tenha uma variação igual a 10 MPa por minuto, na tensão normal máxima.

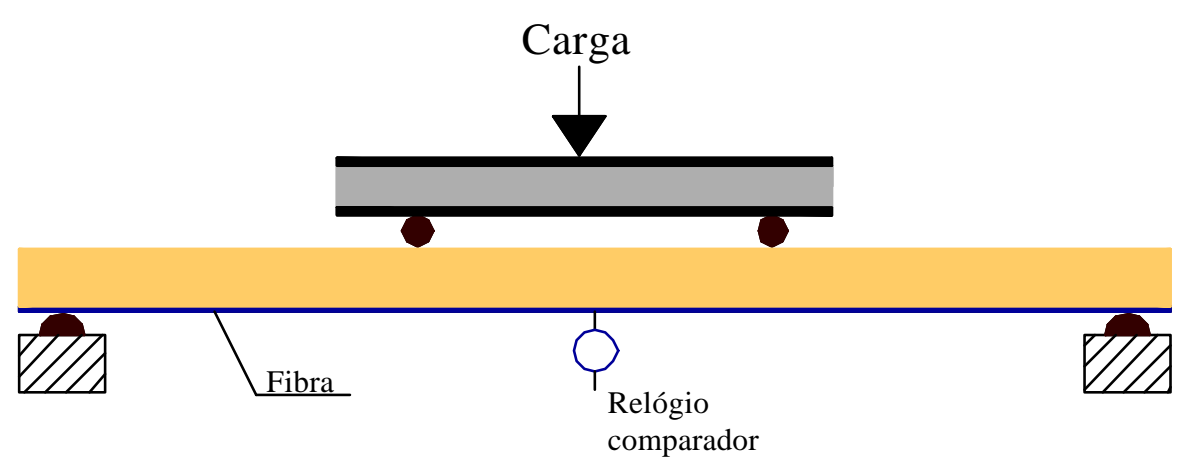

FIGURA 50: Modelo do ensaio de flexão em vigas simplesmente apoiadas

Para a determinação da rigidez à flexão, a norma NBR - 7190/97 - Projeto de estruturas de madeira estipula que devem ser efetuados ciclos de carregamento.

Para tanto, deve ser estimada a força de ruptura $\left(\mathrm{F}_{\mathrm{M} \text {,est }}\right)$ a partir de um ensaio de um corpo-de-prova gêmeo. A providência dos ciclos é necessária para os casos nos quais se deseja avaliar a rigidez à flexão. Esta rigidez é determinada no último ciclo de carregamento, utilizando o incremento de deslocamento vertical ocorrido quando há incremento da força aplicada, de um valor igual a $0,1 \mathrm{~F}_{\mathrm{M} \text {,est }}$ até $0,5 \mathrm{~F}_{\mathrm{M} \text {,est }}$, conforme mostrado na figura 51.

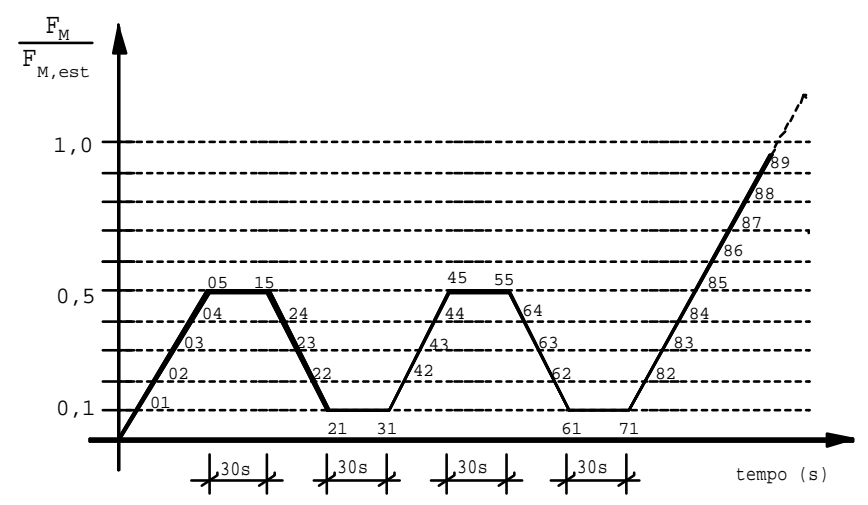

FIGURA 51: Ciclo de carregamento 
Para que os resultados obtidos no ensaio do primeiro corpo-de-prova sem reforço pudessem ser utilizados na comparação da rigidez à flexão, o valor de $\mathrm{F}_{\mathrm{M} \text {,est }}$ foi estipulado como sendo igual ao dobro da força correspondente a uma flecha de L/200, sendo L o vão da viga. Com este procedimento, garantiu-se que a avaliação da rigidez à flexão foi feita no regime elástico linear da viga.

Com os valores de força aplicada e correspondente deslocamento vertical no meio do vão foi possível determinar a rigidez à flexão(EI) de vigas bi apoiadas com cargas concentradas nos terços do vão, de acordo com a seguinte equação:

$$
E I=\frac{23 \cdot L^{3} \cdot \Delta P}{1296 \cdot \Delta v}
$$

Onde:

$\mathrm{L}$ - distância entre apoios

$\Delta \mathrm{P}$ - variação da força (10\% e 50\%)

$\Delta v$ - variação da flecha $(10 \%$ e $50 \%)$

Após a colagem do reforço de fibra, repetiu-se o ensaio de flexão, respeitando os mesmos incrementos de força aplicadas nas vigas antes do reforço. Desta forma determinou-se o valor da rigidez a flexão de vigas de madeira reforçadas com fibra.

Os ensaios de caracterização mecânica das vigas de madeira, utilizadas nos ensaios de flexão, foram realizados de acordo com as especificações da norma NBR 7190/97 - Projetos de estruturas de madeira, da Associação Brasileira de Normas Técnicas. Foram determinados os valores de resistência à compressão e à tração paralela às fibras e módulo de elasticidade à compressão e à tração paralela às fibras da madeira. Os corpos-de-prova foram retirados depois da realização dos ensaios de flexão, de 
regiões da viga, não danificadas.

\subsubsection{Método de aplicação de FRP}

O bom desempenho do reforço de fibras reforçadas com polímeros (FRP), está diretamente ligado ao processo de laminação utilizado. Para reforço em estruturas de madeira, concreto ou aço, utilizando fibras, deve-se realizar o processo de laminação manual, onde a resina é aplicada diretamente sobre a superfície a ser reforçada e também sobre o respectivo tecido. Como produto final obtém-se um material laminado (fibra + resina).

O primeiro passo para realizar a aplicação do reforço com fibras é verificar o estado em que se encontra a estrutura. No caso da madeira, a superfície deve estar limpa, seca, livre de partículas soltas, contaminações de graxas e óleos. Se houver cavidades ou buracos na superfície, estes deverão ser preenchidos com algum tipo de argamassa epóxi. Inicialmente, aplica-se uma camada de resina utilizando um rolo de impregnação (lã) ou pincel, sobre a superfície de madeira. Em seguida coloca-se uma camada de fibra sobre a superfície a ser reparada. Com um rolo de desaeração de alumínio deve-se pressionar a fibra contra o adesivo, eliminando desta forma bolhas de ar que possam existir e prejudicar o reforço. Sobre a fibra aplica-se uma nova camada de resina. Em seguida repte-se o procedimento acima descrito. A cura demanda cerca de 24 a 48 horas. 


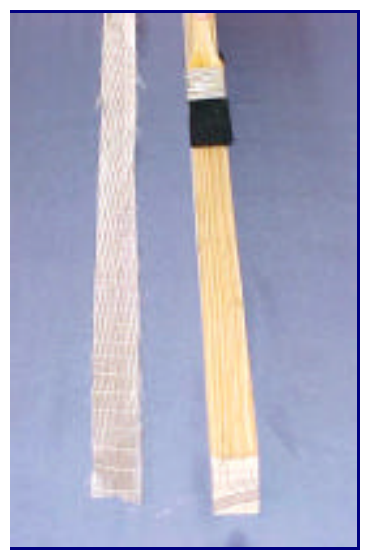

Aplicação de resina sobre a viga de madeira

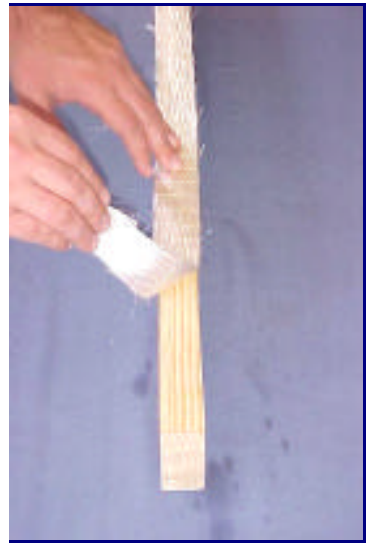

Colagem do tecido de fibra de vidro

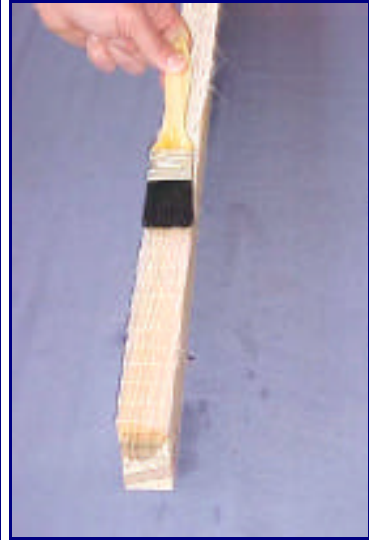

Aplicação da $2^{\mathrm{a}}$ camada Retirada de bolhas de ar de resina

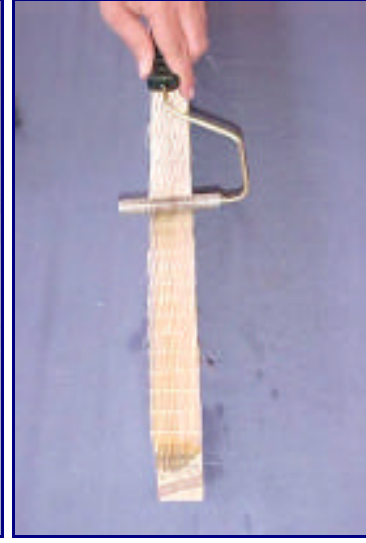
- rolo de desaeração

FIGURA 52: Procedimento de aplicação de fibras de vidro em vigas de madeira

Vale ressaltar que as resinas epóxi perdem aderência quando expostas a altas temperaturas. Ambientes em que a temperatura ultrapasse $60^{\circ} \mathrm{C}$ devem ser isolados para a aplicação da fibra.

A umidade do ar é outro fator que requer cuidados. Em ambientes com umidade acima de $80 \%$, a cura da resina pode ser mais lenta. Em locais molhados, deve-se isolar a área durante a aplicação.

\subsubsection{Realização do ensaio}

Para determinar o aumento da resistência proporcionado pelo reforço com fibra, foram ensaiadas vigas de madeira com e sem reforço. As vigas de madeira foram extraídas da mesma peça, para se ter corpos-de-prova com menor variabilidade de propriedades. Para obter o incremento na rigidez das peças, foram realizados ensaios de flexão antes e depois da aplicação da fibra, para todas as peças. A figura 53 ilustra o ensaio realizado em uma viga com reforço aplicado em sua face inferior. 

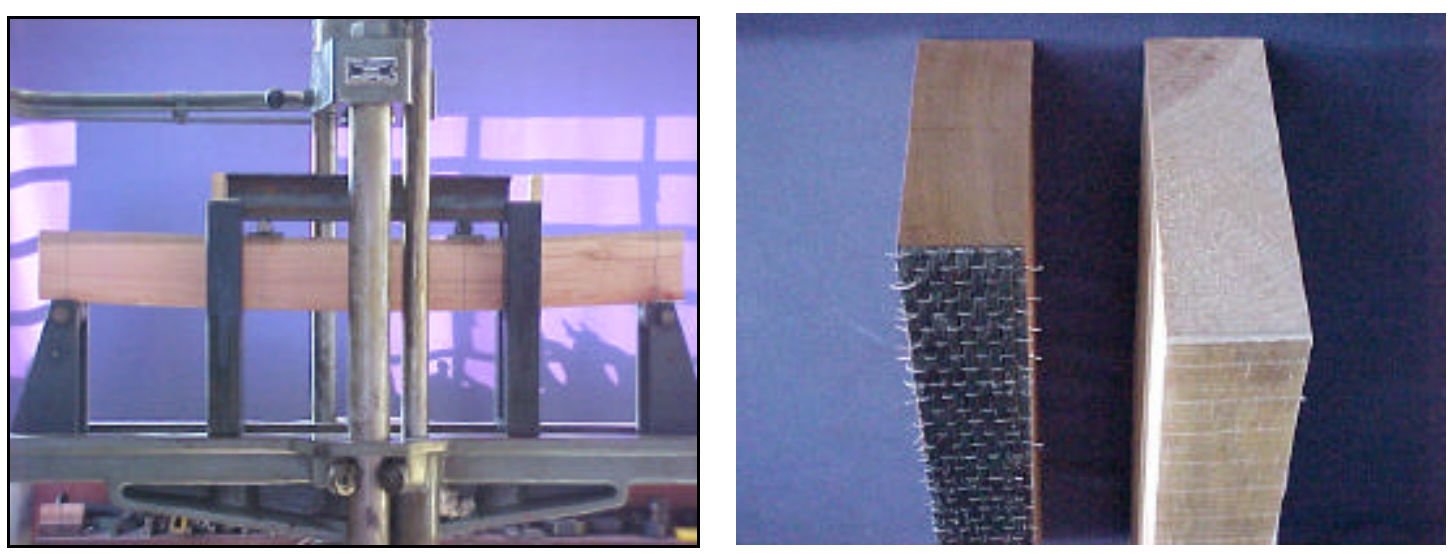

FIGURA 53: Ensaio de flexão e vigas reforçadas com fibras

\subsubsection{Resultados obtidos}

A tabela 34 apresenta valores médios de resistência e elasticidade a compressão e a tração paralela às fibras e os respectivos coeficientes de variação de três corpos-deprova de Pinus e de Eucalipto.

\section{Vigas de Pinus}

Tabela 34: Médias e coeficiente de variação

\begin{tabular}{|c|c|c|c|c|}
\hline \multicolumn{2}{|c|}{ Resistências(MPa) } & \multicolumn{2}{c|}{ Módulos de elasticidade (MPa) } \\
\hline \multirow{2}{*}{ Pinus } & $\mathbf{f}_{\mathbf{c 0}}$ & $\mathbf{f}_{\mathbf{t} \mathbf{0}}$ & $\mathbf{E}_{\mathbf{c 0}}$ & $\mathbf{E}_{\mathbf{t} \mathbf{0}}$ \\
& 40 & 67 & 11.593 & 10.940 \\
& $(4,5)$ & $(6,2)$ & $(3,8)$ & $(8,1)$ \\
\hline Eucalipto & 36 & 70 & 14.292 & 19.064 \\
& $(6,3)$ & $(8,5)$ & $(5,2)$ & $(6,7)$ \\
\hline
\end{tabular}

Onde:

$\mathrm{f}_{\mathrm{co}}$ - resistência à compressão paralela

$\mathrm{f}_{\mathrm{to}}$ - resistência à tração paralela

$\mathrm{E}_{\mathrm{co}}-$ modulo de elasticidade a compressão paralela

$\mathrm{E}_{\mathrm{to}}-$ módulo de elasticidade a tração paralela

As tabelas 35, 36, 37 e 38 apresentam os valores de momento máximo 
experimental resistido pelas vigas, valores de rigidez à flexão (EI) e o modo de ruptura das vigas de Pinus e de Eucalipto.

Tabela 35: Viga de Pinus seção $3 \times 6 \mathrm{~cm}$

\begin{tabular}{|c|c|c|c|c|c|c|c|c|c|}
\hline \multirow{2}{*}{$\begin{array}{c}\mathbf{N}^{0} \text { de } \\
\text { camadas } \\
\text { de fibra }\end{array}$} & \multirow[b]{2}{*}{ Viga } & \multirow{2}{*}{\multicolumn{2}{|c|}{ Seção (mm) }} & \multirow{2}{*}{$\begin{array}{l}\text { Momento } \\
\text { de } \\
\text { ruptura } \\
\text { (kN.cm) }\end{array}$} & \multirow[t]{2}{*}{$\Delta \mathbf{P}$} & \multirow[t]{2}{*}{$\Delta \mathbf{V}$} & \multicolumn{2}{|c|}{ EI (kN.cm²) } & \multirow[b]{2}{*}{$\begin{array}{c}\text { Modo } \\
\text { de } \\
\text { ruptura }\end{array}$} \\
\hline & & & & & & & $\begin{array}{l}\text { sem } \\
\text { reforço }\end{array}$ & $\begin{array}{l}\text { com } \\
\text { reforço }\end{array}$ & \\
\hline \multirow{2}{*}{$\begin{array}{c}\text { Sem } \\
\text { reforço }\end{array}$} & 1 & 29,0 & 61,4 & 138 & 0,85 & 0,36 & 42.116 & & Tração \\
\hline & 2 & 30,2 & 61,2 & 133 & 0,85 & 0,41 & 37.401 & & Tração \\
\hline \multirow{2}{*}{$\begin{array}{c}2 \\
\text { camadas }\end{array}$} & 3 & 30,3 & 61,6 & 157 & 0,85 & 0,31 & 48.501 & 49.296 & Compressão \\
\hline & 4 & 30,9 & 61,3 & 158 & 0,85 & 0,31 & 47.883 & 50.118 & Compressão \\
\hline \multirow{2}{*}{$\begin{array}{c}4 \\
\text { camadas }\end{array}$} & 5 & 30,8 & 61,2 & 174 & 0,85 & 0,27 & 55.277 & 63.980 & Compressão \\
\hline & 6 & 31,4 & 57,8 & 177 & 0,85 & 0,38 & 39.053 & 47.731 & Compressão \\
\hline \multirow{2}{*}{$\begin{array}{c}6 \\
\text { camadas }\end{array}$} & 7 & 30,4 & 58,9 & 177 & 0,85 & 0,30 & 49.296 & 60.141 & Tração \\
\hline & 8 & 30,6 & 60,2 & 183 & 0,85 & 0,45 & 33.045 & 46.262 & Compressão \\
\hline
\end{tabular}

Tabela 36: Viga de Pinus seção $3 \times 12 \mathrm{~cm}$

\begin{tabular}{|c|c|c|c|c|c|c|c|c|c|}
\hline \multirow{2}{*}{$\begin{array}{c}\mathbf{N}^{\circ} \text { de } \\
\text { camadas } \\
\text { de fibra }\end{array}$} & \multirow[b]{2}{*}{ Viga } & & & \multirow{2}{*}{$\begin{array}{l}\text { Momento } \\
\quad \text { de } \\
\text { ruptura } \\
\text { (kN.cm) }\end{array}$} & \multirow[t]{2}{*}{$\Delta \mathbf{P}$} & \multirow[t]{2}{*}{$\Delta \mathbf{V}$} & \multicolumn{2}{|c|}{ EI (kN.cm²) } & \multirow{2}{*}{$\begin{array}{c}\text { Modo } \\
\text { de } \\
\text { ruptura }\end{array}$} \\
\hline & & \multicolumn{2}{|c|}{ Seção (mm) } & & & & sem & com & \\
\hline \multirow{2}{*}{$\begin{array}{c}\text { Sem } \\
\text { reforço }\end{array}$} & 1 & 9,4 & 120,3 & 450 & 3,58 & 0,26 & 244.363 & & Tração \\
\hline & 2 & 30,2 & 120,2 & 466 & 3,58 & 0,30 & 211.781 & & Tração \\
\hline \multirow{2}{*}{$\begin{array}{c}2 \\
\text { camadas }\end{array}$} & 3 & 30,3 & 119,6 & 512 & 3,58 & 0,25 & 249.154 & 250.135 & Tração \\
\hline & 4 & 30,4 & 120,2 & 500 & 3,58 & 0,34 & 235.312 & 254.137 & Tração \\
\hline \multirow{2}{*}{$\begin{array}{c}4 \\
\text { camadas }\end{array}$} & 5 & 30,4 & 120,0 & 500 & 3,58 & 0,25 & 270.359 & 295.508 & Compressão \\
\hline & 6 & 31,3 & 119,6 & 517 & 3,58 & 0,27 & 184.157 & 219.084 & Compressão \\
\hline \multirow{2}{*}{$\begin{array}{c}6 \\
\text { camadas }\end{array}$} & 7 & 30,1 & 119,9 & 520 & 3,58 & 0,23 & 254.137 & 302.544 & Compressão \\
\hline & 8 & 30,2 & 120,6 & 533 & 3,58 & 0,23 & 270.359 & 325.817 & Compressão \\
\hline
\end{tabular}


Tabela 37: Viga de Eucalipto seção $3 \times 6 \mathrm{~cm}$

\begin{tabular}{|c|c|c|c|c|c|c|c|c|c|}
\hline \multirow{2}{*}{$\begin{array}{c}\mathbf{N}^{\circ} \text { de } \\
\text { camadas } \\
\text { de fibra }\end{array}$} & \multirow{2}{*}{ Viga } & \multirow{2}{*}{\multicolumn{2}{|c|}{ Seção (mm) }} & \multirow{2}{*}{$\begin{array}{l}\text { Momento } \\
\text { de } \\
\text { ruptura } \\
\text { (kN.cm) }\end{array}$} & \multirow[t]{2}{*}{$\Delta \mathbf{P}$} & \multirow[t]{2}{*}{$\Delta \mathbf{V}$} & \multicolumn{2}{|c|}{$\mathrm{EI}\left(\mathrm{kN} . \mathrm{cm}^{2}\right)$} & \multirow{2}{*}{$\begin{array}{l}\text { Modo de } \\
\text { ruptura }\end{array}$} \\
\hline & & & & & & & $\begin{array}{l}\text { sem } \\
\text { reforço }\end{array}$ & $\begin{array}{c}\text { com } \\
\text { reforço }\end{array}$ & \\
\hline \multirow{2}{*}{$\begin{array}{c}\text { Sem } \\
\text { reforço }\end{array}$} & 1 & 29,4 & 60,4 & 118 & 1,40 & 0,40 & 61.348 & & Tração \\
\hline & 2 & 30,2 & 60,2 & 108 & 1,40 & 0,39 & 64.201 & & Tração \\
\hline \multirow{2}{*}{$\begin{array}{c}2 \\
\text { camadas }\end{array}$} & 3 & 30,3 & 59,6 & 153 & 1,40 & 0,38 & 65.384 & 69.016 & Compressão \\
\hline & 4 & 30,4 & 61,2 & 163 & 1,40 & 0,36 & 69.016 & 69.988 & Compressão \\
\hline \multirow{2}{*}{$\begin{array}{c}4 \\
\text { camadas }\end{array}$} & 5 & 30,4 & 61,0 & 190 & 1,40 & 0,29 & 85.675 & 93.758 & Compressão \\
\hline & 6 & 31,3 & 57,6 & 203 & 1,40 & 0,37 & 67.700 & 74.837 & Compressão \\
\hline \multirow{2}{*}{$\begin{array}{c}6 \\
\text { camadas }\end{array}$} & 7 & 30,1 & 59,9 & 225 & 1,40 & 0,36 & 76.449 & 90.348 & Tração \\
\hline & 8 & 30,2 & 60,6 & 193 & 1,40 & 0,32 & 69.016 & 85.675 & Tração \\
\hline
\end{tabular}

Tabela 38: Viga de Eucalipto seção $3 \times 12 \mathrm{~cm}$

\begin{tabular}{|c|c|c|c|c|c|c|c|c|c|}
\hline \multirow{2}{*}{$\begin{array}{c}\mathrm{N}^{0} \text { de } \\
\text { camadas } \\
\text { de fibra }\end{array}$} & \multirow[b]{2}{*}{ Viga } & \multirow{2}{*}{\multicolumn{2}{|c|}{ Seção (mm) }} & \multirow{2}{*}{$\begin{array}{l}\text { Momento } \\
\text { de } \\
\text { ruptura } \\
\text { (kN.cm) }\end{array}$} & \multirow[t]{2}{*}{$\Delta \mathbf{P}$} & \multirow[t]{2}{*}{$\Delta \mathbf{V}$} & \multicolumn{2}{|c|}{ EI (kN.cm²) } & \multirow[b]{2}{*}{$\begin{array}{l}\text { Modo de } \\
\text { ruptura }\end{array}$} \\
\hline & & & & & & & $\begin{array}{l}\text { sem } \\
\text { reforço }\end{array}$ & $\begin{array}{c}\text { com } \\
\text { reforço }\end{array}$ & \\
\hline \multirow{2}{*}{$\begin{array}{c}\text { Sem } \\
\text { reforço }\end{array}$} & 1 & 29,4 & 120,3 & 423 & 7,16 & 0,37 & 338.849 & & Tração \\
\hline & 2 & 30,2 & 119,2 & 458 & 7,16 & 0,35 & 357.939 & & Tração \\
\hline \multirow{2}{*}{$\begin{array}{c}2 \\
\text { camadas }\end{array}$} & 3 & 30,3 & 120,3 & 527 & 7,16 & 0,31 & 403.392 & 409.898 & Cisalhamento \\
\hline & 4 & 30,4 & 121,2 & 483 & 7,16 & 0,36 & 423.562 & 435.166 & Cisalhamento \\
\hline \multirow{2}{*}{$\begin{array}{c}4 \\
\text { camadas }\end{array}$} & 5 & 30,4 & 120,2 & 680 & 7,16 & 0,30 & 348.133 & 379.309 & Tração \\
\hline & 6 & 31,3 & 119,8 & 563 & 7,16 & 0,28 & 453.816 & 494.430 & Cisalhamento \\
\hline \multirow{2}{*}{$\begin{array}{c}6 \\
\text { camadas }\end{array}$} & 7 & 30,1 & 120,9 & 517 & 7,16 & 0,34 & 368.315 & 423.562 & Tração \\
\hline & 8 & 30,2 & 119,6 & 533 & 7,16 & 0,37 & 343.428 & 423.562 & Tração \\
\hline
\end{tabular}

A diferença nos resultados apresentados nas tabelas $35,36,37$ e 38 se deve a variabilidade da madeira, que apresentava defeitos.

O emprego do reforço de fibras propicia um aumento dos deslocamentos 
verticais na fase da ruptura. A figura 54 ilustra uma viga de Pinus com flecha bastante acentuada.

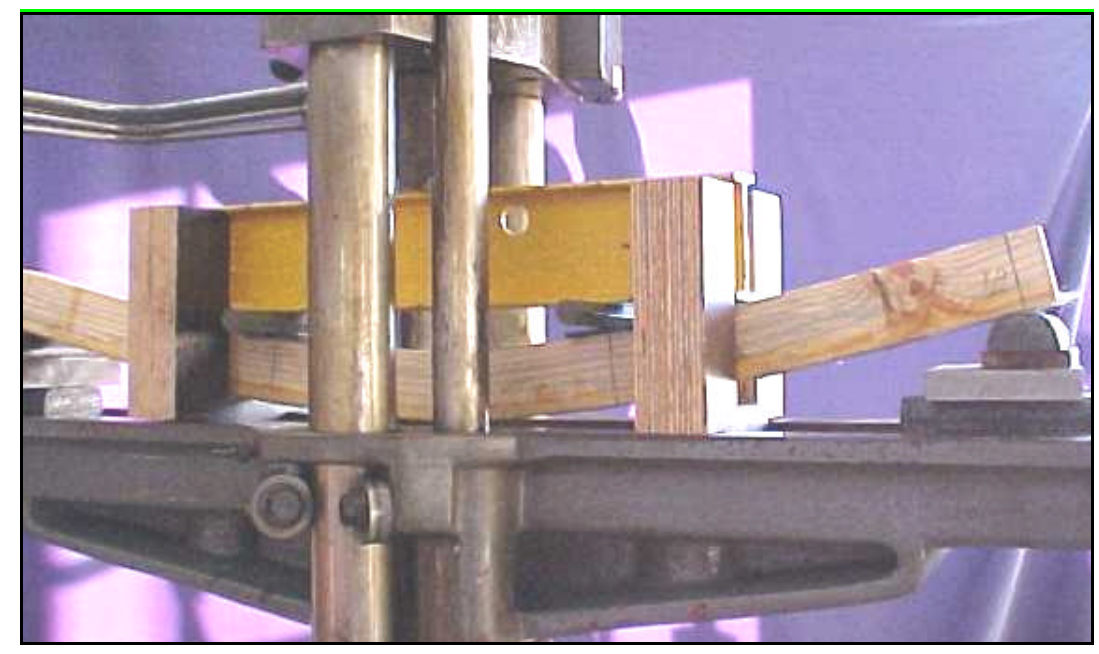

FIGURA 54: Flecha viga de Pinus

\subsubsection{Análise dos resultados}

Este item apresenta uma análise comparativa entres valores experimentais e teóricos de resistência e rigidez. Os valores teóricos foram determinados segundo o modelo de cálculo proposto no capítulo 05. Esta análise permite verificar a eficiência do modelo de cálculo proposto.

\subsubsection{Análise do momento máximo resistido - experimental e teórico}

As figuras 55 e 56 apresentam valores de momento de ruptura experimental e teórico em relação ao número de camadas de fibras. Os resultados teóricos apresentados foram determinados pelo modo de ruptura por tração, por ser o modelo de cálculo que apresentou valores mais críticos. O valor do módulo de elasticidade do tecido de fibra de vidro utilizado no cálculo do momento de ruptura e da rigidez a flexão (EI) é 
apresentado na tabela 30 .
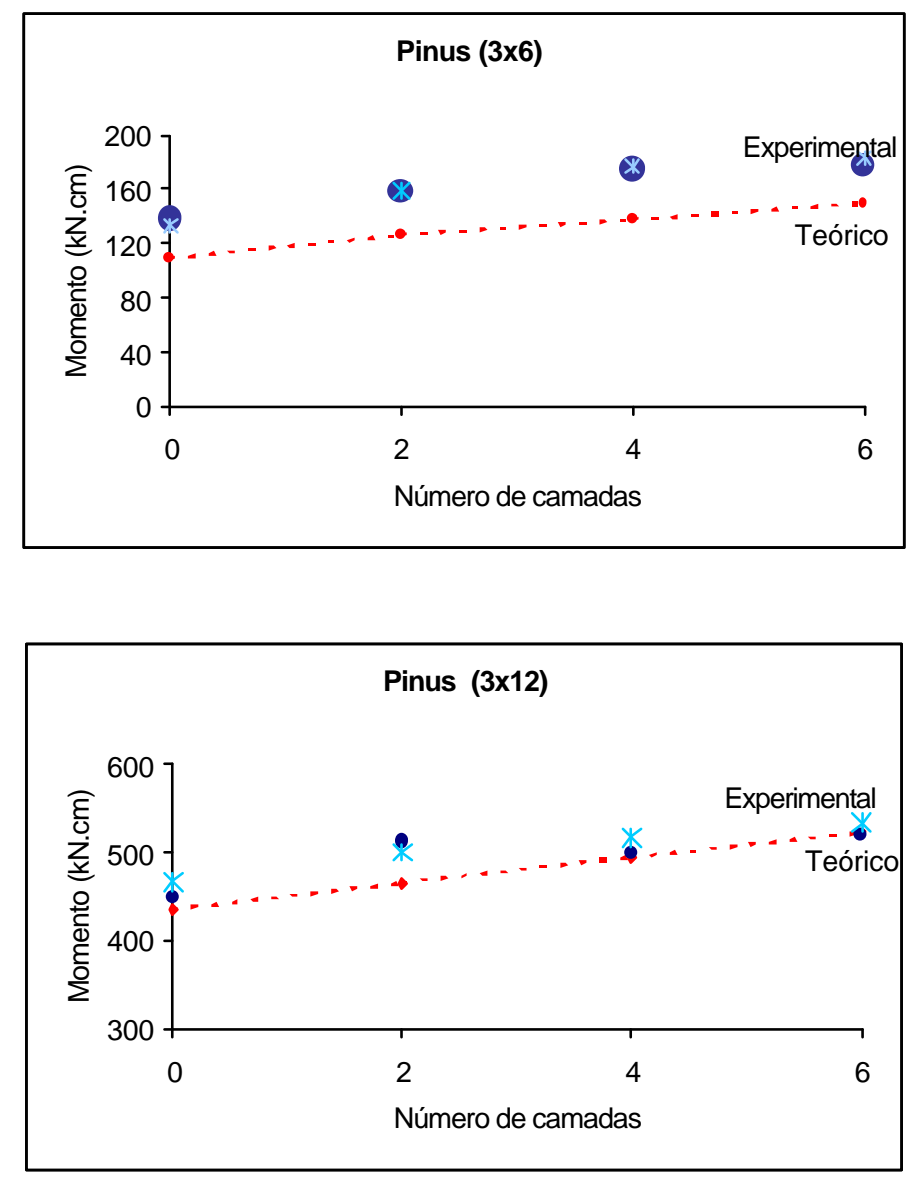

FIGURA 55: Comparação entre momento fletor de ruptura (experimental e teórico)

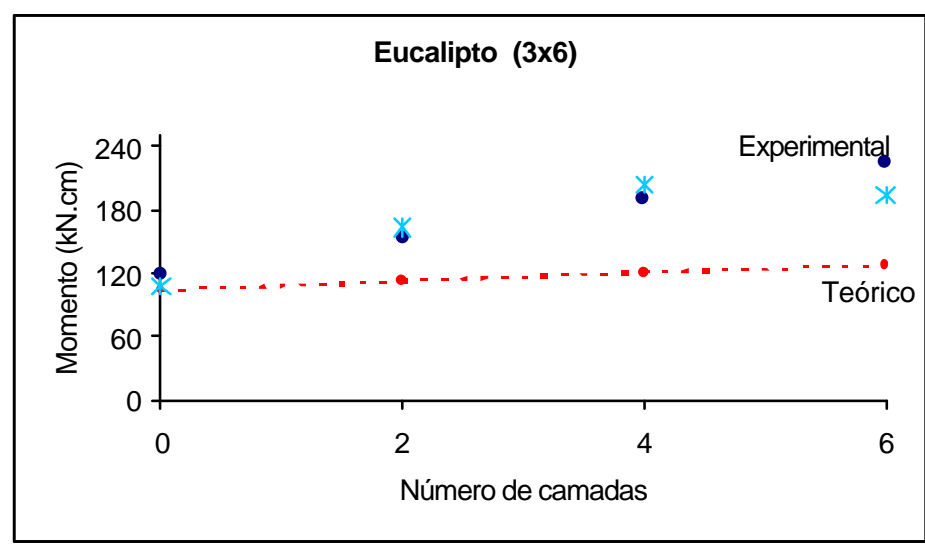




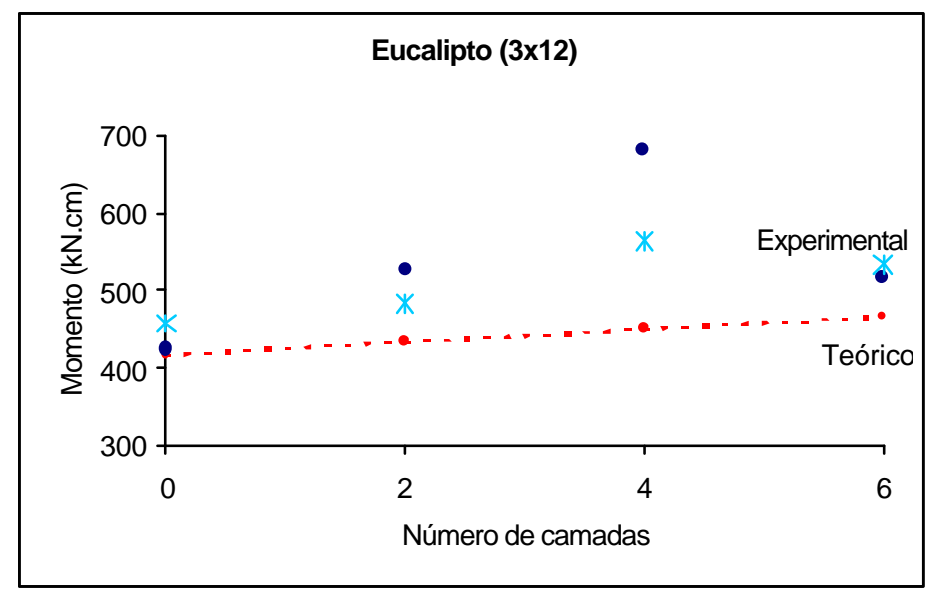

FIGURA 56: Comparação entre momento fletor de ruptura (experimental e teórico)

Observando os valores apresentados nas figuras 55 e 56, para vigas de Pinus com seção $(3 \times 6 \mathrm{~cm})$ reforçadas com seis camadas de fibra de vidro, o aumento no momento fletor de ruptura foi de aproximadamente $35 \%$, em relação a viga sem reforço. Para as vigas de eucalipto de mesma seção, o aumento do momento fletor foi ainda mais significativo, sendo da ordem de 90\%. O modelo teórico conseguiu avaliar o comportamento de maneira satisfatória. Os valores determinados experimentalmente são aproximadamente $10 \%$ superiores aos teóricos estando, portanto a favor da segurança estrutural.

Para as vigas de seção $(3 \times 12 \mathrm{~cm})$, o aumento do momento fletor de ruptura, tanto para vigas de Pinus como para vigas de eucalipto, foi no máximo de 30\%, para seis camadas de reforço.

\subsubsection{Análise da rigidez à flexão}

Este item apresenta uma comparação entre a rigidez à flexão (EI) experimental e teórica. O momento de inércia teórico foi determinado de acordo com o modelo de 
seção transformada. Os valores experimentais são próximos dos valores teóricos, conforme ilustra as figuras 57 e 58 para o Pinus e o Eucalipto, respectivamente. Na maioria das vigas o valor experimental ficou acima do valor teórico, garantindo que o valor da rigidez à flexão calculado, esteja a favor da segurança.

Também pode ser visualizado nas mesmas figuras, o aumento da rigidez à flexão das vigas sem reforço e reforçadas com duas, quatro e seis camadas de fibra.
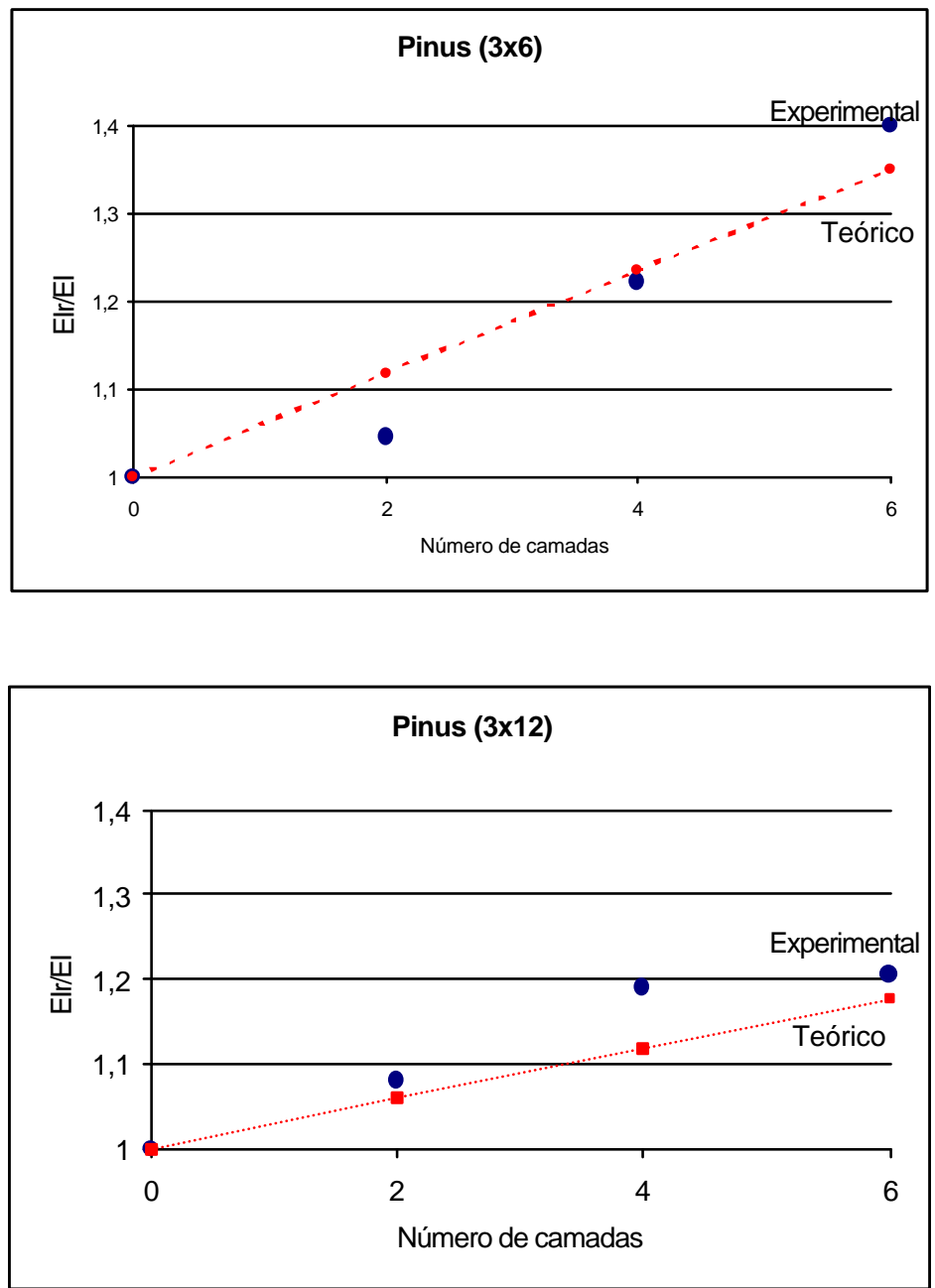

FIGURA 57: Valores EI (reforço)/EI x número de camadas 

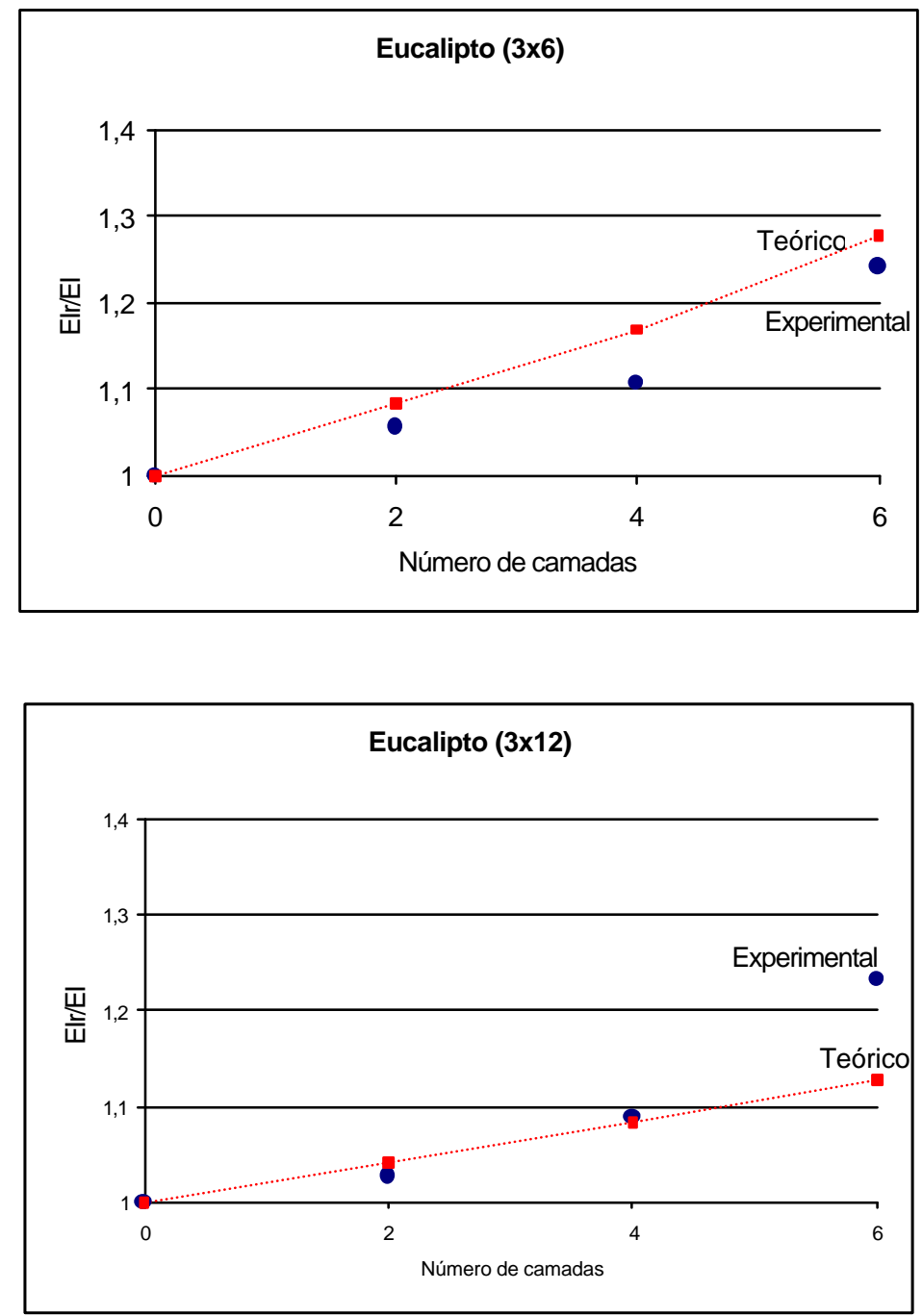

FIGURA 58: Valores EI (reforço)/EI x número de camadas

\subsection{Ensaios principais}

Estes ensaios objetivam verificar o aumento da resistência e rigidez de vigas estruturais de madeira reforçadas com fibra de vidro e com fibra de carbono e também avaliar o modelo teórico de cálculo proposto.

\subsubsection{Materiais utilizados para a confecção das vigas}

As vigas foram confeccionadas com madeiras das espécies Pinus caribea (Pinus caribea var. hondurensis) e Peroba Rosa (Aspidosperma polyneuron). As seções 
transversais das vigas, comprimento e quantidade estão apresentadas na tabela 39.

Estas duas espécies de madeiras foram escolhidas por apresentarem baixa e média densidade.

TABELA 39: Informações referentes às vigas de madeira

\begin{tabular}{|c|c|c|c|}
\hline $\begin{array}{c}\text { Número da } \\
\text { viga }\end{array}$ & $\begin{array}{c}\text { Espécie de } \\
\text { madeira }\end{array}$ & Dimensões & Tipo de reforço \\
\hline 01 & Pinus Caribea & $6 \times 12 \times 300$ & Fibra de vidro \\
\hline 02 & Pinus Caribea & $6 \times 12 \times 300$ & Fibra de vidro \\
\hline 03 & Pinus Caribea & $6 \times 12 \times 300$ & Fibra de carbono \\
\hline 04 & Pinus Caribea & $6 \times 12 \times 300$ & Fibra de carbono \\
\hline 05 & Pinus Caribea & $6 \times 16 \times 300$ & Fibra de vidro \\
\hline 06 & Pinus Caribea & $6 \times 16 \times 300$ & Fibra de vidro \\
\hline 07 & Pinus Caribea & $6 \times 16 \times 300$ & Fibra de carbono \\
\hline 08 & Pinus Caribea & $6 \times 16 \times 300$ & Fibra de carbono \\
\hline 09 & Pinus Caribea & $6 \times 12 \times 300$ & Fibra de vidro \\
\hline 10 & Peroba Rosa & $6 \times 12 \times 200$ & Fibra de vidro \\
\hline 11 & Peroba Rosa & $6 \times 12 \times 200$ & Fibra de vidro \\
\hline 12 & Peroba Rosa & $6 \times 12 \times 200$ & Fibra de carbono \\
\hline 13 & Peroba Rosa & $6 \times 12 \times 200$ & Fibra de carbono \\
\hline
\end{tabular}

As vigas de madeira de Pinus e Peroba Rosa foram reforçadas com seis camadas de fibra de vidro ou com duas camadas de fibra de carbono. Este número de camadas de fibras foi estabelecido baseando-se na análise tórica de cálculo, apresentada no capítulo 5, a qual indica uma proximidade entre os valores de momento máximo resistido por vigas de madeira reforçadas com duas camadas de fibra de carbono e seis camadas de fibra de vidro.

A viga número 9 de Pinus foi reforçada com 20 camadas de fibra de vidro, para verificar se existe diferença de comportamento, quando se utiliza uma maior quantidade de camadas de fibras. 


\subsubsection{Caracterização das peças de madeira}

As peças de madeira utilizadas foram caracterizadas preliminarmente sem 0 reforço, por meio de ensaios de flexão. Para a realização destes ensaios foi utilizado um cilindro hidráulico com capacidade de $50 \mathrm{kN}$ para aplicar o carregamento. A força aplicada foi medida por meio de um anel dinamométrico com capacidade para $50 \mathrm{kN}$ (figura 59). O método de ensaio utilizado foi o mesmo apresentado no item 6.1.3.

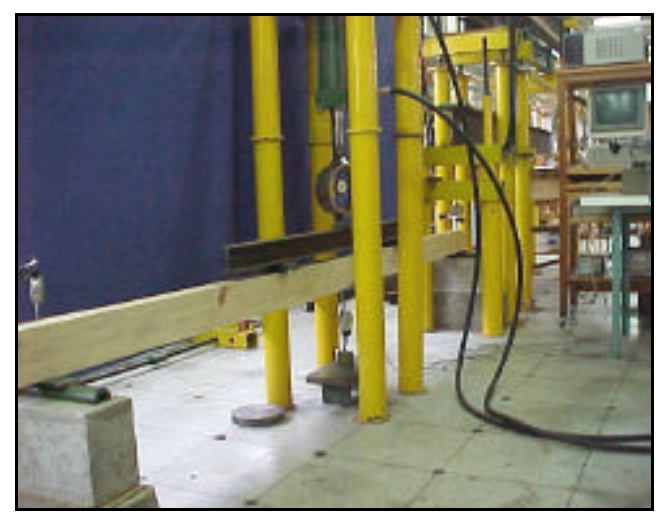

FIGURA 59: Esquema dos ensaios de flexão nas vigas

Após a realização dos ensaios de flexão das vigas reforçadas, foram retirados corpos-de-prova de regiões não danificadas, das próprias vigas, para a realização dos ensaios de caracterização mecânica da madeira. Estes ensaios foram realizados de acordo com as especificações da norma NBR 7190/97 - Projetos de estruturas de madeira, da Associação Brasileira de Normas Técnicas. Foram determinados os valores de resistência e módulo de elasticidade à compressão e à tração paralela às fibras da madeira.

\subsubsection{Instrumentação das vigas}

Nos ensaios de flexão das vigas reforçadas, foram medidos os deslocamentos verticais no meio do vão (flechas), por meio de um relógio comparador, de sensibilidade $0,01 \mathrm{~mm}$ no centro da viga, em sua face inferior. 
Com o objetivo de obter a distribuição de deformações nas vigas, as seguintes oito vigas foram instrumentadas com extensômetros elétricos:

- vigas: 01, 02, 03, 04, 09 (Pinus, seção 6x12 cm)

- vigas: 06 e 08 (Pinus, seção 6x16 cm)

- viga: 11 (Peroba Rosa, seção 6x12 cm)

Os extensômetros elétricos são da marca Kyowa do tipo KFG-10-120-C1-11. As leituras das deformações foram feitas utilizando um medidor analógico StrainmeterKyowa, ligado à mesa de canais Kyowa. Foram instalados cinco extensômetros por viga, fixados nas posições indicadas na figura 60 .

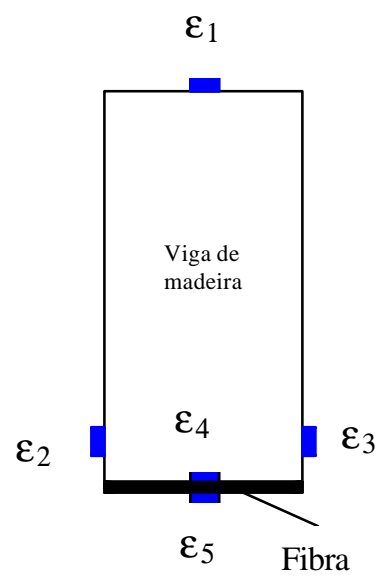

FIGURA 60: Posição dos extensômetros na seção transversal da viga

Salienta-se que na viga 01 , que foi a primeira a ser testada, não foi instalado o extensômetro 4. Após a avaliação dos resultados deste primeiro ensaio, notou-se uma grande variação de deformação entre os extensômetros 2 e 3 instalados na madeira e o extensômetro 5, instalado na fibra. Isto motivou a instalação do extensômetro 4, possibilitando medir a deformação na madeira praticamente na mesma posição da fibra.

Alguns cuidados especiais foram tomados com este extensômetro. Antes da 
colagem do tecido de fibra de vidro o extensômetro foi protegido com fita isolante. Desta forma impediu-se que o mesmo fosse danificado pela resina.

\subsubsection{Resultados obtidos}

Os resultados apresentados nas tabelas 40 e 41 são referentes à caracterização mecânica da madeira e aos ensaios de flexão de vigas de Pinus e Peroba Rosas reforçadas com fibra de vidro e com fibra de carbono.

As tabelas 40 e 41 apresentam valores de resistência e de módulo de elasticidade à compressão e à tração paralela às fibras da madeira.

Tabela 40: Médias e coeficiente de variação

\begin{tabular}{|c|c|c|c|c|}
\hline \multirow[t]{3}{*}{ Viga } & \multicolumn{4}{|c|}{ Pinus Caribea var. Hondurensis } \\
\hline & \multicolumn{2}{|c|}{ Resistência (MPa) } & \multicolumn{2}{|c|}{ Módulo de elasticidade (MPa) } \\
\hline & $\mathbf{f}_{\mathrm{c} 0}$ & $\mathbf{f}_{\mathbf{t 0}}$ & $\mathbf{E}_{\mathbf{c 0}}$ & $\mathbf{E}_{\mathbf{t 0}}$ \\
\hline \multirow[t]{2}{*}{01} & 36 & 73 & 12.410 & 12.109 \\
\hline & $(5,6)$ & $(9,65)$ & $(9,3)$ & $(6,9)$ \\
\hline \multirow[t]{2}{*}{02} & 45 & 69 & 15.087 & 12.771 \\
\hline & $(4,9)$ & $(8,9)$ & $(6,7)$ & $(2,4)$ \\
\hline \multirow[t]{2}{*}{03} & 41 & 62 & 10.492 & 8.002 \\
\hline & $(2,4)$ & $(15,1)$ & $(9,0)$ & $(9,0)$ \\
\hline \multirow[t]{2}{*}{04} & 48 & 68 & 13.044 & 13.442 \\
\hline & $(0,7)$ & $(4,1)$ & $(5 ., 8)$ & $(1,7)$ \\
\hline \multirow[t]{2}{*}{05} & 38 & 42 & 11.841 & 9.426 \\
\hline & $(2,2)$ & $(5,2)$ & $(7,3)$ & $(10,9)$ \\
\hline \multirow[t]{2}{*}{06} & 40 & 56 & 10.995 & 8.702 \\
\hline & $(2,1)$ & $(10,4)$ & $(2,8)$ & $(10,8)$ \\
\hline \multirow[t]{2}{*}{07} & 42 & 65 & 11.921 & 12.458 \\
\hline & $(2,2)$ & $(4,4)$ & $(2,4)$ & $(13,7)$ \\
\hline \multirow{2}{*}{08} & 34 & 44 & 10.685 & 10.835 \\
\hline & $(1,6)$ & $(7,4)$ & $(11,1)$ & $(8,2)$ \\
\hline \multirow[t]{2}{*}{09} & 39 & 59 & 12.446 & 14194 \\
\hline & $(3,6)$ & $(5,3)$ & $(8,1)$ & $(7,8)$ \\
\hline
\end{tabular}


Tabela 41: Médias e coeficiente de variação

\begin{tabular}{|c|c|c|c|c|}
\hline \multirow{3}{*}{ Viga } & \multicolumn{4}{|c|}{ Peroba Rosa } \\
\cline { 2 - 5 } & \multicolumn{3}{|c|}{ Resistência (MPa) } & \multicolumn{2}{c|}{ Módulo de elasticidade (MPa) } \\
\cline { 2 - 5 } & $\mathbf{f}_{\mathbf{c 0}}$ & $\mathbf{f}_{\mathbf{t 0}}$ & $\mathbf{E}_{\mathbf{c 0}}$ & $\mathbf{E}_{\mathbf{t 0}}$ \\
\hline \multirow{2}{*}{10} & 73 & 97 & 16.892 & 17.928 \\
& $(3,1)$ & $(4,6)$ & $(2,3)$ & $(4,2)$ \\
\hline \multirow{2}{*}{11} & 61 & 95 & 10.250 & 16.267 \\
& $(2,0)$ & $(9,1)$ & $(7,5)$ & $(14,6)$ \\
\hline \multirow{2}{*}{12} & 76 & 92 & 12.398 & $(3,5)$ \\
& $(3,2)$ & $(2,8)$ & $(11,7)$ & 18.609 \\
& 72 & 96 & 12.878 & $(6,2)$ \\
\hline \multirow{2}{*}{13} & $(6,0)$ & $(3,9)$ & $(8,6)$ & \\
& & & & \\
\hline
\end{tabular}

As tabelas 42 e 43 apresentam valores de momento de ruptura experimental, de rigidez à flexão (EI) e o tipo de ruptura apresentado pelas vigas de Pinus e de peroba, respectivamente.

Com relação à deformação, os valores estão apresentados no anexo A e de forma gráfica no item 6.2.5.3.

Tabela 42: Vigas de Pinus Caribea

\begin{tabular}{|c|c|c|c|c|c|c|c|c|}
\hline \multirow{4}{*}{$\begin{array}{l}\text { Reforço } \\
\\
\text { Fibra de } \\
\text { vidro }\end{array}$} & \multirow{3}{*}{$\begin{array}{r}\text { Viga } \\
1\end{array}$} & & & \multirow{3}{*}{$\begin{array}{c}\text { Momento } \\
\text { de } \\
\text { ruptura } \\
\text { (kN.cm) }\end{array}$} & \multicolumn{2}{|c|}{ EI (kN.cm²) } & \multirow{3}{*}{$\begin{array}{c}\begin{array}{c}\text { Flecha } \\
\text { máxima } \\
(\mathbf{c m})\end{array} \\
12\end{array}$} & \multirow{3}{*}{$\begin{array}{c}\begin{array}{c}\text { Modo de } \\
\text { ruptura }\end{array} \\
\text { Tração }\end{array}$} \\
\hline & & \multicolumn{2}{|c|}{$\begin{array}{c}\text { Seção } \\
(\mathbf{m m})\end{array}$} & & \multirow{2}{*}{\begin{tabular}{|l}
$\begin{array}{l}\text { sem } \\
\text { reforço }\end{array}$ \\
556.371 \\
\end{tabular}} & \multirow{2}{*}{$\begin{array}{c}\begin{array}{c}\text { com } \\
\text { reforço }\end{array} \\
711.534\end{array}$} & & \\
\hline & & 11,6 & 5,4 & & & & & \\
\hline & 2 & 11,6 & 5,4 & 1051 & 958.128 & 1.081 .958 & 11 & Tração \\
\hline \multirow{2}{*}{$\begin{array}{l}\text { Fibra de } \\
\text { carbono }\end{array}$} & 3 & 11,7 & 5,4 & 978 & 705.910 & 914.934 & 15 & Compressão \\
\hline & 4 & 11,6 & 5,4 & 1072 & 1.054 .281 & 1.236 .808 & 16 & Tração \\
\hline \multirow{2}{*}{$\begin{array}{l}\text { Fibra de } \\
\text { vidro }\end{array}$} & 5 & 15,3 & 5,3 & 1095 & 1.303 .614 & 1.463 .894 & 9 & Tração \\
\hline & 6 & 15,4 & 5,4 & 1301 & 1.450 .813 & 1.669 .113 & 16 & Tração \\
\hline \multirow{2}{*}{$\begin{array}{l}\text { Fibra de } \\
\text { carbono }\end{array}$} & 7 & 15,4 & 5,4 & 1491 & 1.999 .199 & 2.279.938 & 10 & Tração \\
\hline & 8 & 15,4 & 5,7 & 1060 & 1.389 .845 & 1.611 .869 & 12 & Tração \\
\hline F. Vidro & 9 & 11,8 & 5,5 & 1056 & 913.062 & 1.440 .282 & 11 & Tração \\
\hline
\end{tabular}


Tabela 43: Vigas de Peroba Rosa

\begin{tabular}{|c|c|c|c|c|c|c|c|c|}
\hline \multirow[t]{2}{*}{ Reforço } & \multirow[t]{2}{*}{ Viga } & \multirow{2}{*}{\multicolumn{2}{|c|}{ Seção (mm) }} & \multirow{2}{*}{$\begin{array}{l}\text { Momento } \\
\text { de } \\
\text { ruptura } \\
\text { (kN.cm) }\end{array}$} & \multicolumn{2}{|c|}{ EI $\left(\mathbf{k N} . \mathrm{cm}^{2}\right)$} & \multirow{2}{*}{$\begin{array}{c}\text { Flecha } \\
\text { máxima } \\
\text { (cm) }\end{array}$} & \multirow{2}{*}{$\begin{array}{l}\text { Modo } \\
\text { de } \\
\text { ruptura }\end{array}$} \\
\hline & & & & & sem & com & & \\
\hline \multirow{2}{*}{$\begin{array}{l}\text { Fibra de } \\
\text { vidro }\end{array}$} & 10 & 11,3 & 5,5 & 1258 & 1.125 .733 & 1.220 .987 & 6 & Tração \\
\hline & 11 & 11,3 & 5,0 & 1195 & 732.921 & 927.283 & 11 & Tração \\
\hline \multirow{2}{*}{$\begin{array}{l}\text { Fibra de } \\
\text { carbono }\end{array}$} & 12 & 11,3 & 5,0 & 1211 & 929.454 & 1.102 .436 & 9 & Tração \\
\hline & 13 & 11,5 & 5,0 & 1351 & 1.102 .280 & 1.269 .827 & 8 & Tração \\
\hline
\end{tabular}

Observa-se que o emprego do reforço de fibra propicia que a ruptura ocorra na presença de grandes deslocamentos verticais, conforme mostrado na figura 61, aumentando a segurança.
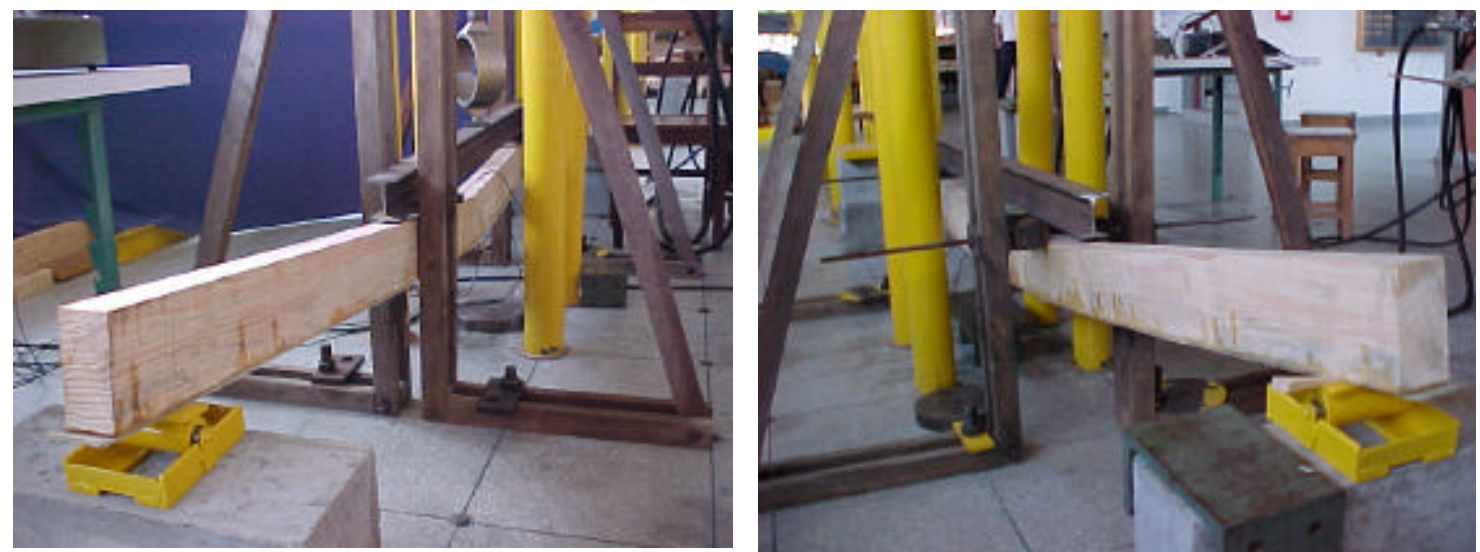

Figura 61: Flecha na viga

Para as vigas reforçadas, apesar do esmagamento das fibras superiores por compressão, observa-se aumento na capacidade da viga até o colapso, que varia com o número de camadas de reforço, que se inicia com a ruptura por tração na parte inferior da madeira. 

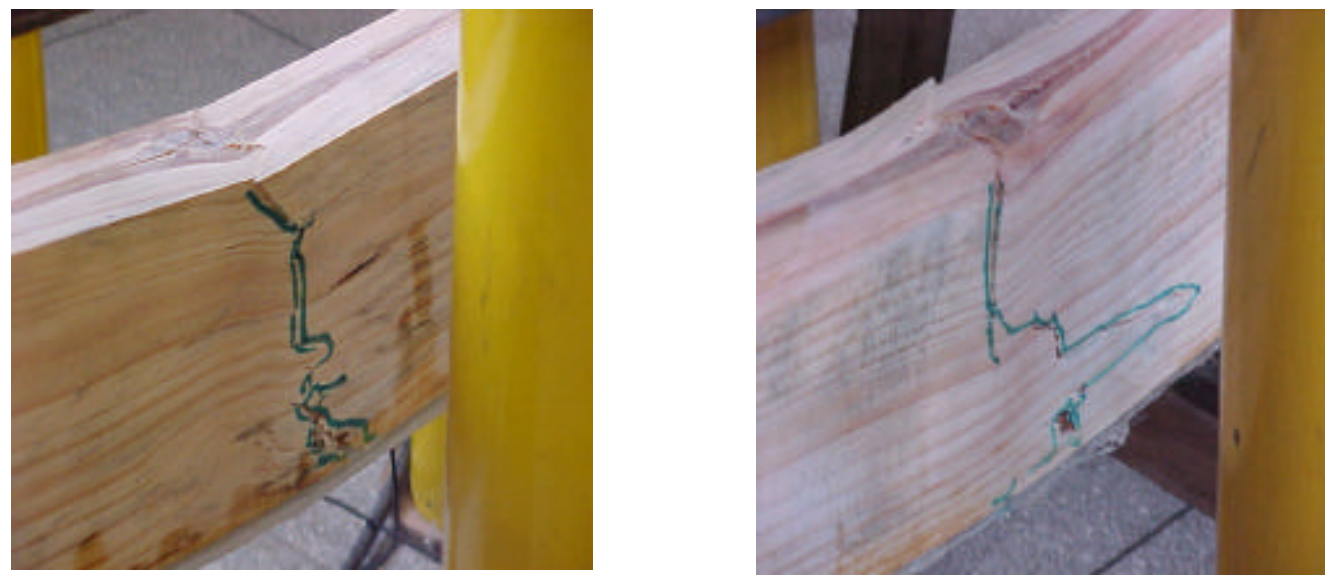

Figura 62: Ruptura por tração na madeira

\subsubsection{Análise dos resultados}

Este item apresenta uma análise comparativa entres valores experimentais e teóricos para a resistência e a rigidez à flexão. Os valores teóricos foram determinados segundo o modelo de cálculo proposto no capítulo 05.

\subsubsection{Análise do momento de ruptura - experimental e teórico}

As tabelas 44 e 45 apresentam valores de momento de ruptura experimental e teórico, este último determinado segundo o modelo de ruptura por tração, por ser o modelo que apresentou valores mais críticos. É apresentada, também, uma comparação entre os valores de momento de ruptura experimental e teórico. Os valores de módulo de elasticidade dos tecidos de fibra de vidro e de fibra de carbono, utilizados no cálculo do momento de ruptura teórico, são os apresentados na tabela 30. 
Tabela 44: Vigas de Pinus Caribea

\begin{tabular}{|c|c|c|c|c|}
\hline Reforço & Viga & $\begin{array}{l}\text { Momento de } \\
\text { ruptura } \\
\text { experimental } \\
(\mathrm{kN.cm})\end{array}$ & $\begin{array}{l}\text { Momento de } \\
\text { ruptura } \\
\text { teórico } \\
\text { (kN.cm) }\end{array}$ & $\begin{array}{c}\text { Relação } \\
\mathbf{M}_{\text {exp }} / \mathbf{M}_{\text {teórico }}\end{array}$ \\
\hline \multirow{2}{*}{$\begin{array}{l}\text { Fibra de } \\
\text { vidro }\end{array}$} & 1 & 920 & 871 & 1,05 \\
\hline & 2 & 1051 & 938 & 1,12 \\
\hline \multirow{2}{*}{$\begin{array}{l}\text { Fibra de } \\
\text { carbono }\end{array}$} & 3 & 978 & 934 & 1,04 \\
\hline & 4 & 1071 & 935 & 1,14 \\
\hline \multirow{2}{*}{$\begin{array}{l}\text { Fibra de } \\
\text { vidro }\end{array}$} & 5 & 1094 & 1085 & 1,00 \\
\hline & 6 & 1301 & 1400 & 0,93 \\
\hline \multirow{2}{*}{$\begin{array}{l}\text { Fibra de } \\
\text { carbono }\end{array}$} & 7 & 1491 & 1474 & 1,01 \\
\hline & 8 & 1060 & 1144 & 0,93 \\
\hline F. vidro & 9 & 1118 & 1056 & 1,06 \\
\hline
\end{tabular}

Tabela 45: Vigas Peroba Rosa

\begin{tabular}{|l|c|c|c|c|}
\hline Reforço & Viga & $\begin{array}{c}\text { Momento de } \\
\text { ruptura } \\
\text { experimental } \\
\text { (kN.cm) }\end{array}$ & $\begin{array}{c}\text { Momento de } \\
\text { ruptura } \\
\text { teórico } \\
\text { (kN.cm) }\end{array}$ & $\begin{array}{c}\text { Relação } \\
\mathbf{M}_{\text {exp }} / \mathbf{M}_{\text {teórico }}\end{array}$ \\
\hline \multirow{2}{*}{$\begin{array}{l}\text { Fibra de } \\
\text { vidro }\end{array}$} & $\mathbf{1 0}$ & 1258 & 1243 & 1,01 \\
\cline { 2 - 5 } & $\mathbf{1 1}$ & 1195 & 1021 & 1,17 \\
\hline $\begin{array}{l}\text { Fibra de } \\
\text { carbono }\end{array}$ & $\mathbf{1 2}$ & 1211 & 1075 & 1,12 \\
\cline { 2 - 5 } & $\mathbf{1 3}$ & 1351 & 1109 & 1,21 \\
\hline
\end{tabular}

Os resultados de momento de ruptura, apresentados nas tabelas 44 e 45 , indicam uma proximidade entre os valores teóricos e experimentais tanto para vigas de Pinus como para vigas de Peroba Rosa. Na maioria dos casos observados percebe-se uma uniformidade entre os valores. Pode-se concluir que o modelo de cálculo proposto é válido para avaliar vigas de madeira reforçadas com fibras.Observa-se que as vigas de Pinus de números 06 e 08 apresentam valores experimentais abaixo dos valores teóricos. Isto ocorreu, pois estas vigas apresentavam defeitos (nós) nas regiões centrais da peça, que influenciaram de maneira negativa na resistência da viga. 


\subsubsection{Análise da rigidez à flexão}

As tabelas 46 e 47 apresentam os valores de rigidez a flexão denominados a seguir, bem como uma comparação entre eles.

- $\quad \mathrm{EI}_{\mathrm{exp}}$ - valor experimental de rigidez à flexão da viga sem reforço;

- $\quad \mathrm{EI}_{\mathrm{r}, \exp }$ - valor experimental de rigidez à flexão da viga com reforço;

- $\quad \mathrm{EI}_{\mathrm{r}}$ - valor teórico de rigidez à flexão da viga com reforço;

$\mathrm{O}$ valor da rigidez a flexão teórico da viga reforçada $\left(\mathrm{EI}_{\mathrm{r}}\right)$, foi determinado de acordo com o modelo de seção transformada, apresentado no item 5.2.1 do capítulo 05.

Tabela 46: Vigas de Pinus Caribea

\begin{tabular}{|c|c|c|c|c|c|c|}
\hline \multicolumn{7}{|c|}{ Rigidez a flexão EI (kN.cm²) } \\
\hline Reforço & Viga & $\begin{array}{l}\mathbf{E I}_{\text {exp }} \\
\text { (exp.) }\end{array}$ & $\begin{array}{l}\mathbf{E I}_{\mathbf{r}, \exp } \\
(\mathrm{c} / \text { reforço) }\end{array}$ & $\begin{array}{l}\mathbf{E I _ { \mathbf { r } }} \\
\text { (teórico) }\end{array}$ & 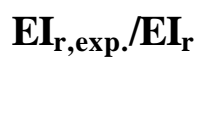 & $E I_{r, \exp } / \mathbf{E I}_{\mathbf{e x p}}$ \\
\hline \multirow{2}{*}{$\begin{array}{l}\text { Fibra de } \\
\text { vidro }\end{array}$} & 1 & 556.371 & 711.534 & 645.390 & 1,10 & 1,28 \\
\hline & 2 & 958.128 & 1.081 .958 & 1.073 .103 & 1,01 & 1,13 \\
\hline \multirow{2}{*}{$\begin{array}{l}\text { Fibra de } \\
\text { carbono }\end{array}$} & 3 & 705.910 & 914.934 & 847.092 & 1,08 & 1,30 \\
\hline & 4 & 1.054 .281 & 1.236 .808 & 1.222 .966 & 1,02 & 1,17 \\
\hline \multirow{2}{*}{$\begin{array}{l}\text { Fibra de } \\
\text { vidro }\end{array}$} & 5 & 1.303 .614 & 1.463 .894 & 1.473 .084 & 0,99 & 1,12 \\
\hline & 6 & 1.450 .813 & 1.669 .113 & 1.653 .927 & 0,99 & 1,15 \\
\hline \multirow{2}{*}{$\begin{array}{l}\text { Fibra de } \\
\text { carbono }\end{array}$} & 7 & 1.999 .199 & 2.279 .938 & 2.239 .103 & 1,02 & 1,14 \\
\hline & 8 & 1.389 .845 & 1.611 .869 & 1.570 .524 & 1,03 & 1,16 \\
\hline F. vidro & 9 & 913.062 & 1.440 .282 & 1.396 .985 & 1,03 & 1,58 \\
\hline
\end{tabular}

Tabela 47: Vigas Peroba Rosa

\begin{tabular}{|c|c|c|c|c|c|c|}
\hline \multicolumn{7}{|c|}{ Rigidez a flexão EI (kN.cm²) } \\
\hline Reforço & Viga & $\begin{array}{l}\text { EI } \mathbf{I}_{\text {exp }} \\
(\text { exp.) }\end{array}$ & $\begin{array}{c}\mathbf{E I}_{\mathbf{r}, \exp } \\
\text { (c/reforço) }\end{array}$ & $\begin{array}{c}\mathbf{E I}_{\mathbf{r}} \\
\text { (teórico) }\end{array}$ & $\mathbf{E I}_{\mathbf{r}, \exp .} / \mathbf{E I}_{\mathbf{r}}$ & $\mathbf{E} \mathbf{I}_{\mathbf{r}, \mathbf{e x p}} / \mathbf{E I}_{\text {exp. }}$ \\
\hline \multirow{2}{*}{$\begin{array}{l}\text { Fibra de } \\
\text { vidro }\end{array}$} & 10 & 1.125 .733 & 1.220 .987 & 1.272 .078 & 0,96 & 1,08 \\
\hline & 11 & 732.921 & 927.283 & 911.021 & 1,02 & 1,26 \\
\hline \multirow{2}{*}{$\begin{array}{l}\text { Fibra de } \\
\text { carbono }\end{array}$} & 12 & 929.454 & 1.102 .436 & 1.099 .544 & 1,01 & 1,19 \\
\hline & 13 & 1.102 .280 & 1.269 .827 & 1.278 .645 & 0,99 & 1,15 \\
\hline
\end{tabular}


A análise da rigidez das vigas sem reforço e reforçadas com fibra compara valores obtidos em ensaios experimentais com valores teóricos determinados de acordo com o modelo de seção transformada. Verifica-se, de maneira geral, que os resultados experimentais apresentam boa concordância em relação a rigidez à flexão teórica estimada. Pode-se concluir que o modelo de seção transformada é valido para determinar a rigidez de vigas de madeira reforçadas com fibra de vidro.

Para as vigas de Pinus reforçadas com seis camadas de fibra de vidro ou com duas camadas de fibra de carbono o aumento da rigidez da seção transversal variou entre $15 \%$ e $30 \%$.

Para a viga de Pinus reforçada com vinte camadas de fibra de vidro o aumento da rigidez foi significativo, aproximadamente $60 \%$.

Para as vigas de Peroba Rosa o aumento da rigidez foi de $10 \%$ a $25 \%$.

$\mathrm{Na}$ maioria das vigas o valor experimental ficou acima do valor teórico, garantindo que o valor da rigidez à flexão calculado esteja a favor da segurança.

\subsubsection{Análise das deformações}

As figuras 64 a 66 apresentam a variação da deformação em função da variação do momento fletor para vigas de Pinus e de Peroba Rosa sem reforço e reforçadas com fibras de vidro e com fibras de carbono. As vigas sem reforço foram ensaiadas até o limite de flecha igual a L/200 do vão. 

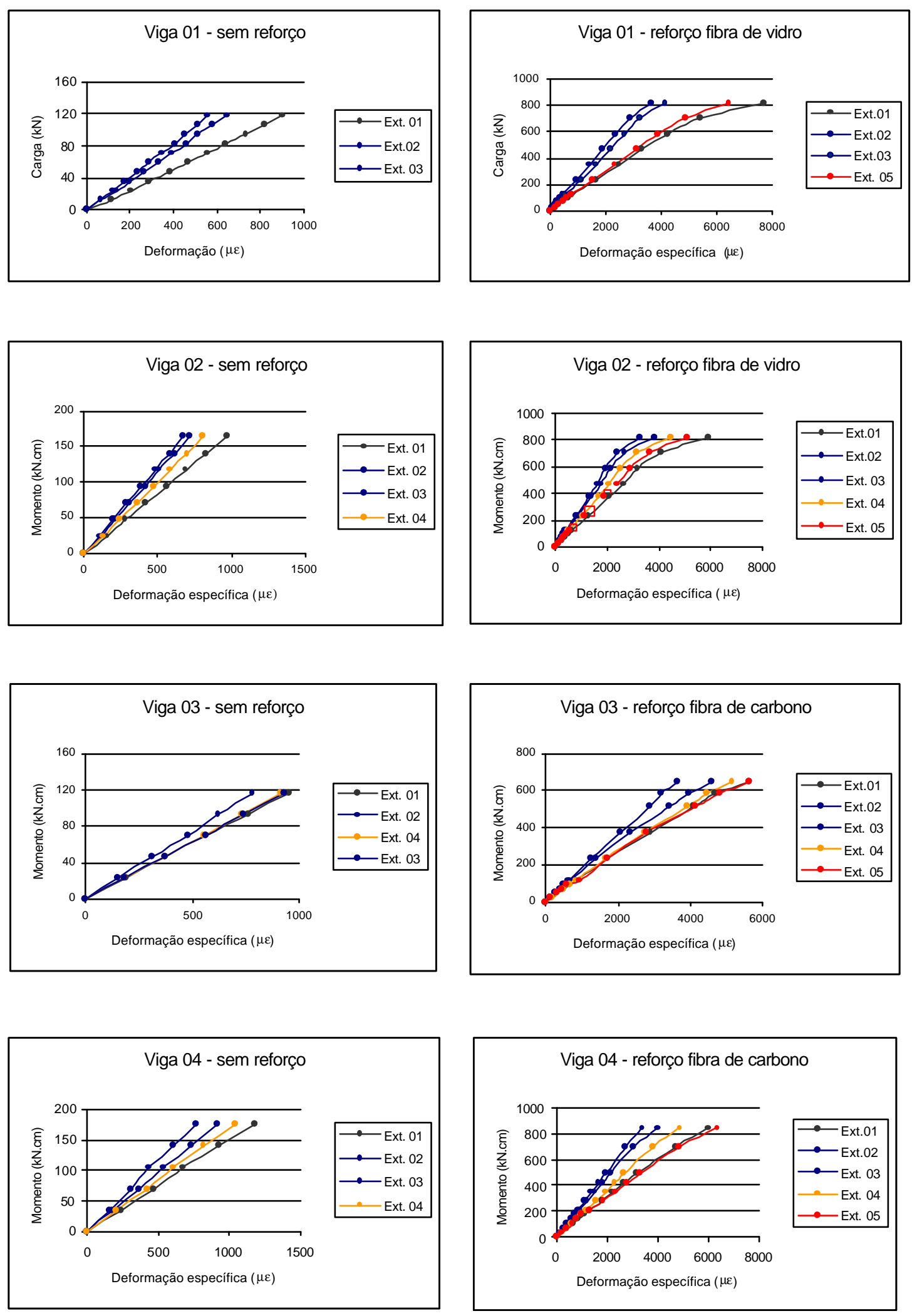

FIGURA 63: Força x deformação específica de vigas Pinus seção $(6 \times 12 \mathrm{~cm})$ 

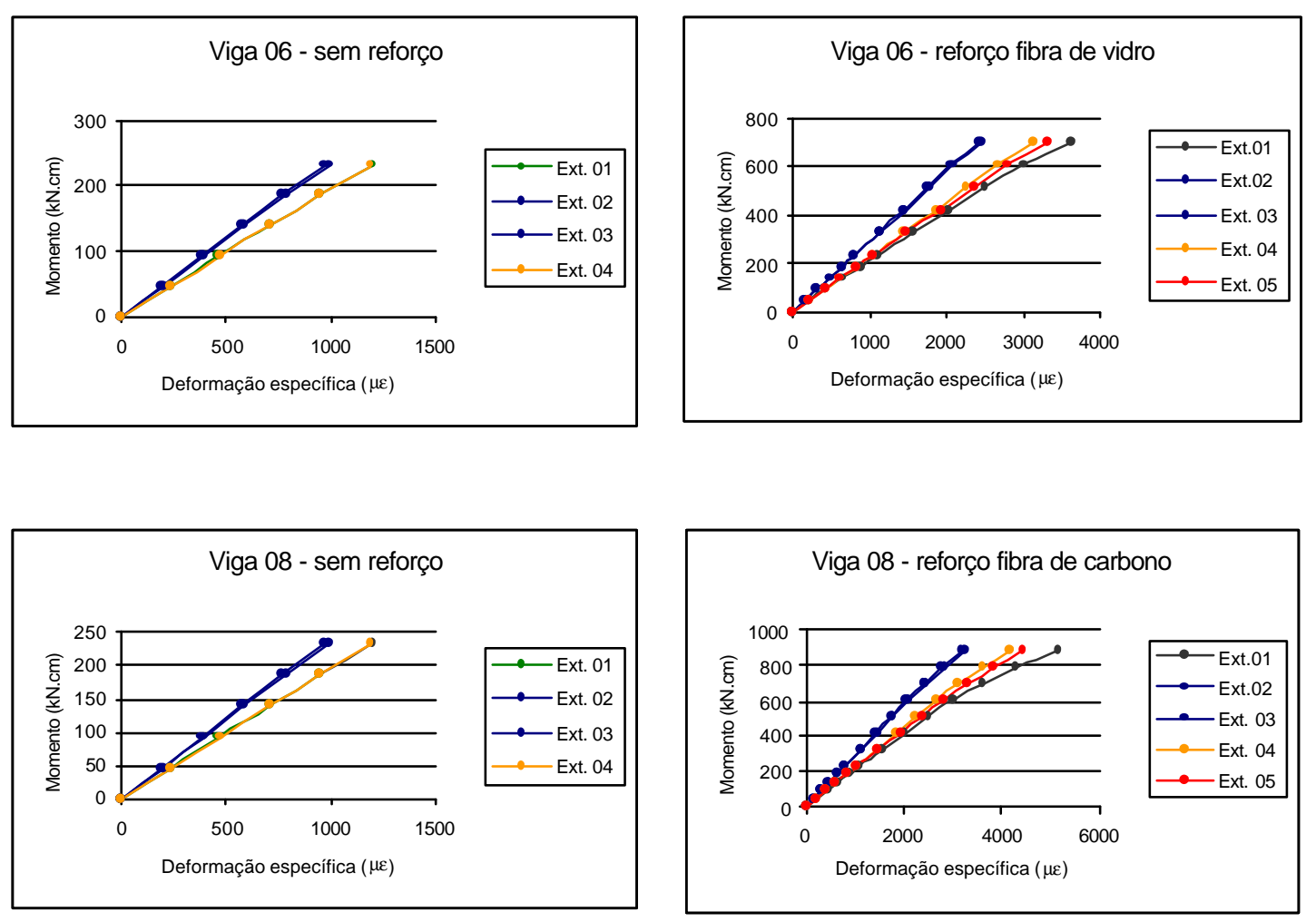

FIGURA 64: Força x deformação específica de vigas Pinus seção $(6 \times 16 \mathrm{~cm})$
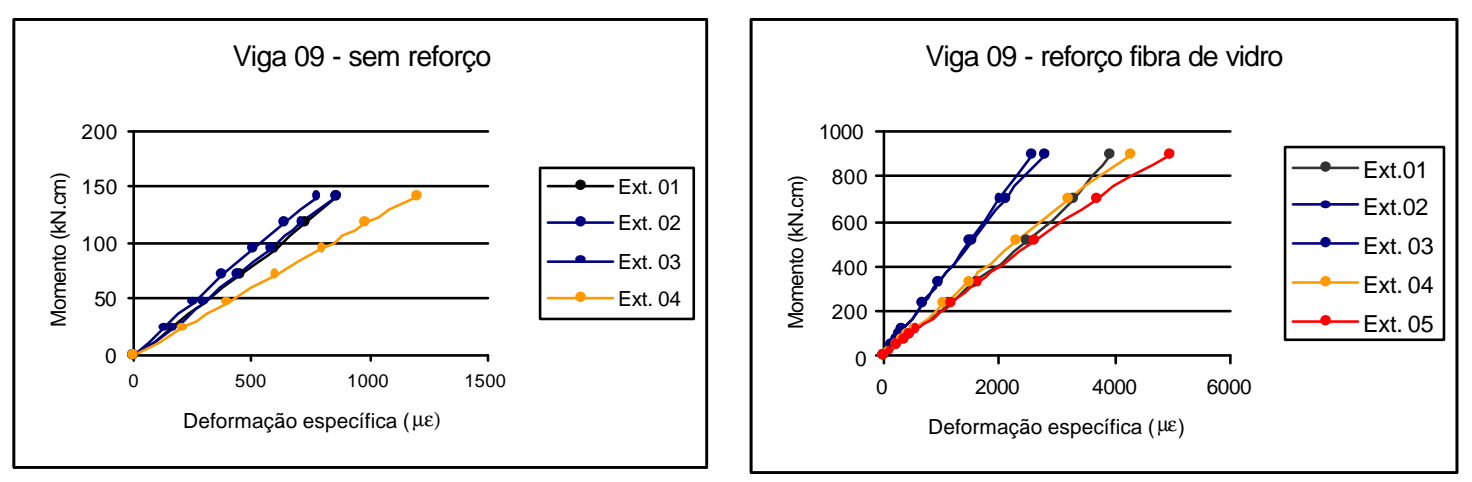

FIGURA 65: Força x deformação específica de vigas Pinus seção $(6 x 12 \mathrm{~cm})$ - 20 camadas de fibra 

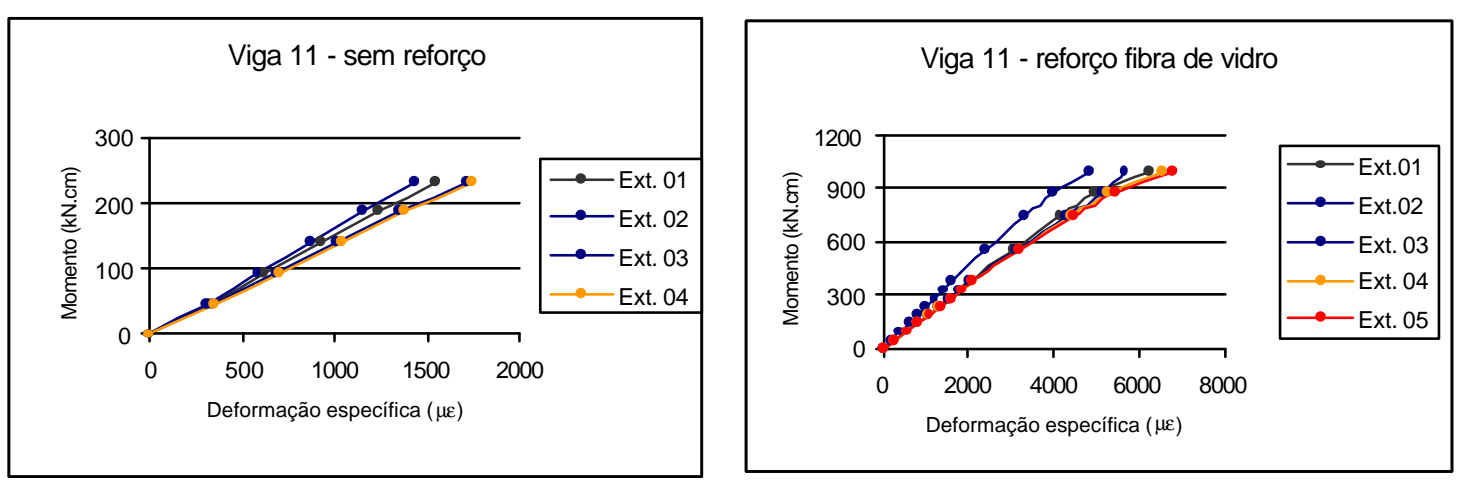

FIGURA 66: Força x deformação específica de vigas de Peroba Rosa seção (6x16 cm)

As figuras 67 a 74 permitem visualizar a distribuição de deformação ao longo da altura da seção das vigas, para vários estágios de força aplicada.

Para os extensômetros 02 e 03, localizados na mesma posição vertical da viga, foi utilizada a média entre os valores de deformações. 


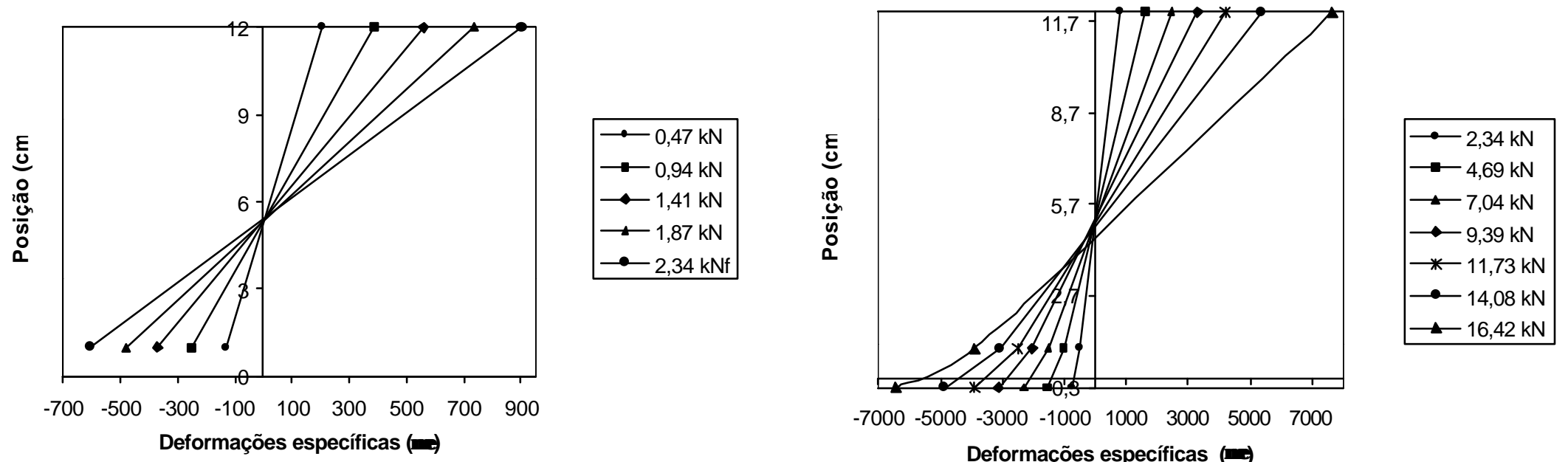

FIGURA 67: Variação da deformação ao longo da altura da seção transversal da viga 01 sem reforço e reforçada 


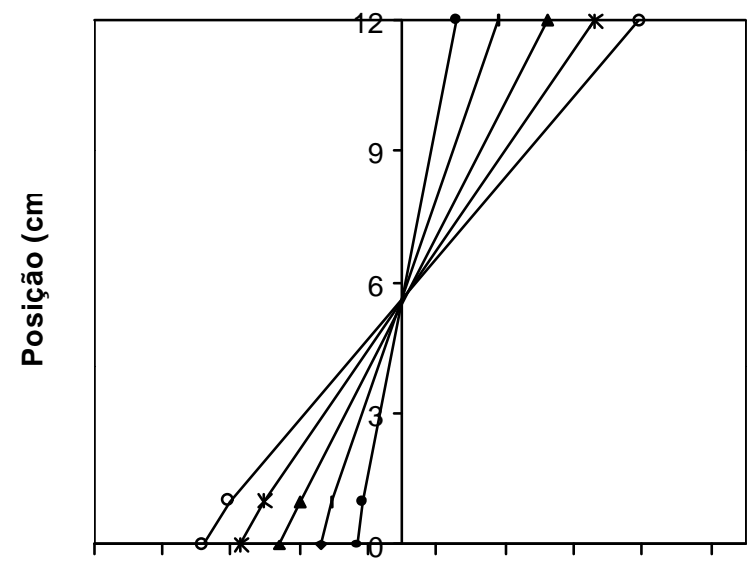

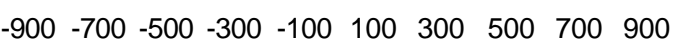
Deformações específicas ( $\mu \varepsilon$ )

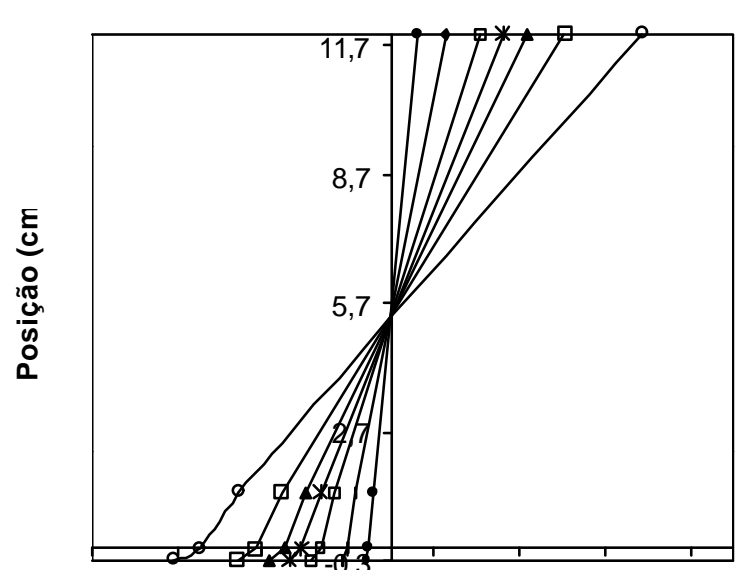

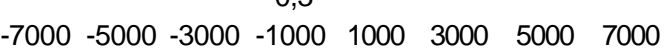
Deformações específicas $(\mu \varepsilon)$

FIGURA 68: Variação da deformação a longo da altura da seção transversal da viga 02 sem reforço e reforçada 

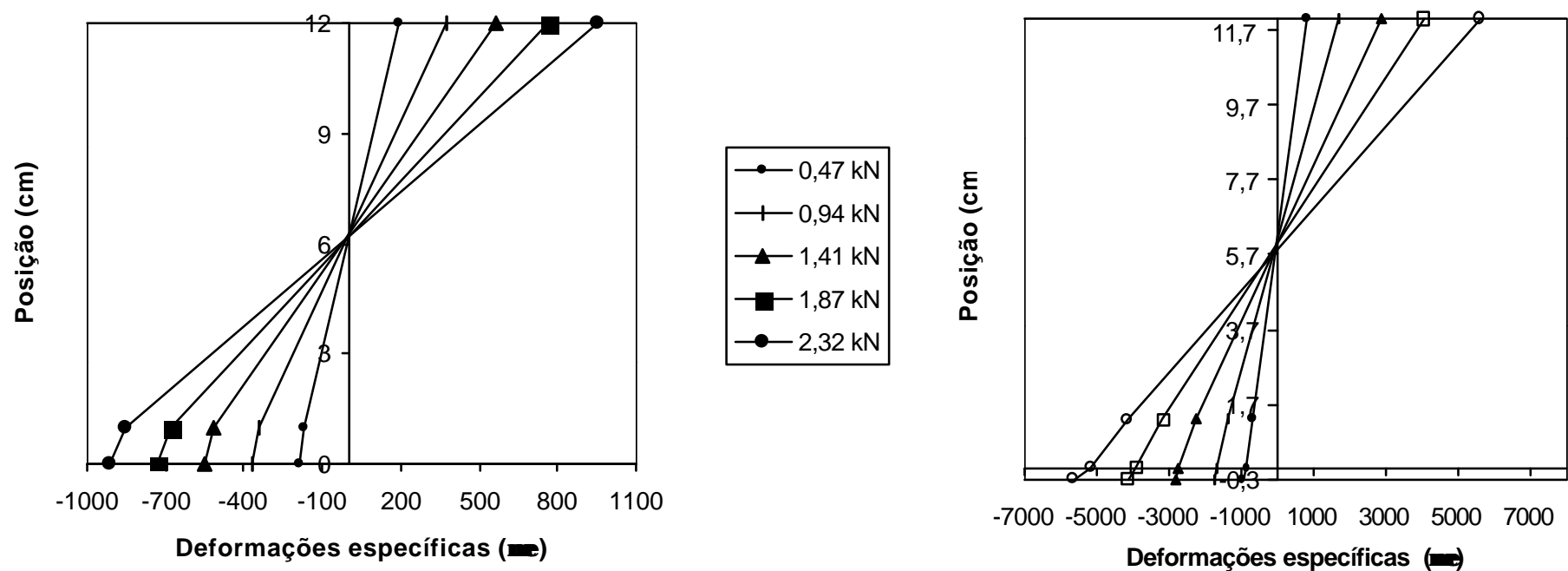

$-7000-5000-3000-10001000300050007000$

Deformações específicas $(\mu \varepsilon)$

\begin{tabular}{|}
$--2,32 \mathrm{kN}$ \\
$\longrightarrow-4,66 \mathrm{kN}$ \\
$-7,45 \mathrm{kN}$ \\
$\square-10,25 \mathrm{kN}$ \\
$--11,65 \mathrm{kN}$ \\
\hline
\end{tabular}

FIGURA 69: Variação da deformação ao longo da altura da seção transversal da viga 03 sem reforço e reforçada 

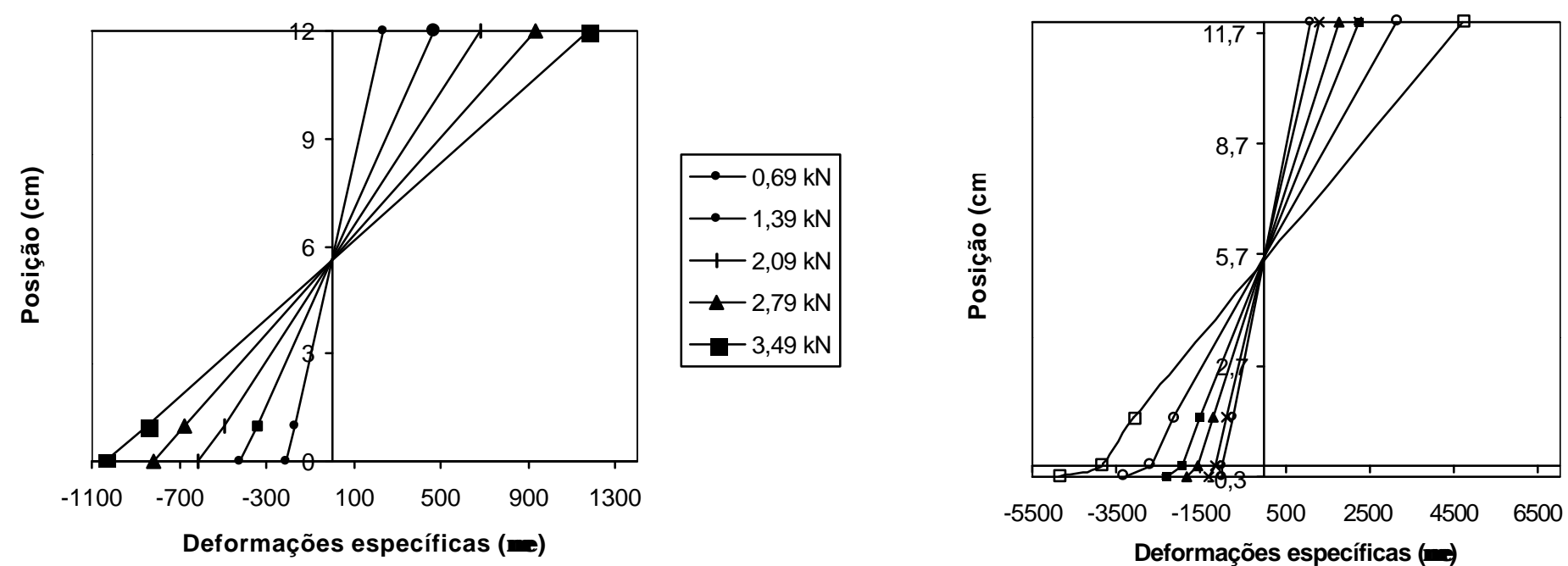

\begin{tabular}{|}
$\longrightarrow 3,49 \mathrm{kN}$ \\
$\longrightarrow-4,19 \mathrm{kN}$ \\
$-5,59 \mathrm{kN}$ \\
$\longrightarrow-6,98 \mathrm{kN}$ \\
$\longrightarrow-9,78 \mathrm{kN}$ \\
$\square-13,98 \mathrm{kN}$ \\
\hline
\end{tabular}

FIGURA 70: Variação da deformação ao longo da altura da seção transversal da viga 04 sem reforço e reforçada 

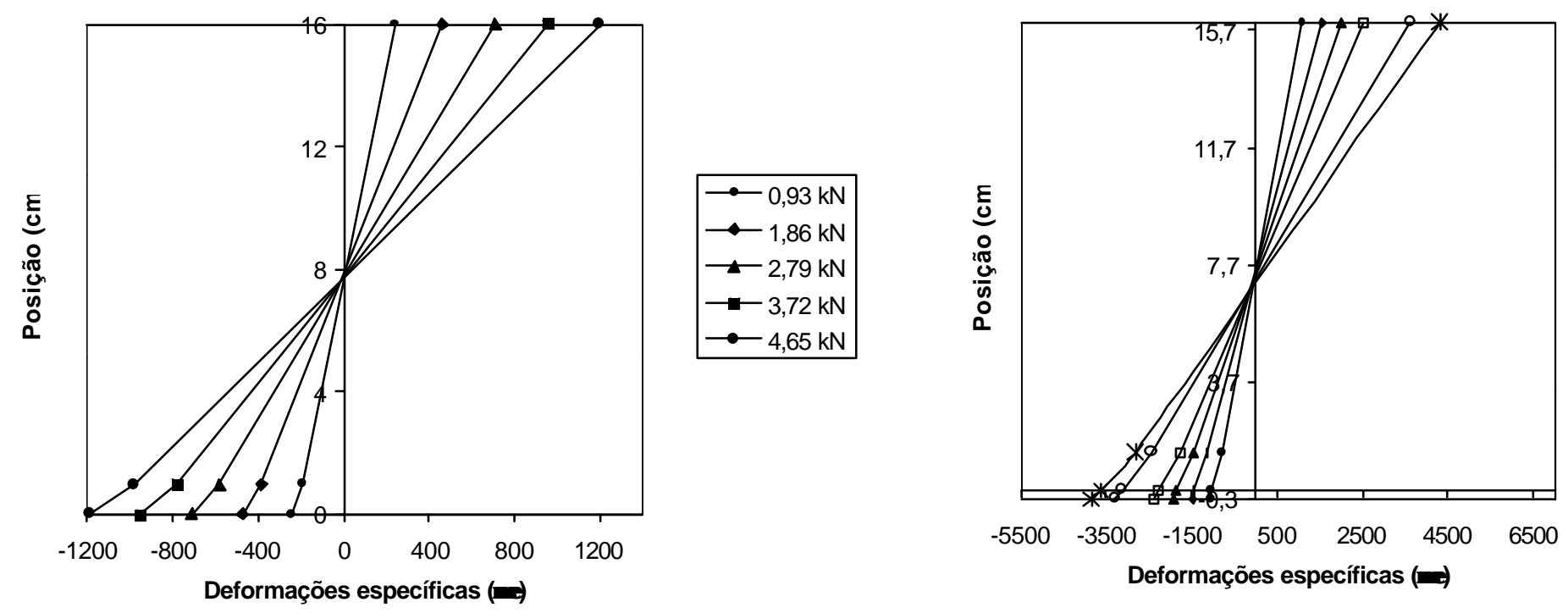

FIGURA 71: Variação da deformação ao longo da altura da seção transversal da viga 06 sem reforço e reforçada 

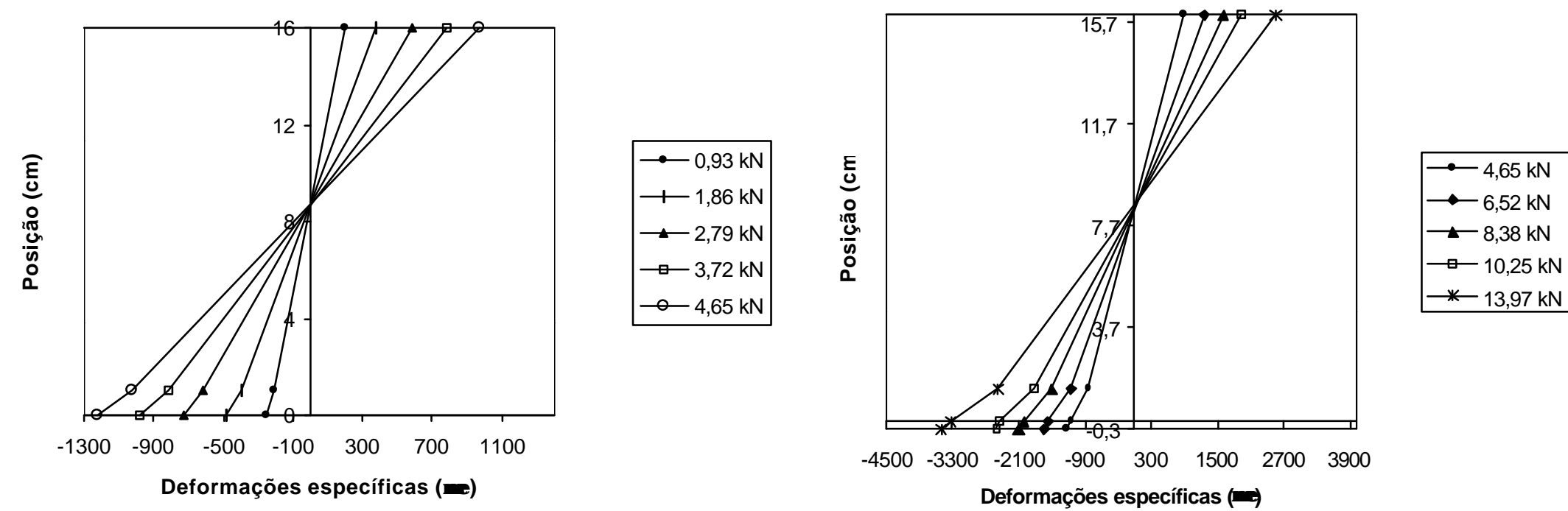

FIGURA 72: Variação da deformação ao longo da altura da seção transversal da viga 08 sem reforço e reforçada 

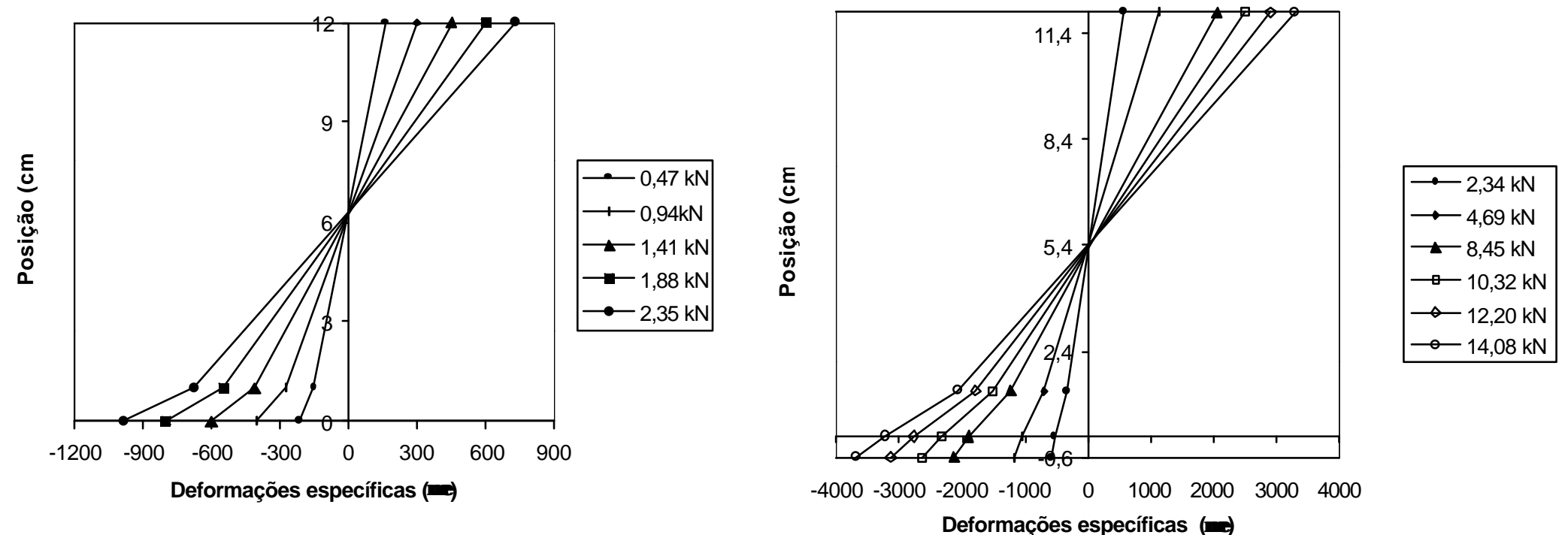

FIGURA 73: Variação da deformação ao longo da altura da seção transversal da viga 09 sem reforço e reforçada com 20 camadas de fibra 

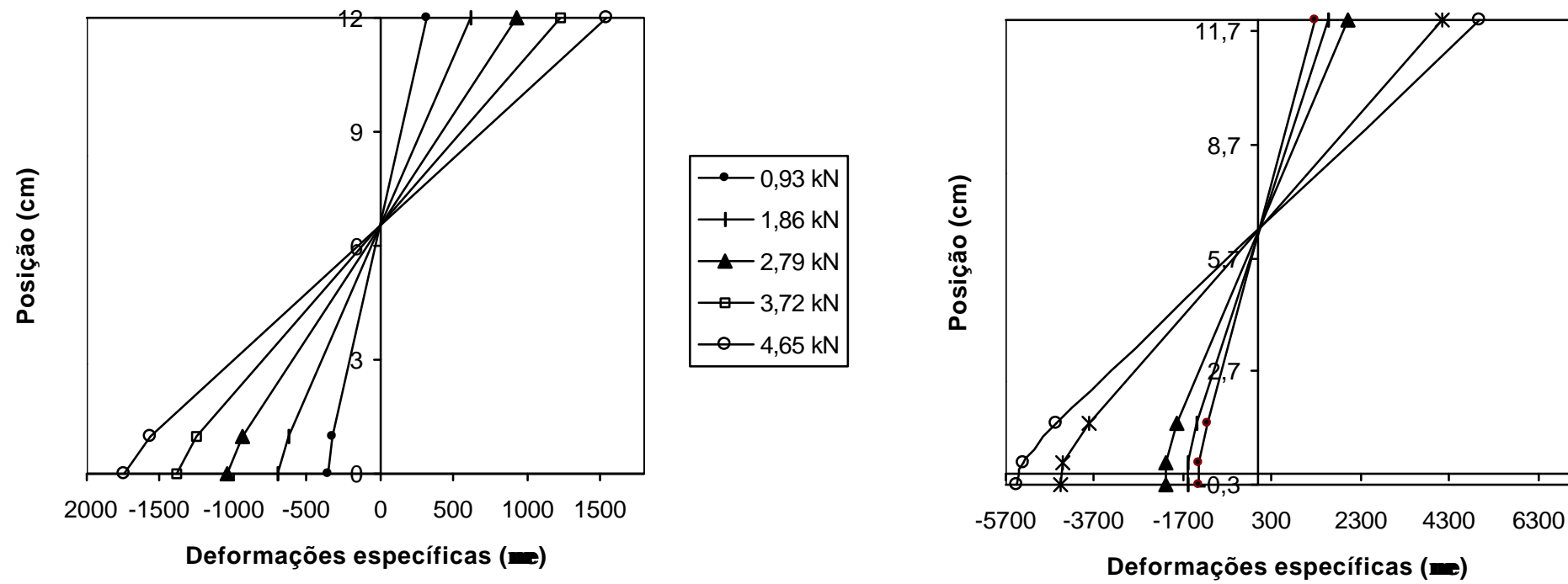

FIGURA 74: Variação da deformação ao longo da altura da seção transversal da viga 11 sem reforço e reforçada 
Observando a variação da deformação apresentada nas figuras 67 a 74, podese dizer que a seção praticamente permaneceu plana, indicando a validade da hipótese adotada no modelo teórico.

Na maioria dos casos a diferença entre as deformações na madeira e na fibra foi pequena (extensômetros 4 e 5). 


\section{7 - CONCLUSÕES}

A utilização de fibras reforçadas com polímeros (FRP) coladas à madeira surgiu devido à necessidade de reforçar estruturas em uso, ou para compor um novo elemento estrutural, com propriedades mecânicas superiores às iniciais. Com as FRP as estruturas de madeira passam a contar com uma técnica de reforço onde a madeira em união com as fibras forma um material compósito com ótimas propriedades mecânicas.

Tanto o tecido de fibra de vidro como o de fibra de carbono avaliado, apresentaram bom desempenho em reforço de vigas. O uso das fibras proporcionou um incremento nas propriedades mecânicas de resistência e rigidez da madeira.

Apesar do tecido de fibra de vidro possuir propriedades mecânicas inferiores às do tecido de fibra de carbono, resultados significativos de aumento de resistência e rigidez são conseguidos com o uso de um número maior de camadas de fibras. Tendo em vista o seu menor custo, em relação à fibra de carbono, a sua utilização parece ser mais indicada.

Por meio das análises teóricas e experimentais constatou-se que o aumento de resistência e de rigidez é proporcional ao aumento do número de camadas, e que o uso de uma camada de fibra de carbono equivale ao uso de três camadas de fibra de vidro.

Os adesivos Resorcinol Formaldeído (Cascophen) e o adesivo à base de mamona não apresentaram bons resultados na laminação das fibras e na colagem das fibras à madeira, recomendado-se o uso de adesivo epóxi, que apresentou desempenho superior aos adesivos de mamona e Cascophen tanto na laminação quanto na fixação das fibras a madeira. 
Um fator importante a salientar é quanto ao modo de ruptura do compósito, observado experimentalmente: inicialmente, ocorre esmagamento da madeira na região comprimida da seção transversal, com conseqüente abaixamento da Linha Neutra, e posterior ruptura por tração e/ou cisalhamento da madeira.

Por este motivo, as vigas de madeira reforçadas com fibras apresentaram grandes deslocamentos na proximidade da ruptura, em comparação às vigas de madeira sem reforço. Este comportamento da estrutura reforçada é positivo, pois garante uma maior segurança estrutural, uma vez que a ruptura é aninciada por grandes deslocamentos.

O modelo teórico para avaliação da rigidez, baseado no método da seção transformada, e o modelo teórico desenvolvido, baseado na hipótese de NavierBernoulli, apresentaram boa concordância com os valores obtidos experimentalmente, demonstrando a validade dos mesmos.

Tendo em vista os comentários e conclusões apresentados ao longo deste trabalho, conclui-se pela viabilidade de aplicação das fibras de vidro e das fibras de carbono no reforço e na recuperação de vigas de madeira. Esta técnica, além de fácil execução, proporciona um aumento da resistência e da rigidez dos elementos estruturais reforçados. Além disso, propicia uma maior confiabilidade ao sistema, diminuindo a possibilidade de ruptura por tração devido a defeitos.

Como continuidade deste trabalho, propõe-se o estudo de vigas de madeira laminada colada (MLC) reforçadas com fibra de vidro. O reforço de fibra deve ser aplicado nas linhas de cola das regiões solicitadas por maiores tensões de tração. Entre as vantagens deste sistema, está a diminuição do peso próprio dos elementos estruturais e também uma maior economia de materiais, devido à otimização da seção. 


\section{8 - REFERÊNCIAS BIBLIOGRÁFICAS}

ABDEL-MAGID, B.; DAGHER, H.J.; and KIMBALL, T. "The Effect of Composite Reinforcement on Structural Wood”. ASCE 1994. MATERIALS ENGINNERING CONFERENCE, INFRASTRUCTURE: NEW MATERIALS AND METHODS FOR REPAIR, San Diego, Califórnia, nov. 14-19.

AMERICAN SOCIETY for TESTING and MATERIALS. (1993). Standard Test Methods for Fire Tests of Building Construction Materials. ASTM E 199-88 (1993). Philadelphia, PA.

AMERICAN SOCIETY for TESTING and MATERIALS. (1984). Methods of Static Tests of Timbers in Structural Sizes. ASTM D198-84. Philadelphia, PA.

AMERICAN SOCIETY for TESTING and MATERIALS. (1995). Standard Test Method for Tensile Properties of Polymer Matrix Composite Materials. ASTM D3039-95.

ASKELAND, D.R.. The Science and Engineering of Materials. (1996). Chapman \& Hall.

ASSOCIAÇÃO BRASILEIRA DE NORMAS TÉCNICAS. NBR 7190-Cálculo e execução de estruturas de madeira. Rio de Janeiro, ABNT, 1982.

ASSOCIAÇÃO BRASILEIRA DE NORMAS TÉCNICAS. NBR 7190-Projeto de estruturas de madeira. Rio de Janeiro, ABNT, 1997.

BAKOSS, S., GREENLAND, A., CREWS, K. Aplication of Advanced Fibre Reinforced Plastic Composites To Structural Timber. In: WORLD CONFERENCE ON TIMBER ENGINEERING, 17-20 august 1998, Montreux, Switzerland. Anais. v.2, p.716-717.

BARRACUDA (2000). Tecidos Prepregs. http://www.barracudatec.com.br

BEBER, A.J., Campos, A .F., Campagnolo, J.L., Flexural Strenghening of $R / C$ Beans with CFRP Sheets. In: INTERNATIONAL CONFERENCE ON STRUCTURAL FAULS AND REPAIR, 1999, London, ECS Publications (CDROM).

BELPERIO, R., GRAD, IE. The Performance of Glulam Beams Reinforced with Carbon Fibre. In: PACIFIC TIMBER ENGINEERING CONFERENCE, 14-18 march 1999, New Zeland. Anais. v.2, p.99-106.

BERGMEISTER, K., LUGGIN, W. Innovative Strengthening of Timber Structuress Using Carbon Fibres. In. INTERNATIONAL ASSOCIATION FOR BRIDGE AND STRUCTURAL ENGENNEERING, March 2001, Malta, Anais. p. 361366.

BUI, Q.D., MILNER, H.R., WILLIAMS, J.M. Fibre Reinforced Finger Joints. In: INTERNACIONAL WOOD ENGINEERING CONFERENCE, October 1996, 
New Orleans, Lousiana, USA. Anais. v.1, p.427-430.

BULLEIT, W.N. Reinforcement of wood materials a review. Wood and Fiber Sci. 16 (3), 391-397, (1994).

CASTRO, C.H., NASCIMENTO, J.F.F., PINTO, R.S., ANDRADE, W.P., Reparos em Estruturas de Concreto - Avaliação da Eficiênciade Resinas Epóxi: In: $41^{\circ}$ IBRACON, 1999, Salvador - BA.

CARVALHO, W.S.. Otimização da Interface/Interfase de Fibra de Carbono/Termoplástico. Dissertação (Mestrado). Universidade Frederal de São Carlos - UFSCar, 1998.

CHI-JEAN, Chean. Mechanical Behavior of Fiberglass Reinforced Timber Joints. In: WORLD CONFERENCE ON TIMBER ENGINEERING WCTE, 31 july - 03 august 2000, Canada. Anais.

DAGHER, H.J., FRP-Reinforced Wood in Bridge Applications. In: $1^{\text {st }}$ RILEM Symposium TIMBER ENGINEERING, 13-15 september 1999, Stockholm, Sweden. Anais. p.591-598.

DAGHER, H.J., High - Performance Wood Composites for Construction. In: VII EBRAMEM, julho 2000, São Carlos - Brasil. Anais.

DAVIDS, W.G., Experimental and Numerical Study on Creep of FRP Reinforced Glulam Beams. In: $1^{\text {st }}$ RILEM Symposium TIMBER ENGINEERING, 13-15 september 1999, Stockholm, Sweden. Anais. p.581-590.

FORSBERG, T.E. Long-Span Timber Trusses - Evaluating a Repair Method. Practice Periodical on Structural Design and Construction, may 1996.

HENRIQUES DE JESUS, J.M, CALIL JR, C., CHIERICE, G.O. Adesivo poliuretano alternativa para uso em MLC. In: ENCONTRO BRASILERIO DE MADEIRA E ESTRUTURAS DE MADEIRA, 6, Florianópolis, 1998. Anais, vol1, p337-343.

HENRIQUES DE JESUS, J. M. Estudo do adesivo poliuretano à base de mamona em madeira laminada colada (MLC). Dissertação (Doutorado). Escola de Engenharia de São Carlos. Universidade de São Paulo, jul 2000.

HOUWINK, R.; SALOMON, G. (1965). Adhesion and adhesives. 2ed.New York, Elsevier Publishing Company.

HULL, D., AN INTRODUCTION TO COMPOSITE MATERIALS. Cambridge University (1995).246p.

JANG, B.Z.. Advanced Polymer Composites. ASTM International (1994).

KOLLMANN, F.F.P.; KUENZI, E.W.; STAMM, A.J. Principles of wood science and technology. V2. (1975). New York, Springer-Verlag.

MANTILLA CARRASCO, E.V. Ligações estruturais de madeira por adesivos. São 
Carlos, 2v. Dissertação (Mestrado). Escola de Engenharia de São Carlos.

Universidade de São Paulo, jul 1984.

MARTIN, Z.A.; STITH, J.K.; TINGLEY, D.A. Strength and stiffness performance of FRP reinforced White. In: WORLD CONFERENCE ON TIMBER ENGINEERING WCTE, 31 july - 03 august 2000, Canada. Anais.

MARTIN, Z.A.; TINGLEY, D.A. Fire resistance of FRP reinforced glulam beams. In: WORLD CONFERENCE ON TIMBER ENGINEERING WCTE, 31 july - 03 august 2000, Canada. Anais.

MATTHEWS. F.L. RAWLINGS, R.D., COMPOSITE MATERIALS: ENGINEERING AND SCIENCe. (1996). London. P.29-53

METTEM, C.J.; ROBINSON, G.C., The Repair of Structural Timber. In: INTERNATIONAL TIMBER ENGINEERING CONFERENCE LONDON, 2-5 September 1991, London. Anais. p.4.56-4.65.

NORRIS, T.; SAADATMANESH, H. (1994). Improving the Serviceability of Concrete Beams Using Carbon Fiber Reinforced Polymer (CFRP) Sheets, FHA, Grant No. DDEGRF-93-P-05.

OLIVEIRA, J.T.; FREITAS, A.R. (1995). Painéis à base de madeira. São Paulo, Boletim Técnico BT/PCC/149, Escola Politécnica da USP. Departamento de Engenharia de Construção Civil, EPUSP.

OLMOS, M.A.C. Equipamento e Processo de Fabricação de Chapas Aglomeradas a Partir de Resíduos de Madeira . Dissetação de Mestrado, EESC-USP. 22 outubro 1992, 112p.

PARDINI, L.C. (1990). Comportamento Dinâmico-Mecânico e à Fratura de Materiais Compostos Epoxi/ Elastomêro/ Fibra de Carbono. Dissertação (Mestrado), Universidade Federal de São Carlos-UFSCar

PIGGOTT, M.A. Load-Bearing Fibre Composites. University of Toronto (1996). $277 \mathrm{p}$.

RITCHIE, P.; THOMAS, D.; LU, W.L.; AND CONNELLY, G. (1991). "External Reinforcement of concrete beans using fiber reinforced plastics" ACI STRUCTURAL JOURNAL, ACI, Vol. 88, pp 490-500.

RITTER, Michael A., TIMBER BRIDGES: DESIGN, CONSTRUCTION, INSPECTION, AND MAINTENANCE. Washington (1990), DC. 944p.

SAMLAIC, J. Os atuais problemas e as possibilidades dos adesivos para madeira. REVISTA DA MADEIRA No374 (1993), p.7-10.

SUNDERS, K.J. Polymer Chemistry, $2^{\text {a }}$ ed. Ed. Chapman \& Hall, (1988). Pág.144146.

SIKA (2000) Colagem rígida a base de epóxi. http://www.sika.com.br 
SIKA (2000). Catálogo - Technology and Concepts for Sika Carbodur Structural Strengthening Systems.

Saint - Gobain Vetrotex (2000) - Catálogo.

TICHY, R., Properties and Aplications of Wood-Plastic Composites. In: WORLD CONFERENCE ON TIMBER ENGINEERING, 17-20 august 1998, Montreux, Switzerland. Anais. v.2, p.616-623.

TINGLEY, D., GILHAM, P. Long Term Load Performance of FRP Reinforced Glulam Bridge Girders. In: NATIONAL CONFERENCE on WOOD TRANSPORTATION STRUCTURES, 1994, Anais. v.1, p.201-206.

TINGLEY, D., CEGELKA, S. High-Strength-Fiber-Reinforced-Plastic Reinforced Wood. In: INTERNACIONAL WOOD ENGINEERING CONFERENCE, 28-31 October 1996, New Orleans, Lousiana, USA. Anais. v.3, p.57-64.

TINGLEY, D., KENT, S. Structural Evaluation of fiber reinforced hollow wood beams. In. INTERNATIONAL ASSOCIATION FOR BRIDGE AND STRUCTURAL ENGENNEERING, March 2001, Malta, Anais. p. 367-372.

TRIANTAFILLOU, T. and DESKOVIC, N. "Prestressed FRP sheets as external reinforcement of wood members". JOURNAL OF STRUCTURAL ENGENEERING, (1992) ASCE, 118 (5), 1270-1284. 
ANEXO A 


\begin{tabular}{|c|c|c|c|c|}
\hline \multicolumn{5}{|c|}{ VIGAS SEM EXTENSÔMETROS } \\
\hline \multicolumn{5}{|c|}{ Viga de Pinus } \\
\hline \multirow{3}{*}{$\begin{array}{c}\text { Força } \\
(\mathrm{kN})\end{array}$} & \multicolumn{2}{|c|}{ Viga 05} & \multicolumn{2}{|c|}{ Viga 07} \\
\hline & S/reforço & C/Reforço & S/reforço & C/Reforço \\
\hline & \multicolumn{4}{|c|}{ Flecha $(\mathrm{mm} / 100)$} \\
\hline 0 & 0 & 0 & 0 & 0 \\
\hline 0,93 & 330 & 310 & 320 & 355 \\
\hline 1,86 & 665 & 610 & 670 & 645 \\
\hline 2,79 & 1010 & 910 & 990 & 950 \\
\hline 3,72 & 1360 & 1225 & 1335 & 1260 \\
\hline 4,66 & 1700 & 1530 & 1660 & 1530 \\
\hline
\end{tabular}

\begin{tabular}{|c|c|c|c|c|c|c|}
\hline \multicolumn{7}{|c|}{ Viga de Peroba Rosa } \\
\hline \multirow{7}{|c|}{ Viga 10 } & \multicolumn{2}{c|}{ Viga 12 } & \multicolumn{2}{c|}{ Viga 13 } \\
\hline \multirow{2}{*}{$\begin{array}{c}\text { Força } \\
(\mathrm{kN})\end{array}$} & \multicolumn{7}{|c|}{ Flecha (mm/100) } \\
\cline { 2 - 7 } & S/reforço & c/Reforço & s/reforço & c/Reforço & s/reforço & c/Reforço \\
\cline { 2 - 7 } & \multicolumn{7}{|c|}{ (mEM EXTENSÔMETROS } \\
\hline 0 & 0 & 0 & 0 & 0 & 0 & 0 \\
\hline 0,93 & 346 & 265 & 215 & 165 & 262 & 245 \\
\hline 1,86 & 703 & 540 & 418 & 390 & 558 & 485 \\
\hline 2,79 & 1042 & 800 & 622 & 585 & 828 & 715 \\
\hline 3,72 & 1380 & 1060 & 825 & 770 & 1109 & 945 \\
\hline 4,66 & 1711 & 1300 & 1059 & 935 & 1392 & 1155 \\
\hline
\end{tabular}




\begin{tabular}{|c|c|c|c|c|c|}
\hline \multicolumn{2}{|c|}{ VIGA 01 - Pinus sem reforço } \\
\hline $\begin{array}{c}\text { Força } \\
(\mathrm{kN})\end{array}$ & $\begin{array}{c}\text { Flecha } \\
(\mathrm{mm} / 100)\end{array}$ & \multicolumn{4}{|c|}{ Deformação $(\boldsymbol{\mu} \boldsymbol{\varepsilon})$} \\
\hline & & $\boldsymbol{\varepsilon}_{\mathbf{1}}$ & $\boldsymbol{\varepsilon}_{\mathbf{2}}$ & $\boldsymbol{\varepsilon}_{\mathbf{3}}$ & $\boldsymbol{\varepsilon}_{\mathbf{4}}$ \\
\hline 0 & 0 & 0 & 0 & 0 & \\
\hline 0,23 & 158 & 115 & 65 & 65 & \\
\hline 0,47 & 309 & 205 & 120 & 140 & \\
\hline 0,70 & 439 & 290 & 175 & 200 & \\
\hline 0,94 & 587 & 385 & 235 & 265 & \\
\hline 1,17 & 711 & 465 & 285 & 330 & \\
\hline 1,41 & 854 & 560 & 345 & 395 & \\
\hline 1,64 & 990 & 640 & 405 & 460 & \\
\hline 1,88 & 1134 & 735 & 455 & 510 & \\
\hline 2,11 & 1279 & 820 & 510 & 580 & \\
\hline 2,35 & 1423 & 905 & 560 & 650 & \\
\hline
\end{tabular}

\begin{tabular}{|c|c|c|c|c|c|}
\hline \multicolumn{5}{|c|}{ VIGA 01 - Pinus reforço - reforço com seis camadas de fibra de vidro } \\
\hline $\begin{array}{c}\text { Força } \\
(\mathrm{kN})\end{array}$ & $\begin{array}{c}\text { Flecha } \\
(\mathrm{mm})\end{array}$ & & \multicolumn{4}{c|}{ Deformação $(\boldsymbol{\mu} \boldsymbol{\varepsilon})$} \\
\cline { 3 - 6 } & & $\boldsymbol{\varepsilon}_{\mathbf{1}}$ & $\boldsymbol{\varepsilon}_{\mathbf{2}}$ & $\boldsymbol{\varepsilon}_{\mathbf{3}}$ & $\boldsymbol{\varepsilon}_{\mathbf{4}}$ \\
\hline 0 & 0 & 0 & 0 & 0 & 0 \\
\hline 0,47 & 240 & 160 & 90 & 120 & 160 \\
\hline 0,94 & 487 & 320 & 180 & 230 & 310 \\
\hline 1,41 & 724 & 480 & 270 & 340 & 460 \\
\hline 1,88 & 966 & 640 & 360 & 450 & 620 \\
\hline 2,35 & 1216 & 810 & 450 & 560 & 770 \\
\hline 2,81 & 1456 & 960 & 550 & 670 & 930 \\
\hline 3,29 & 1703 & 1130 & 640 & 770 & 1080 \\
\hline 3,75 & 1955 & 1300 & 730 & 880 & 1240 \\
\hline 4,22 & & 1460 & 830 & 1000 & 1400 \\
\hline 4,69 & & 1630 & 930 & 1110 & 1550 \\
\hline 7,51 & & 2625 & 1480 & 1750 & 2425 \\
\hline 8,45 & & 2970 & 1690 & 1970 & 2810 \\
\hline
\end{tabular}




\begin{tabular}{|c|l|l|l|l|l|}
\hline 9,39 & & 3320 & 1870 & 2180 & 3110 \\
\hline 10,32 & & 3640 & 2050 & 2390 & 3410 \\
\hline 12,20 & & 4430 & 2450 & 2790 & 4070 \\
\hline 13,14 & & 4900 & 2690 & 3010 & 4450 \\
\hline 15,02 & & 6020 & 3150 & 3500 & 5350 \\
\hline
\end{tabular}

\begin{tabular}{|c|c|c|c|c|c|c|}
\hline \multicolumn{7}{|c|}{ VIGA 02 - Pinus sem reforço } \\
\hline $\begin{array}{c}\text { Força } \\
(\mathrm{kN})\end{array}$ & $\begin{array}{c}\text { Flecha } \\
(\mathrm{mm})\end{array}$ & \multicolumn{5}{c|}{ Deformação $(\boldsymbol{\mu} \boldsymbol{\varepsilon})$} \\
\cline { 3 - 7 } & & $\boldsymbol{\varepsilon}_{\mathbf{1}}$ & $\boldsymbol{\varepsilon}_{\mathbf{2}}$ & $\boldsymbol{\varepsilon}_{\mathbf{3}}$ & $\boldsymbol{\varepsilon}_{\mathbf{4}}$ & $\boldsymbol{\varepsilon}_{\mathbf{5}}$ \\
\hline 0 & 0 & 0 & 0 & 0 & 0 & \\
\hline 0,47 & 245 & 160 & 110 & 120 & 130 & \\
\hline 0,94 & 448 & 280 & 200 & 210 & 240 & \\
\hline 1,41 & 662 & 420 & 290 & 310 & 360 & \\
\hline 1,88 & 878 & 560 & 390 & 420 & 470 & \\
\hline 2,35 & 1092 & 690 & 480 & 510 & 580 & \\
\hline 2,81 & 1310 & 830 & 580 & 620 & 690 & \\
\hline 3,28 & 1534 & 970 & 670 & 720 & 800 & \\
\hline
\end{tabular}

\begin{tabular}{|c|c|c|c|c|c|c|}
\hline \multicolumn{7}{|c|}{ VIGA 02 - Pinus reforço - reforço com 06 camadas de fibra de vidro } \\
\hline $\begin{array}{c}\text { Força } \\
(\mathrm{kN})\end{array}$ & $\begin{array}{c}\text { Flecha } \\
(\mathrm{mm})\end{array}$ & \multicolumn{5}{|c|}{ Deformação $(\boldsymbol{\mu} \boldsymbol{\varepsilon})$} \\
\cline { 3 - 7 } & & $\boldsymbol{\varepsilon}_{\mathbf{1}}$ & $\boldsymbol{\varepsilon}_{\mathbf{2}}$ & $\boldsymbol{\varepsilon}_{\mathbf{3}}$ & $\boldsymbol{\varepsilon}_{\mathbf{4}}$ & $\boldsymbol{\varepsilon}_{\mathbf{5}}$ \\
\hline 0 & 0 & 0 & 0 & 0 & 0 & 0 \\
\hline 0,47 & 215 & 130 & 90 & 90 & 110 & 120 \\
\hline 0,94 & 413 & 260 & 160 & 170 & 210 & 220 \\
\hline 1,41 & 602 & 380 & 240 & 250 & 310 & 330 \\
\hline 1,88 & 800 & 500 & 320 & 330 & 410 & 440 \\
\hline 2,35 & 997 & 640 & 390 & 410 & 510 & 550 \\
\hline 2,82 & 1298 & 760 & 460 & 500 & 620 & 680 \\
\hline 3,28 & 1397 & 900 & 560 & 600 & 720 & 790 \\
\hline 3,75 & 1602 & 1030 & 630 & 680 & 820 & 900 \\
\hline 4,22 & 1801 & 1150 & 720 & 770 & 930 & 1020 \\
\hline
\end{tabular}




\begin{tabular}{|l|l|l|l|l|l|l|}
\hline 4,69 & 2008 & 1280 & 800 & 860 & 1030 & 1140 \\
\hline 5,63 & & 1560 & 960 & 1040 & 1250 & 1400 \\
\hline 6,57 & & 1810 & 1120 & 1210 & 1450 & 1640 \\
\hline 7,51 & & 2080 & 1280 & 1390 & 1660 & 1880 \\
\hline 8,45 & & 2350 & 1440 & 1570 & 1870 & 2130 \\
\hline 9,39 & & 2630 & 1610 & 1750 & 2080 & 2370 \\
\hline 10,32 & & 2910 & 1770 & 1930 & 2290 & 2630 \\
\hline 11,26 & & 3180 & 1920 & 2110 & 2500 & 2860 \\
\hline 12,20 & & 3470 & 2080 & 2300 & 2730 & 3110 \\
\hline 13,14 & & 3770 & 2250 & 2490 & 2950 & 3320 \\
\hline
\end{tabular}




\begin{tabular}{|c|c|c|c|c|c|c|}
\hline \multicolumn{7}{|c|}{ VIGA 03 - Pinus sem reforço } \\
\hline $\begin{array}{c}\text { Força } \\
(\mathrm{kN})\end{array}$ & $\begin{array}{c}\text { Flecha } \\
(\mathrm{mm})\end{array}$ & \multicolumn{6}{c|}{ Deformação $(\boldsymbol{\mu \varepsilon})$} \\
\cline { 3 - 7 } & & $\boldsymbol{\varepsilon}_{\mathbf{1}}$ & $\boldsymbol{\varepsilon}_{\mathbf{2}}$ & $\boldsymbol{\varepsilon}_{\mathbf{3}}$ & $\boldsymbol{\varepsilon}_{\mathbf{4}}$ & $\boldsymbol{\varepsilon}_{\mathbf{5}}$ \\
\hline 0 & 0 & 0 & 0 & 0 & 0 & \\
\hline 0,46 & 395 & 190 & 160 & 190 & 180 & \\
\hline 0,93 & 800 & 380 & 320 & 370 & 370 & \\
\hline 1,39 & 1180 & 580 & 480 & 560 & 550 & \\
\hline 1,86 & 1675 & 760 & 630 & 750 & 740 & \\
\hline 2,33 & 1980 & 950 & 790 & 940 & 920 & \\
\hline
\end{tabular}

\begin{tabular}{|c|c|c|c|c|c|c|}
\hline \multicolumn{6}{|l|}{ VIGA 03 - Pinus reforço - reforço com 02 camadas de fibra de carbono } \\
\hline $\begin{array}{c}\text { Força } \\
(\mathrm{kN})\end{array}$ & $\begin{array}{c}\text { Flecha } \\
(\mathrm{mm})\end{array}$ & \multicolumn{5}{c|}{ Deformação $(\boldsymbol{\mu \varepsilon})$} \\
\cline { 3 - 7 } & & $\boldsymbol{\varepsilon}_{\mathbf{1}}$ & $\boldsymbol{\varepsilon}_{\mathbf{2}}$ & $\boldsymbol{\varepsilon}_{\mathbf{3}}$ & $\boldsymbol{\varepsilon}_{\mathbf{4}}$ & $\boldsymbol{\varepsilon}_{\mathbf{5}}$ \\
\hline 0 & 0 & 0 & 0 & 0 & 0 & 0 \\
\hline 0,46 & 310 & 160 & 135 & 130 & 160 & 150 \\
\hline 0,93 & 625 & 330 & 260 & 260 & 330 & 390 \\
\hline 1,40 & 945 & 500 & 395 & 400 & 490 & 530 \\
\hline 1,86 & 1250 & 660 & 525 & 540 & 660 & 690 \\
\hline 2,34 & 1565 & 830 & 660 & 680 & 820 & 840 \\
\hline 2,79 & 1885 & 1000 & 790 & 820 & 1000 & 1100 \\
\hline 3,26 & 2210 & 1170 & 925 & 960 & 1160 & 1260 \\
\hline 3,73 & 2545 & 1340 & 1060 & 1100 & 1320 & 1430 \\
\hline 4,19 & 2885 & 1520 & 1195 & 1250 & 1480 & 1520 \\
\hline 4,66 & & 1710 & 1335 & 1400 & 1660 & 1710 \\
\hline 6,05 & & 2300 & 1775 & 1880 & 2200 & 2210 \\
\hline 7,45 & & 2900 & 2205 & 2350 & 2730 & 2790 \\
\hline 8,85 & & 3450 & 2610 & 2800 & 3210 & 3340 \\
\hline 10,25 & & 4070 & 3135 & 3400 & 3890 & 4120 \\
\hline 11,65 & & 4680 & 3580 & 3960 & 4460 & 4800 \\
\hline 13,04 & & 5610 & 4115 & 4580 & 5150 & 5620 \\
\hline
\end{tabular}




\begin{tabular}{|c|c|c|c|c|c|c|}
\hline \multicolumn{7}{|c|}{ VIGA 04 - Pinus sem reforço } \\
\hline $\begin{array}{c}\text { Força } \\
(\mathrm{kN})\end{array}$ & $\begin{array}{c}\text { Flecha } \\
(\mathrm{mm})\end{array}$ & \multicolumn{6}{c|}{ Deformação $(\boldsymbol{\mu} \boldsymbol{\varepsilon})$} \\
\cline { 3 - 8 } & & $\boldsymbol{\varepsilon}_{\mathbf{1}}$ & $\boldsymbol{\varepsilon}_{\mathbf{2}}$ & $\boldsymbol{\varepsilon}_{\mathbf{3}}$ & $\boldsymbol{\varepsilon}_{\mathbf{4}}$ & $\boldsymbol{\varepsilon}_{\mathbf{5}}$ \\
\hline 0 & 0 & 0 & 0 & 0 & 0 & \\
\hline 0,69 & 342 & 240 & 180 & 160 & 210 & \\
\hline 1,39 & 695 & 470 & 370 & 310 & 420 & \\
\hline 2,09 & 1018 & 680 & 540 & 440 & 610 & \\
\hline 2,79 & 1380 & 930 & 730 & 610 & 820 & \\
\hline 3,49 & 1740 & 1180 & 920 & 770 & 1040 & \\
\hline
\end{tabular}

\begin{tabular}{|c|c|c|c|c|c|c|}
\hline \multicolumn{6}{|c|}{ VIGA 04 - Pinus reforço - reforço com 02 camadas de fibra de carbono } \\
\hline $\begin{array}{c}\text { Força } \\
(\mathrm{kN})\end{array}$ & $\begin{array}{c}\text { Flecha } \\
(\mathrm{mm})\end{array}$ & \multicolumn{5}{c|}{ Deformação $(\boldsymbol{\mu} \boldsymbol{\varepsilon})$} \\
\cline { 3 - 7 } & & $\boldsymbol{\varepsilon}_{\mathbf{1}}$ & $\boldsymbol{\varepsilon}_{\mathbf{2}}$ & $\boldsymbol{\varepsilon}_{\mathbf{3}}$ & $\boldsymbol{\varepsilon}_{\mathbf{4}}$ & $\boldsymbol{\varepsilon}_{\mathbf{5}}$ \\
\hline 0 & 0 & 0 & 0 & 0 & 0 & 0 \\
\hline 0,69 & 340 & 230 & 150 & 160 & 220 & 210 \\
\hline 1,39 & 655 & 440 & 290 & 300 & 400 & 410 \\
\hline 2,09 & 992 & 680 & 450 & 460 & 610 & 640 \\
\hline 2,79 & 1275 & 880 & 585 & 600 & 790 & 810 \\
\hline 3,49 & 1578 & 1100 & 730 & 750 & 980 & 1020 \\
\hline 4,19 & 1895 & 1330 & 875 & 900 & 1170 & 1310 \\
\hline 5,59 & 2531 & 1790 & 1170 & 1210 & 1560 & 1850 \\
\hline 6,98 & 3000 & 2230 & 1460 & 1520 & 1930 & 2320 \\
\hline 8,38 & 3500 & 2690 & 1750 & 1820 & 2300 & 2810 \\
\hline 9,78 & 4000 & 3150 & 2035 & 2120 & 2680 & 3310 \\
\hline 11,18 & 4500 & 3640 & 2210 & 2420 & 3040 & 3790 \\
\hline 12,58 & 5000 & 4180 & 2480 & 2750 & 3430 & 4320 \\
\hline 13,98 & 5500 & 4720 & 2915 & 3080 & 3820 & 4850 \\
\hline 15,37 & 6000 & 5350 & 3050 & 3460 & 4270 & 5480 \\
\hline 16,77 & & 6020 & 3700 & 4000 & 4880 & 6380 \\
\hline
\end{tabular}




\begin{tabular}{|c|c|c|c|c|c|c|}
\hline \multicolumn{7}{|c|}{ VIGA 06 - Pinus sem reforço } \\
\hline $\begin{array}{c}\text { Força } \\
(\mathrm{kN})\end{array}$ & $\begin{array}{c}\text { Flecha } \\
(\mathrm{mm})\end{array}$ & \multicolumn{5}{c|}{ Deformação $(\boldsymbol{\mu} \boldsymbol{\varepsilon})$} \\
\cline { 3 - 8 } & & $\boldsymbol{\varepsilon}_{\mathbf{1}}$ & $\boldsymbol{\varepsilon}_{\mathbf{2}}$ & $\boldsymbol{\varepsilon}_{\mathbf{3}}$ & $\boldsymbol{\varepsilon}_{\mathbf{4}}$ & $\boldsymbol{\varepsilon}_{\mathbf{5}}$ \\
\hline 0 & 0 & 0 & 0 & 0 & 0 & \\
\hline 0,93 & 310 & 240 & 200 & 190 & 240 & \\
\hline 1,86 & 611 & 460 & 390 & 380 & 470 & \\
\hline 2,79 & 918 & 710 & 590 & 570 & 710 & \\
\hline 3,72 & 1228 & 950 & 790 & 770 & 950 & \\
\hline 4,66 & 1541 & 1200 & 990 & 970 & 1190 & \\
\hline
\end{tabular}

\begin{tabular}{|c|c|c|c|c|c|c|}
\hline \multicolumn{7}{|c|}{ VIGA 06 - Pinus reforço - reforço com 06 camadas de fibra de vidro } \\
\hline $\begin{array}{c}\text { Força } \\
(\mathrm{kN})\end{array}$ & $\begin{array}{c}\text { Flecha } \\
(\mathrm{mm})\end{array}$ & \multicolumn{5}{c|}{ Deformação $(\boldsymbol{\mu} \boldsymbol{\varepsilon})$} \\
\cline { 3 - 7 } & & $\boldsymbol{\varepsilon}_{\mathbf{1}}$ & $\boldsymbol{\varepsilon}_{\mathbf{2}}$ & $\boldsymbol{\varepsilon}_{\mathbf{3}}$ & $\boldsymbol{\varepsilon}_{\mathbf{4}}$ & $\boldsymbol{\varepsilon}_{\mathbf{5}}$ \\
\hline 0 & 0 & 0 & 0 & 0 & 0 & 0 \\
\hline 0,93 & 260 & 210 & 165 & 160 & 210 & 210 \\
\hline 1,86 & 530 & 430 & 315 & 310 & 410 & 410 \\
\hline 2,79 & 795 & 650 & 475 & 470 & 610 & 610 \\
\hline 3,72 & 1080 & 880 & 640 & 640 & 830 & 820 \\
\hline 4,65 & 1330 & 1100 & 800 & 800 & 1040 & 1040 \\
\hline 6,52 & 1890 & 1560 & 1125 & 1130 & 1450 & 1470 \\
\hline 8,38 & 3000 & 2020 & 1435 & 1460 & 1860 & 1930 \\
\hline 10,25 & 3500 & 2500 & 1765 & 1780 & 2260 & 2360 \\
\hline 12,11 & 4000 & 3000 & 2080 & 2100 & 2670 & 2810 \\
\hline 13,98 & 4500 & 3620 & 2435 & 2460 & 3130 & 3310 \\
\hline 15,84 & 5000 & 4300 & 2810 & 2840 & 3620 & 3850 \\
\hline 17,70 & 6000 & 5170 & 3220 & 3250 & 4170 & 4440 \\
\hline 19,57 & 7000 & 6070 & 3670 & 3750 & 4870 & 5200 \\
\hline
\end{tabular}




\begin{tabular}{|c|c|c|c|c|c|c|}
\hline \multicolumn{7}{|c|}{ VIGA 08 - Pinus sem reforço } \\
\hline $\begin{array}{c}\text { Força } \\
(\mathrm{kN})\end{array}$ & $\begin{array}{c}\text { Flecha } \\
(\mathrm{mm})\end{array}$ & \multicolumn{6}{c|}{ Deformação $(\boldsymbol{\mu} \boldsymbol{\varepsilon})$} \\
\cline { 3 - 8 } & & $\boldsymbol{\varepsilon}_{\mathbf{1}}$ & $\boldsymbol{\varepsilon}_{\mathbf{2}}$ & $\boldsymbol{\varepsilon}_{\mathbf{3}}$ & $\boldsymbol{\varepsilon}_{\mathbf{4}}$ & $\boldsymbol{\varepsilon}_{\mathbf{5}}$ \\
\hline 0 & 0 & 0 & 0 & 0 & 0 & \\
\hline 0,93 & 335 & 200 & 210 & 210 & 250 & \\
\hline 1,86 & 643 & 380 & 410 & 390 & 480 & \\
\hline 2,79 & 962 & 580 & 630 & 600 & 730 & \\
\hline 3,72 & 1284 & 780 & 840 & 800 & 980 & \\
\hline 4,65 & 1620 & 970 & 1040 & 1000 & 1220 & \\
\hline
\end{tabular}

\begin{tabular}{|c|c|c|c|c|c|c|}
\hline \multicolumn{7}{|c|}{ VIGA 08 - Pinus reforço - reforço com 02 camadas de fibra de carbono } \\
\hline $\begin{array}{c}\text { Força } \\
(\mathrm{kN})\end{array}$ & $\begin{array}{c}\text { Flecha } \\
(\mathrm{mm})\end{array}$ & \multicolumn{5}{c|}{ Deformação $(\boldsymbol{\mu} \boldsymbol{\varepsilon})$} \\
\cline { 3 - 7 } & & $\boldsymbol{\varepsilon}_{\mathbf{1}}$ & $\boldsymbol{\varepsilon}_{\mathbf{2}}$ & $\boldsymbol{\varepsilon}_{\mathbf{3}}$ & $\boldsymbol{\varepsilon}_{\mathbf{4}}$ & $\boldsymbol{\varepsilon}_{\mathbf{5}}$ \\
\hline 0 & 0 & 0 & 0 & 0 & 0 & 0 \\
\hline 0,93 & 275 & 180 & 165 & 170 & 220 & 280 \\
\hline 1,86 & 550 & 360 & 320 & 330 & 440 & 560 \\
\hline 2,79 & 725 & 540 & 490 & 510 & 680 & 730 \\
\hline 3,72 & 1110 & 720 & 665 & 690 & 920 & 1060 \\
\hline 4,65 & 1383 & 900 & 835 & 870 & 1140 & 1230 \\
\hline 6,52 & 1922 & 1250 & 1160 & 1210 & 1570 & 1650 \\
\hline 8,38 & 2474 & 1600 & 1495 & 1560 & 2000 & 2100 \\
\hline 10,25 & 3200 & 1930 & 1810 & 1890 & 2430 & 2500 \\
\hline 12,11 & 4200 & 2240 & 2135 & 2240 & 2880 & 3010 \\
\hline 13,98 & 5000 & 2550 & 2470 & 2600 & 3320 & 3500 \\
\hline 15,84 & & 2800 & 2850 & 3090 & 4000 & 4260 \\
\hline 17,70 & & 3080 & 3255 & 3550 & 4570 & 4750 \\
\hline 19,57 & & 3360 & 3705 & 4060 & 5250 & 5420 \\
\hline
\end{tabular}




\begin{tabular}{|c|c|c|c|c|c|c|}
\hline \multicolumn{7}{|c|}{ VIGA 10 - Pinus sem reforço } \\
\hline $\begin{array}{c}\text { Força } \\
(\mathrm{kN})\end{array}$ & $\begin{array}{c}\text { Flecha } \\
(\mathrm{mm})\end{array}$ & \multicolumn{6}{c|}{ Deformação $(\boldsymbol{\mu} \boldsymbol{\varepsilon})$} \\
\cline { 3 - 8 } & & $\boldsymbol{\varepsilon}_{\mathbf{1}}$ & $\boldsymbol{\varepsilon}_{\mathbf{2}}$ & $\boldsymbol{\varepsilon}_{\mathbf{3}}$ & $\boldsymbol{\varepsilon}_{\mathbf{4}}$ & $\boldsymbol{\varepsilon}_{\mathbf{5}}$ \\
\hline 0 & 0 & 0 & 0 & 0 & 0 & \\
\hline 0,46 & 262 & 160 & 170 & 130 & 210 & \\
\hline 0,93 & 502 & 300 & 300 & 250 & 400 & \\
\hline 1,40 & 756 & 450 & 440 & 380 & 600 & \\
\hline 1,86 & 1000 & 600 & 580 & 510 & 800 & \\
\hline 2,34 & 1240 & 730 & 710 & 640 & 980 & \\
\hline
\end{tabular}

\begin{tabular}{|c|c|c|c|c|c|c|}
\hline \multicolumn{7}{|c|}{ VIGA 10 - Pinus - reforço com 20 camadas de fibra de vidro } \\
\hline $\begin{array}{c}\text { Força } \\
(\mathrm{kN})\end{array}$ & $\begin{array}{c}\text { Flecha } \\
(\mathrm{mm})\end{array}$ & \multicolumn{5}{c|}{ Deformação $(\boldsymbol{\mu} \boldsymbol{\varepsilon})$} \\
\cline { 3 - 7 } & & $\boldsymbol{\varepsilon}_{\mathbf{1}}$ & $\boldsymbol{\varepsilon}_{\mathbf{2}}$ & $\boldsymbol{\varepsilon}_{\mathbf{3}}$ & $\boldsymbol{\varepsilon}_{\mathbf{4}}$ & $\boldsymbol{\varepsilon}_{\mathbf{5}}$ \\
\hline 0 & 0 & 0 & 0 & 0 & 0 & 0 \\
\hline 0,46 & 262 & 120 & 80 & 90 & 120 & 130 \\
\hline 0,93 & 502 & 230 & 140 & 150 & 220 & 240 \\
\hline 1,40 & 756 & 340 & 210 & 220 & 320 & 360 \\
\hline 1,86 & 1000 & 440 & 260 & 280 & 410 & 460 \\
\hline 2,34 & 1240 & 560 & 330 & 350 & 530 & 580 \\
\hline 4,66 & & 1140 & 680 & 710 & 1060 & 1180 \\
\hline 6,52 & & 1610 & 960 & 980 & 1480 & 1660 \\
\hline 8,39 & & 2060 & 1220 & 1250 & 1900 & 2130 \\
\hline 10,25 & & 2510 & 1490 & 1540 & 2320 & 2640 \\
\hline 12,11 & & 2900 & 1760 & 1820 & 2760 & 3130 \\
\hline 13,98 & & 3300 & 2020 & 2120 & 3210 & 3680 \\
\hline 15,84 & & 3600 & 2280 & 2440 & 3700 & 4200 \\
\hline 17,70 & & 3910 & 2560 & 2790 & 4280 & 4950 \\
\hline 19,57 & & 4000 & 2860 & 3190 & 4940 & 5700 \\
\hline
\end{tabular}




\begin{tabular}{|c|c|c|c|c|c|c|}
\hline \multicolumn{7}{|c|}{ VIGA 11 - Peroba rosa sem reforço } \\
\hline Força & \multirow{2}{*}{$\begin{array}{c}\text { Flecha } \\
(\mathrm{kN})\end{array}$} & \multicolumn{5}{c|}{ Deformação $(\boldsymbol{\mu} \boldsymbol{\varepsilon})$} \\
\cline { 3 - 7 } & & $\boldsymbol{\varepsilon}_{\mathbf{1}}$ & $\boldsymbol{\varepsilon}_{\mathbf{2}}$ & $\boldsymbol{\varepsilon}_{\mathbf{3}}$ & $\boldsymbol{\varepsilon}_{\mathbf{4}}$ & $\boldsymbol{\varepsilon}_{\mathbf{5}}$ \\
\hline 0 & 0 & 0 & 0 & 0 & 0 & \\
\hline 1,39 & 283 & 310 & 350 & 300 & 350 & \\
\hline 2,79 & 551 & 610 & 680 & 580 & 700 & \\
\hline 4,19 & 824 & 910 & 1030 & 870 & 1040 & \\
\hline 5,59 & 1097 & 1220 & 1370 & 1160 & 1390 & \\
\hline 6,98 & 1359 & 1520 & 1710 & 1430 & 1730 & \\
\hline
\end{tabular}

\begin{tabular}{|c|c|c|c|c|c|c|}
\hline \multicolumn{7}{|c|}{ VIGA 11 - Peroba rosa - reforço com 06 camadas de fibra de vidro } \\
\hline $\begin{array}{c}\text { Força } \\
(\mathrm{kN})\end{array}$ & $\begin{array}{c}\text { Flecha } \\
(\mathrm{mm})\end{array}$ & \multicolumn{5}{c|}{ Deformação $(\boldsymbol{\mu} \boldsymbol{\varepsilon})$} \\
\cline { 3 - 7 } & & $\boldsymbol{\varepsilon}_{\mathbf{1}}$ & $\boldsymbol{\varepsilon}_{\mathbf{2}}$ & $\boldsymbol{\varepsilon}_{\mathbf{3}}$ & $\boldsymbol{\varepsilon}_{\mathbf{4}}$ & $\boldsymbol{\varepsilon}_{\mathbf{5}}$ \\
\hline 0 & 0 & 0 & 0 & 0 & 0 & 0 \\
\hline 1,39 & 230 & 270 & 200 & 270 & 270 & 280 \\
\hline 2,79 & 456 & 550 & 400 & 540 & 550 & 560 \\
\hline 4,19 & 669 & 800 & 620 & 800 & 820 & 840 \\
\hline 5,59 & 882 & 1050 & 820 & 1050 & 1080 & 1100 \\
\hline 6,98 & 1086 & 1290 & 1020 & 1300 & 1330 & 1360 \\
\hline 8,38 & 1285 & 1540 & 1210 & 1550 & 1590 & 1600 \\
\hline 9,78 & 1490 & 1780 & 1400 & 1800 & 1850 & 1850 \\
\hline 11,18 & & 2020 & 1600 & 2050 & 2100 & 2100 \\
\hline 13,04 & & 2350 & 1860 & 2390 & 2450 & 2450 \\
\hline 14,91 & & 2720 & 2140 & 2750 & 2820 & 2830 \\
\hline 16,77 & & 3050 & 2420 & 3120 & 3190 & 3210 \\
\hline 18,64 & & 3430 & 2720 & 3500 & 3580 & 3630 \\
\hline 20,50 & & 3760 & 3020 & 3900 & 3980 & 4050 \\
\hline 22,36 & & 4150 & 3330 & 4300 & 4400 & 4480 \\
\hline 24,23 & & 4520 & 3660 & 4720 & 4850 & 4950 \\
\hline 26,09 & & 4970 & 4000 & 5150 & 5310 & 5430 \\
\hline 27,95 & & 5580 & 4400 & 5680 & 5900 & 6050 \\
\hline 29,82 & & 6240 & 4870 & 6300 & 6570 & 6780 \\
\hline
\end{tabular}

